\title{
THE ATMOSPHERIC INFRARED CONTINUUM
}

by

K. J. Bignell, B.Sc., A.R.C.S.

Department of Meteor ology,

Imperial College of Science and Technology

May 1965

A Thesis submitted for the Degree of Doctor of Philosophy at the University of London 


\section{Abstract}

This thesis is an account of two major experiments to study the atmospheric infrared continuum in the region 4 to $21 \mu$, using a high resolution $\left(1.0 \mathrm{~cm}^{-1}\right.$ at $\left.20 \mu\right)$ grating spectrometer with Golay cell detector and Nernst source. Using open horizontal atmosphere paths of 10,200 and $400 \mathrm{~m}$, extinction coefficients were measured in 7 windows between 14.0 and $20.9 \mu$. An extremely high correlation was found with the amount of water vapour in the path; aerosol seemed to have very little effect except under extremely hazy or foggy conditions. The absorption coefficients increased with the partial pressure of water vapour, suggesting a self-toforeign broadening factor much greater than the value of 6 observed for line centres. However, because of the strong correlation between vapour pressure and temperature in the open air, it proved difficult to distinguish between temperature dependence and self broadening, so the investigation was transferred to the laboratory.

Using a $15.5 \mathrm{~m}$ multiple reflection cell giving path lengths in the range $100-400 \mathrm{~m}$, with temperature and humidity control, the inferences of the open air experiment were confirmed and extended to include the region $4-12 \mu$. Unexpectedly high absorption was observed in this latter region. 
These results inspired a reexamination of all

available previous work, from which it was concluded that the extinction arises from two separate effects with different frequency and temperature dependence. They are i) a foreignbroadened component, roughly proportional to the foreign gas pressure and probably positively temperature dependent $(0.5$ to $1 \%$ per $\left.{ }^{\circ} \mathrm{C}\right)$; and $\left.i i\right)$ a self-broadened component roughly proportional to partial vapour pressure and with a strong negative temperature dependence $\left(2 \%\right.$ per ${ }^{\circ} \mathrm{C}$ at $\left.30^{\circ} \mathrm{C}\right)$.

On the basis of several assumed line shapes, the accumulated wings of lines in the $50 \mu$ rotation band were computed at several points in the range $12-40 \mu$ : the Lorentz shape gave a very good fit $( \pm 10 \%)$ to the foreign-broadened component, but none gave a satisfactory fit to the selfbroadened component. *

The $15 \mu_{\mathrm{CO}_{2}}$ band was found to give no detectable absorption (< $1 \%$ for 43 atm - $\mathrm{cm}$ of $\mathrm{CO}_{2}$, the equivalent of $1.4 \mathrm{~km}$ of air at sea level) outside the range 12.7 to $17.8 \mu$. The horizontal path experiment has already been reported in a joint paper with F. Saiedy and P. A. Sheppard, entitled 'On the Atmospheric Infrared Continuum', J.O.S.A. 53, 466 (1963); a copy is attached to this thesis. During this research a further paper, on the related topic of terrestrial heat balance, entitled Heat-balance measurements from an earth satellite - an analysis of possibilities' was published in Quart. J. Roy. Met. Soc., 87, 231 (1961); a copy is attached. 
CONTENTS

CHAPTER I

INTRODUCTORY SURVEY

Page

1.1 Introduction 1

1.2 Theoretical background 3

1.2.1 Definitions and units 3

1.2.2. Line shape 4

1.2.2.1 Introduction 4

1.2.2.2 Impact or interruption theories 6

1.2.2.3 Statistical theory 9

1.3 Aim of the investigation 9

$\begin{array}{lll}1.4 & \text { Previous work } & 10\end{array}$

CHAPTER 2

HORIZONTAL PATH EXPERIMENT - OPEN AIR

2.1 Introduction 13

$\begin{array}{lll}2.2 & \text { Design of experiment } & 13\end{array}$

2.3 Apparatus 15

2.3.1. Source 15

2.3.2. Optical system 15

2.3.3. Spectrometer 17

2.3.4. Detector system 18

2.3.5. Filters 19

2.4 Performance of the system 19

2.4.1 Typical spectra 19

2.4.2 Calibration 19 


\begin{tabular}{|c|c|}
\hline 2.4 .3 & Resolution \\
\hline 2.4 .4 & Stray radiation \\
\hline 2.4 .5 & Linearity of detector system \\
\hline 2.4 .6 & Stability of system \\
\hline 2.5 & Experimental technique \\
\hline 2.5 .1 & Choice of method \\
\hline 2.5 .2 & Measurement of $\beta_{17}-\beta_{4}$ \\
\hline 2.5 .3 & Measurement of $\beta_{14}-\beta_{4}$ \\
\hline 2.5 .4 & $\begin{array}{l}\text { Measurement of } \beta_{i}-\beta_{4} \text { for Windows } \\
14,15,16,18,19 \text { and } 20\end{array}$ \\
\hline 2.5 .5 & Measurement of water vapour \\
\hline 2.5 .6 & $\begin{array}{l}\mathrm{CO}_{2} \text { absorption in the region } \\
1300-478 \mathrm{~cm}^{-1}\end{array}$ \\
\hline 2.5 .7 & Extinction by aerosol \\
\hline 2.6 & Results \\
\hline 2.6 .1 & Windows 17 and 19 \\
\hline 2.6 .2 & Windors 18 and 20 \\
\hline 2.6 .3 & Windows 14,15 and 16 \\
\hline 2.7 & Discussion \\
\hline 2,8 & Conclusion \\
\hline
\end{tabular}

\section{CHAPTER 3}

\section{THE LABORATORY EXPERIMENT}

3.1 Design requirements 45

3.2 Apparatus 47

*3.2.1 Cell construction 47

3.2.2 Temperature and humidity control 47

3.2.3 Temperature and humidity measurement 49

3.2.3.1 Dry-bulb temperature 49

3.2.3.2 Wet-bulb depression 50

3.2.3.3 Comparison With Assmann psychometer 52

3.2.4 Optical system 52 
3.2.5 Spectrometer, source and detection $\begin{array}{r}\text { Page } \\ 56\end{array}$ system

3.3

3.3 .1

3.3 .2

3.3 .3

3.3 .4

3.3 .5

3.3 .6

3.3 .7

3.4

3.4 .1

3.4 .2

3.4 .3

3.4 .4

3.4 .5

3.5

3.5 .1

3.5 .1$.

3.5 .1 .2

$3 \cdot 5 \cdot 1.3$

$3.5 \cdot 1.4$

3.5 .1 .5

3.5 .2

3.5 .2 .1

3.5 .2 .2

$3 \cdot 5 \cdot 2.3$

3.5 .3

3.6

3.7
Performance of the system

Calibration, resolution and linearity

Transmittance of polyethyleze window

Variation of mirror reflectivity with humidity

Scattering from mirrors and window

60

Stray radiation

61

Aerosol absorption

61

Ozone and carbon dioxide absorption

62

Experimental technique

62

Choice of method

62

Measurement of $k_{17}-k_{4}$

62

Measurement of $k_{18}-k_{17}, k_{19}-k_{17}$,

64 $k_{20}-k_{17}$

Absolute measurement of $k_{8}, k_{11}$ and $k_{13} \quad 64$ Absolute measurements in window near $4 \mu 65$

Results and discussion

65

$17-21 \mu$ region

65

Window 17

65

Windows 18,19 and 20

69

Systematic differences between Lond on and 71 Ascot results

Summary of results

Discussion and comparison with previous work

$7-12 \mu$ region and $4 \mu$ windows

77

Windows $8,11,13$ and 4

77

$4 \mu$ windows

79

Discussion and comparison with previous

79 work

Summary of all results

85

Comparison between theory and onservation 85

Conclusion 
APPENDICES

2.1 Observational data for Windows 14,17 and 94 19 (Ascot)

2.2 Observational data for Windows 15, 16, 18 and 20 (Ascot)

3.1 Observational data for Windows 17, 18, 19100 and 20 (I ondon)

3.2 Observational data for Windows $4,8,11$ and 102 13 (London)

\section{IIST OF FIGURES}

Fig, Number

1.1 Schematic picture of interaction at collision

2.1 External Optical system at Ascot

2.2 Arrangemenc of spectrometer

2.3 Filter characteristics

2.4 Location of windows

2.5 Effect of stray radiation 21

2.6 Variation of source output with current 22

2.7 Typical continuum run for Window $17 \quad 25$

$2.8 \mathrm{CO}_{2}$ absorption between $10 \mu$ and $21 \mu$

2.9 Atmospheric aerosol distributions 31

2.10 Extinction coofficients in Windows 17 and $19 \quad 36$ 
2.11 Absorption coefficients in Windows 18 and 20

2.12 Extinction coefficients in Windows 14, 15 and 16.39

3.1 Layout of $15.5 \mathrm{~m}$ multiple reflection cell 47

3.2 Distribution of temperature and vapour pressure 48 in cell

3.3 Effect of diffusion through walls of cell 48

3.4 Diagram of electrical temperature sensors 50

3.5 Circuit diagram of electrical thermometers 51

3.6 Difference between electrical and Assmann 52 humidities

3.7 Optical system (London)

3.8 Perspective view of optical path for 12 transits of cell

3.9 Typical run for Window 17

65

3.10 Extinction in Window $17 \quad 66$

3.11 Absorption coefficient in Window 17 as a 67 function of vapour pressure and temperature

3.12 Extinction in Window 18

3.13 Extinction in Findow 19

3.14 Extinction in Window $20 \quad 70$

3.15 summary of results in the $17-21 \mu$ region 72

3.16 Comparison between present work and the 74 results of Bolle

3.17 Laboratory measurements of Palmer $\quad 74$

$3.18\}$ Absorption coefficients derived from Palmer 75 $3.19\}$

3.20 Extinction in Window 8 and its temperature 77 dependence

3.21 Extinction in Wind ow 11 and its temperature 78 dependence

3.22 Extinction in Window 13 and its temperature 78 dependence

3.23 Extinction in Window 4 and its temperature 78 dependence 
3.24 Extinction in $4 \mu$ mindows

3.25 Extinction of solar radiation in the region 80 $871-908 \mathrm{~cm}^{-1}$ (from Roach and Goody, 1958)

3.26 Effect of diurnal evaporation on solar intensity measurements

3.27 Variation of absorption coefficient with time of day and precipitable water in the zenith (Bolle, 1963)

3.28 Variation of absorption coefficients with time of day, visual opacity and zenith precipitable water (Dave 1963)

3.29 Extinction at $3.97 \mu$ and $9.1 \mu$ (Taylor and Yates, 1957)

3.30 Self- and foreign-broadened absorption coefficients, $8-40 \mu$

3.31 Contribution of rotation lifnes to continuum at 86 $\nu=800,559.4$ and $261 \mathrm{~cm}$

3.32 Comparison between observation and the ory 88

$\left.\begin{array}{l}3.31 \\ 3.32\end{array}\right\}$ Amended versions of the above

\section{IIST OF PLATES}

1. External optical system at Ascot

2. Magnesium oxide reststrahlen filter and chopper attenuators

3. Temperature sensing head 


\subsection{Introduction}

The existence of a continuous absorption throughout the atmospheric infrared window between 8 and 13 wicrons has been know for a long time, Elsagser (1938) probably being the first to draw attention to it. It has been observed many times since by all workers in the study of atmospheric radiation, both in transmission observations using the sun and artificial sources, and in emission studies from ground and space observatories. Only recently has serious effort been concentrated on the systematio study of the nature of the continuum, most of the earlier work having been direoted to the easier praotical problem of absorption by spectral lines and bands.

W1th the development of new infrared techniques, the range of application in the atmosphere hes inoreased correspondingly. Nearly always the continuum casts a veil over the clear picture which must eventually be extracted from combined line ond continuum effects, so that aocurate knowledge of the continuum has become very desirsble to clarify the picture. The following examples may be quotedz-

i) The estimation of the distribution of atmospheric ozone from surface observations of the $9.6 \mu$ band in emission.

ii) Study of the solar, Iunar and planetary surfaces throughout the infrared and microwave spectrum.

Both of these have been pursued for several years from ground observations and the results have always been subject to some uncertainty regarding the manner of correction for the continuum. 
iii) Since the advent of artificial earth satellites, several infrared emission experiments have been proposed, or in some cases already been carried out, to determine the earth's surface temperature distribution, cloud top height, ozone and carbon dioxide distribution, and temperature structure in the upper atmosphere. AII of these, except possibly the last, require correction to some extent for the continuum.

Much discussion has centred on the question of the origin of the continuum absorption; there is no doubt that it is largely due to water vapour, but the role of aerosol is less certain. That it is necessary to appeal to sonething other than water vapour appears to be due to the fact that measurements of oontinuum absorption by different workers do not seem to be consistent when compared on the basis of the existing picture of the water vapour continuum alone. Whilst it is not disputed that aerosol absorption in the 8 - $13 \mu$ region can be significant under extremely hazy conditions, the evidence for a definite correlation between extinction and aerosol concentration under more typical conditions is very questionable, and one of the results of this research suggests that the apparent discrepancies may arise through forcing the data to fit an inadequate model of the continuum.

Meteorologically, the continuum, because of its complete spectral coverage, is surprisingly effeotive in cooling the atmosphere by radiation, Möller (1942) calculated a cooling rate of about $1^{\circ 0}$ per day under representative conditions in the lowest two kilometres of the atmosphere. 
In addition to the above, the continuum is of interest in its own right, yielding information about the shape of the extreme winga of spectral lines in the water vapour bands. No theory speoffically Intended to treat line wings more than a few wavenumbers from the Iine centre has yet been presented, and one of the objects of this researoh is to discover in what respects the observed continuun differs from that to be expected on the basis of the various line shapes which have been proposed.

1.2. Theoretical Background

The following is not intended to be a logical presentation of the theory of molecular spectroscopy, this being fully treated in several standard references. Only the relevent results are given here as a basis for discussion.

1.2.1. Definitions and Units

Many systems of units are in use in quantitative speotroscopy, and that adopted in this thesis is as follows:-

1) Wavelengths are denoted by $\lambda$, expressed in wicrons, and wavenumber $\left(-\frac{t}{\lambda}\right)$ by $\nu$, expressed in $\mathrm{cm}^{-1}$

2) Absorption coefficient. This term invariably means the mass extinction coefficient, $k$, defined by the relation

$$
\frac{d I}{d m}=-k I
$$

where $\mathrm{dI}$ is the change in intensity of a beam of radiation of intensity I passing through a path containing a mass dm of absorber expressed in $\mathrm{g} \mathrm{cm}^{-2}$, so that $\mathrm{k}$ is expressed in 
$\mathrm{g}^{-I} \mathrm{~cm} .^{2}$ To avoid introduoing subscripts except where essential, it is understood that monochromatio radiation is implied in the above definition. .

3) Line intensity. This is defined as the integrated absorption coefficient over the line by the relation

$$
s=\int_{0}^{\infty} k_{\nu} d v
$$

and is expressed in vnits of $g^{-1} \mathrm{~cm}$. in this thesis.

\subsubsection{Line Shape}

1.2.2.1. Introduction

A transition between two molecular energy levels gives rise to emission or absorption of a photon which is of well defined wavelength; with, however, a small but definite spread. Three distinct meohanisms (natural, Doppler and collision broadening) are responstble for the spread, and they produce characteristic line profiles end half-width.

Natural broadening, representing the lowest possible limit to the spread, is attributed in classical terms to radiative damping of gn isolated stationary oscillator; the resulting line width $\left(10^{-5}\right.$ to $10^{-11} \mathrm{~cm}^{-1}$ ) is negligible compered with that due to the other two mechanisms.

Doppler broadening arises from relative motion of the absorbing and emitting molecule, and though it becomes important in the upper atmosphere, it is negligible in comparison with collision broadening under typical tropospheric oonditions. A typical Dopplex half-width would be $3 \times 10^{-4} \mathrm{om}^{-1}$ 


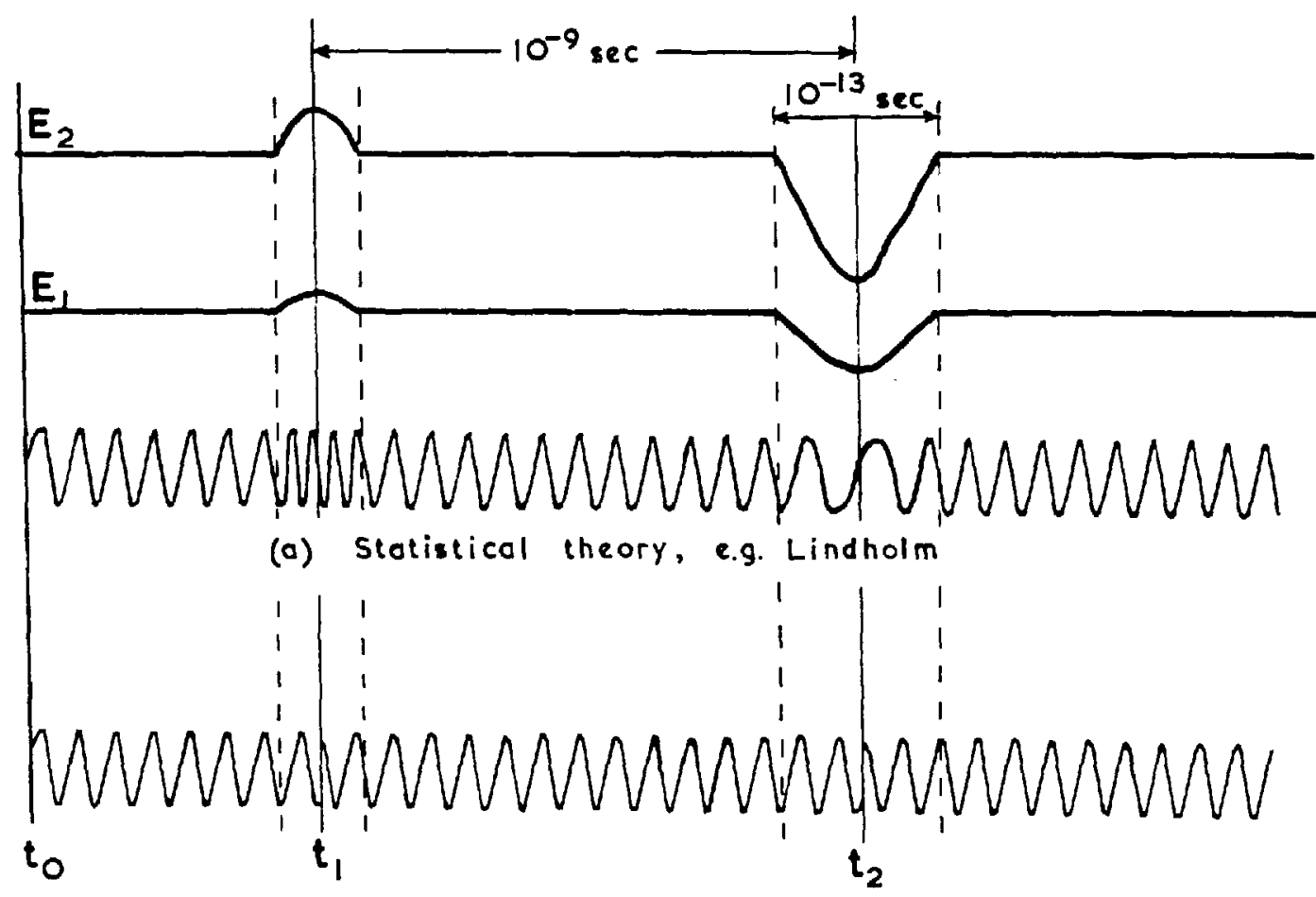

(b) Impact theory, e.g. Lorentz

Fig 1.1 . Schematic picture of interaction at collision.

A molecule is emitting a wavetrain as a result of a transition between $E_{2}$ and $E_{1}$ at time $t_{0}$. Two interactions are illustrated: at $t_{1}$ a weak interaction, and at $t_{2} a$ strong interaction. 
Collision broadening has received much attention and several theories have been advanced, each making different assumptions about the interaction at collisions. The relevant theories will be discussed with the aid of Fig.1.1, which serves to fix our ideas. Two energy levels $E_{1}$ and $E_{2}$ of an isolated molecule are shom as a function of time. When a second molecule approaches sufficiently closely, such as at $t_{1}$ and $t_{2}$, the energy levels are temporarily shifted (usually by different amounts), the molecule in effect assuming different moments of inertia and dipole moment owing to the distortion produced by the foreign force field. Fig. 1.1 is intended to illustrate two collisions, one much closer than the other, trnugh the duration of the encounter has been greatly exaggerated, this being in reality only about $10^{-3}$ or $10^{-4}$ of the mean time between collisions. Assume that the molecule begins to emit a photon at $t_{0}$ as the result of a transition from $\mathbb{E}_{2}$ to $E_{1}$ this process continues for a time which is usually long compared with the interval between collisions, so that during the interval illustrated the emitted wavetrain may be considered to have constant amplitude (upper wavetrain in Fig. 1.1.). Near the times $t_{1}$ and $t_{2}$, there will be a temporary shift of the wavenumber of the photon from $v_{0}=\frac{E_{2}-E_{1}}{h c} t_{0} v=\nu_{0}+\frac{\left(E_{2}-E_{1}\right)}{h c}$.

Iine broadening theories seek to describe the probability distribution of the shift $y-\nu_{0}$, and fall into one of several classes outlined below. They all assume that the interaction produces frequency modulation so that the phase of the oscillation is changing continuously during the 
encounter. Use is mate of the following terms:-

1)

2) Teak interaction.

3) Adiabetic interaction.

4) Non-adiabatio interation.

5) Resonance.
Total phase chenge during colligion large $(>2 \pi)$

Total phase change during collision small $(\ll 2 \pi)$

No transition induced by collision Transition induced by colliston. A non-adiabatic interaction in which a transition of nearly the same magnitude but of opposite sign is induced in both molecules.

1.2.2.2. Impact or intermuption theories.

The molecule is assumed to radiate monochromatically at all times except that at collisions there is an instantaneous change of phase, as illustrated in the lower wavetrain of Fig.l. This represents a strong adiabatic interaction. The precise nature of the perturbation during the collision is imsterial in this theory and is justified by the relatively very small proportion of the time spent in collision. The resulting line profile of absorption coefficient $k$ is given by

$$
k_{\nu}=k_{\nu_{0}} \frac{\alpha^{2}}{\left(\nu-\nu_{0}\right)^{2}+\alpha^{2}}
$$

where the line half-width $(\alpha)=\frac{1}{2 \pi \bar{\tau} c}$ with $c=$ velocity of light and $\vec{\tau}=$ the mean time between

collisions. The same profile results from Anderson's (1949) analysis of non-adiabatic resonant interactions, though here the line-width is 
formulated in quantum mechanical terms.

Eq.I is the Lorentz profile, well known in many problems involving damped oscillation. From the definition of line intensity we find

$$
s=\int_{0}^{\infty} k_{\nu} d \nu \quad-k_{\nu_{0}} \pi \alpha
$$

so that from Eq.I

$$
h_{\nu}=\frac{S \alpha}{\pi\left(\left[\nu-\nu_{0}\right]^{2}+\alpha^{2}\right)}
$$

Eq2. presents a contradiotion with the Debye formulation for statio polarisation for a line with $\nu_{0} \quad 0$, which suggests that a modifioation is required for this, the miorwave region. An assumption in the Lorentz derivation is that $\nu-\nu_{0} \gg \alpha$, when this is no longer the case, then a slightly different profile results

$$
k_{\nu}=\frac{S \alpha}{\pi} \frac{\nu}{\nu_{0}}\left[\frac{1}{\left(\nu-\nu_{0}\right)^{2}+\alpha^{2}}-\frac{1}{\left(\nu+\nu_{0}\right)^{2}+\alpha^{2}}\right]
$$

However a further important factor as $\nu_{0} \rightarrow 0$ in the derivation of Eq. 3 is the assumption made regarding the velooity and displacement of the oscillator immediately after the collision. Eq. 3 is derived from a random distribution, whereas a Maxwell distribution would be more appropriate, assuming that the collisions set up a thermal equilibrium. Then there results

$$
k_{\nu}=\frac{s \alpha}{\pi}\left(\frac{\nu}{\nu_{0}}\right)^{2}\left[\frac{1}{\left(\nu-\nu_{0}\right)^{2}+\alpha^{2}}+\frac{1}{\left(\nu+\nu_{0}\right)^{2}+\alpha^{2}}\right]^{*}
$$


Eq. 4 is the Van Vleck and. Weisskopf (1945) profile and experimental evidence suggests that it gives a good approximation in the microwave region. It should be pointed out however that it cannot hold throughout the spectrum since Eq. 4 tends to the constant value $\frac{s \alpha}{\pi \nu_{0}}$ as $\nu \rightarrow \infty$, implying infinite line intensity. Against the derivation it might be argued that the duration of the interactions is too small to establish thermal equilibrium and that the distribution of velocities and displacements is more nearly random than Maxwellian. This argues for $\mathrm{Eq}$. 3 rather than $\mathrm{Eq} .4$.

In any event, the line vings would be expected to be stronger than the value obtained from Eq. 2. using the val ue of $\bar{\tau}$ as defined there. This is because $\tau$ has a wide spread among individual molecules and a different type of mean is required for the central and wing regions. From Eq. 2. we see that $k_{\nu_{0}}=\frac{s}{\pi \alpha}=2 S c \tau$ so that here the mean time between collisions is the correct interpretation of $\bar{\tau}$ In the wings, on the other hand, $k_{\nu}=\frac{s \alpha}{\pi\left(\nu-\nu_{0}\right)^{2}}=\frac{s}{2 \pi^{2} c\left(\nu-\nu_{0}\right)^{2}} \frac{1}{\tau}$ so that we are now coneerned with $\overline{\left(\frac{1}{\tau}\right)}$. For any distribution of $\tau$, $\overline{\left(\frac{1}{\tau}\right)}>\frac{1}{\tau} \quad$ and computation for billiard-ball type collisions indicate that the wing absorption predicted by Eq. 2 should be multiplied by 1.146 (Goody 1964, p.107).

Near line centres, both Eq. 4 and $\mathrm{Eq}_{\text {. }} 3$ reduce to Eq. 2, so that studies involving line absorption will be insensitive to the choice of profile。 


\subsubsection{Statistical theory}

Here the perturbation of the oscillator during weak interactions is accounted for by Lindholm (1945) on the basis of an assumed molecular force field, resulting in an asymetric line profile with a shifted centre. The theory was developed for transitions far from resonance, e.g. optical spectra, add it is not surprising that experimental data do not fit the Lindholm profile in the extreme rings of infrared lines. No further consideration will be given to this theory.

1.3. Aim of the present investigation

Experimental messurements of line profile are hampered by inadequate resolution to observe the central regions in detail, since spectrometer slit widths are usually at least ten times the line halfwidth. Indirect methods involving the study of absorption by whole lines or bands are usually resorted to, and some uncertainty must always remain because the small variation in such absorption resulting from different profiles is indistingmishable from that due to uncertainty in the line intensity or half-widths.

A more direct way for investigating line wings is to measure the continuum absorption in the $8-20$, thegion away from the influence of lines, and to compare the results with those computed from accumulated line wings of the different profiles mentioned above. The influence relative to the rotation band of the much reaker $6.3 \mu$ vibration-rotation band, for which absolute computation of line intensity is not possible, may be neglected in the $16-20 \mu$ region, 
but might influence the $8-12 \mu$ region. The $12-16 \mu$ region is Inaccessible unless elaborate preoautions are taken to exclude oarbon dloxide from the apparatus.

By observing the temperature dependence, a further indication as to the origin of the continuum may be possible, since the very high Iine intensities near the band centre have a negative temperature dependence, whilst the others are positively temperature dependent.

\section{4. Previous Work}

The first spectrometric measurements of atmospheric absorption were made in the $8-12 \mu$ solar speotrum by Adel (1939) using a rook galt prism giving resolution certainly no better than $10 \mathrm{~cm}^{-1}$, which is insufficient to separate line and continuum absorption. This might account for his result at $900 \mathrm{~cm}^{-1}$ being about double the more recent values. This work is of little more than historical interest. The next measurements were made by Gebbie et al (1951) using a horizontal path of about $2 \mathrm{~km}$ over water; they observed the transmission in the $2.2-1.1 .5 \mu$ region relative to that at $0.61 \mu$. The low resolntion made it impossible to untangle selective ard continuum absorption, and acoess to the raw data would be necessary to reinterpret it in the light of recent findings. Anthony (1952) employed a solar absorption technique from Table Mountain, California, and obtained a few results (the orly publishod dats to date) for 19.0, $17.6,12.8,12.0,11.5,10.5,9.0$ and $8,0 \mu$; the circumstances of the observations and instrumental details are not available. Palmer (1957 b, c) published a series of spectra for the $20-40 \mu$ region with 
resolution $2.5 .-5 \mathrm{~cm}^{-1}$, taken under controlled laboratory conditions with difierent total and partial pressures of air and water vapour; this work provides a valuable source of data which is analysed in Chapter 3. Yates and Taylor (1960) carried out an experiment over horizontal atmospheric paths of $0.3,5.5$ and $16.25 \mathrm{~km}$ under different atmospheric conditions; little of this data was published and no analysis in terms of the continuum has appeared. Roach and Goody (1958) using resolution of $7 \mathrm{~cm}^{-1}$ in the $8-12 \mu$ window, observed solar. intensity as a function of zerith angle from observatories in London and Ascot. Some correction for selective absorption was necessary, with attendant uncertainty, but there remained no doubt that the London results indicated much stronger absorption than those taken at Ascot. Roach attributed this to aerosol absorption in the excessively polluted London atmosphere. Vigroux (1959) observed the zenith angle dependence of solar radiation at $1041 \mathrm{~cm}^{-1}$ from Arosa. (1800 m in the Swiss Alps) and deduced the continum absorption coefficient, this determination can be presumed free of aerosol effects. Saiedy carried out very careful observations of solar intensity at Ascot in several windows between $790 \mathrm{~cm}^{-1}$ and $1202 \mathrm{~cm}^{-1}$ using resolution of $2 \mathrm{~cm}^{-1}$. The results, published in Bignell, Saiedy and Sheppard (1963) (hereafter referred to as B.S.S. (1963)), confirmed an overwhelming correlation between absorption and water vapour, with only slight evidence of aerosel extinction. There was some evidence of a temperature effect, but its interpretation was not clear. Dave, Sheppard and Walshaw (1963), working with the same spectrometer as in the present research, observed 
emission in three windows near $10 \mu$ : the results showed considerable soatter, some of which was attributed to aerosol absorption, with an added tendency for higher absorption in the summer months. Whilst the mean value of Dave at $898 \mathrm{~cm}^{-1}$ was $10 \%$ higher than that of Saiedy at $901 \mathrm{~cm}^{-1}$, his value at $996.5 \mathrm{~cm}^{-1}$, even under the haziest conditions, was 15 per cent lower than Saiedy's, which is difficult to explain on the grounds of gerosol absorption.

Taking an overall look at the results of the previous work Iisted above, it was concluded that there were differences which could not be explained by errors of observation. Nor did it seem reasonable on the basis of some rough calculations that aerosol absorption could become significant in the $8-20 \mu$ region before the visibility had become so poor that the haze could not fail to be noticed. It was felt that the differences were arising rather from the use of an incomplete description of continuum absorption. The aim of the present work was to discover in which respects this description was lacking, rather than merely to measure the absorption coefficient in a previously unexplored region. The latter would only have the doubtful merit of adding another discrepant determination to an already long list without pointing the way to a unified picture. 


\subsection{Introduction}

Earlier work on the atmospheric water vapour continuum cited in Chapter I concentrated mainly on the $8-13 \mu$ window, and most workers have used the atmosphere to provide the necessary long path to give sufficient absorption of the solar bean, or, al ternatively, sufficient emission to give a precise measurement.

Between 13 and $17 \mu, \mathrm{CO}_{2}$ absorption precludes the use of these techniques. Beyond $17 \mu$, whilst relatively free of absorption by other gases, the absorption by water vapour is so strong that under typical conditions very little solar energy reaches sea level, and atmospheric emission almost equals the black body intensity, so that neither technique is applicable at sea level. At the time of the inception of the present work, the only published continuum measurements in the 17 - $20 \mu$ region were those of Anthony (1952) by a solar method from a mountain site. This region of the spectrum offered the best opportunity of obtaining reliable continuum measurements with relatively short paths which could be monitored accurately.

\subsection{Degign of Experiment}

At the outset, two distinct courses of action were possible either a laboratory study or an open atmospheric experiment. The former, undoubtedly the more attractive, presented several problems whose solutions were not immediately apparent. Moreover, the then simple picture of continuum absorption outlined in Chapter I suggested that 
the open atmosphere experiment would provide the required answers. $\triangle$ major consideration supporting this view was that a horizontal path could be used, avoiding much uncertainty introduced by the slant atmospheric paths used by most previous workers. The decision was therefore made in favour of the horizontal path experiment.

The path length required was determined from the following considerations. The transmittance $T$ of a path containing $m g \mathrm{~cm}^{-2}$ of precipitable water is given by $T=e^{-k m}$ where $k$ is the mass absorption coefficient, so that $k=-\frac{1}{\mathrm{~m}}$ loge T. The fractional error in the determination of $k$ resulting from errors in m and $T$ is then given by

$$
\frac{\Delta k}{k}=-\frac{1}{\log _{e} T} \frac{\Delta T}{T}+\frac{\Delta m}{m}
$$

The transmittance is measured as the ratio of two signals $S_{1}$ and $S_{2}$, i.e. $T=\frac{S_{1}}{S_{2}}$, so that for random errg's of equal magnitude in $S_{1}$ and $S_{2}$, $\frac{\Delta T}{T}=\sqrt{2} \frac{\Delta S_{2}}{S_{2}} \cdot \frac{1+T}{T}$. We then see from Eq 2.1 that to minimise $\frac{\Delta k}{k}$ we must minimise $\frac{1+T}{T \log _{e} T}$ Thia gives $T=0.28$ or $k_{\text {m }}=1.3$

The range of $\mathrm{k}$ to be measured ( 1 to $4 \mathrm{~g}^{-1} \mathrm{~cm}^{2}$ ) and the natural variability of atmospheric water vapour density (say 5 to $15 \mathrm{~g} \mathrm{~m}^{-3}$ ) mean that some compromise must be reached. Path longths of $200 \mathrm{~m}$ and $400 \mathrm{~m}$ enable near optimum conditions to be obtained for the whole range of absorption coefficient expected. 


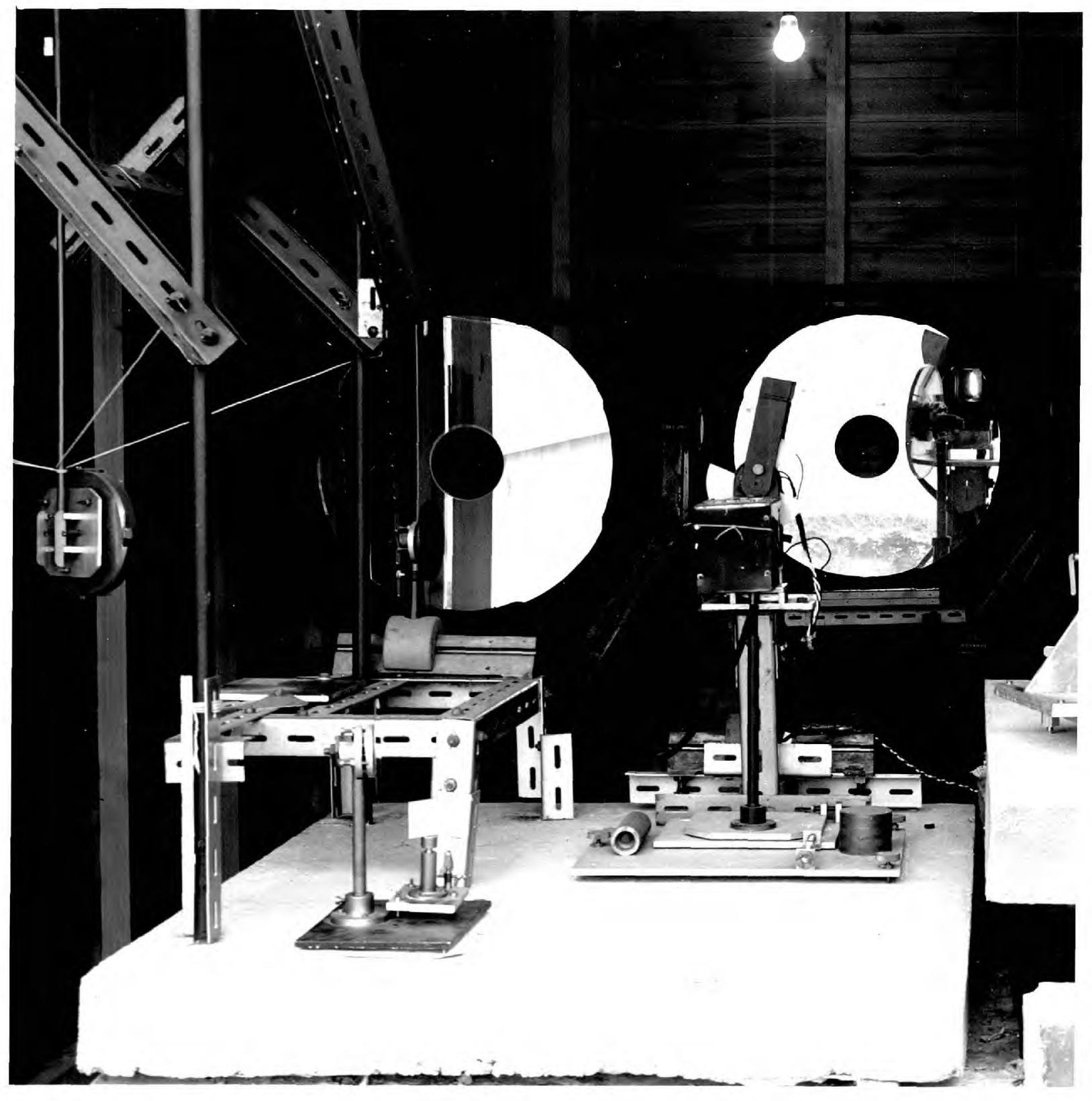


that at best (with $T=0.28$ ) $\frac{\Delta R}{k}=3 \Delta T$, neglecting any error in $m$. An optimistic value for $\Delta T$ would be 0.01 , implying a signal to noise ratio of the order of 100 , which is a fairly realistic target to aim for. We would then be able to measure $k$ to 3 per cent.

A rough order of magnitude calculation was made to see if a signal to noise ratio of 100 . I was feasible with the available equipment when used at a resolution of 1 to $2 \mathrm{~cm}^{-1}$. Using a Nernst filament at $1500^{\circ} \mathrm{K}$ and Golay detector, it was confirmed that there would be some margin for imperfect optics even after allowing for reasonable losses in other sections of the path.

\subsection{Apparatus}

The equipment to be described was set up at the Imperial

College Field Station at Ascot, about $40 \mathrm{~km}$ WSW of central London. This site gives reasonable freedom from the excessive pollution experienced nearer London.

\section{3 .1 Source}

A B.T.H, Nernst filament of length $2.5 \mathrm{~cm}$ and $0.25 \mathrm{~cm}$ diameter was supplied from a constant voltage transformer through series barretter tubes for stabilisation. The Nernst was operated in a shield to minimise the effects of draughts.

2.3.2. Optical System

Fig. 2.1 and Plate 1 show the external optical system. The Plate 1. External optical system at Ascot. 

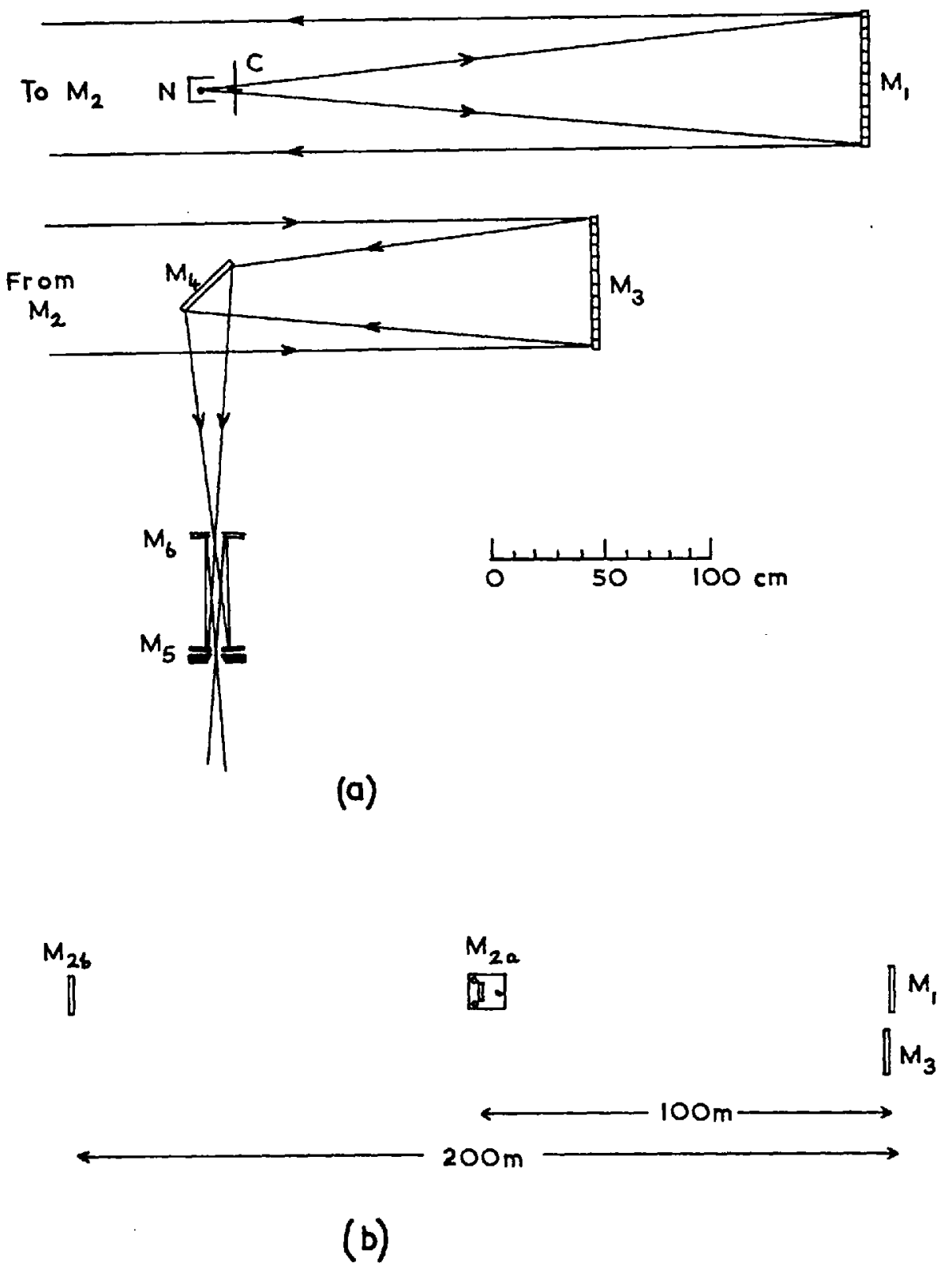
Fig 2.1. External Optical System at Ascot

(a) The Nernst filament $\mathbb{N}$ is shielded from draughts and is mounted just outside the focus of paraboloid $\mathrm{MI}_{1}$ ( $f=305 \mathrm{~cm}$, diameter $63 \mathrm{~cm})$ so as to give an image on $\mathrm{M}_{2}$, which is a spherical mirror of either $200 \mathrm{~m}$ radius, $50 \mathrm{~cm}$ diameter, mounted at $200 \mathrm{~m}$ distance, or of $100 \mathrm{~m}$ radius, $25 \mathrm{~cm}$ diameter mounted at $100 \mathrm{~m}$ distance. In each case the centre of curvature of $\mathbb{M}_{2}$ is midway between those of $M_{1}$ and $\mathbb{M}_{2}$, so that $\mathbb{M}_{1}$ is imaged on $\mathbb{M}_{3}$. $A I I$ mirrors are front - surface aluminised. The chopper (c) frequency is $10 \mathrm{c} / \mathrm{s}^{\circ}$

(b) Layout of Iong path optics.

$M_{1}, M_{2 a}, \mathbb{M}_{2 b}$ are mounted in a straight line. $\mathbb{M}_{2 a}$ is supported on a tall kinematio mount to facilitate its removal from the beam to $\mathrm{M}_{2 \mathrm{~b}}$. 
parabolic $f / 5$ projector mirror $\mathbb{M}_{I}$ focussed on image of the Nernst on $M_{2}$, one of two spherical mirrors located $100 \mathrm{~m}$ or $200 \mathrm{~m}$ away over a ploughed field. $M_{2}$ was adjusted so that its oentre of curvature lay midway between $\mathbb{M}_{1}$ and $M_{3}$, the latter being identical to $M_{1}$. AII radiation leaving $M_{1}$ therefore returned to $M_{3}$. Matching into the $f / 10$ spectrometer was then achieved by $\mathrm{M}_{5}$ and $\mathrm{M}_{6}$, $\mathrm{M}_{4}$ turning the beam through $90^{\circ}$. All concave mirrors were used axially, so that a very sharp image was formed on the entrance slit.

For reasons which will become apparent in $\{2,5.2,16$, geometry of the $200 \mathrm{~m}$ and $400 \mathrm{~m}$ paths had to be as similar as possible. This was achieved by mounting $\mathbb{M}_{1}, \mathbb{M}_{2 a}$ and $\mathbb{M}_{2 b}$ in a straight line; $\mathrm{M}_{2 \mathrm{a}}$ was supported on a tall kinematic mount so that when not required it could be removed bodily from the beam, allowing the beam to carry on to $\mathrm{M}_{2 b}$. Focussing was effected by a micrometer adjustment on the Nernst mounting, and by a slide mechanism on the modified gun mounting used to support $M_{3}$. Adjustment of $M_{2 a}$ and $M_{2 b}$ proved to be very critical and was facilitated by three small plane mirrors mounted around the circumference of $\mathrm{M}_{3}$, aligned with their normals passing near $\mathrm{M}_{2 \mathrm{a}}$ and $\mathrm{M}_{2 \mathrm{~b}}$; with the latter incorrectly adjusted, one of the three plane mirrors oould be seen brightly illuminated when viewed from $\mathbb{M}_{2}$, and the appropriate correction could readily be made. In this way, $\mathrm{M}_{1}$ could be imaged on $\mathbb{M}_{3}$ to within $1 \mathrm{~cm}$.

\section{3 .3 Spectrometer}

The spectrometer shown in Fig 2.2 was basically that designed 


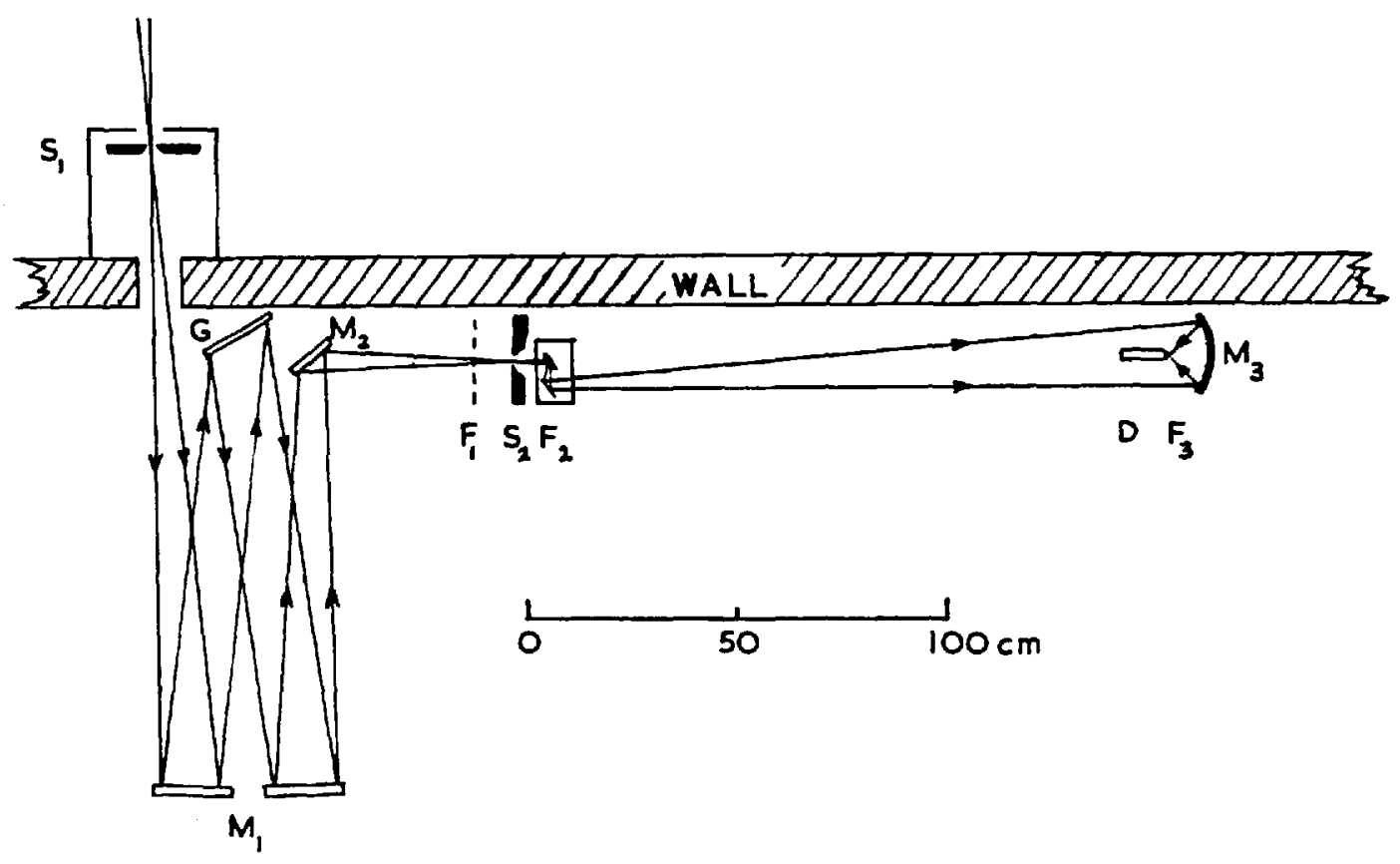

Fig 2.2. Arrangement of spectrometer.

D Golay detector

$F_{1}$ Terylene filter, $12 \mu$ thick

$F_{2}$ Double reststrahlen magnesium oxide filter for $\lambda>13 \mu$, or aluminised mirrors for $\lambda<13 \mu$.

$F_{3}$ Bloomed indium antimonide filter

$G$ Merton replica grating $15 \mathrm{~cm} \times 15 \mathrm{~cm}, 473$ lines $/ \mathrm{cm}$

$M_{1}$ Ebert mirror (2 identical spherical mirrors)

$M_{2}$ Flat mirror

$M_{3}$ Condenser mirror

$S_{1}$ Entrance slit (outside wall of laboratory)

$\mathrm{S}_{2}$ Exit slit 
by Goody (1957) for emission studies. It was equipped for this experiment with a $15 \mathrm{~cm}$ square Merton replica grating of $473 \mathrm{lines} / \mathrm{cm}$ blazed for $20 \mu$ in the first order. Using $f / 10$ Ebert optics of focal length $150 \mathrm{~cm}$, large slits $2.5 \mathrm{~cm}$ long and up to $0.4 \mathrm{~cm}$ wide gave good energy gathering porer whilst retaining high resolution. $A$ kinematic mount for a reststrahlen magnesium oxide filter was placed just after the exit slit, and the condenser mirror gave an 8 to 1 reduotion in order to accommodate the image on the sensitive area $(0.3 \mathrm{~cm}$ diameter) of the Unicam Golay detector. Spectral scanning at various speeds was effected by a mains - driven synchronous motor and change gears, with provision for manul operation.

\subsubsection{Detector System}

The standard Unicam Golay deteotor system was employed using $10 \mathrm{c} / \mathrm{s}$ chopping frequency. The signal was recorded on a $15 \mathrm{mV}$ Honeywell Brown potentiometer reoorder giving a chart width of $28 \mathrm{~cm}$. All power supplies were derived from a constant voltage transformer. The overall time constant of the system was about 1 sec, and although this could have been increased to give a less noisy record, it was considered prefereable to retain the 'lively' record and perform the smoothing where necessary by eye.

The chopper unit, mounted outside the laboratory, was shielded from daylight to prevent fluctuation of the zero reading which otherwise occurred when the illumination varied. Even so, significant fluctuations of both the zero reading and the sensitivity of the system 


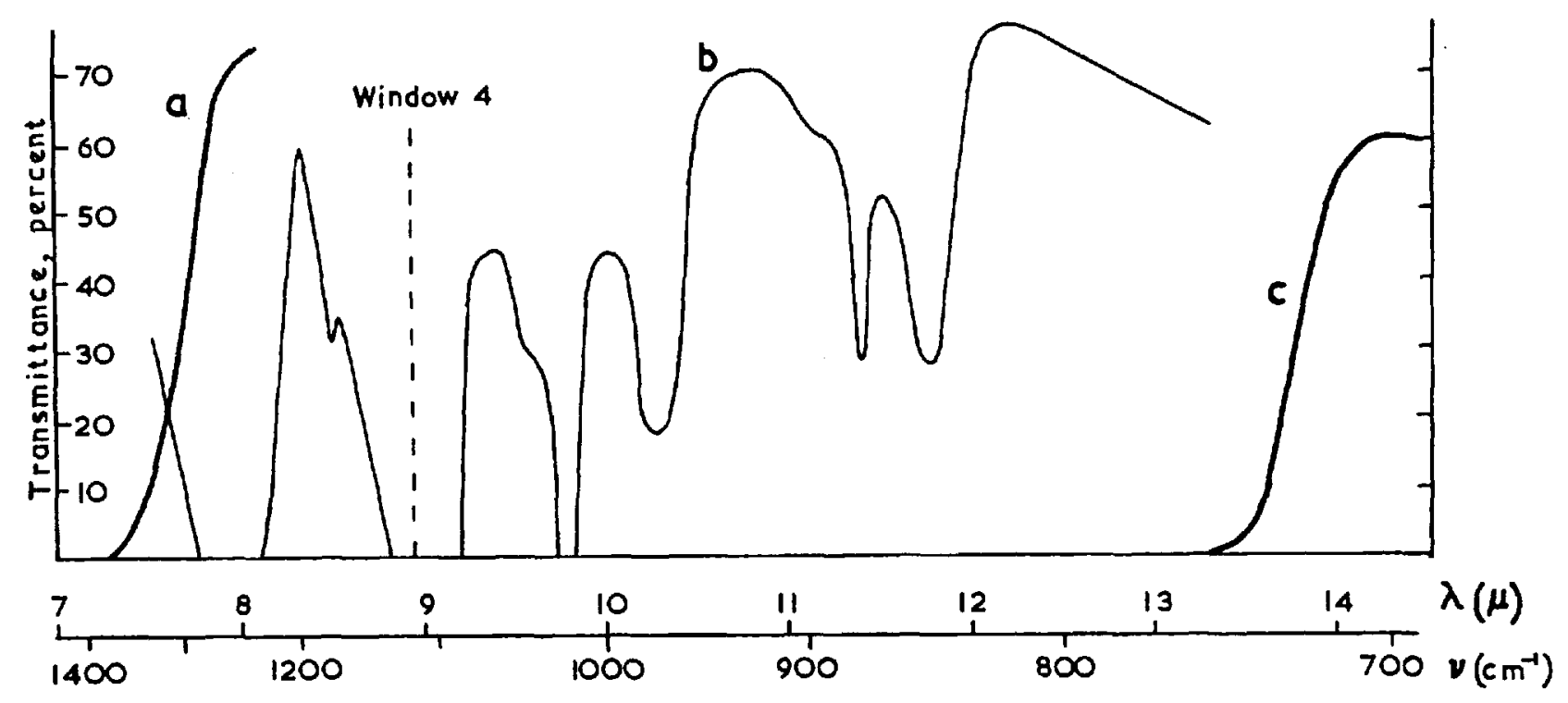

Fig 2.3. Filter characteristics.

a Cut-on for bloomed indium antimonide. Beyond $8 \mu$ the transmittance decreases slowly to about $50 \%$ at $20 \mu$.

b Transmittance of terylene film, $12 \mu$ thick.

c Cut-on for double reststrahlen magnesium oxide. Beyond $14 \mu$ the transmittance remains at about $60 \%$. 


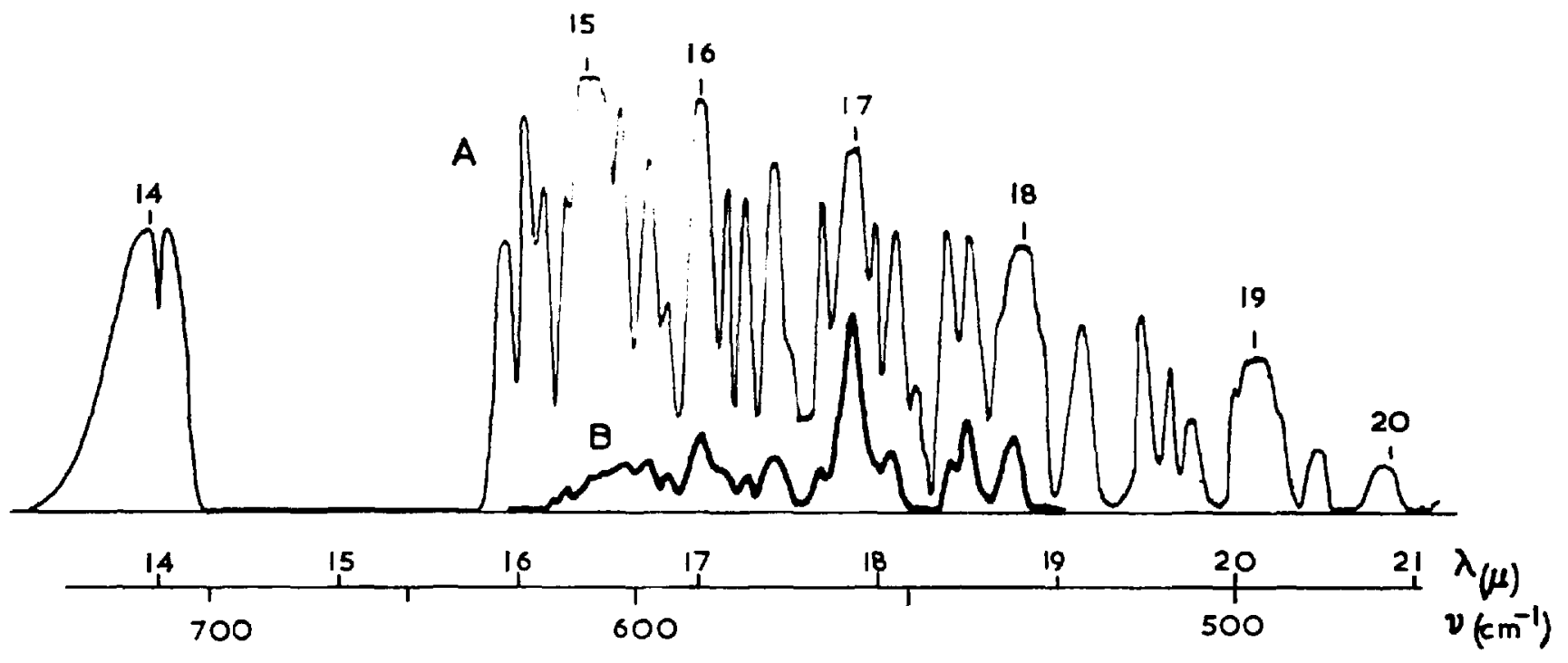

Fig 2.4. Location of windows.

A Spectrum over a horizontal path of $200 \mathrm{~m}$, with $0.250 \mathrm{~g} \mathrm{~cm}^{-2}$ of water vapour in the path.

B Solar spectrum; $\sim 3 \mathrm{~g} \mathrm{~cm}^{-2}$ water vapour in slant path. 


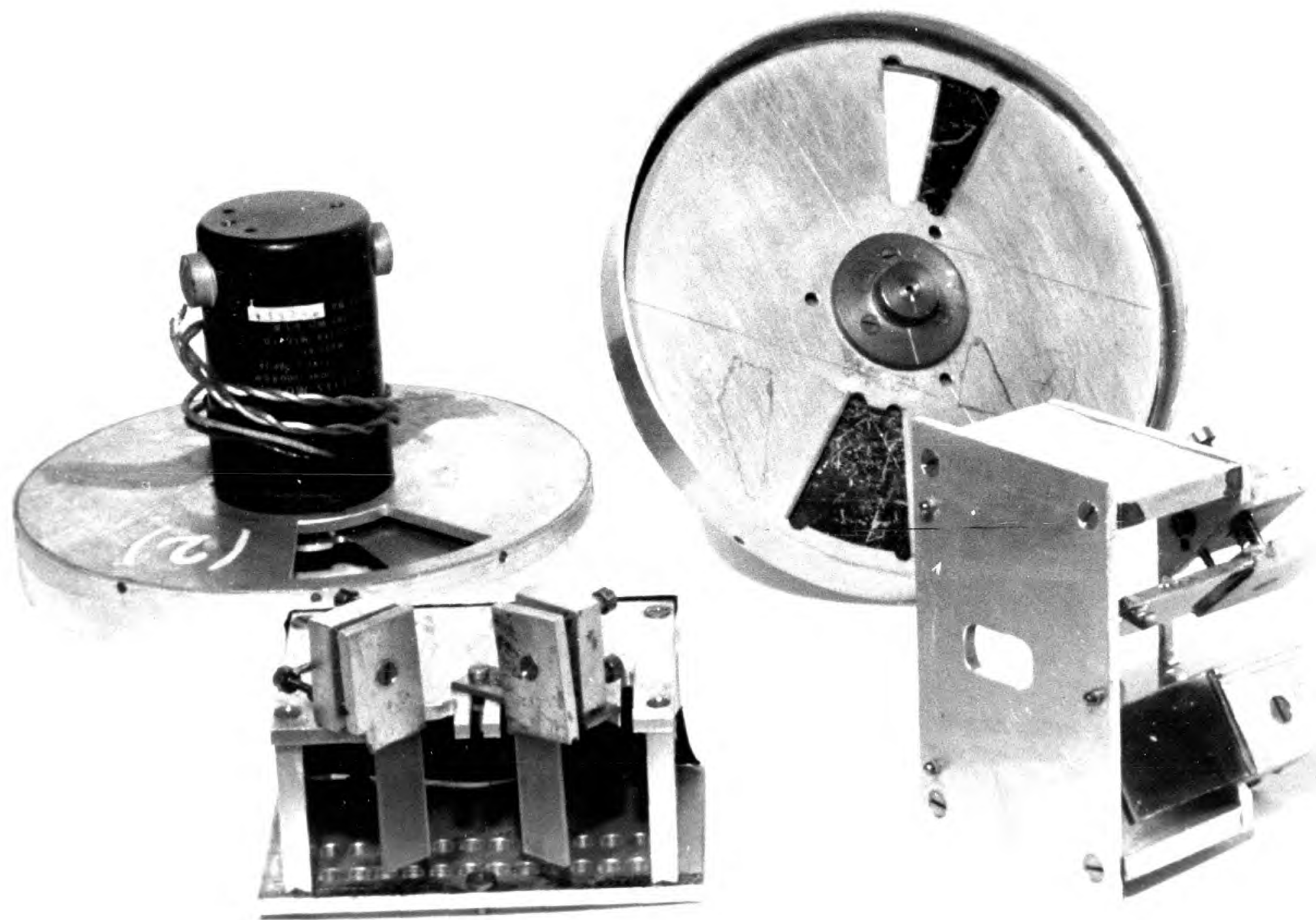


necessitated frequent zero and calibration signals.

\subsubsection{Filters}

Separation of orders was achieved with a variety of filters, whose charscteristics are shown in Fig 2.3. A permanent bloomed indium antimonide filter mounted over the Gelay window removed all radiation of $\lambda<7.3 \mu . \quad$ A double reststrahlen magnesium oxide filter, shown in Plate 2, was mounted kinematically behind the exit slit cutting off nearly all radiation of $\lambda<13.3 \mu$. This filter sould be replsced by an identically mounted pair of aluminised mirrors when working in the $7-13 \mu$ region. A terylene filter mounted after the exit slit was used for a special purpose described in $\oint 2.5 .2 .(n .2 x)$

\subsection{Performance of the System}

\subsubsection{Typical Spectra}

Fig 2.4 shows a speotrum over a path of $216 \mathrm{~m}$ with $0.250 \mathrm{~g} \mathrm{~cm}^{-2}$ of precipitable water. Much of the fine detail can not be shown. A solar spectrum is also shown for comparison, demonstrating the great opacity of the atmosphere at these wavelengths. The windows selected for measurement are shown by numbers 14 to 20 and are listed in Table 2.4 , the numbering continuing a sequence beginning in the $8-13 \mu$ region.

2.4 .2 Celibration

The spectrometer was calibrated by reference to several Plate 2. Magnesium oxide reststrahlen filter and chopper attenuators. 
isolated single lines throughout the speotrum, identified from the solar atlas of Migeotte et al (1956, 1957).

\section{$2.4: 3$. Resolution}

The resolution achieved oame very close to the theoretical value, as inferred from a comparison of the observed central absorption of a line of known intensity and half-width and that computed on the assumption of a triangular slit function. Typical working resolution ranged from $1.9 \mathrm{~cm}^{-1}$ at $17 \mu$ to $1.2 \mathrm{~cm}^{-1}$ at $21 \mu$, these figures representing the full width of the triangular slit function at half height。 It was the practice to work with constant slit width.

\section{4 .4 Stray radiation}

A conclusive test of stray radiation is difficult to realise, apart from broad tests of the separation of different order spectra. The best test is offered by an absorber with a narrow opaque band in a transparent regions if the signal drops to zero in the band, then stray must be absent. A few such tests were possible, e.g. the three opaque terylene bands in the $8-10 \mu$ region, the $15 \mu \mathrm{CO}_{2} \mathrm{Q}$ branch, and a few strong water vapour lines beyond $18 \mu$, which were black under high resolution. No stray was found at any of these points, so it is reasonable to assume that none should occur in the window regions.

However, it is instructive to consider the consequences of stray radiation on the results, Suppose that when the spectrometer is set to observe wavenumber $\mathcal{V}_{1}$, it actually passes in addition 


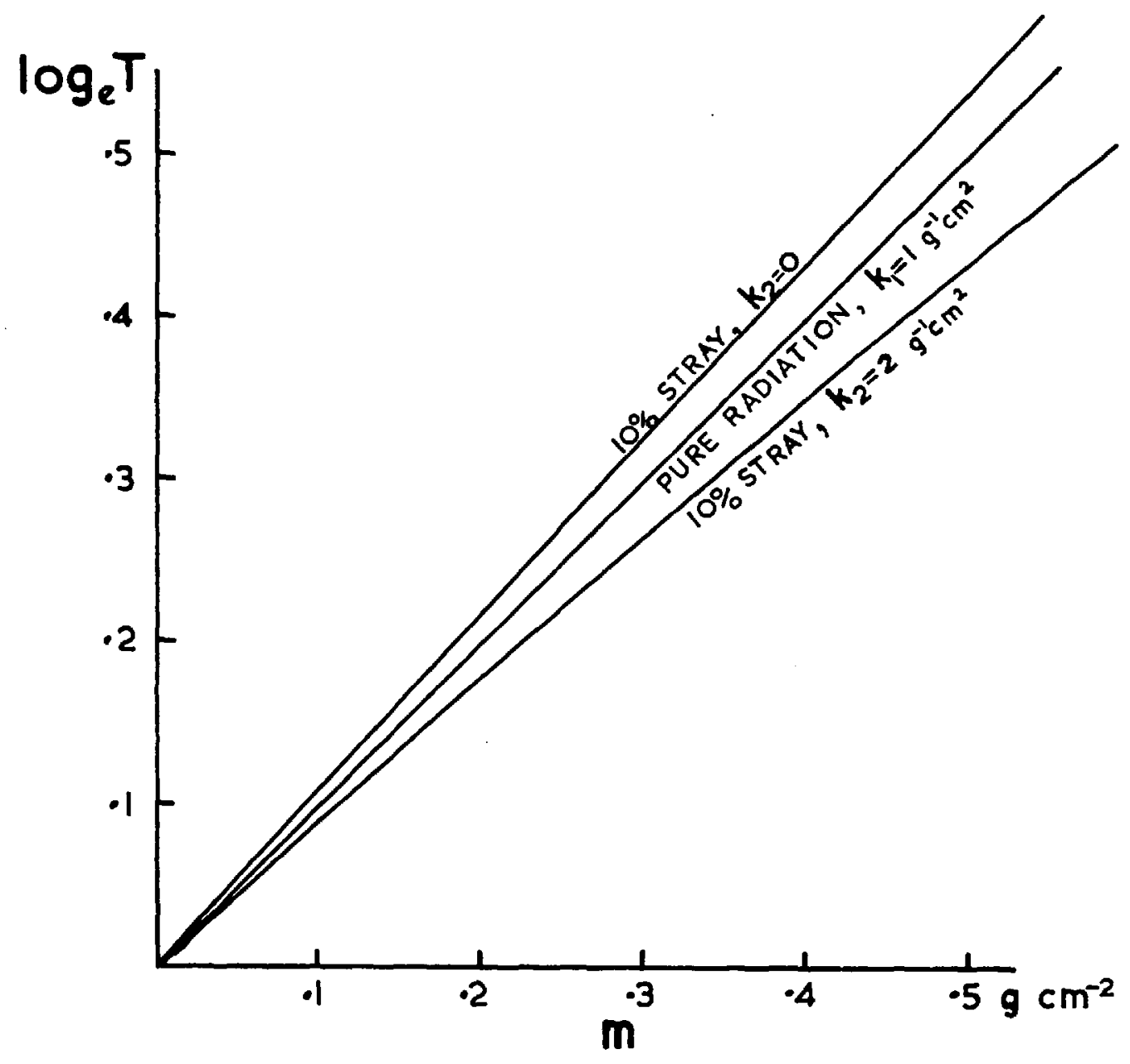

Fig 2.5. Effect of stray radiation.

Extinction for $k=1 g^{-1} \mathrm{~cm}^{2}$ with $10 \%$ of stray radiation of $k=0$ and $k=2 g^{-1} \mathrm{~cm}^{2}$. 
some atray radiation of wavenumber $V_{2}$ amounting to a fraction $r_{2}$ of that inoident on the entranoe slit. If the intensities are $I_{1}$ and $I_{2}$ at the source then after transmission through a path containing m $\mathrm{g} \mathrm{cm}^{-2}$ of absorber having mass absorption coefficients $\mathrm{k}_{1}$ and $\mathbf{k}_{2}$ respectively, the apparent transmittance will be given by

$$
T=\frac{I_{1} e^{-k_{1} m}+r_{2} I_{2} e^{-k_{2} m}}{I_{1}+r_{2} I_{2}}
$$

With

$$
\begin{aligned}
& \frac{r_{2} I_{2}}{I_{1}} \ll 1 \quad \text { there follows } \\
& -\log _{2} T=k_{1} m+\frac{r_{2} I_{2}}{I_{1}}\left[1-e^{-\left(k_{2}-k_{1}\right) m}\right] \\
& -\frac{d \log _{e} T}{d m}=k_{1}+\frac{T_{2} I_{2}}{I_{1}}\left(k_{2}-k_{1}\right) e^{-\left(k_{2}-k_{1}\right) m}
\end{aligned}
$$

so that the slope of the $-\log _{\ominus} T$ ws m plot always decreases with $m$, regardless of the sign of $k_{2}-k_{1}$. Consequently, when data near m $=0$ are lacking the best straight line through the observations always has a positive intercept. However, the curvature and intercept resulting from a small proportion ( $20 \%$ ) of stray are too small to be detected. Fig 2.5 shows the effect of $10 \%$ stray radiation for $k_{2}-k_{1}=1$ and $-1 \mathrm{~g}^{-1} \mathrm{~cm}^{2}$, with $k_{1}=1 \mathrm{~g}^{-1} \mathrm{om}^{2}$. These polnts will be

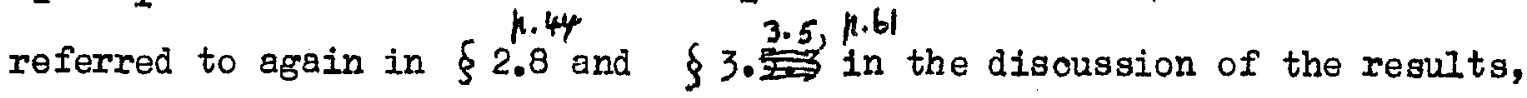
which exhibit a negative intercept and curvature the other way.

\section{4 .5 Iinearity of the detector system}

The linearity of the detecting system: waghocked periodically 


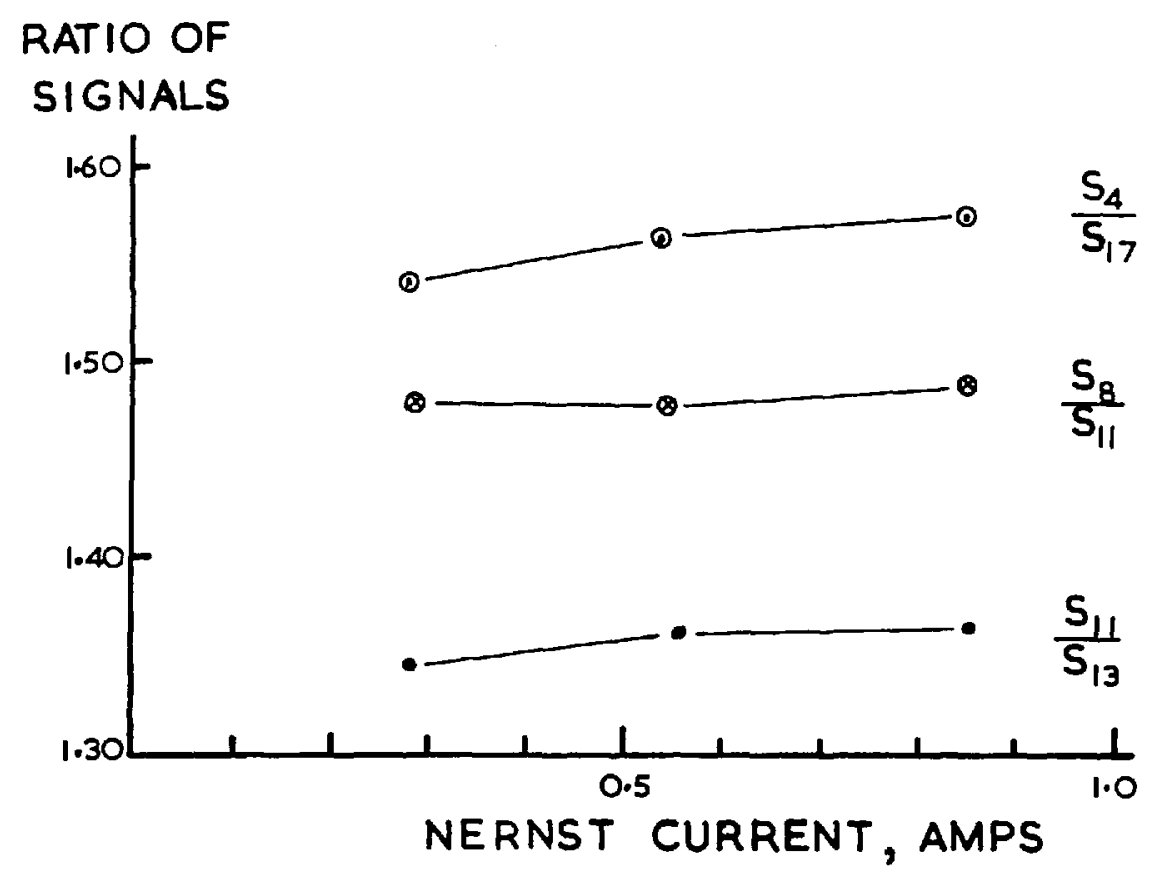

Fig 2.6. Variation of $\frac{S_{4}}{S_{17}} \frac{S_{8}}{S_{11}}$ and $\frac{S_{11}}{S_{13}}$ with Nernst current. 
by use of a set of high speed chopper attenuators of accurately measured geometrical transmittance. These have been described by Saiedy (1959) and two of them are shom in Plate 2. At no time was any significant departure (1.e. $0.5 \%$ ) from linearity observed over the full range of signal/in the experiment.

\subsubsection{Stability of the System}

An appreciable fluctuation of the overall sensitivity and zero reading of the system was observed. Part at least originated somewhere in the detector system, and it is likely that the long path optios suffered slow drifts. Probably the largest effect was the variation of water vapour in the path. Also to be considered was the possible variation of source output with variation in the power supply and ventilation: the effect of the former and indirectly of the latter was investigated by varying the current supply to the Nernst, and Fig 2.6 shows the results for windows 4 and 17 (and also for windows 8, 11, 13, to be considered in Chapter 3) over a wide range of current certainly far more than would occur under working conditions. The important point to note is that $\frac{I_{4}}{I_{17}}$ changes by only $2 \%$ over the whole range.

\subsection{Experimental Technique}

2.5.1. Choice of method

Examination of the stability of the system indicated that little reliance could be placed on any technique involving the comparison of 
signals obtained with time separations greater than a few minuted. This consideration ruled out the commonly adopted procedure of recording complete spectra from which window intensities are read off at the peaks between lines. Instead, it would be necessary to make observations at carefully selected wavelengths with the grating stationary, interpolating frequent calibration signals and zero levels.

An absolute method of measuring extinction involves in principle measuring the intensity before and after passing through the absorbing path. This would be possible if, for example, we could perfect a long and a short path giving identical illumination of the aperture of the spectrometer and with identical reflection losses. In such a large apparatus, exposed at times to infavourable conditions, si these demands were condered unattainable. Recourse to a relative method was indicated, in which geometrical effects were eliminated by comparing signals at two wavelengths.

Consider the ratio $y_{i, r}=\frac{S_{i}}{S_{T}}$ of the two signals $s_{i}$ and $s_{r}$ in two windows $i$ and $r$. Let $S_{i}$ and $S_{r}$ be the signals which would be obtained if there were no absorption in the atmospheryic path. Then

$$
y_{i, \tau}=\frac{S_{i} e^{-\beta_{i} l}}{S_{r} e^{-\beta_{r} l}}=S_{i, r} e^{-\left(\beta_{i}-\beta_{r}\right) l}=S_{i, r} e^{-\beta_{i-r} l}
$$

where $\beta$ is the extinction coefficient per unit length of path and $l$ is the path length. 
By observing $y_{i, r}$ for two values of $l$, assuming constant $s_{i,+}$, we can determine $\beta_{i-t}$. A very short path suggests itself for one value of 1 , whilst either of the long paths provide the other value. This method was in fact used in a preliminary set of observations, but for reasons which will be given in $\oint 2.5 .2$ this was later changed so that the $400 \mathrm{~m}$ and $200 \mathrm{~m}$ paths were used to provide the two required values.

2.5.2. Measurement of $\beta_{17-4}$.

In order to establish an absolute value for $\beta_{i}$ it is necessary to choose a window + for which $\beta_{r}$ is known. Saiedy has measured continuum absorption coefficients in the $\theta-12 \mu$ region using the sun as source, and the results are published in B.S.S. (1963). In this region the absorption coefficients are an order of magnitude smaller than those between 17 and $20 \mu$, so that even if $k_{r}$ were not known, little error would result from assuming $\beta_{r}=0$ in Eq. 2 above.

One difficulty in choosing a reference window near $10 \mu$ was that it was then impossible to observe the $17-20 \mu$ region without changing the filtering arrangements, thus risking disturbance of the set-up. However, a fortuitous combination of circumstances suggested a very simple solution. It was noticed that terylene film $12 \mu$ thick has an opaque band at a frequency exactiy double that of window 17 ( $\left.559.4 \mathrm{~cm}^{-1}\right)$. It was therefore a straight forward matter to compare the signal in window 17 with that at $\nu=1118.8 \mathrm{om}^{-1}$ (referred to as window 4 hereafter) by setting the grating for window 17 in the firat 


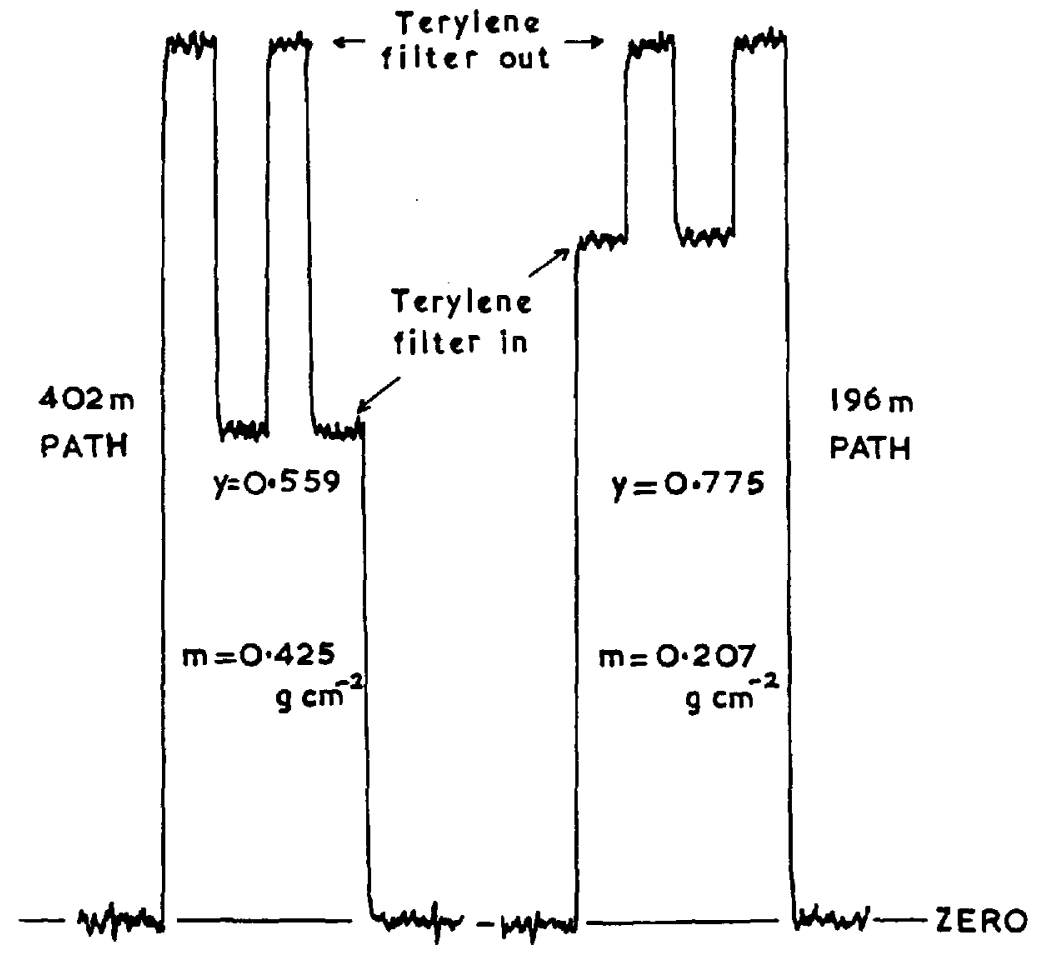

$$
\begin{aligned}
T_{0} & =20.0{ }^{\circ} \mathrm{C} \\
T_{W} & =15.3{ }^{\circ} \mathrm{C} \\
e & =14.2 \mathrm{mb} \\
\rho & =10.5 \mathrm{~g} \mathrm{~m}^{-3} \\
k_{n-4} & =1.64 \mathrm{~g}^{-1} \mathrm{~cm}^{2}
\end{aligned}
$$

Fig 2.7. Typical run for window 17. 
order, making use of the second-order spectrum/window 4. Signals were obtained with and without the terylene filter, an auxiliary sector attenuator of transmittance $K$ being used in the latter case to bring the aignals to approximate equality. A typical mun is illustrated in Fig 2.7. Let the ratio of these two signals be $y$. with the terylene filter, only the first-order spectrum of window 17 was transmitted; without it the much more intense second-order spectrum of window 4 mas also transmitted. Higher-order speotra were eliminated by the indium antimonide filter.

\section{Let}

$F_{i}$ be the transmittance of the terylene filter in window is

$S_{i}$, the signal which would be obtained in window $i$ in the absence of absorption along the atmospheric path;

$\beta_{i}$, the extinction coefficient per unit length in window 1 ; and

1 , the path length ( $I_{2}$ and $I_{1}$ are used to denote different path lengths). Then Lambert's law gives

$$
y=\frac{F_{17} S_{17} e^{-\beta_{17} l}+F_{4} S_{4} e^{-\beta_{4} l}}{K\left[S_{17} e^{-\beta_{17} l}+S_{4} e^{-\beta_{4} l}\right]}
$$

For terylene film of $12 \mu$ thickness, $F_{4}=0$ and Eq. 2.3 can be written

$$
\beta_{17-4}=\log _{e} s_{17,4}+\log _{e}\left(\frac{F_{17}}{k y}-1\right)
$$

where $S_{17,4}=S_{17} / S_{4}$. Thus, given $F_{17}$, observations of $y$ for two values of 1 provide $\beta_{17}-4$ provided $S_{17,4}$ is the same for both determinations of $y . W_{\theta}$ then have 


$$
\beta_{17-4} L=\log _{2}\left(\frac{F_{17} y_{2}-1}{\frac{F_{1} z_{y_{1}}-1}{k}}\right)=\log _{2} \frac{y_{2}}{y_{1}}\left(\frac{1-\frac{k}{F_{17}} y_{2}}{1-\frac{k}{F_{17}} y_{1}}\right) \quad 2.5
$$

where $I=I_{2}-I_{1}$

With $\mathrm{F}_{17}=0.55, K=0.069$ and $\mathrm{y} \sim \mathrm{l}$, the computation of $\beta_{17-4}$ from Eq 2.5 is very insensitive to the value of $\mathrm{K} / \mathrm{k}$, a $20 \%$ error giving less than $1 \%$ error in $\beta_{17}-4^{*}$. The value of $F_{17}$ was in fact measured for every pair of observations of $y$ by taking the ratio of the signals obtained with and without the filter, the secondorder speotrum of Window 4 being eliminated in both by a second fixed terylene filter.

The condition of constancy of $S_{17,4}$ requires care for achievement. Its value depends on the relative magnitude in windows 4 and 17 of (i) the intensity I of radiation emitted by the source; (ii) the product, $R$, of the reflectances of all the mirrors in the system; (iii) the response of the detection system, including the grating and filters.

Regarding (i), it was found that $I_{4} / I_{17}$ was greater by 5 to $10 \%$ at the center than at the edge of the filament. It was therefore necessary to focus and align the image very carefully to ensure that the same part of the source was used in each pair of observations. The variation of $\mathrm{I}_{4} / \mathrm{I}_{17}$ with filament temperature mas less than $2 \%$ over the range $1500^{\circ}-2000^{\circ} \mathrm{K}$, which was certainly much greater than 
the temperature variations induced by draughts, (see $\oint 2.4 .6$.

Regarding ( $i i)$ there was some slight doubt about the constancy of the reflectance of the mirrors with change in humidity, owing to a possible growth of hygroscopic nuclei on the mirror surfaces. Evidence was diffioult to obtain, but tests were possible on occssions with near saturation, when a heater near $\mathrm{M}_{2}$ could be switched on to lower the relative humidity quickly (all other mirrors were kept in heated enclosures). No significant change of $y_{17,4}$ was observed. The effect was however of no consequence since each pair of observations was made in the minimum interval (about $5 \mathrm{~min}$ ) to effect the necessary changes, so as to keep changes in humidity to a minimum. It was necessary moreover to assume that $R_{17} / R_{4}$ was the same at any one time for each of the mirrors used for $\mathbb{M}_{2}$; which is reasonable because the mirrors were aluminized at the same time and were subsequently kept under similar conditions.

Regarding (iii) the transmiasion of the terylene filter was found to be uniform over its whole surface, but that of the indium antimonide was somewhat nonuniform, possibly because of variations in the antireflection coating. The efficiency of the grating was also nonuniform and it was therefore essential to ensure identity of position and distribution of illumination in the beams derived from the extermal optical systems - by accurate alignment and focu/sing, and the introduction of a stop on $\mathbb{M}_{6}$ to cover the images of obstructions in the beam. 
In the course of the experiment, several changes were made in order to improve the reproducibility of $\mathrm{S}_{17,4^{\circ}}$ The experimental method and optical layout described in $\oint 2.5 .1^{n .22}$ and $\$ 2.3^{n .15}$ was the final form. It superseded a version in which it was possible to obtain a short path of $10 \mathrm{~m}$ as well as paths of 200 and $400 \mathrm{~m}$, but this invoived the off-axis use of spherical mirrors, giving considerable distortion, In this earlier method, the values of 1 used for a paix of observations were $I_{2}=10 \mathrm{~m}$ and $I_{1}=200$ or $400 \mathrm{~m}$. Some systematic error was, however, possible: firstly, from the use of four mirrors not common to both beams (though with the same total number of reflections), with the possibility that different relative reflectances $R_{17} / R_{4}$ were involved; secondly, from uncertainty in fulfilling condition (iii) above owing to distortion and different beam geometry. These uncertainties were much reduced in the final method since only one mirror was not common to both beams, and with axial optios it was possible to ensure that both beams were identical.

There was reasonable agreement, however, between the results derived from both methods, indicating that the unfertainties present in the earlier method were not serious. It is probable that $s_{17,4}$ was feproducad to better than $1 \%$ in each pair of observations in the final method. Support for this view is afforded by the faot that noticeable deliberate misalignments produced no systematic change in $y$. 
2.5 .3 Measurement of $\beta_{14-4}$.

Employing first-order spectra in both cases, the ratio $x_{14,4}$ $\left(=\frac{S, 4}{S_{4}}\right)$ of the signals in windows 14 and 4 was measured. We then have

$$
x_{14,4}=\frac{s_{14}}{s_{4}} \exp -\left(\beta_{14}-\beta_{4}\right) l .
$$

Then from observations over two paths, subject to the experimental precautions stated previously, a value of $\beta_{14}-\beta_{4}$ may be found. 2.5.4 Measurement of $\beta_{i}-\beta_{4}$

A double reststrahten magnesium oxide filter was mounted kinematically behind the exit slit, cutting off almost entirely all radiation of $\lambda<13 \mu$. This filter was readily interchangeable with a pair of identically mounted aluminized mirrors, used for $\lambda<13 \mu$. The ratios $x_{i, 17}$ of the signals for each of the Windows $15,16,18$, 19 and 20 to that for Window 17 were determined for two path Iengths, and $\beta_{i-17}$ may be found as in $\$ 2.5 .3$. With simultaneous measurements of $\beta_{17-4}$ we finally obtain $\beta_{i-4}$.

\subsubsection{Meanurement of Water Vapoux}

The depth of precipitable water in the path was obtained from readings of an Assmann psyohrometer exposed at the mean height ( $\sim \mathrm{Im}$ ) of the beam, oocasional checks being made with a second psychrometer for uniformity along the path. 


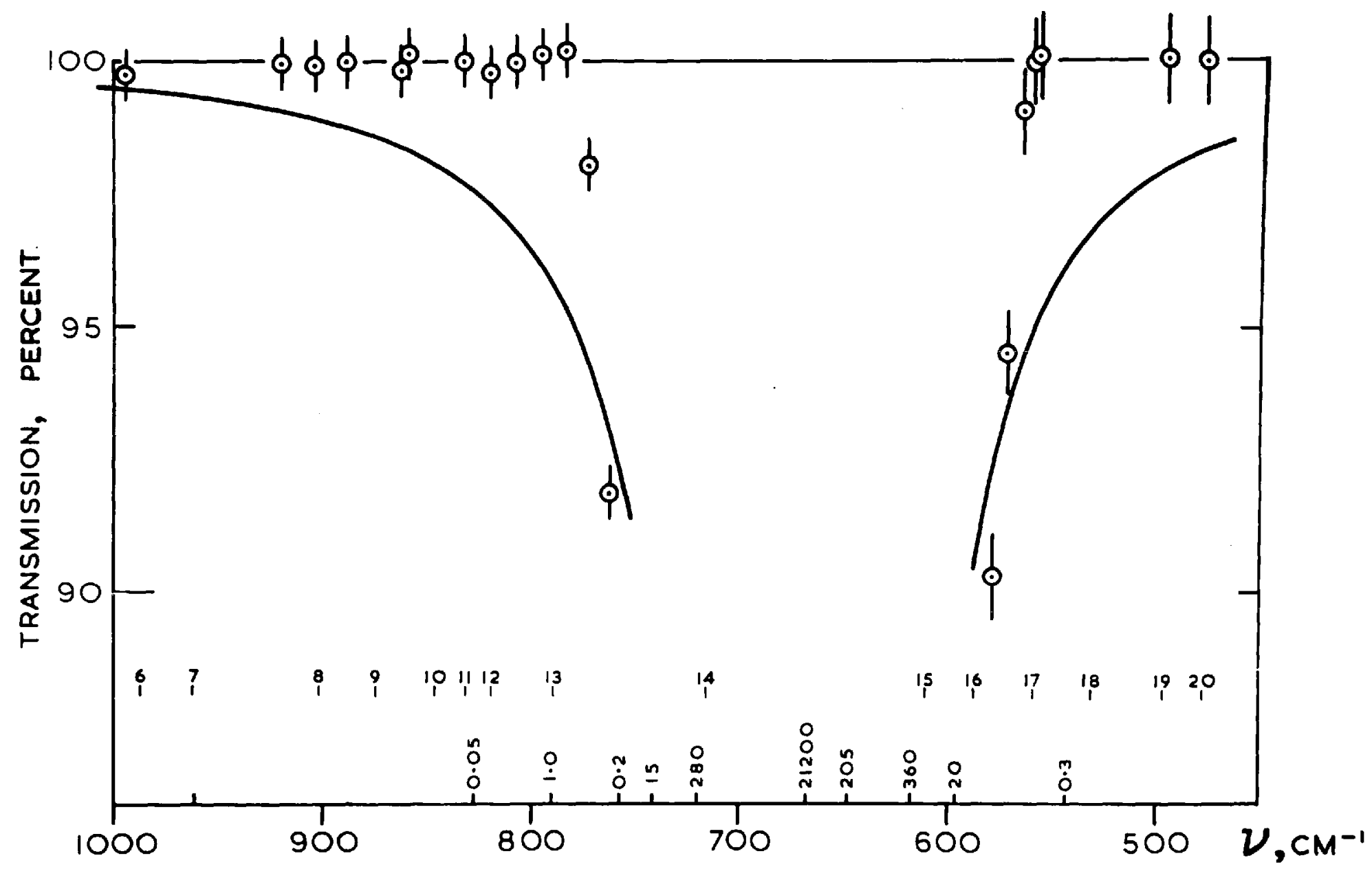

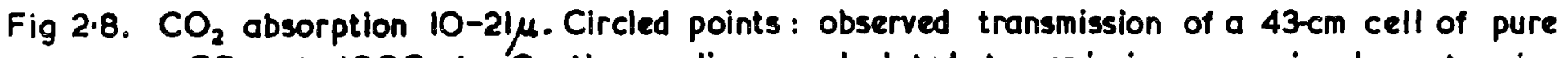
$\mathrm{CO}_{2}$ at $1000 \mathrm{mb}$. Continuous lines: calculated transmission, assuming Lorentz wings (neglecting minor bands, whose positions and strengths $\left(g^{-1} \mathrm{~cm}\right)$ are shown on the abscissa) The positions of windows 6-20 are shown. 
2.5.6. $\mathrm{CO}_{2}$ ABSORPTION IN THE REGION $1300-478 \mathrm{~cm}^{-1}$.

Before disoussing the results on the water-vapor continuum out to $21 \mu$, it is appropriate to consider the possibility of this continuumstoing overlaid by that from oarbon dioxide and aerosol. Regarding the former, a $43-\mathrm{cm}$ cell of pure $\mathrm{CO}_{2}$, with windows of polythene, was inserted in the beam, giving "depth" of $0.082 \mathrm{~g} \mathrm{~cm}^{-2}$, the equivalent of $1.4 \mathrm{~km}$ of air at sea level. The transmissions on ei ther side of the $\nu_{2}$ band are shown in Fig 2.8, and are compared with those to be expected if the wings of the $\mathrm{CO}_{2}$ lines have Lorentz shape, taking the $\nu_{2}$ band intensity to be $1.22 \times 10^{5} \mathrm{~g}^{-1}$ om and the mean line half-width $0.064 \mathrm{~cm}^{-1}$ at $I$ atm and $298^{\circ} \mathrm{K}$ (Kaplan and Eggers, 1956). We see that the observed absorption is considerably less than from Lorentz wings until quite close to the band center, the absorption due to line centers of the weaker bands indicated in Fig. 2.8 being first apparent. Kaplan (1953) and Benediot (1955) have argued for a decrease faster than Lorentz in the $\mathrm{CO}_{2}$ wings, and they suggest $\mathrm{s}$ wing profile which is consistent with the negligible absorption observed in the present work outside the range 790 to $560 \mathrm{~cm}^{-1}$. Only Windowa 14, 15 and 16 were found to be affected by $\mathrm{CO}_{2}$ absorption, this being attributed to nearby lines, and is therefore analyzed accordingly.

\subsubsection{EXTINCTION BY AEROSOL .}

During the experiment, it was suspected that the extinction was greater under very hazy conditions, and it was therefore necessary to allow for aerosol attenuation in the analyais. No direct measurements 


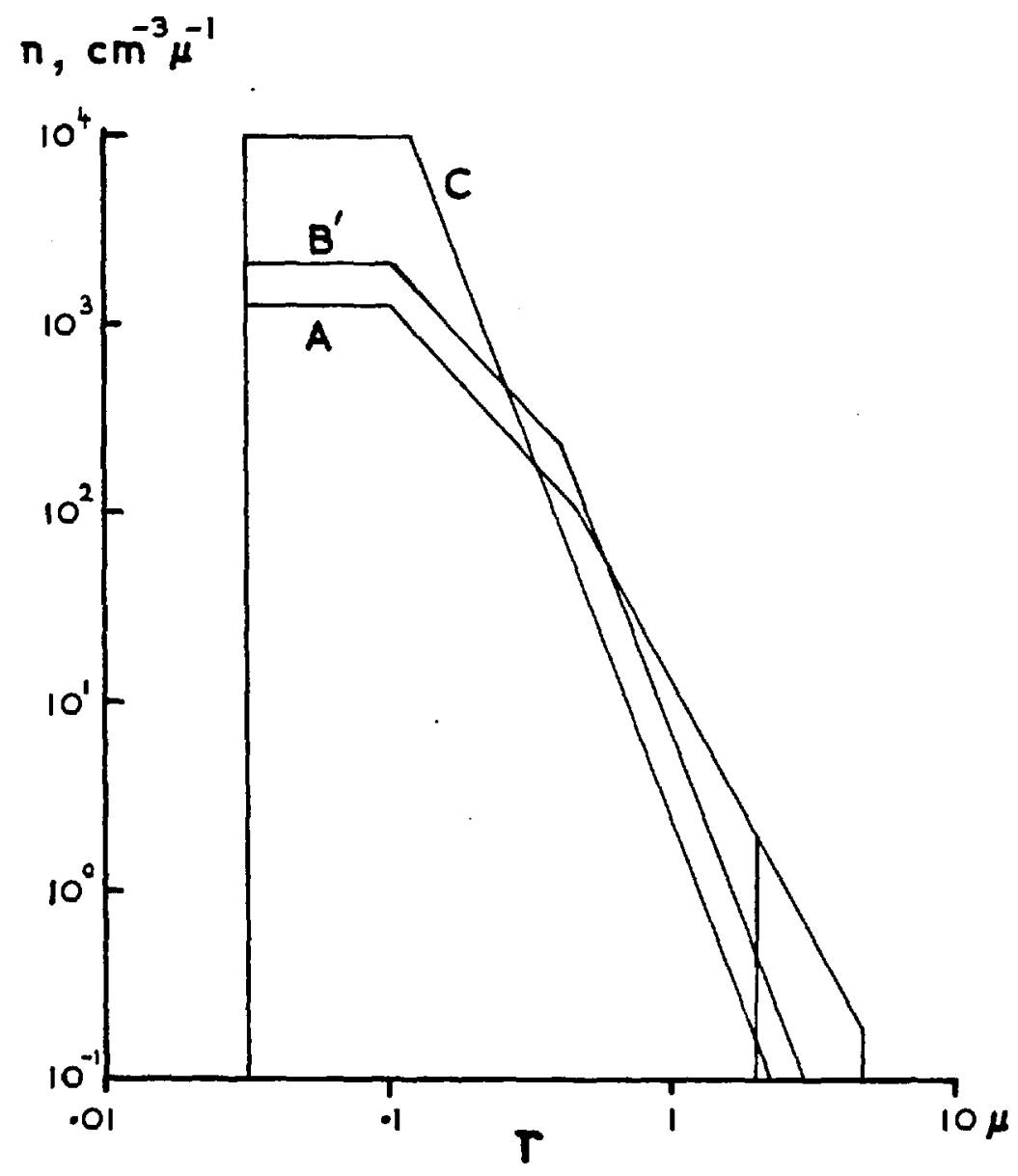

Fig 2.9. Typical aerosol distributions.

A Turbulent marine air.

$B^{\prime}$ Coastal air.

C Continental air.

(From Deirmendjian, Ann. Geophys., 15, p. 222). 
of particle concentration and size were made, but local visibility data were available and it is of interest to inquire to what extent these could be used to infer the opacity due to aerosol in the 10 $20 \mu$ region. Deirmendjian (1959, 1960) has computed extinction coesficients from 0,625 to $14 \mu$ for a number of realistic aerosol distributions, illustrated in Fig 2.9. Values for $0.625,8.6,10.0$, 12.0 and $14.0 \mu$ are reproduced in Table 2.1 .

\section{Tabje 2.I}

Extinction coefficient for different aerosol distributions

HPZE

MODEL

$\begin{array}{llllll}A(2 \mu) & 0.245 & 23 & 29 & 6.2 & 6.7 \\ B(2 \mu) & 0.127 & 38 & 42 & 14 & - \\ C(2 \mu) & 0.0822 & 33 & 38 & 12 & 7.6 \\ A(4.48 \mu) & 0.328 & 4.3 & 11 & 4.5 & 3.7 \\ B(4.48 \mu) & 0.136 & 16 & 27 & 11 & - \\ O(4.48 \mu) & 0.0864 & 19 & 29 & 10 & 6.3\end{array}$

The tabulated quantities are the computed values of $\beta$ in the expression $T=e^{-\beta L}$ where $T$ is the transmittance for a path Jength I Rm. The haze models are illustrated in Fig 2. $9 ;$; the number in. brackets is the radius of the largest particle. For absorption and scattering by water spheres. (After Deirmendjian (1960)).

It can be seen that the ratios of the extinction coefficient at $0.625 \mu$ to those at $10.0,12.0,14.0 \mu$ are approximately 30,11 and 7 respectively, for all distributions except $\Delta(4.48 \mu)$. (which has 
many large particles), suggesting that the distribution is not very important and that the extinction in the region $8-14 \mu$ may be taken to be proportional to that at $0.625 \mu$.

The above computations may be extended to $20 \mu$ using a series expansion of the Mie theory for small droplets given by Penndorf (1952) (small droplets in this context would be less than about $2 \mu$ radius).

The extinction efficiencies $K_{S}$ and $K_{Q}$ for scattering and absorption (defined as the ratio of the extinotion oross-section to the geometrical area), are given by

$$
K_{5}=\frac{8}{3} \alpha^{4}\left|\frac{m^{2}-1}{m^{2}+2}\right|^{2}\left\{1+\frac{6}{5\left|m^{2}+2\right|^{2}}\left[\left(n^{2}+k^{2}\right)^{2}-4\right] \alpha^{2}-\frac{8 n k}{\left|m^{2}+2\right|^{2}} \alpha^{3}\right\} \quad 2.6
$$

$$
K_{a}=\frac{24 n k \alpha}{\left|m^{2}+2\right|^{2}}+\frac{4 n k \alpha^{3}}{15}\left\{1+\frac{25}{\left|2 m^{2}+3\right|^{2}}+\frac{18}{\left|m^{2}+2\right|^{4}}\left[7\left(n^{2}+k^{2}\right)^{2}+4\left(n^{2}-k^{2}-5\right)\right]\right\} 2.7
$$

where $m=n-i k=$ complex refractive index $\alpha=\frac{2 \pi r}{\lambda}$ with $\gamma=$ radius of droplet and $\lambda=$ wavelength.

The values caloulated from these formulae have been found by welI

Penndorf to agree frith those computed from the full theory for $\alpha<0.8$, $k \leqslant 1$ and $1.25<n<1.75$.

Using the absorption coefficients given by Plyler and Acquista (1954) and the refractive index data from Dorsey (1940, p.185) 
for 28 and $20 \mu, \mathrm{K}_{a}$ and $\mathrm{K}_{s}$ were calculated for selected wavelengths in the $8-20 \mu$ region, giving some overlap with the computations of Deirmendjian for comparison. The results are given in Table 2.2.

\section{Table 2.2}

Absorption and scattering efficiencies for small droplets

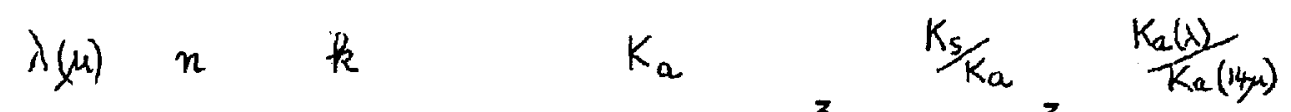

$\begin{array}{lllllll}8.94 & 1.27 & 0.050 \quad .0819 \mathrm{R}+.0125 \mathrm{R}^{3} \quad .242 \mathrm{R}^{3} \quad .22\end{array}$

$\begin{array}{llllllll}10.0 & 1.212 & 0.061 & .0915 R+.0089 R^{3} & .092 R^{3} \quad .25(.25)\end{array}$

$\begin{array}{lllllllll}11.0 & 1.190 & 0.13 & .182 & R+.0133 R^{3} & .0267 R^{3} \quad .50\end{array}$

$12.0 \quad 1.1650 .2058 \quad .269 \mathrm{R}+.0150 \mathrm{R}^{3} \quad .0144 \mathrm{R}^{3} \quad .73(.81)$

$\begin{array}{lllllll}14.0 & 1.309 & 0.3582 & .367 \mathrm{R}+.0289 \mathrm{R}^{3} \quad .0261 \mathrm{R}^{3} \quad I\end{array}$

$\begin{array}{llllllll}18.0 & 1.43 & 0.48 & .349 \mathrm{R}+.0238 \mathrm{R}^{3} & .0165 \mathrm{R}^{3} \quad .95\end{array}$

$20.0 \quad 1.480 \quad 0.360 \quad .228 \quad R+.0130 R^{3} \quad .0150 R^{3} \quad .62$

$\mathrm{K}_{\mathrm{a}}$ and $\mathrm{K}_{\mathrm{g}}$ are the ratios of the absorption and scattering cross-sections to the geometrical area, computed from Eqs. 2.7 and 2.6. $\mathrm{n}$ and $\mathrm{k}$ are the real and imaginary parts of the complex refractive index. Valid for $R<2$ where $R$ is the droplet radius expressed in microns. The values in braokets for 10.0 and $12.0 \mu$ are taken from Deirmendjian (1960).

The value of $\mathrm{n}$ for 10,11 , and $12 \mu$ is just outside the range giving high accuracy, but the error should not exceed $20 \%$. In all cases the fraction of the total extinction attribut to scattering is small for droplets up to $1 \mu$ radius, and decreases as the cube of the 
radius, so that scattexing is entirely negligible for all except the largest droplets. We note that $\frac{K_{a}(10)}{K_{a}(14)}$ and $\frac{K_{a}(12)}{K_{a}(14)}$ calculated from Eq. 2.7 are in reasonable agreement with Deirmendjians values of $\frac{\beta(10)}{\beta(14)}$ and $\frac{\beta(12)}{\beta(14)}$ respectively. The computations offable 2.2 may now be used with reasonable confidence to extend $\mathrm{Tabl} \theta 2.1$ to $20 \mu$, using the normalising wavelength of $14 \mu$, with the result that $\mathbb{K}_{18 \mu}=.13 \mathrm{~K}_{0.625 \mu}$ and $\mathrm{K}_{20 \mu}=0.09 \mathrm{~K}_{0.625 \mu}$.

The final step in the argument is to assume that the visual extinction coefficient $\beta_{\text {vis }}$ is proportional to $\beta_{0.625 \mu}$. Whilst this is not likely to be very accurate, we are only concemed here with a factor of 2 or so. We may then write

$$
\begin{aligned}
\beta_{a, i}=D_{i} \beta_{\text {vis }} \quad \text { where } \beta_{a, i} & =\text { aerosol extinction coefficient } \\
& \text { in window } i \\
D_{i} & =\text { constant. }
\end{aligned}
$$

For the purpose of the discussion $(\xi 2.16)^{6.37}$ of observations in windows 17 and 19 relative to window 4 , we note from the above that if we assume $\beta_{\text {vis }}=\beta_{0.625 \mu}$, then $D_{19}=0.09, \quad D_{17}=0.13$ and $D_{4}=0.05$.

$\beta_{\text {vis }}$ was estimated from the visual range $\nabla$ by $\beta_{\text {vis }}=\frac{3.9}{V}$ (Middleton 1952, p.105). Owing to the difficulty of estimating visual ranges $\nabla_{A}$ greater than $2 \mathrm{~km}$ on the site at Asoot, the data $\nabla_{L}$ from Iondon Airport, $16 \mathrm{~km}$ to the north-east, were used on these occasions (the great majority, in fact) and adjusted if necessary for any 
difference of relative muidity between the two sites by the working expression

$$
V_{A}=V_{L} \frac{100-H_{L}}{100-H_{A}}
$$

vinere $H_{L}, H_{A}$ are the relative humidities $(\%)$ at London Airport and Ascot respectively.

This procedure is satisfactory if the nucleus spectrum is the same at the two sites, any difference in visual range then being a function of the respective relative humidities. The form of the above rough correction was suggested by an examination of the theoretical and observed variation of visual range with relative humidity (Wright, 1940).

Some idea of the order of magnitude of aerosol absorption to be expected at $18 \mu$ under hazy conditions may readily be calculated. Suppose $V=5 \mathrm{~km}$. Then $\beta_{18 \mu}=0.13 \times \frac{3.2}{5}$ per $\mathrm{km}=0.10$ per $\mathrm{km}$. Over a $400 \mathrm{~m}$ path, the transmittance would then be $e^{-0.4 \times 0.10}=0.960$, or $4 \%$ absorption. The absorption due to water vapour, on the other hand, would be between $30 \%$ and $50 \%$, depending on the humidity, indicating that aerosol absorption is relatively unimportant.

2.6. Results 2.6.1. Windows 17 and 19

The regression equation relating the observed extinction to p.30 vapour content and visibility $(\$ 2.5 .7)$ may be written 


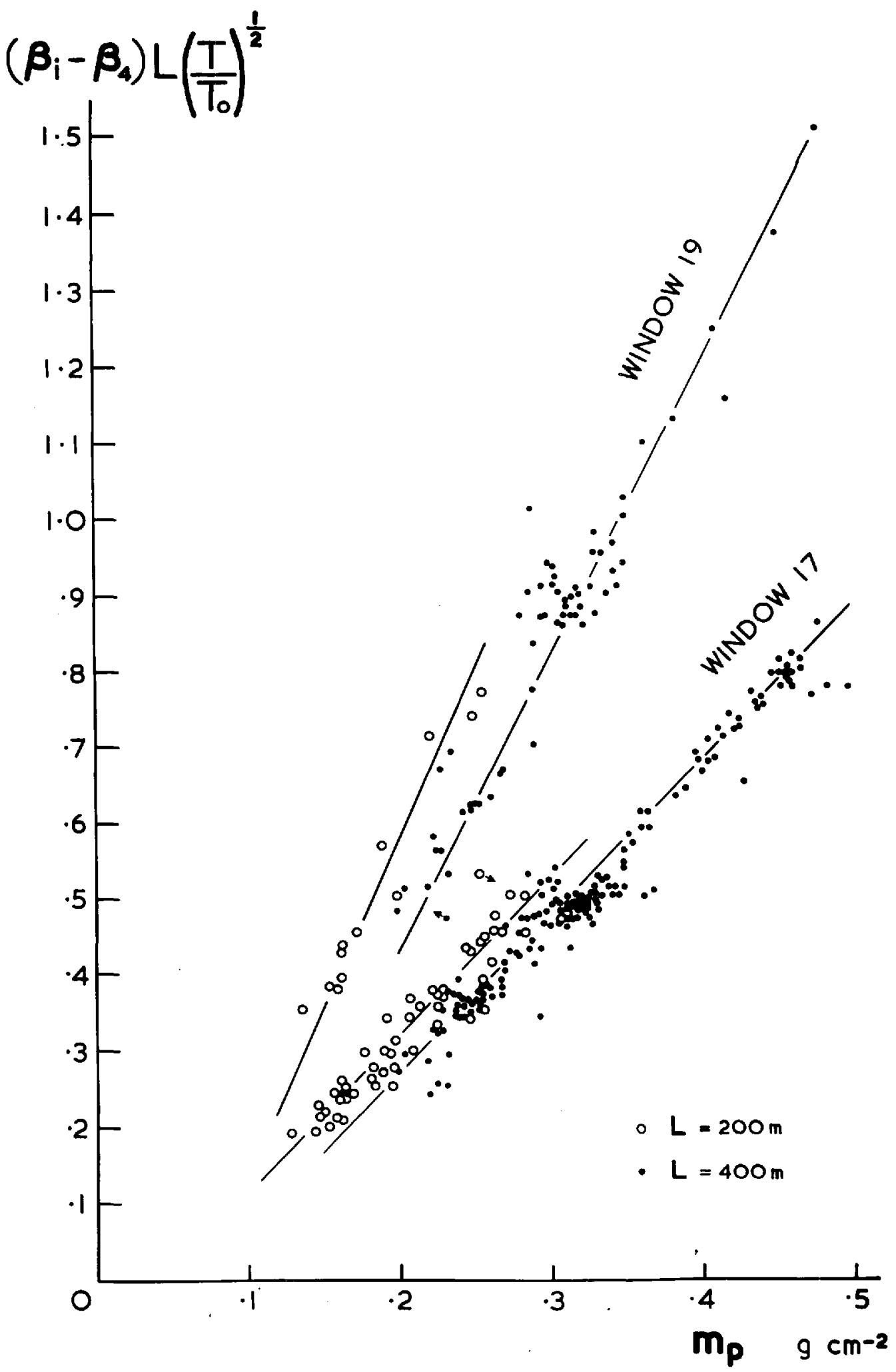

Fig 2:10. Observed extinction coefficients for windows 17 and 19 as a function of water vapour in the path. 


$$
\beta_{i-4}=k_{i-4} \frac{m}{L}+\frac{3.9}{V} D_{i-4}
$$

where $\mathrm{k}$ is the mass absorption coefficient, $i=17$ or 19 , m is the mass of water vapour per $\mathrm{cm}^{2}$ in the path and $\mathrm{L}=l_{2}-l_{1}$ (see $\$ 2.5 .2$ )。 It will be assumed that the variation of the half-width $\alpha$ and intensity $S$ of absorption lines with temperature and pressure may be witten

$$
\begin{aligned}
& \alpha(P, T)=\alpha\left(\mu_{0}, T_{0}\right) \frac{P}{\mu_{0}}\left(\frac{T_{0}}{T}\right)^{\frac{1}{2}}, \\
& S(T)=S\left(T_{0}\right)\left[1+\epsilon\left(T-T_{0}\right)\right],
\end{aligned}
$$

where $P=p+8 \theta, \quad p$ and $e$ being the partial pressures of dry aix and water vapour, respectively, a is the ratio of self-to air-broadening, and $p_{0}, T_{0}$ are standard values of pressure $(1000 \mathrm{mb})$ and temperature $\left(0^{\circ} \mathrm{C}\right)$. Then Eq. 2.8 can be written, to good approximation;

$$
\frac{L \beta_{i-4}}{m_{\mu}}\left(\frac{T}{T_{0}}\right)^{\frac{1}{2}}=k_{i-4}\left(\mu_{0}, T_{0}\right)\left[1+\epsilon\left(T-T_{0}\right)+\frac{q e}{n}\right]+\frac{3.9 D_{i-4} L}{V m_{\mu}},
$$

where

$$
m_{p}=m \frac{n}{p_{0}} \text {. }
$$

Figure 2.10 shows observations of $\mathrm{L} \beta i-4\left(\frac{T}{T_{0}}\right)^{\frac{1}{2}}$ as a function of $m_{p}$ for windows 17 and 19. Each point is the result of a pair of observations; the open circles result from $l_{2}=414 \mathrm{~m}$, $l_{1}=216 \mathrm{~m}$; the full circles from $l_{2}=414 \mathrm{~m}, l_{1}=10 \mathrm{~m}$. The data are tabulated in Appendix 2.1. A strong correlation is evident, but the 
observations for each window fall distinctly into two groups according as $L=400$ or $200 \mathrm{~m}$, and the best straight lines through each set of points have significant negative intercepts. For both windows the extinction is apparently greater at a given value of $m_{p}$ for the shorter path for which the vapour density must be double that on the longer path, so that self-broadening suggests itself as an explanation. However, points of $l 0 w \mathrm{~m}_{\mathrm{p}}$ on all lines were obtained under cold, dry conditions and those of high $m_{p}$ under warm, humid conditions, so that it is equally possible that a positive temperature dependence of absorption is partly or wholly responsible for the difference in extinction coefficient. A sufficient number of observations ranging as widely as possible over these variables was therefore necessary to discriminate between these effects by multiple regression analysis.

With 224 sets of observations for window 17 , and 71 for window 19, such an analysis was possible, and the results are given in Table 2.38. For both windows it appears that $\epsilon$ is not significantly different from zero.

The correlations with aerosol are weak but significant, and the observed values of $D_{17}-4$ and $D_{19}-4,0.02$ and 0.03 , respectively, may be compared with 0.06 and 0.04 expected from the reasoning of $\$ 2.5 .7$; better agreement could hardly be expected in view of the uncertainties involved. The correlation with vapour pressure is highly significant. The values of 26 and 38 for a for windows 17 
and 19, respectively, are remarkably high compared with the figure between 5 and 10 which has been found for the central parts of lines (Palmer 1960); Benedict has suggested, however, that the wings are subject to greater self-broadening than are line centres. Although only about half of the total variance can be accounted for, and this almost entirely by the correlation with vapour pressure, we have fair confidence in ascribing the negative intercepts to self-broadening. If this inference is verified it will be of the utmost importance in the analysis of remote radiation measurements which involve correction for the water-vapour continuum.

Table 2.3

Results of the regression analysis for Windows 17 and 19

\begin{tabular}{|c|c|c|c|c|c|c|c|}
\hline $\begin{array}{c}\text { Wind ow } \\
i\end{array}$ & $\begin{array}{c}\lambda \\
(\mu)\end{array}$ & $\begin{array}{c}\nu \\
\left(\mathrm{cm}^{-1}\right)\end{array}$ & $\begin{array}{c}k_{i-4}\left(h_{0}, e_{0}, T_{0}\right. \\
\left(g^{-1} \mathrm{~cm}^{2}\right)\end{array}$ & $a$ & $\begin{array}{c}\epsilon \\
\left({ }^{-1} C^{-1}\right)\end{array}$ & $D_{i-4}$ & $\begin{array}{c}\text { No. of } \\
\text { obs. }\end{array}$ \\
\hline 17 & 17.88 & 559.4 & $1.22 \pm 0.13$ & $26 \pm 4$ & $0.0006 \pm 0.001$ & $0.022 \pm 0.005$ & 224 \\
\hline 19 & 20.12 & 497.0 & $2.09 \pm 0.16$ & $38 \pm 6$ & $-0.001 \pm 0.001$ & $0.034 \pm 0.008$ & 71 \\
\hline
\end{tabular}

Results of a least squares fit of the observations to the relation $k_{i-4}(\mu, e, T)=k_{i-4}\left(\mu_{0}, e_{0}, T_{0}\right)\left[\frac{\mu+a e}{\mu_{0}}\right]\left[1+\epsilon\left(T-T_{0}\right)\right]$ where $p$, e are the partial pressures of ary air and water vapour, respectively $\left(p_{0}=1000 \mathrm{mb}, e_{0}=0 \mathrm{mb}\right)$, and $\mathrm{T}_{0}=0^{\circ} \mathrm{C} . \mathrm{D}_{\mathrm{i}-4}$ represents the aerosol contribution (see $\$ 2.5 .7$ ).

M.34.

2.6.2 Windows 18 and 20

With insufficient observations to permit a multipleregression analysis, it seems reasonable in the light of the 


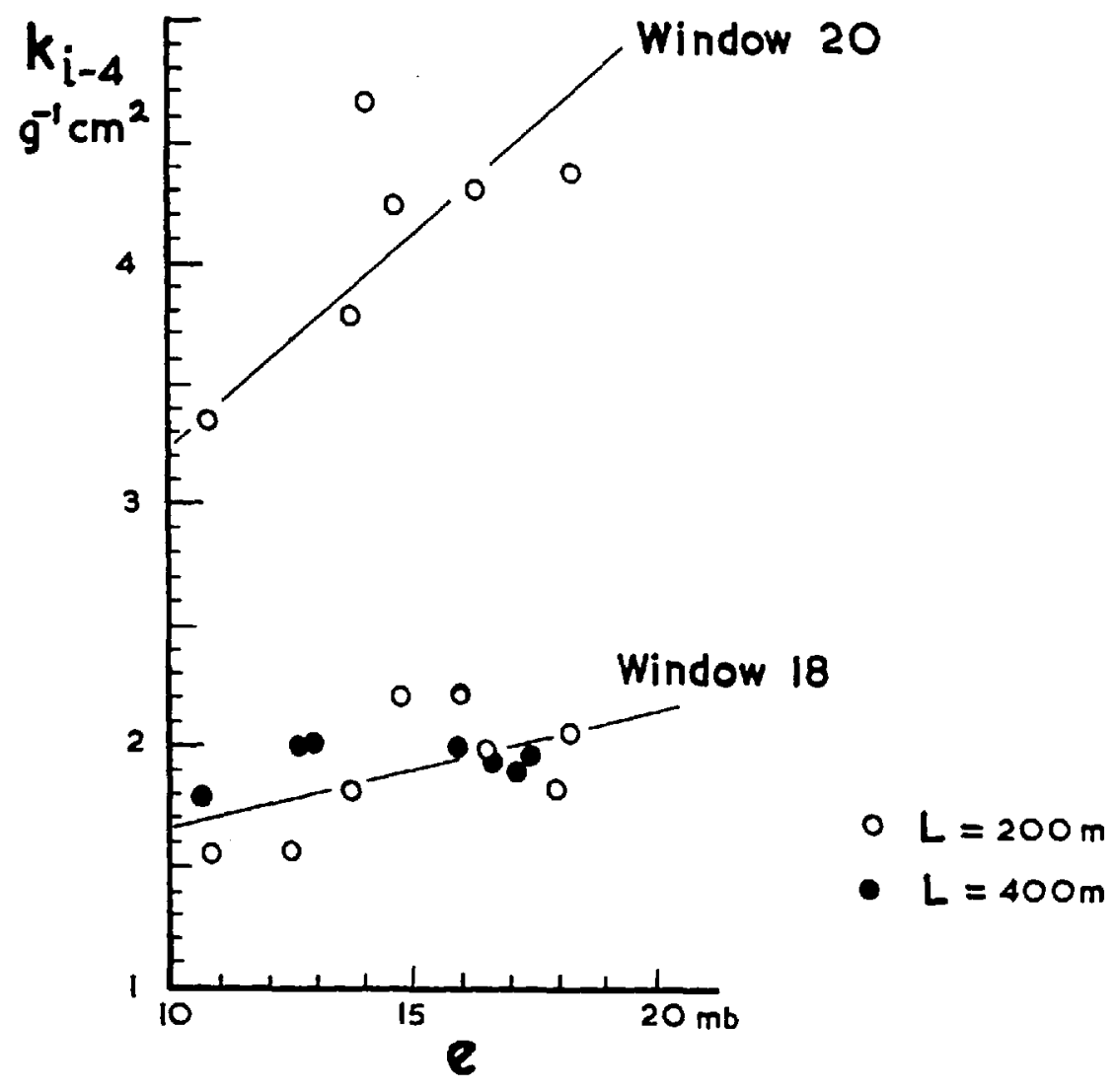

Fig 2.11. Absorption coefficients in windows 18 and 20 as a function of vapour pressure. 

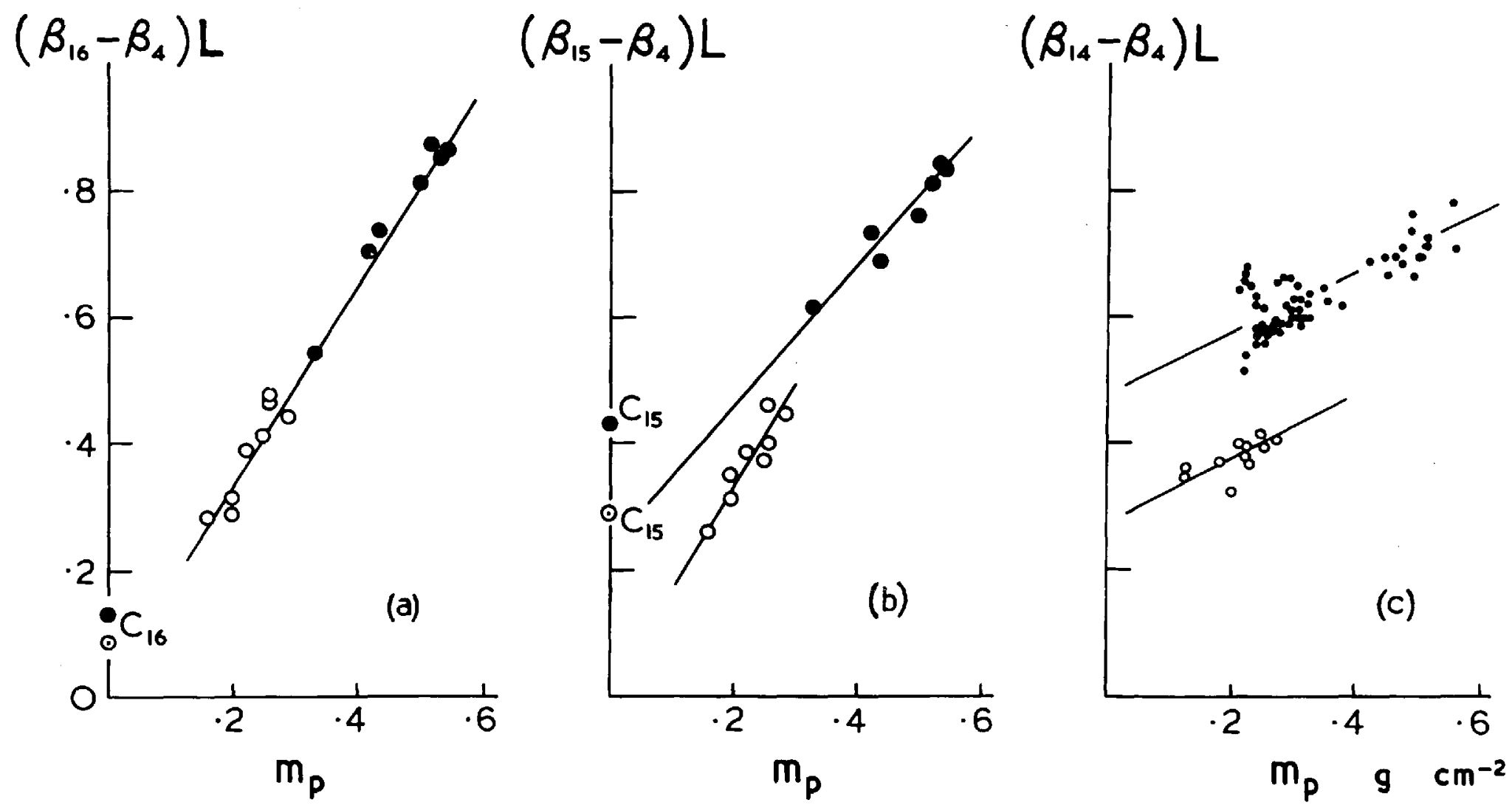

Fig 2.12. Observed extinction coefficients for windows 14,15 and 16 . Full circles : 400m path. Open circles: $200 \mathrm{~m}$ path. Points denoted by ' $C$ ' represent the estimated $\mathrm{CO}_{2}$ contribution, from measurements with a cell of $\mathrm{CO}_{2}$ 
results for Windows 17 and 19 to assume that the temperature and aerosol terms may be ignored in Eq. 2.9. P1ots of $k_{i-4}\left(=\frac{\beta_{i-4}}{m_{p}}\right)$ against vapour pressure e are shown in Fig. 2.11, where a tendency for $\mathrm{k}_{\mathrm{i}-\mathrm{l}}$ to increase with $\mathrm{e}$ is again apparent. For neither window is the sample large enough to allocate a value of a, though for window 18 it is of the order of 30. Observational data are tabulated in Appendix 2.2. 1.99 .

Mean values of $\mathrm{k}_{18}$ and $\mathrm{k}_{20}$ corresponding to the mean vapour pressure of $15 \mathrm{mb}$ are given in Table 2.4 with corresponding values for Windows 17 and 19 for comparison. Use has been made here of the value $\mathrm{k}_{4}=0.08 \mathrm{~g}^{-1} \mathrm{~cm}^{2}$, interpolated from saiedy (B.S.S., 1963).

2.6.3. Windows 14,15 and 16

1.30 $\mathrm{CO}_{2}$ absorbs significantly in these windows (see Fig. $2.8 \%$, and Eq. 2.9 must now be written (neglecting aerosol and temperature terms)

$$
\beta_{i-4}=k_{i-4}\left(\mu_{0}\right) \frac{m_{n}}{L}\left[1+\frac{a e}{p}\right]+C_{i},
$$

where $C_{i}$ is the $\mathrm{CO}_{2}$ contribution in Window $i\left(c_{4}=0\right)$. Figures 2.12 (a) and (b) show $\beta_{i-4} I$ against $m_{p}$ for Windows 16 and 15. We see that the best straight lines do not intercept at the values $C_{i}$ inferred by scaling the laboratory $\mathrm{CO}_{2}$ absorption measurements $(\S 2.5 .6)$ to the mass in the horizontal path (regular band absorption assumed). Indeed, graphs of $\beta_{i-4}-c_{i}$ against $m_{p}$ for these windows would have identical features to those for Windows 17 and 19 (Fig. 2.10 ) discussed in 82.6 .1 , 
and it seems likely that the interpretation would be the same. Mean values of $k_{i}$, corresponding to the mean vapour pressure of $15 \mathrm{mb}$, are given in Table 2.4 , asauming $k_{4}=0.08 \mathrm{~g}^{-1} \mathrm{~cm}^{2}$.

\section{Table 2.4}

Details of windows measured and observed absorption coefficients

\begin{tabular}{|c|c|c|c|c|c|c|}
\hline $\begin{array}{c}\text { Windort } \\
i \\
4\end{array}$ & $\begin{array}{c}\lambda \\
(\mu) \\
8.94\end{array}$ & $\begin{array}{c}\nu \\
\left(\mathrm{cm}^{-1}\right) \\
1118.8\end{array}$ & $\begin{array}{c}\text { RESOLUTiON } \\
\left(\mathrm{cm}^{-1}\right) \\
3.5\end{array}$ & $\begin{array}{l}k i\left(n_{0}, e\right) \\
g^{-1} \mathrm{~cm}^{2} \\
0.08 *\end{array}$ & $0^{\Delta k_{i}\left(k_{0}, T_{0}\right)}$ & $\begin{array}{l}\text { No. of } \\
\text { o8s. } \\
\text {... }\end{array}$ \\
\hline 14 & 13.96 & 716 & 2.8 & $0.6 \pm 0.2$ & 0 & 131 \\
\hline 15 & 16.38 & 610.5 & 2.2 & $0.8 \pm 0.1$ & $0.13,+0.7$ & 15 \\
\hline 16 & 17.02 & 587.4 & 1.9 & $1.4 \pm 0.1$ & $0.42,+1.3$ & 15 \\
\hline 17 & 17.88 & 559.4 & 1.7 & $1.7 \pm 0.1$ & $0.23,+1.0$ & 224 \\
\hline 18 & 18.83 & 531.2 & 1.6 & $1.8 \pm 0.1$ & $0.44,+1.1$ & 15 \\
\hline 19 & 20.12 & 497.0 & 1.3 & $3.0 \pm 0.1$ & $0.78,+1.2$ & 71 \\
\hline 20 & 20.88 & 478.9 & 1.2 & $3.6 \pm 0.1$ & $1.3,+1.7$ & 6 \\
\hline
\end{tabular}

$k_{i}\left(p_{0}, e\right)$ is the mass absorption coefficient for partial air pressure of $1000 \mathrm{mb}$ and water vapour pressure of $15 \mathrm{mb} . \mathrm{v}_{i}\left(\mathrm{p}_{0}, \mathrm{~T}_{0}\right)$ is the contribution to $k_{\text {. }}$ from wings of lines within $10 \mathrm{~cm}$ computed for $p_{0}=-1000 \mathrm{mb}$ and $\mathrm{T}_{0}=14^{\circ} \mathrm{C}$; the computed temperature coefficient $\left(\%{ }^{\circ} \mathrm{C}^{-1}\right)$ of $\Delta \mathrm{k}_{i}$ is also shown. Sheppard, 1963).

$$
\text { * By interpolation from Saiedy (Bignell, Saiedy and }
$$

\section{(n.49)}

Figure 2.12(c)/shows the observations for Window 14; in this case absorption by $\mathrm{CO}_{2}$ is much greater and the scatter is increased by the diurnal and daily variations in the concentration of atmospheric $\mathrm{CO}_{2}$. Only a rough estimate of $\mathrm{k}_{14-4}$ may be obtaimed 
from the slope of the regression line, and the value of $k_{14}$ is entered in Table 2.4 , assuming $\mathrm{k}_{4}=0.08 \mathrm{~g}^{-1} \mathrm{~cm}^{2}$. Observational data for windows 14,15 and 16 are tabulated in Appendices, 2.1 and 2.2 .94

\section{h. 40}

All results are collected in Table 2.4 , and in so far as a vapour pressure dependence has been inferred, they correspond to the mean pressure of the series of observations, i.e. about $15 \mathrm{mb}$. An estimate of the contribution due to lines within $10 \mathrm{~cm}^{-1}$ is included in Table 2.4 , computed for the Lorentz line shape (see Chapter 3, 1..85 $\$ 3.6)$.

2.7. Discussion.

The only previous work available for comparison with the present results appears to be that of Anthony (1952), Palmer (1957 b) and Yates and Taylor (1960).

Anthony (1952) measured continuum absorption coeffi cients at $17.6 \mu$ and $19.0 \mu$ from Table Mountain, California (6000 ft), by a solar method, but the results $\left(0.87\right.$ and $\left.0.98 \mathrm{~g}^{-1} \mathrm{~cm}^{2}\right)$ are not readily comparable with the present work ( 1.5 and $2.0 \mathrm{~g}^{-1} \mathrm{~cm}^{2}$ ) since the circumstances of the observations were not reported. However, it is reasonable to assume that the partial water vapour pressure at the mountain station would not have been higher than about $10 \mathrm{mb}$, so that if the self-broadening effect inferred from the present work is correct, then one would indeed expect Anthony's results to be lower, though the self-broadening term would have to be about twice as large 
as that found in $\oint 2.6 .1$ to account for the diserepancy noted above.

Palmer (1957 b,c) carried out an extensive laboratory experiment in a multiple traversal cell $33 \mathrm{~m}$ long, giving a total path length of $196 \mathrm{~m}$. He adopted the procedure of recording transmission spectra from $20-40 \mu$ for different partial water vapour pressures in the range $0.16 \mathrm{mb}$ to $10 \mathrm{mb}$, pressure-broadened with nitrogen in the range $0-800 \mathrm{mb}$, at room temperature $\left(\sim 20^{\circ} \mathrm{C}\right)$. From the published dimensionsff the grating spectrometer (Palmer, 1957a), the calculated resolution at 30,25 and $20 \mu$ was $2.2,3.5$ and $5.0 \mathrm{~cm}^{-1}$ respectively, this being the full width of the triangular slit function at half-height. It is unfortunate that no critical analysis of the results has appeared, so that one is forced to make the best of the published spectra, which undoubtedly lack a great deal of the original detail and in which the thickness of the line represents $2 \%$ in transmission. The only window common to Palmer's and the present work is window $20\left(478.8 \mathrm{~cm}^{-1}\right)$ in which the resolution achieved by the former $\left(5 \mathrm{~cm}^{-1}\right)$ is very much lower than that used in the latter $\left(1.2 \mathrm{~cm}^{-1}\right)$. Palmer was unable to exclude two rather strong lines at $481.8 \mathrm{~cm}^{-1} \mathrm{~K}$, so it is not surprising that his result for the absorption coefficient is rather higher than the value obtained from the present mork $\left(5 \mathrm{~g}^{-1} \mathrm{~cm}^{2}\right.$ as against $\left.4 \mathrm{~g}^{-1} \mathrm{~cm}^{2}\right)$.

The full potential of Palmer's work was not reali sed at the field stage of the present study, but a full analysis became possible in the light of the further work described in Chapter 3 , 
1.73

and this is discussed in $\oint 3.5 .1 .5$.

Yates and Taylor (1960) messured the transmi ttanoe over open horizontal atmospheric paths of $0.3,5.5$ and $16.25 \mathrm{~km}$ over Chesapeake Bay and another path of $27.7 \mathrm{~km}$ at an altitude of about $3 \mathrm{~km}$ between Mauna Lao and Mauna Kea in the Hawailan Islands. They used carbon arc soúces and prism spectrometer giving resolution of about $3 \mathrm{~cm}^{-1}$ at $10 \mu$. The transmittance of one of the long paths was determined from the ratio of the long path signal to that from the $0.3 \mathrm{~km} \mathrm{path}$, allowance for the different beam geometry being made by an independent absolute determination of the transmittence at $0.55 \mu$ by $a$ transmissometer. The results from a single run in the $15-21 \mu$ recion are included in Fig 3.30 , where reasonable agreement with the present work is seen. This may, however, be fortuitous, since the general level of scatter in Yates and Taylor's work is very large, exemplified by their observations at $9.1 \mu$ and $3.97 \mu$ for which several runs were made (see $\{3.5 .2 .3$ and Fig 3.29 for fulzer discusgion). Whilst some scatter is to be expected on account of aerosol absorption, this can only lead to values greater than the pure water vapour contribution, and it is not clear how to explain those results falling below this level, which has been fairly reliably estimated at $0.06 \mathrm{~g}^{-1} \mathrm{~cm}^{2}$ for $\lambda=9.1 \mu$ by Roach: and Goody (1958), Vigroux (1959) and Saiedy (B.S.S., (1963)).

\subsection{Conclusion}

In view of the consequences of a large self-broadened 
contribution to the continuum, much attentron was devoted to the question of the reality of this effect. Recalling that the inference arose from the interpretation of the negative intercepts in Fig $2.10 \%$, an exhaustive investigation was carried out to establish that this was not of instrumental origin, arising for example from the effects of non-linearity, stray radiation, or error in humidity measurement. All these possibilities were finally ruled out: indeed, stray radiation could only have produced a positive intercept $(\oint 2.4 .4)$. Further, independent, evidence of a systematic effect leading to the negative intercepts was afforded by the work of Saiedy (B.S.S., (1963)), who obtained qualitatively the same effect at $\nu=832 \mathrm{~cm}^{-1}$ and $901 \mathrm{~cm}^{-1}$ by a solar method.

Whilst the above analysis suggested that self broadening may account for the observations, the evidence could hardly be regarded as conclusive, and an obligation wasffelt to confirm (or otherwise) this feature of the results. There appeared to be no alternative to a controlled laboratory experiment if the uncertainties and frustrations of an open atmospheric experiment were to be avolded: an account of the laboratory experiment follows in Chapter 3. 


\section{The Laboratory Experiment}

\subsection{Design requirements}

The implications of the results of the horizontal path experiment concerning self broadening were considered sufficiently far-reaching to require confirmation from a laboratory experiment in which humidity and temperature could be controlled. The factors considered in the design of this new experiment were as follows:-

(i) Sufficient path length to cause at least $50 \%$ absorption without resorting to high temperatures or high water vapour partial pressures was essential. This is because the temperature and self broadening effects are uncertain and extrapolation to the conditions more typical of the atmosphere would be unreliable. From $2_{2.2}^{4.14}$ me see that a path length of about $500 \mathrm{~m}$ would be required.

(ii) The humidity and temperature should be reasonably uniform throughout the path, with provision for accurate measurement. Some means of mixing appeared essential.

(1ii) Aerosol absorption should be kept to a minimum. This did not appear to present any difficulty in principle, since a closed cell could be used, and the relative humidity could be kept low $(<60 \%)$ onsuring that hygroscopic nuclei are at least very small. 
(iv) Although facilities for working under reduced pressure would be valuable, it was decided that the programme could be carried out at atmospheric pressure throughout. This would cut down the constructional work enormously.

(v) The spectral resolution must be at least as good as $1.5 \mathrm{~cm}^{-1}$ in the $16-20 \mu$ region with $100: 1$ signal to noise ratio, Using a Nernst filament at $1500^{\circ} \mathrm{K}$ and a Golay cell we saw in $\{2.2$ that this is possible with the available spectrometer。

A multiple reflection cell of the type described by White (1942) was selected as offering the best way of achieving a long path in a small space, which, by use of collimated beams, makes the most economical use of energy. From an energy standpoint, a few transits of a long cell is preferable to many transits of a short cell, because reflection losses may become appreciable in the latter case (about $50 \%$ at $20 \mu$ for 30 reflections), quite apart from the fact that aberrations and scattering by mirrors cause further loss of energy. On the other hand, a very long cell increases the problems with temperature and humidity control and, moreover, requires larger mirrors to achieve the same aperture ratio. The main consideration in the final design of the cell was the very rapid increase in the cost of mirrors as the diameter surpasses $30 \mathrm{~cm}$. The solution adopted was to build the longest possible cell using $30 \mathrm{~cm}$ mirrors, the upper limit being set by the attendant increase in image size, 
Facing P. 47

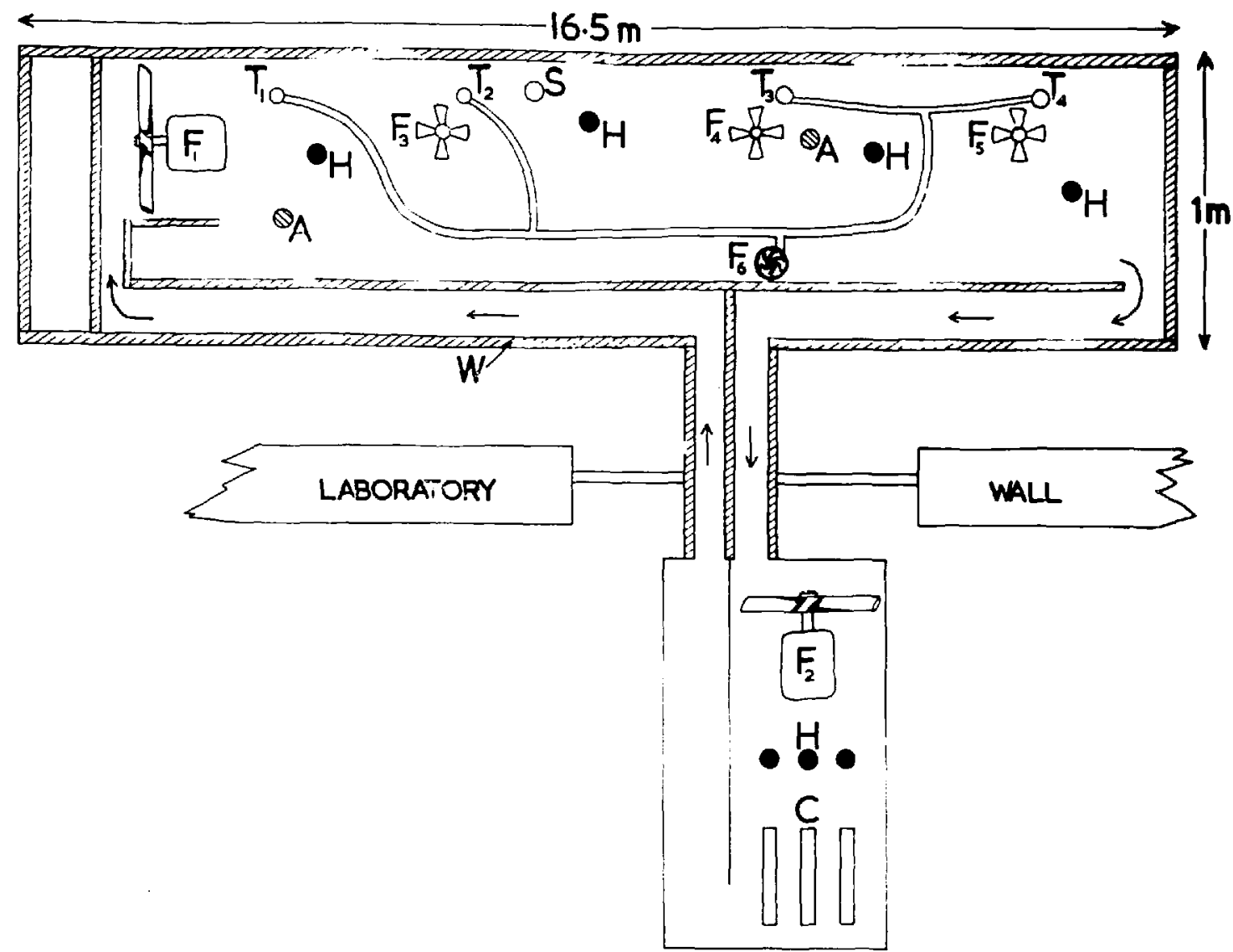

Fig 3.1. Layout of cell (excluding optics). Not to scale.
A Assmann psychrometers.
C Cooling fins, filled with solid $\mathrm{CO}_{2}$ when required.
$F_{1}, F_{2}$ Large axial flow fans ( $45 \mathrm{~cm}$ diameter) for circulating air.
$F_{3}, F_{4}, F_{5}$ Small fans ( $15 \mathrm{~cm}$ diameter) for mixing air.
Fo Extractor fan for ventilating temperature sensors.
$H$ Heaters.
$S$ Steam generator.
$T_{1}, T_{2}, T_{3}, T_{4} \quad$ Nickel resistance thermometers (dry) and thermocouples (wet bulb depression).

W Walls, expanded polystyrene $5 \mathrm{~cm}$ thick, with inner seal of 0015 inch polyethylene and outer seal of aluminium foil. 
giving image-overlapping; this length turns out to be about $15 \mathrm{~m}$.

3.2. Apparatus

3.2.1. Cel1 construction

Calculation using manufacturers' data indicated that-sufficient heat insulation would be afforded by 2 inch walls of expanded polystyrene, and that sufficient sealing against water vapour diffusion should be provided by an inner lining of polyathylene sheet 0,0015 inch thick. Lack of convenient laboratory space meant that the cell had to be constructed outside the laboratory which housed all the measuring equipment. To provide protection against the weather, the outside of the cell was sealed with metal foil and finally roofed over. The layout of the cell and associated equipment is shown diagrammatioally in Fig 3.1 .

It was decided that the optical path in the spectrometer and auxiliary optics need not be maintained at the same temperature and humidity as that in the cell, the experimental technique allowing of the elimination of the absorption in the laboratory path. Sealing of the opening between the cell and laboratory was effected with a window of polyethylene $35 \mu$ thick.

3.2.2. Temperature and humidity control

To ensure thorough mixing a closed circuit system was considered necessary. The air was extracted from one end of the cell 


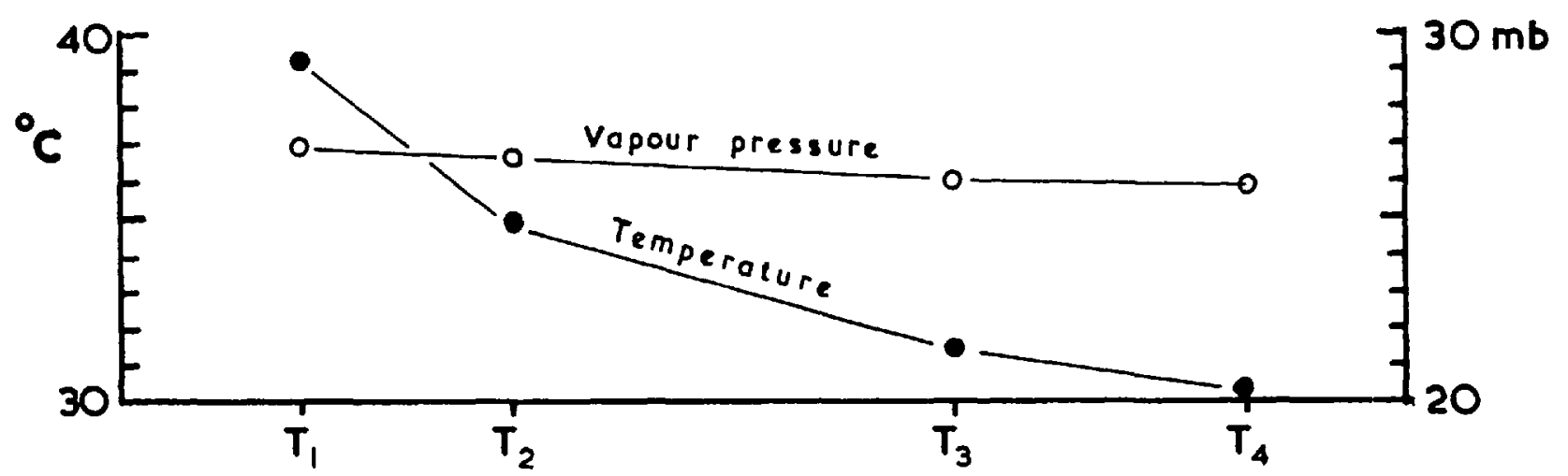

Fig 3.2. Typical temperature and vapour pressure distributions in the cell (outside values $0^{\circ} \mathrm{C}$ and $5 \mathrm{mb}$ ).

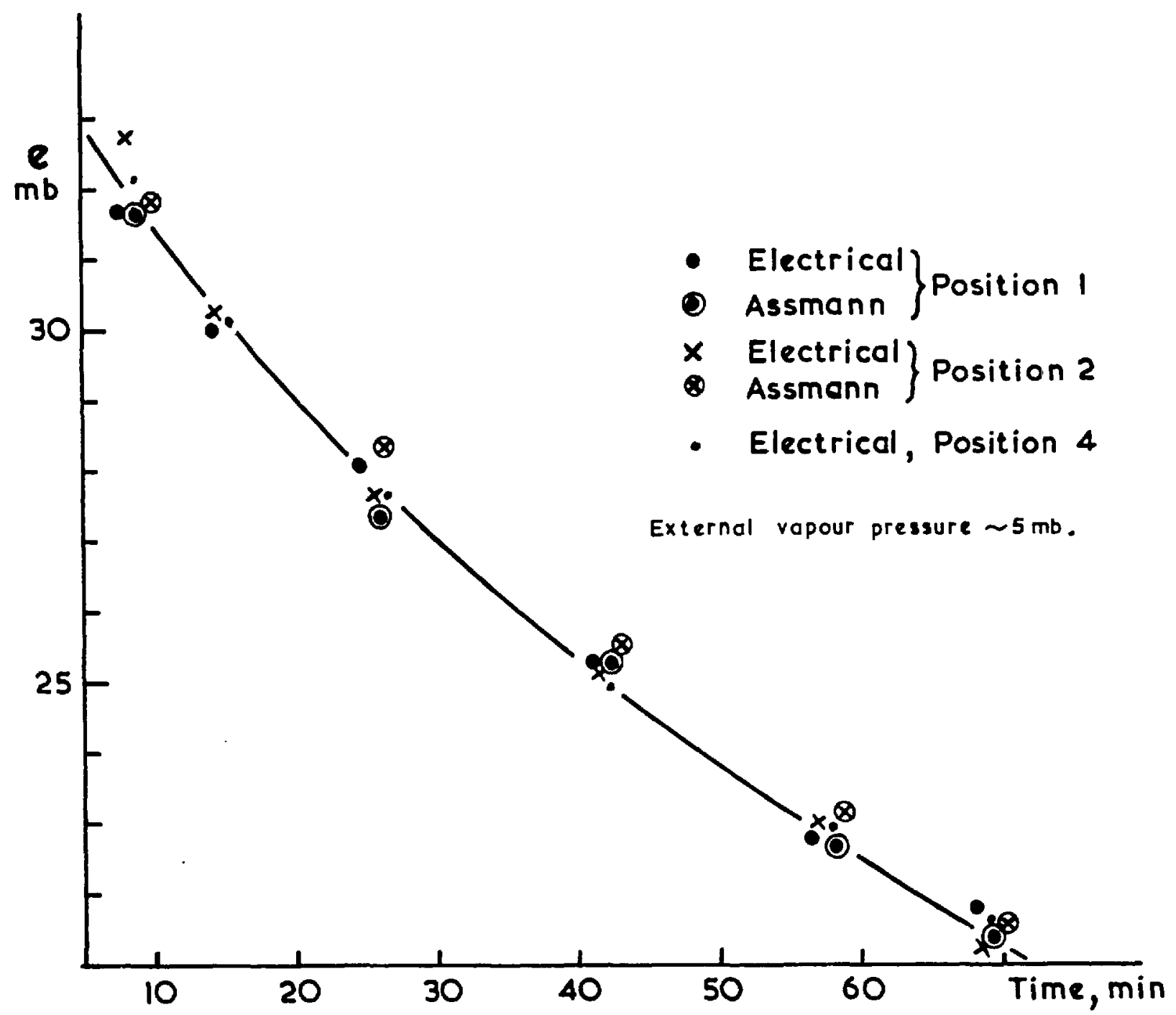

Fig 3.3. Effect of diffussion through walls of cell. 
and returned to the other, passing through a heat exchanger on the way. Three amall fans at intervals along the cell reinforced the mixing near the temperature sensors. The time taken for one complete circuit of the cell was about 2 minutes. Heaters in the cell and heat exchanger permitted an excess of $40^{\circ} \mathrm{C}$ over the outside temperature to be maintained; provision for cooling below ambient temperature was included, but the capacity of the heat sink turned out to be inadequate, sufficiest only to absorb the heat generated by the circulating fans. Fartunately, it turned out to be unncessary to work at low temperature.

Water vapour was introduced by boiling a small flask of water with a $700 \mathrm{~W}$ immersion heater, situated towards the 'upstream' end of the cell. Diffusion was usually relied upon to restore the humidity to the ambient level, but for runs conducted below ambient humidity a rapid extraction could be effected by cooling the aluminium top-plate of the heat exchanger with dry ice.

The degree of control over both temperature and humidity did not come up to expectation. Gradients of temperature and vapour density were observed, indioating a much greater loss ofheat and vapour by diffusion than was expected. Typical distributions along the cell are shown in Fig 3.2, whilst Fig 3.3 shows the decrease of vapour pressure with time after switching off the steam generator. The experimental technique was designed to exploit the latter unforeseen behaviour, and is described in $\$ 3.4 .2$. Much better uniformity of temperature $\left( \pm 1^{\circ} \mathrm{C}\right)$ was later attained by use 


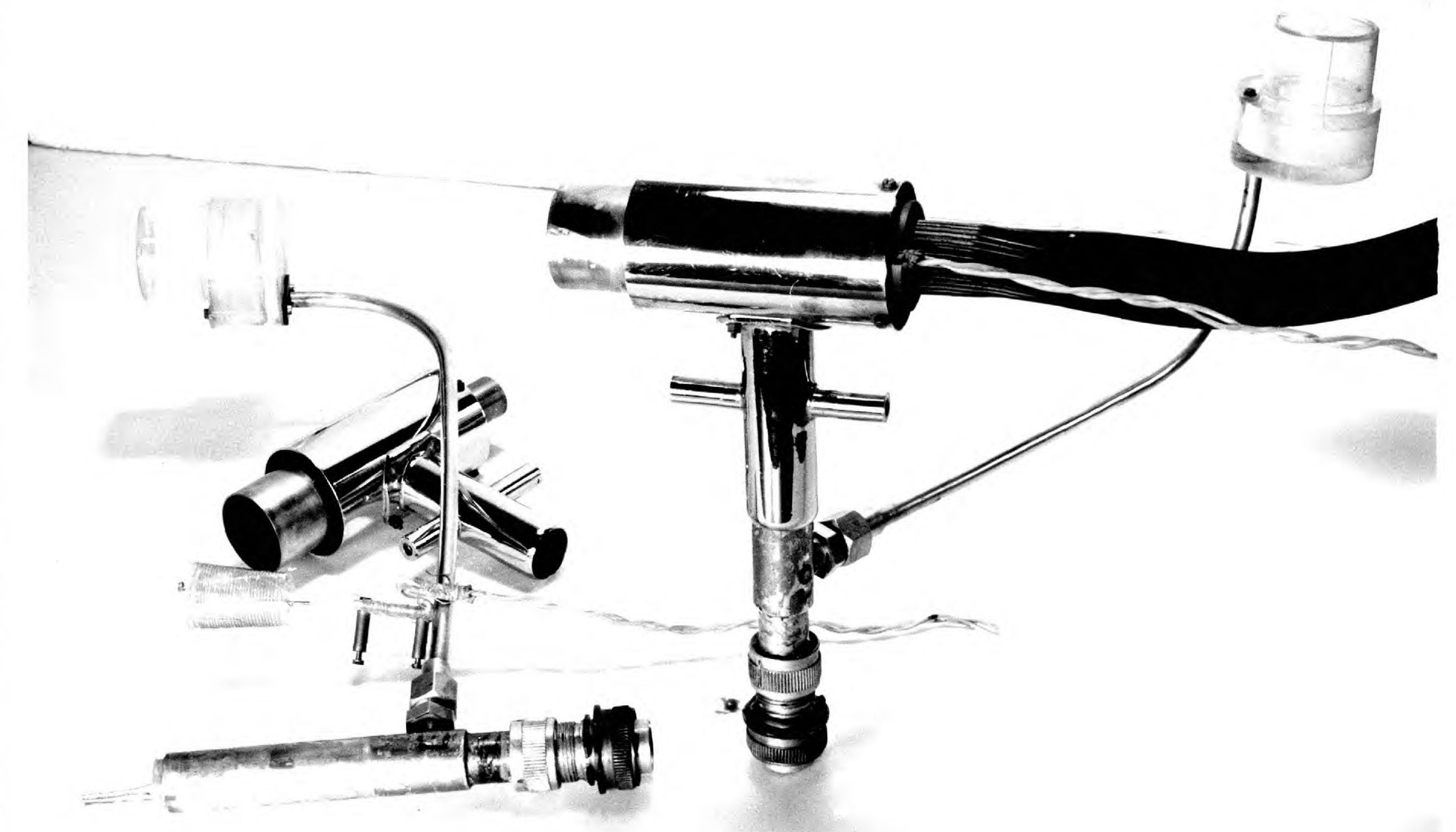


of suitably placed additional heaters in the cell. 3.2.3 Temperature and humidity measurement .

With a very large number of temperature measurements envisaged, remote reading thermometers were essential. The choice of techniçue for humidity measurement needed careful consideration: unquestionably the best method would have been dewpoint hygrometry, However, owing to the lack of a suitable remote reading instrument, tiiis was reluctantly rejected, and the psychrometer method was again adopted.

3.2.3.1. Dry bulb temperature.

Iry buib temperature was measured with nickel resistance $(1.47)$ thermometers mounted at four points in the cell (Fig 3.1) and the wet bulb depression was measured at the same points with constantanmanganin thermocouples connected differentially. Both sensors were fully ventilated with air drawn over them through hoses by an extractor fan in the cell. A diagram of the sensors is show in $(h .50)$

Fig 3.4 and the sensing head is illustrated in Plate 3.

The dry sensor consigted of a 25 olm coil of $40 \mathrm{~S} \mathrm{WG}$ annealed nickel wire. This was made by winding the wire on a glass tube $2 \mathrm{~cm}$ in diameter and setting it in a very thin film of perspex cement. When dry, the coil was removed from the tube so that it would not be subject to strain effects (earlier coils wound on 


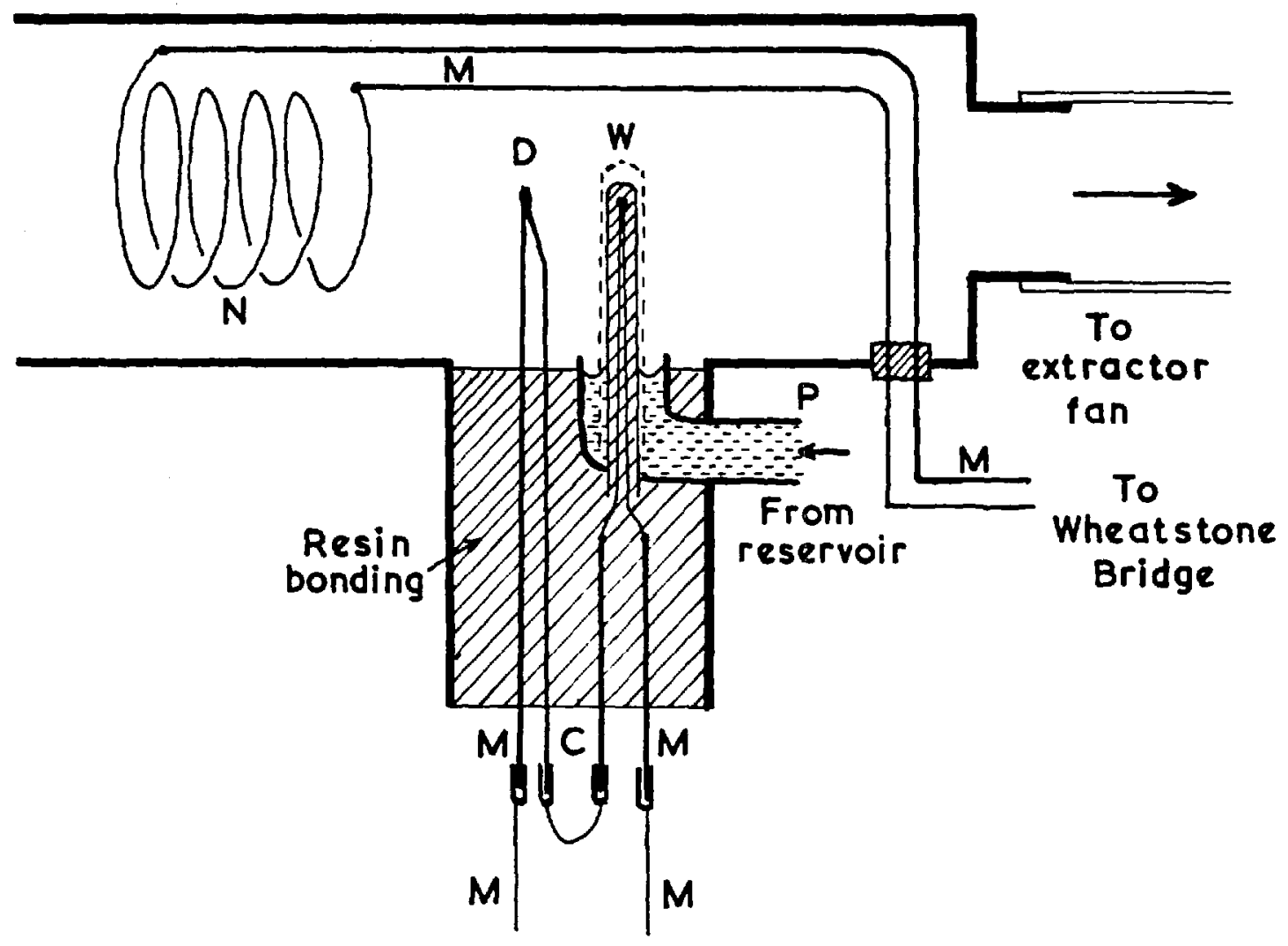

Fig 3.4. Electrical temperature sensors. (actual size)

N Nickel resistance thermometer.

D Welded manganin-constantan dry junction, 22 SWG.

$W$ Manganin-constanton wet junction, 48 sWG, sealed in 22 sWG stainless steel tube, with tissue wick.

$M$ Manganin wires.

C Constontan wires.

P Polycthylene tube. 
rigid formers proved very unreliable). After cyoling the coils many times between freezing point and $70^{\circ} \mathrm{C}$, they were calibrated over the range $0-40^{\circ} \mathrm{C}$. They were found to retain their calibration to $\pm 0.02^{\circ} \mathrm{C}$ over a period of a month. It was considered advantageous to be able to read the temperature directly from a decade resistance box in a wheatstone bridge circuit, and this was readily achieved by adjusting the resistance of the coil so that it increased by $0.100 \mathrm{ohm}$ per ${ }^{\circ} \mathrm{C}$. No attempt was made to linearise the resistance - temperature characteristic, but by arranging for the indication to be correct at $20^{\circ} \mathrm{C}$ and $40^{\circ} \mathrm{C}$, only a small correction was required at other temperatures $\left(+0.25^{\circ} \mathrm{C}\right.$ at $30^{\circ} \mathrm{C},-0.4^{\circ} \mathrm{C}$ at $10^{\circ} \mathrm{C}$ ). All connections from the nickel coil to the bridge were made with $20 \mathrm{~S} \mathrm{~W}$ G manganin wire; electrical details are given in Fig 3.5 .

\subsubsection{Wet bulb depression.}

Fig 3.4 shows the construction of the thermocouple head. Physically, the exposed surfaces of the dry and wet junctions were of the same dimensions, but the wet junction was made of $48 \mathrm{~S} \mathrm{~W} \mathrm{G}$ enamelled wires in order to allow of sealing in $22 \mathrm{SWG}$ stainless steel tube, the latter having the same dimensions as the dry junction. The wet junction was kept moist by a wick of two layers of Kleenex tissue paper rolled tightly round the stainless steel tube, dipping into distilled water supplied through a polyethylene tube from a reservoir. The exposed length of wick leading up to the junction was $2 \mathrm{om}$, sufficient to reduce conduction errors to an acceptable level. 


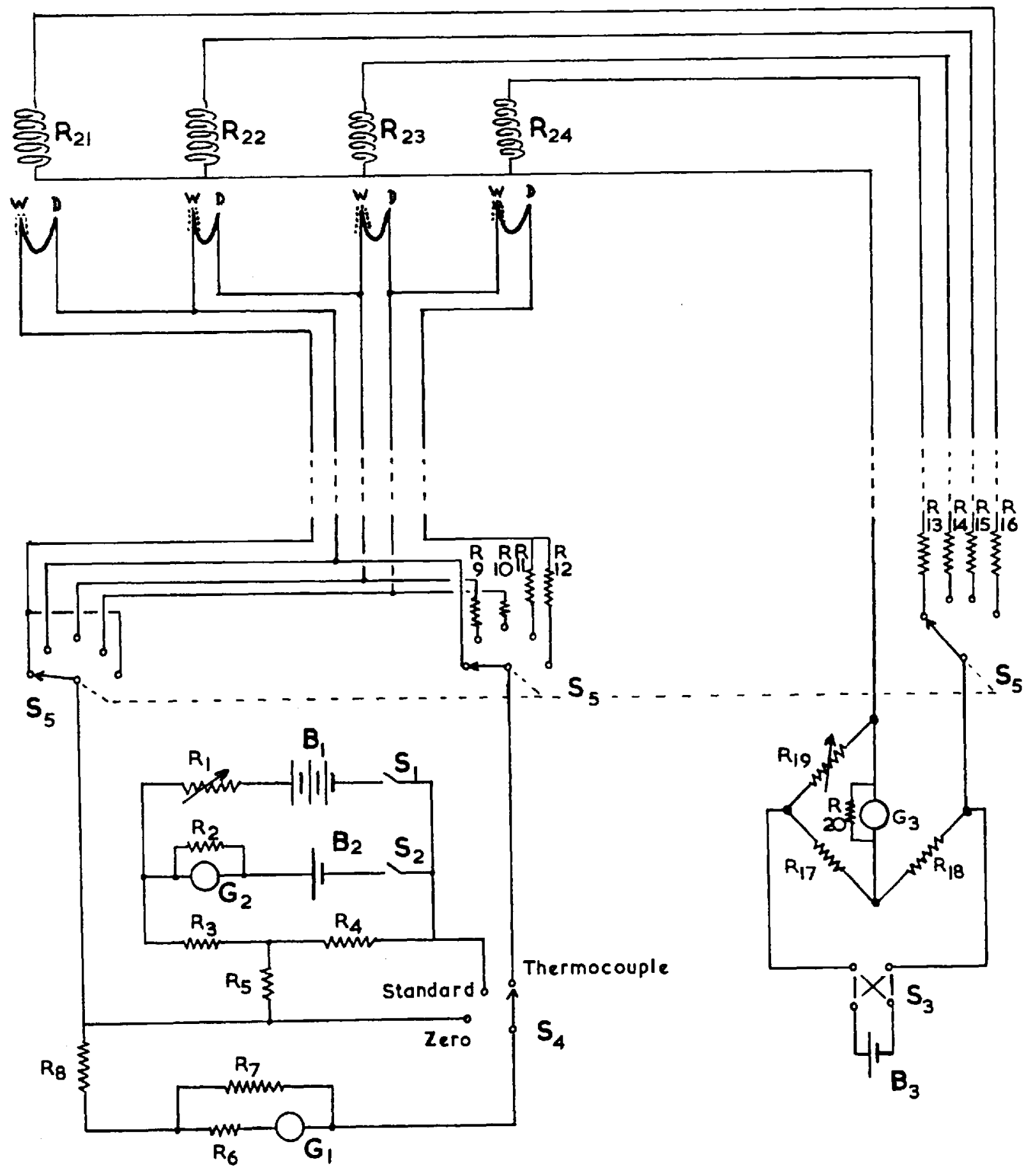


Fig. 3.5. Circuit diagram of electrical thermometers.

Resistance values (ohms)

Function

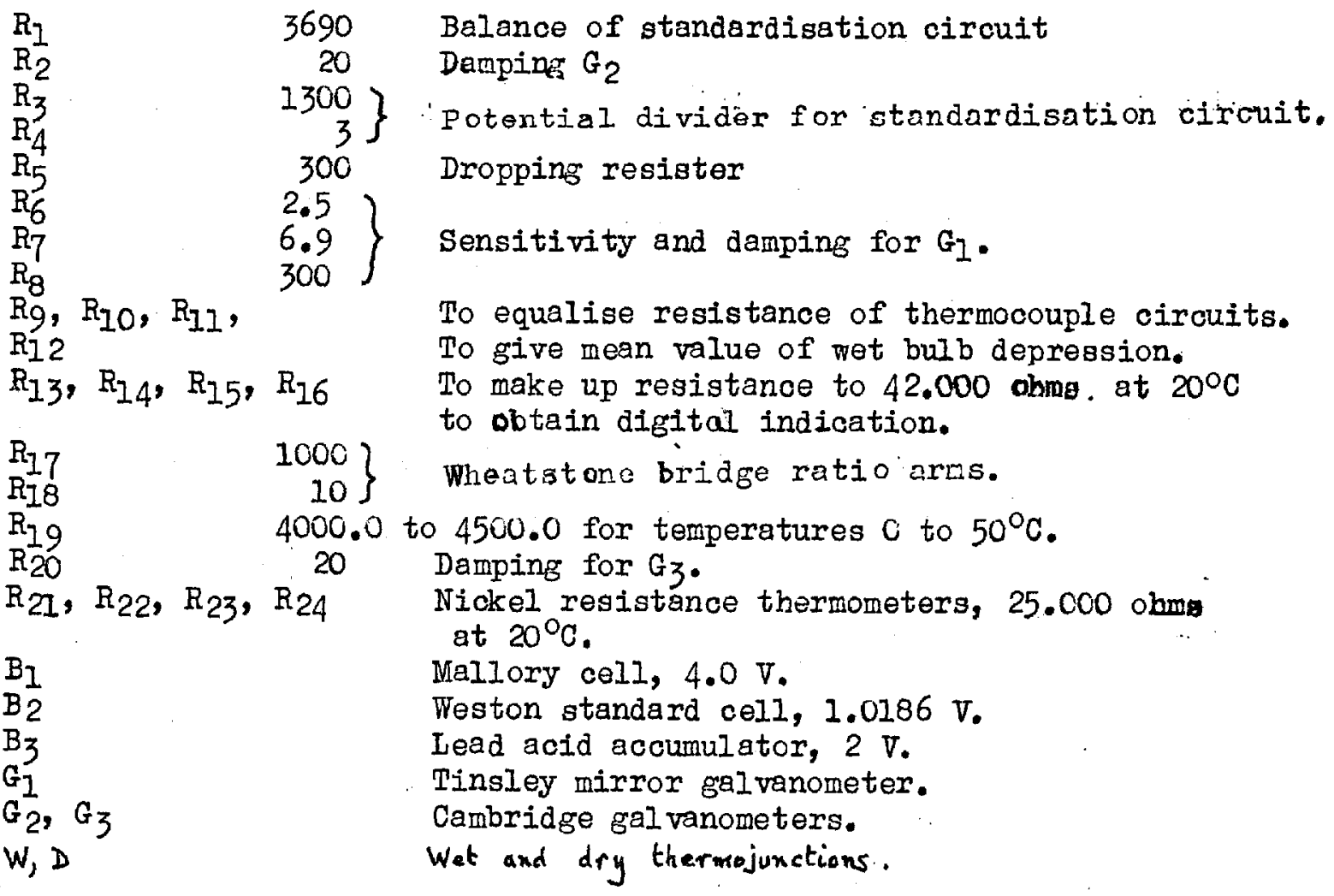

Standardisation of $G_{I}$.

1) $\mathrm{s}_{4}$ to ' $S T M N D A R D$ '

2) Close $s_{1}$

3) Close $\mathrm{s}_{2}$

4) Balance $G_{2}$ with $B_{1}$

5) $\operatorname{Read} G_{1}$

6) Open $s_{2}$

7) Open $s_{1}$ 


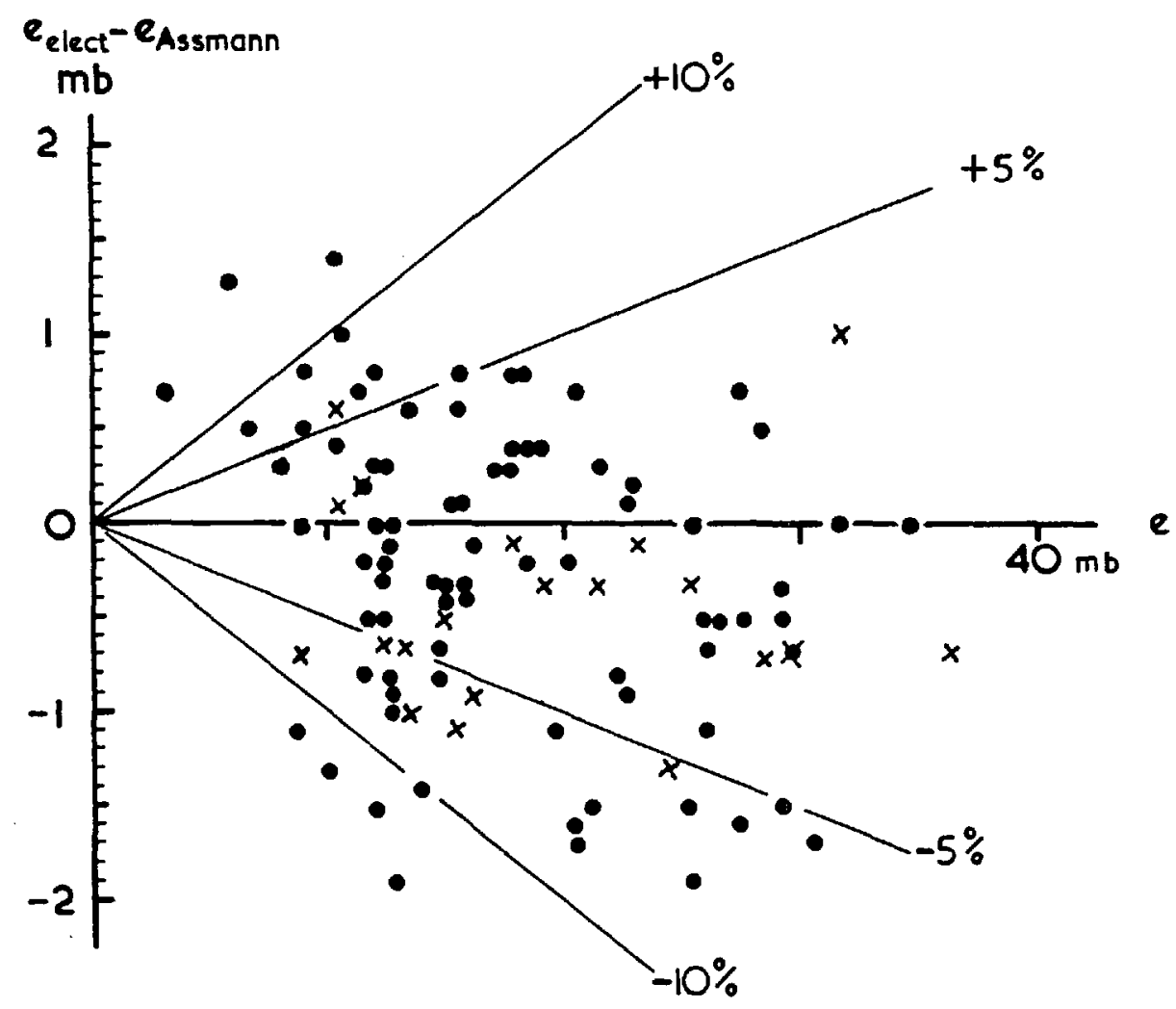

Fig 3.6. Difference between electrical and Assmann humidities.
- Position No. 1 .
$\times$ Position No. 3 . 
The e.m.f. generated by the thermocouple was measured by a wall mounted Tinsley mirror galvanometer. The sensitivity was arranged so that the wet bulb depression could be read directly in ${ }^{\circ} \mathrm{C}$, subject to small corrections for non-Iinearity in the gil vanometer scale and for the variation of the thermoelectric efficiency with temperature. A standardisation circuit (see Fig 3.5) permitted day-to-day checks of the galvanometer circuit, and in fact no change of sensitivity was found throughout the programme.

\subsubsection{Comparison with Assmann psychrometer.}

Periodic comparisons were made between the vapour pressures derived from the electrical thermometers and electrically aspirated Assmann psychrometers mounted close to heads $I$ and 3. (see Fig 3.I). The results of all comparisons are shown in Fig 3.6, and those of an individual run are included in Fig 3.3 . It is thought that the greatest uncertainty in the experiment lies in the humidity measurements. Although the greatest care was taken, it can be seen that discrepancies of $1 \mathrm{mb}$ in vapour pressure were not uncommon, No systematic trend in the residuals could be found, and it was concluded that the differences were real. However, such differences do not affect the main conclusions of the experiment, though reservations are prudent in some cases.

3.2.4. Optical system

(p.5s) n.54

Fig 3.7 shows the optical system in plan, and Fig 3.8 shows in perspective the path of radiation in the cell. The design and layout 


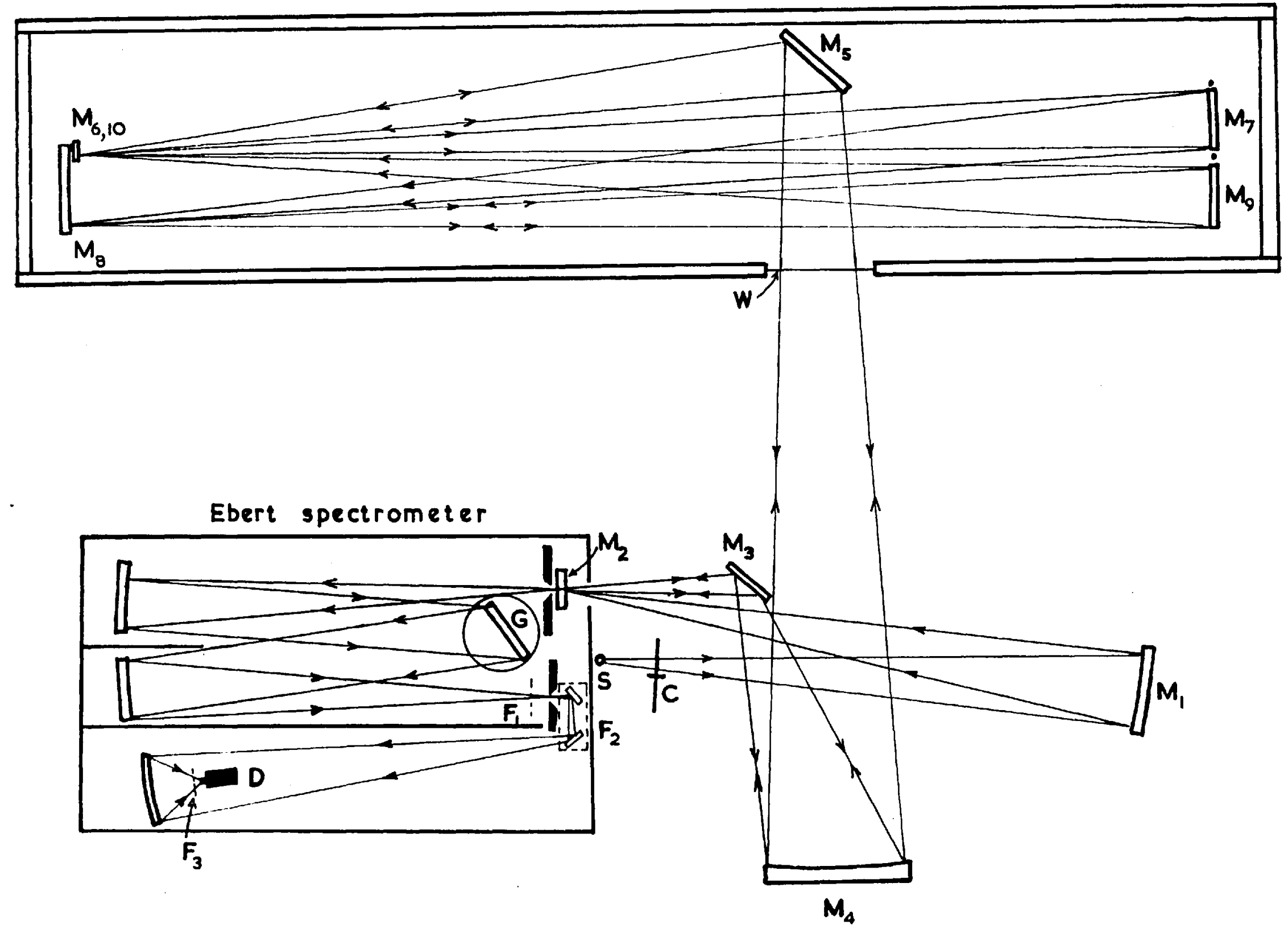

0
0
$n$
0
0
0
$\vdots$
wैl 

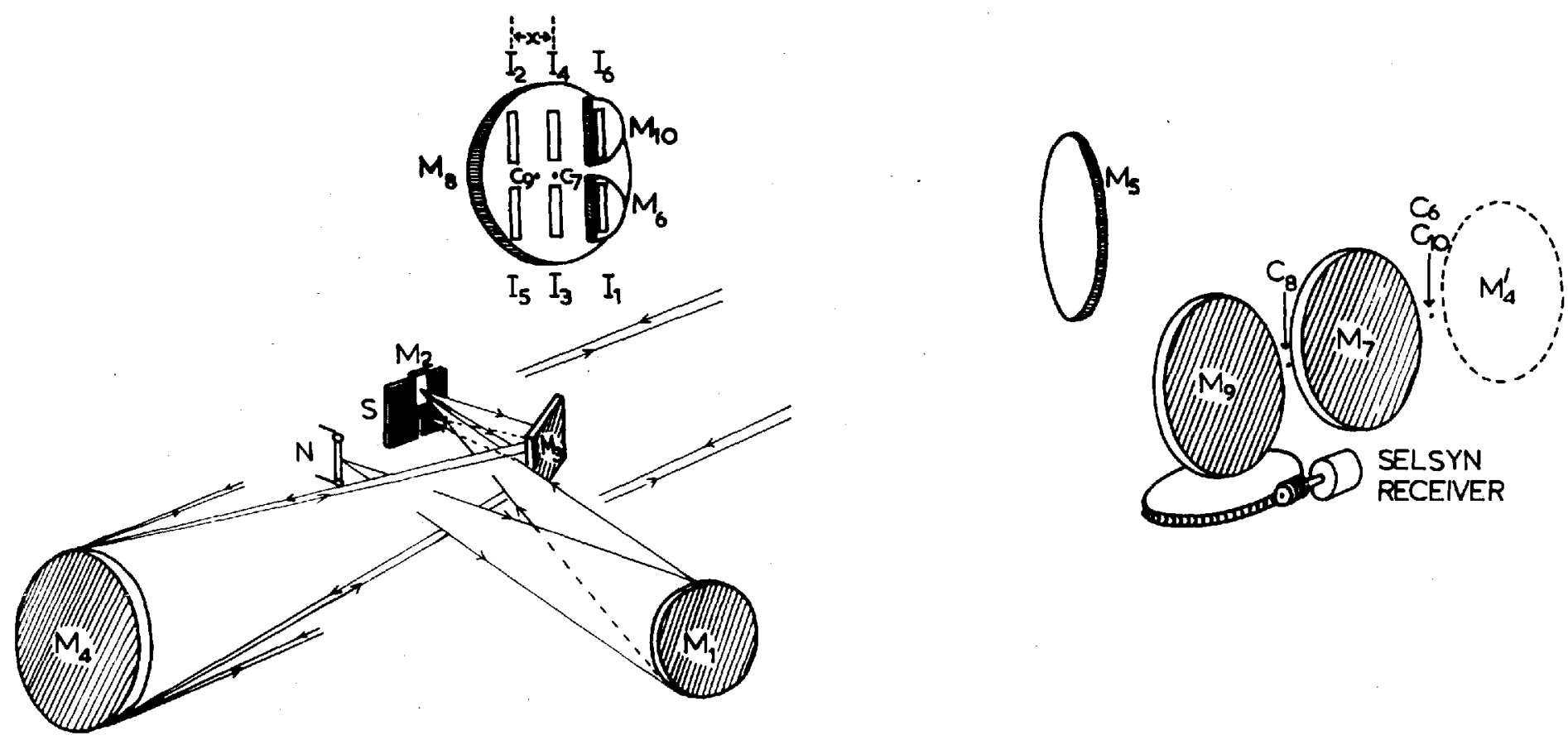

7
0

0
0
0
$\vdots$

Fig 3.8. Perspective view of optical path for 12 transits of cell (not to scale).

$$
\begin{array}{ll}
N & \text { Nernst filament, } 0.25 \times 2 \mathrm{~cm} . \\
S & \text { Entrance slit jaws. } \\
C_{6}, C_{7}, C_{8}, C_{9}, C_{10} & \text { Centres of curvature of } M_{6}, M_{7}, M_{8}, M_{9}, M_{10} .
\end{array}
$$

Path of rays :

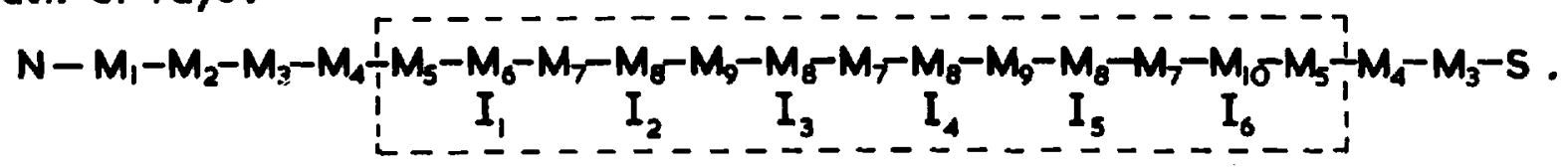


Fig. 3.7. Diagram of optical system (London) (not to scale)

S Nernst source, $0.25 \mathrm{~cm} \times 2.5 \mathrm{~cm}$.
C. Chopper, $10 \mathrm{c} / \mathrm{s}$.
$G \quad$ Merton replica grating $15 \mathrm{~cm} \times 15 \mathrm{~cm}, 473$ or 985 lines/cm.
$F_{1} \quad \begin{aligned} & \text { Polystyrene or terylene filter. } \\ & F_{2}\end{aligned} \quad \begin{aligned} & \text { Double reststrahlen magnesium oxide filter for } \lambda>13 \mu \text { or } \\ & \text { aluminised mirrors for } \lambda<13 \mu\end{aligned}$
F $_{3}$ Bloomed indium antimonide filter.
D Golay detector.
W $\quad$ Polyethylene window, $30 \mu$ thick.

Mirrors. $\quad \frac{\text { Diameter }}{(\mathrm{cm})} \quad \frac{\text { Radius of }}{\frac{\text { Curvature }}{(\mathrm{cm})}} \frac{\text { Separation: }}{(\mathrm{cm})}$

(Source)

MI

15

$\mathrm{M}_{2}$

$0.5 \times 1.5$

$\mathrm{M}_{3}$

$15 \times 15$

$\mathrm{Mi}_{4}$

$\mathrm{M}_{5}$

$\mathrm{M}_{6,10}$

$\mathrm{Mr}$

30

33.6

$\mathrm{M}_{8}$

$\mathrm{M}_{9}$

10, semicircular

30

30

30

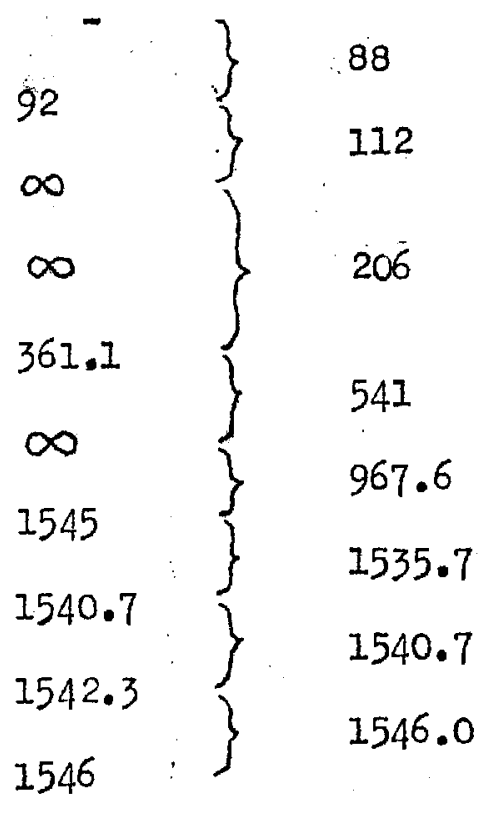

Laboratory + spectrometer path $=1324+730=2086 \mathrm{~cm}$.

Possible coll path lengths (m) $115.5,177.2,239.0,300.7,362.4$,

$$
424.2,485.9,547.6 \text {. }
$$


of the optios was dictated mainly by the shape and size of the laboratory space available, the latter not permitting the use of the simpler version described by White (1942). The tolerances on the radii and on the figure of the mirrors for satisfactory performance are not severe, these subjects being fully discussed by White. The mirrors used in the present work were figured to $\frac{1}{2}$ - wavelength in the visible, with radii equal to within $2 \mathrm{~cm}$ in $1550 \mathrm{~cm}$, though a tolerance 10 times greater would have been acceptable.

The essential details of the system are given in the legends (k.53)

to Fig 3.7 and 3.8, and only the following need special comment.

(i) $\mathbb{M}_{2}$ and $\mathbb{M}_{4}$ are used off-axis. The off-axis angle is kept to a minimum by allowing the smallest possible clearance between the beam from $M_{1}$ to $M_{2}$ and the mounts for the source and chopper, and between $\mathbb{M}_{3}$ and the two beams passing it.

(ii) $M_{4}$ is the image of $M_{4}$ in $M_{5} \cdot M_{6}$ and $M_{10}$, the two halves of a centrally divided circular mirror, are adjusted with their centres of curvature coincident, mid-way between $\mathrm{M}_{4}$ and $\mathrm{M}_{7}$. $\mathrm{M}_{7}$ is fixed with its centre of curvature at the centre of $M_{8}$, and $M_{8}$ with its centre of curvature mid-way between $\mathbb{M}_{7}$ and $\mathbb{M}_{9}$.

(iii) $\mathbb{M}_{9}$ is mounted on a turntable whose rotation moves $\mathrm{C}_{9}$ along a horizontal line through the centre of $\mathrm{M}_{8}$. The adjustment is made remotely using a Selsyn transmitter and receiver. 
(iv) Since $M_{I O}$ is imaged on the entrance slit of the spectrometer via $\mathbb{M}_{5}, \mathbb{M}_{4}$ and $\mathbb{M}_{3}$, the slit will only be illuminated when $\mathbb{M}_{9}$ is adjusted to one of the discreet settings that give an image on $\mathrm{M}_{10}$. The settings are such that the separation of $\mathrm{C}_{9}$ and $\mathrm{C}_{7}$ is $\frac{x}{n}$, where $\mathrm{n}=1,2,3$. and $\mathrm{x}$ is shown in Fig 3.8; the number of traversals of the cell is then $4(n+1)$. Fig 3.8 illustrates the case of $n=2$

AII mirrors were mounted on sturdy platforms each consisting of 4 slabs of concrete 2 ft square and 2 in thick, separated by rubber spacers which were found to remove all traces of vibration. The platforms for the cell mirrors had to be isolated mechanically from the cell structure, because it was found that some vibration was being transmitted. This was achieved by leaving 2 in clearance between the concrete slabs and the polystyrene floor of the cell, making good the seal with 2 sheets of thin polyethylene.

The initial setting up presented no problems and is summarised below:

(i) Set $M_{7}$ and $M_{9}$ at their correct distances from $\mathbb{M}_{8}$, i.e. with their centres of curvature on $\mathrm{M}_{8}$. This could be done to $\pm 0.5 \mathrm{~cm}$ using the Foucault knife edge technique (e.g. Strong, 1940, p.69)

(ii) Adjust $\mathbb{M}_{7}$ and $\mathbb{M}_{9}$ so that their axes pass through the centre of $M_{8}$ ( $M_{8}$ is then imeged back on itself by ${ }^{2} 7$ and $\mathrm{M}_{9}$ ) 
(iii) Adjust $M_{8}$ so that its axis passes midway between $M_{7}$ and $\mathbb{M}_{9}\left(M_{7}\right.$ is then imaged on $\left.\mathbb{M}_{9}\right)$

(iv) $M_{6}$ and $M_{10}$ set with oentres of curvature coincident, just off edge of $M_{7}$.

(v) $\mathbb{M}_{5}$ adjusted so that $\mathbb{M}_{4}$ imaged on $M_{7}$, via $M_{5}$ and $M_{6}$, $M_{10}$.

Once the initial adjustments had been made as above, routine cheoking was facilitated by three small lamps and screens set up as. follows:

(i) Lamp and soreen just off edge of $M_{7}$; image formed by $\mathbb{M}_{6}$, $M_{8}$ and $\mathbb{M}_{10}$ (all three are on one mounting), checking $M_{6}, M_{8}, M_{10}$

(ii) Lump just off edge of $M_{4}$; image formed on same screen as used in (i) via $\mathbb{M}_{5}, \mathbb{M}_{6}$ and $\mathbb{M}_{10}$, thus ohecking the alignment of $\mathrm{MH}_{5}$.

(iii) Lamp off edge of $M_{B}$, soreen diametrically opposite; images formed by $M_{7}$ and $M_{9}$, thus checking both.

By noting the positions of the images after the initial alignment, a routine cheok could be made in $2 \mathrm{~min}$. In fact, the mountings turned out to be so stable that no correction was required during 1 year.

3.2.5. Spectrometer, source and detection system

The spootrometer, described in Chapter $2(\xi 2.3 .3)$, was the 
same instrument as used in the Ascot experiment, having been made nore compact. The source, chopper, detector, amplifier and recorder again were all as described in $\$ 2.3$, run from a stabilised power supply.

\subsection{Performance of the system}

Before attempting any absorption measurements, it was necessary to complete an exhaustive series of tests to confirm that all parts of the system were behaving as expected, and to investigate several potential sources of error. They are dealt with in order below. 3.3.1 Calibration, resolution and linearity

The spectrometer was calibrated using 4 isolated water vapour lines, taking the observed wavelengths of Migeotte et al (1956, 1957). Then linearity was tested as described in $\$ 2.4 .5$; no significant departure from linearity was detected. Owing to improved illumination of the aperture of the spectrometer and a new Golay cell with higher signal-to-noise ratio, the resolution attainable was improved by about $40 \%$ as compared with the Ascot experiment.

3.3.2. Transmittance of polyethylene window

Since the experimental technique involved the measurement of the transmittance of the cell as a function of humidity, it was absolutely essential to be sure that the polyethylene cell window was not affected by changes in humidity. This might conceivably 
happen if hygroscopic nuclei adhere to the window, whose radii would then vary with the relative humidity, or through adsorption of water molecules by the window.

To test this possibility, a short cell with polyethylene windows was placed in the beam in front of $\mathbb{M}_{4}$, giving four transits through each window. The humidity in the short cell was raised, monitoring the signal at $\nu=559.4 \mathrm{~cm}^{-1}$. No change in signal was detected until actual condensation appeared on the windows, suggesting that any effect caused by the two transits through the main cell window should be negligible, especially since saturation was never approached in the main cell (relative humidities were nearly always below $60 \%$ ).

During the course of the main experiment, a run was made without the polyethylene cell window, sealing being effected in this case by a metal sheet which was removed only briefly when making a measurement of transmittance. This run gave the same result as all the others, indicating that the transmittance of the window did not vary detectably with humidity.

\subsubsection{Variation of reflectivity of mirrors with humidity}

For the same reasons given in $\oint 3.3 .2$, the mirror reflectivity might vary with humidity, and this required careful investigation. Three tests were devised, all showing that no signifioant change of reflectivity occurred on raising the humidity to the highest levels used in the experiment. 
The first test was to flood $M_{8}$ with dry air fron a oylinder, having previously brought the hurnidity to a high level. With the cell adjusted for 24 transits ( 12 reflections off $M_{8}$ ), the signals at $\nu=559.4 \mathrm{~cm}^{-1}$ and $1118.8 \mathrm{~cm}^{-1}$ were monitored. No detectable change $\left(<\frac{1}{2} \%\right)$ was observed.

For the second test, an air tight partition was ingerted in the cell $1.5 \mathrm{~m}$ in front of $\mathrm{M}_{7}$ and $\mathrm{M}_{9}$. The humidity in the longer section, containing $M_{5}, M_{6}, M_{8}$ and $M_{10}$ was now brought to a high level (vapour pressure, $e,=27 \mathrm{mb}$ ), leaving the short section containing $\mathrm{M}_{7}$ and $\mathrm{M}_{9}$ much drier $(e=6 \mathrm{mb}$ ). Having achieved uniform mixing in the two sections of the cell, the fans were switched off and the partition was suddenly withdrawn. With the cell set for 24 transits, the signals at $\nu=559.4 \mathrm{~cm}^{-1}$ and $1118.8 \mathrm{~cm}^{-1}$ were then recorded continuously, together with humidity measurements at sensing head $(1,47)$

number 4 (Fig 3.1) to show the progress of the mixing between the two sections. If the reflectivity of $\mathrm{M}_{7}$ and $\mathrm{M}_{9}$ decreased with increasing humidity then a decrease of signal would have been expected as the mixing progressed. On the contrary, an increase of signal occurred. The cause of this effect was later traced to selfbroadening and subsequent results explained exactly the increase of signal observed, suggesting that no change occurred in the mirrors.

In the final test, the partition was again used, but the steam generator was moved into the short section containing $\mathrm{M}_{7}$ and $\mathrm{M}_{9}$. The signal was now monitored as mixing progressed from initial values 
of $e=27 \mathrm{mb}$ in the short section and $e=6 \mathrm{mb}$ in the long section. An increase of signal would now be expected if there were any increase in the reflectivity of $M_{7}$ and $\mathbb{M}_{9}$. In fact, the signal remained constant, which was again consistent with no change $(<2 \%)$ in the overall refleotivity ( 12 reflections).

It was finally concluded that the reflectivity of the mirrors was independent of the humidity in the oell.

\subsubsection{Scattering from mirrors and window}

It will be seen that $\mathbb{M}_{4}$ and $\mathbb{M}_{5}$ are used by both the beams entering and leaving the cell. There is therefore the possibility of backscattering of radiation from the ingoing beam into the emerging one. The same might happen at the polyethylene window.

If either of these occurred, the signal should not drop to zero when a shutter is inserted after $M_{5}$. In fact, the signal did disappear completely in this test, confirming that there were no scattering problems at $\mathrm{M}_{4}, \mathbb{M}_{5}$ or the window.

A related source of error in a multiple traversal system is the possibility of scattering from one beam into another. An immediate test of this is to check that the signal drops to zero for settings of $\mathbb{M}_{9}$ between the discreet positions giving an image on $\mathbb{M}_{10}$. This was in fact found to be the case, anless the images were so close as to cause tro to fall on $M_{10}$ at the same time. 


\section{3 .5 Stray radiation}

It is always difficult to be sure that stray radiation has been eliminated in the spectrometer. The usual tests involve filters having opaque absorption bands, checking that the signal drops to zero on inserting the filter. This test is satisfactory for stray radiation of greatly different wavelength, but always leaves some in respect doubt/ of wavelengths in the immediate neighbourhood of the one required. The tests applied were as follows:

(i) Glass plate - Zero signal, showing no stray visible radiation.

(ii) Terylene filter (narrow opaque band at $9.0 \mu$ ) - Zero signal at $9.0 \mu$, showing pure spectrum at $9.0 \mu$

(iii) $15 \mu \quad \mathrm{CO}_{2}$ band. Zero signal at centre of $Q$ branch, showing pure spectrum at $15.0 \mu$.

(iv) Several strong water vapour lines between 17 and $20 \mu$. Line centres were fully absorbed under high resolution, showing pure spectrum at these points.

These satisfactory results were taken to indicate that stray radiation was of negligtble proportions.

\section{3 .6 Aerosol absorption}

In a closed cell it is possible in principle tio renove aerosol filtering. However, measuremonts using polluted air dram from the by outside were found to give the seme results as those made with clean 
air which had been allowed to settle over a long period in the cell. It should be remembered that the relative humidity in the cell was rarely allowed to rise above $60 \%$, so that hygroscopic nuclei should have remained very small. In the circums tances, it was considered that aerosol absorption would be negligible.

\subsubsection{Ozone and carbon dioxide absorption}

The use of many electric motors led to the generation of ozone in the cell, and probably also $\mathrm{N}_{2} \mathrm{O}$ and $\mathrm{CO}_{2}$. Is a result, it was only possible to work in windows well away from absorption bands of these gases, i.e. windows $4,8,11,13,17,18,19,20$ (see $\oint 2.4 .1$ ).

3.4. Experimental technique

3.4.1. Choice of Method

With the facilities to control the humidity, an absolute method of measuring absorption coefficients looked attractive, observing the signal in each window as a function of mumidity. However, the longterm stability of the detector system referred to in $\$ 2.4 .6$ proved to be inadequate and a relative method was again selected. The techniques used were broadly similar to those in the sscot experiment, wi th some improvements,

3.4.2. Measurement of $k_{17}-k_{4}$

With the grating set to observe window 17 in the first order, 
the second order spectrum of window 4 was removed by a terylene filter of thickness $12 \mu$. Without moving the grating, window 4 was now observed by changing the terylene filter for a polystyrene one, thickness $200 \mu$. The latter is opaque in window 17 whilst transmitting window 4 . The signals $S_{17}$ and $S_{4}$ were made roughly equal by adding polyethylene sheets totalling about $75 \mu$ thickness to the polystyrene filter. Defining $y_{17,4}$ as $s_{17 / s_{4}}$, we have

$$
y_{17,4}=A_{17,4} \exp \left\{-\left(k_{17}-k_{4}\right) m\right\}
$$

where $A_{17,4}$ is a constant involving the relative reflectivities and transmissivities of the mirrors, grating and filters in Windows 17 and 14 ,

and $m$ is the mass of water vapour per unit area of path, so that a plot of $\mathrm{y}_{13,4}$ against m would give $\mathrm{k}_{17}-\mathrm{k}_{4}$.

A $r$ un was usually carried out in the following manner, An initial observation of $y_{17,4}$ was made with the humidity at the ambient value and the temperature set roughly at the desired value (a long period, of order 3 hours, was required for the temperature to reach a steady value). The humidity was then raised rapidly to a high level and readings of $y_{17,4}$, with simultaneous humidities, were taken periodically as the humidity returned slowly towards the ambient value by diffusion Ioss. This took a further 3 or 4 hours, during which time the air in the cell was circulated cortinuously. The final observation was compared with the first, and agreement Within experimental error was invariably found. 
3.4.3. Measurement of $k_{18}-k_{17}, k_{19}-k_{17}, k_{20}-k_{17}$.

With second order spectra removed by a double reststrahlen magnesium oxide filter, the signals in windows 18,19 and 20 were compared in turn with that in window 17 , rough equality of signal being achieved initially by suitable combinations of polyethylene filters. Then the value of $k_{17}-k_{i}$ was determined as in $\oint 3.4 .2$, using

$$
y_{17, i}=A_{17, i} \exp \left\{-\left(k_{17}-k_{i}\right) m\right\} \text {. }
$$

3.4.4. Absolute measurements of $\mathrm{k}_{4}, \mathrm{k}_{8}$ and $\mathrm{k}_{13}$.

$\Lambda$ few observations of the change of signal $s_{i}$ in windows 8, II and 13 with humidity were obtained in an attempt to establish absolute values here. To minimise the effects of drifts in the detector system or optics, the measurement was carried out as quickly a possible by introducing steam at the maximum rate, recording the signal continuously. At the end of the run the whole system was checked for drifts by noting the signal after quickly returning the humidity to its original value by opening the cell to the atmosphere. A complete run took $20 \mathrm{~min}$, and about $20 \%$ were rejected because the signal did not return to its original level. We then use

$$
S_{i}=\text { const } e^{-R_{i} m} \text {. }
$$

The measurements of $\mathrm{s}_{4}$ taken in the runs for $\mathrm{k}_{17}-4$ were also examined for variation with m. Mlthough these runs often took several 

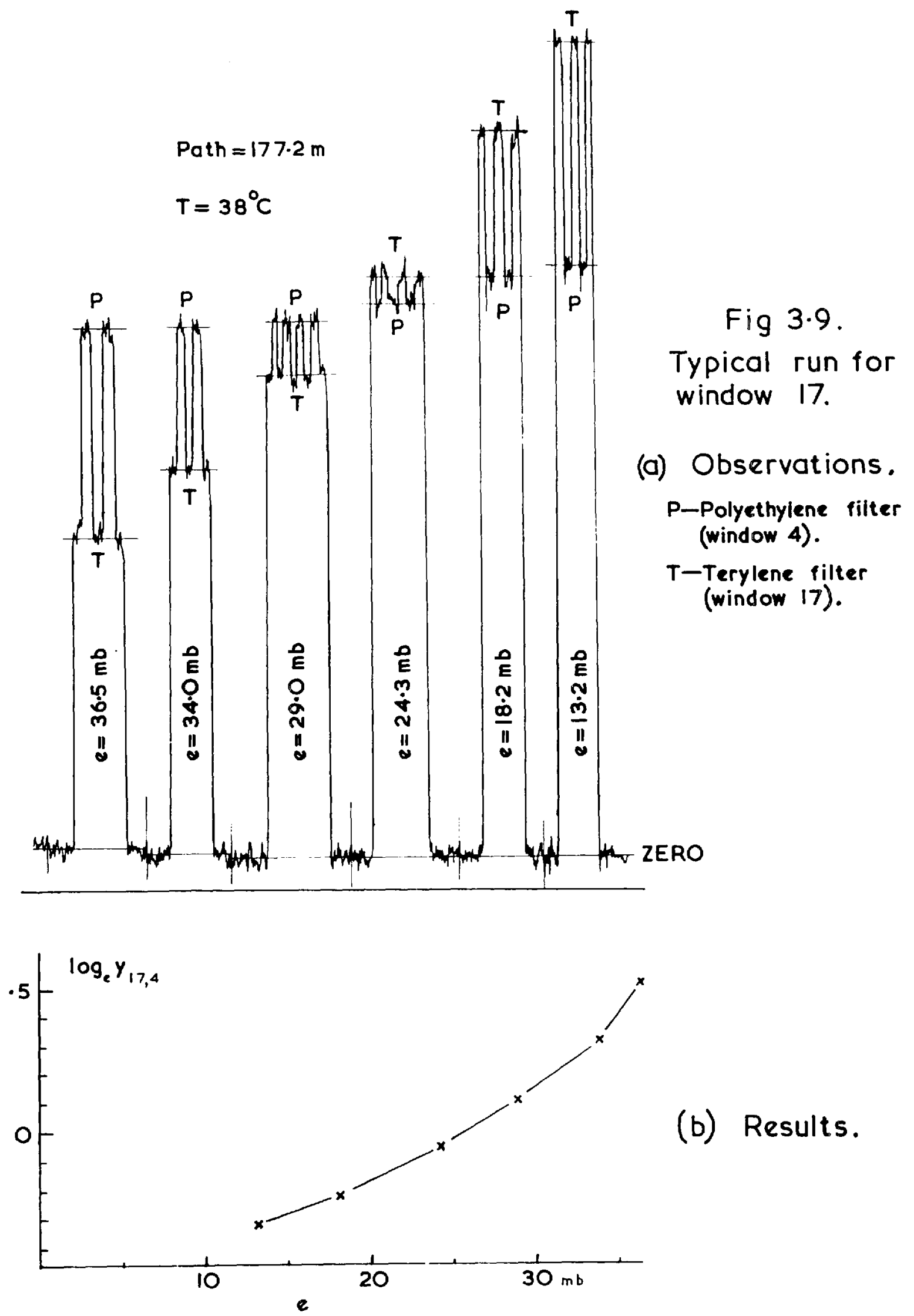

(b) Results. 
hours, the drift was nearly always small enough to permit their use to give an absolute value of $k_{4}$.

3.4.5. Absolute measurements in windows near $4 \mu$

The absorption in four windows $(\nu=2687,2613,2502$ and $2403 \mathrm{~cm}^{-1}$ ) near $4 \mu$. was measured as described in $\oint 3.4 .4$, the indium antimonide filter having been replaced by indium arsenide, which cuts on at $3.3 \mu$.

3.5. Results and discussion

$3.5 .1 \quad 17-21 \mu$ region

3.5.1.1. Window 17

This measurement, being the simplest to make and involving the movement of only one filter, is regarded as providing a 'standard window' with which others in the $18-21 \mu$ region may be compared.

A typical run is illustrated in Fig 3.9, together with the p.63

results. From Eq. 3.1 we have

$$
\log _{2} y_{17,4}=\log _{2} A_{17,4}-\left(k_{17}-k_{4}\right) m .
$$

A strong curvature in the plot is at once apparent, consistent with a very large degree of self-broadening. Under these circumstances $k_{17}-k_{4}$ can not be determined from the slope of the curve, but must instead be evaluated point by point, for which a value of $\log _{e} A_{17,4}$ is required. The only/ to measure $A_{17,4}$ is to observe $y_{17,4}$ with 
Facing $p .66$

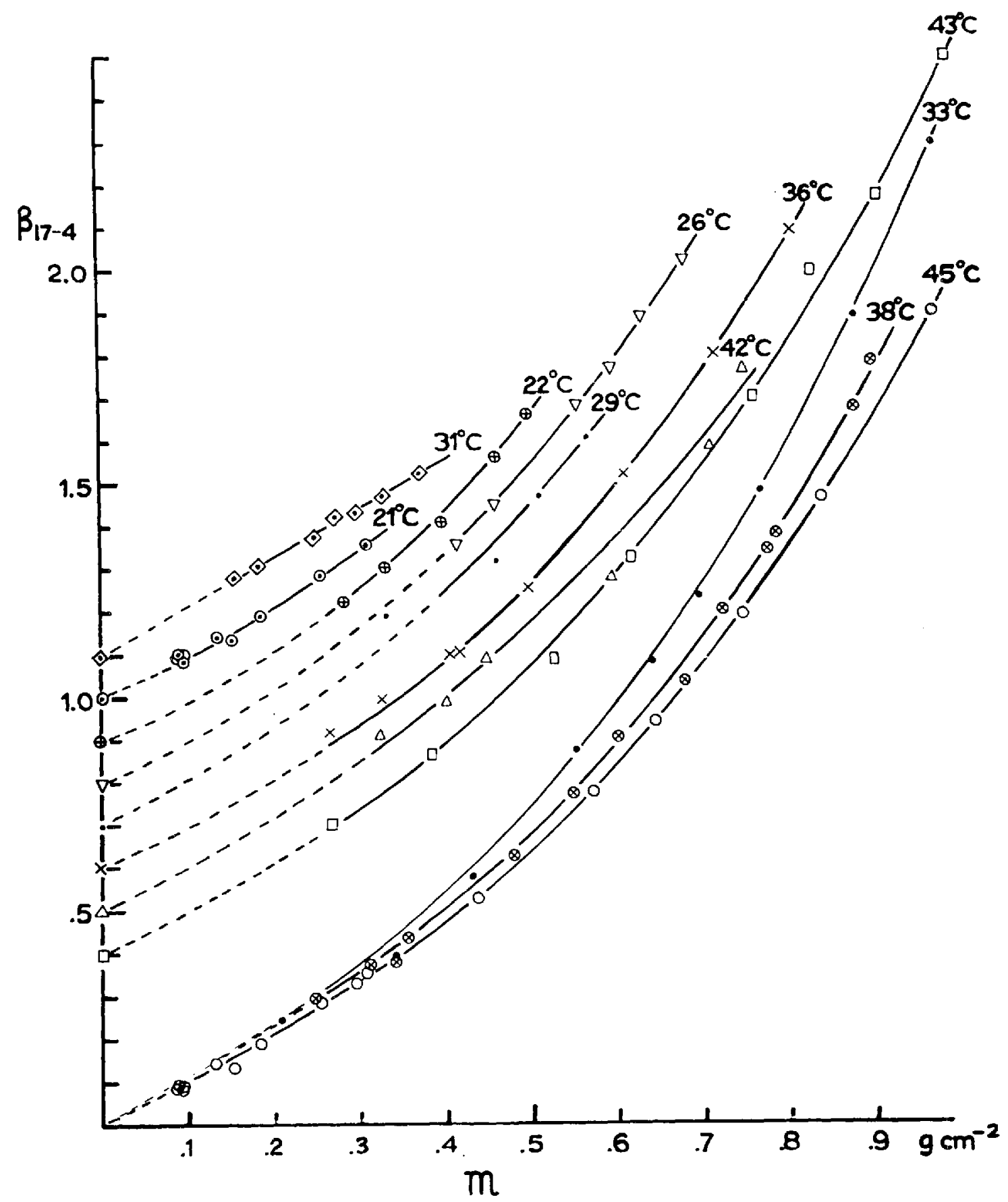

Fig 3.10. Extinction in window 17 for different temperatures. The origin of the upper eight runs is displaced as shown. 
the cell completely dried out; this was attempted on three occasions by freezing the water vapour onto the inside walls of the heat exchanger (area $\sim 1 \mathrm{~m}^{2}$ ), which was surrounded for this purpose with dry ice. Unfortunately, the vapour pressure could not be reduced below 3 mb because at this stage the capacity of this means of extraction was only just keeping up with diffusion from outside (vapour pressure $\sim 10 \mathrm{mb}$ ). It was felt, however, that the curves obtained from these low humidity runs could be extrapolated to $m=0$ : with confidence to give a value of $\log _{e} \Lambda_{17,4}$; it was noted moreover that its value did not vary detectably over the period of the investigation and has therefore been assumed to have had the same value in those runs (the large majority) in which the vapour pressure was not taken below $10 \mathrm{mb}$.

A further complication became apparent when muns were carried out at different temperatures. Fig 3.10 shows the results of 11 mung at temperatures between $2 I^{\circ} \mathrm{C}$ and $45^{\circ} \mathrm{C}$, showing a strong negative temperature dependence, at least at vapour pressures above about $15 \mathrm{mb}$, (all the results have been scaled to a path length of $402 \mathrm{~m}$ to facilitate comperison with the Ascot results presented in Chapter 2). The extropolated portion of each curve is shown as a broken line, the intercept on the abscissa having been inferred as described above. Values of $k_{17}-k_{4}$ are next evaluated from

$$
k_{17-4}=-\frac{1}{m}\left[\log _{a} y_{17,4}-\log _{e} A_{17,4}\right]
$$




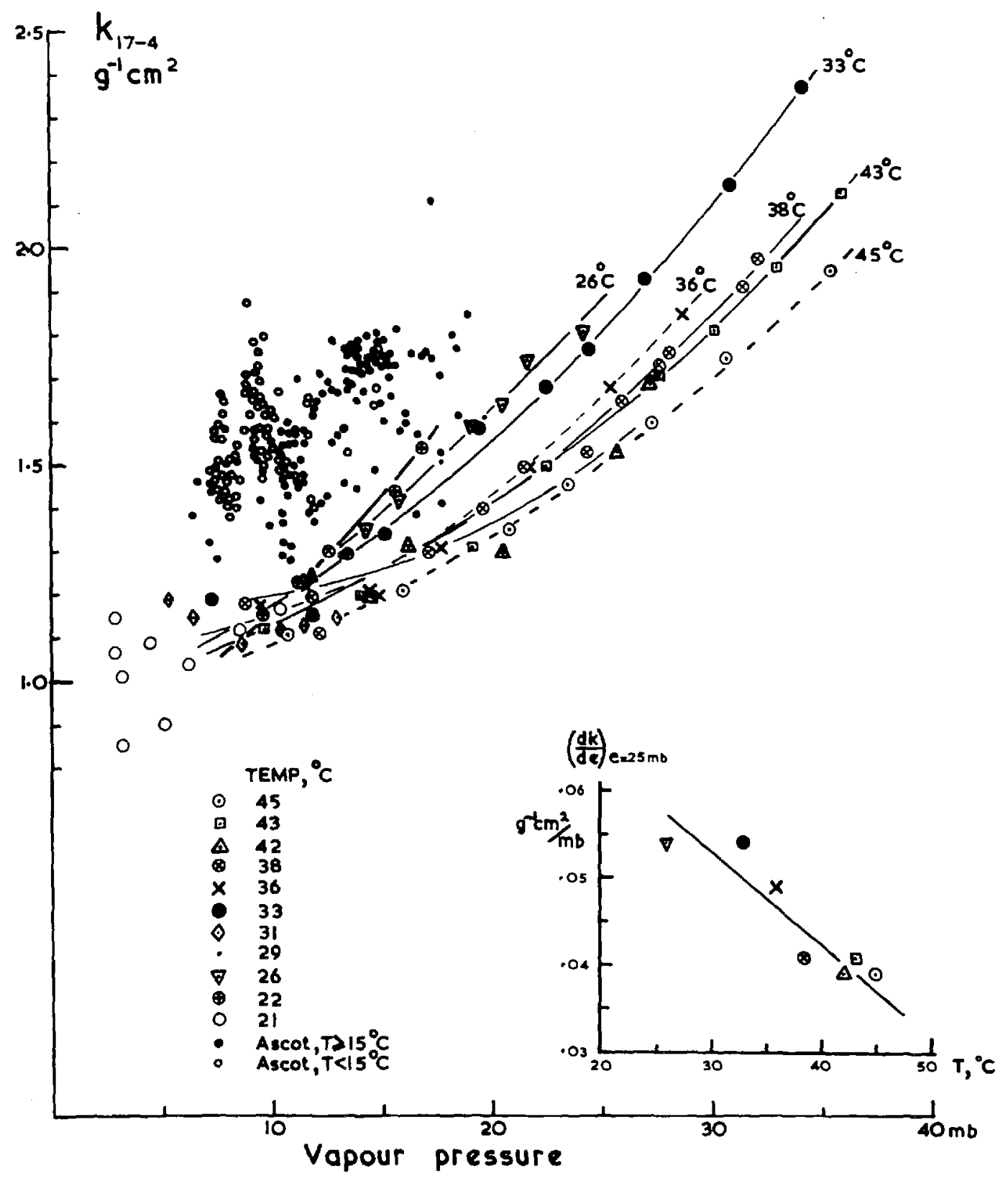

Fig 3.11. Absorption coefficients in window 17 relative to window 4 as a function of vapour pressure and temperature. 
and all the results are shown in Fig 3.11 as a function of vapour pressure. The data are tabulated in Appendix 3.1. Apart from the obvious increase of $k_{17-4}$ with $e$, the negative temperature dependence is very marked at the higher vapour pressures, but seems to become smaller, or even to disappear, near $e=10 \mathrm{mb}$, This suggests that the absorption coefficient $k$ is composed of two parts; $\mathrm{k}_{\mathrm{s}}$ due to self broadening with a negative temperature dependence and $k_{f}$ due to foreign broadening with positive temperature dependence. There will therefore be a vapour pressure below which the total absorption coefficient increases with temperature, but thereafter the negatively dependent self-broadening term becomes predominant. Unfortunately, with path lengths of $400 \mathrm{~m}$ or less, the level of scatter in observations with e $<10 \mathrm{mb}$ is too great to permit any conclusion regarding the temperature dependence there.

The form of the functions relating $k, e$ and $T$ can not be deduced from the results but rough values for the parameters in an assumed linear relation can be found. Conaidering the temperature dependence first, we can assume

$$
k\left(n, e_{1}, T_{1}\right)=k_{f}\left(\mu, T_{1}\right)+k_{S}\left(e_{1}, T_{0}\right)\left[1+\alpha\left(T_{1}-T_{0}\right)\right]
$$

from which

$$
\begin{aligned}
& \left(\frac{\partial k}{\partial e}\right)_{T=T_{1}}=\left[1+\alpha\left(T_{1}-T_{0}\right)\right]\left(\frac{\partial R_{s}}{\partial e}\right)_{T=T_{0}} \\
& e=e_{1} \\
& =\left[1+\alpha\left(T_{1}-T_{0}\right)\right]\left(\frac{\partial R}{\partial e}\right)_{T=T_{0}} \text { since } k_{f} \neq f(e) \\
& e=e_{1}
\end{aligned}
$$


so that a plot of $\frac{\partial R}{\partial R}$ as a function of $T$ will give $\alpha$. The results, $1.67{ }^{2}$
show in Fig 3.1. from runs for which $\frac{\partial k}{\partial e}$ may be evaluated between $\theta=20$ and $30 \mathrm{mb}$, indicate a negative temperature dependence of about $2 \%$ per ${ }^{\circ} \mathrm{C}$ at $30^{\circ} \mathrm{C}$.

The vapour pressure dependence seems to be significantly non-linear, but this feature is very sensitive to the value adopted for $A_{17,4}$, and a reasonable error here could account for the nonlinearity in Fig 3.11. Accordingly it is felt that the observations do not warrant examination beyond first order terms. The best straight Iine through observations taken at $\mathrm{T}=30^{\circ} \mathrm{C}$ gives $\mathrm{k}_{17}-4=1+0.033 \mathrm{e}$ $\mathrm{E}^{-1} \mathrm{~cm}^{2}$, where $\mathrm{e}$ is in millibars, so that the results can be represented roughly by the expression

$$
\begin{aligned}
& k_{17-4}(T, e)=1.0 f(n, T)+0.033 e[1-0.02(T-30)] \mathrm{g}^{-1} \mathrm{os}^{2} \\
& \text { in the range } \\
& 0<e<35 \mathrm{mb} \\
& 20<T<45^{\circ} \mathrm{C} .
\end{aligned}
$$

$f(p, T)$ is an undetermined function of dry air pressure $p$ and temperature, but it is to be expected on theoretical grounds to be Iinear in $p$. Furthermore, the apparent disappearance of the temperature dependence of $\mathrm{k}_{17}-4$ near $e=10 \mathrm{mb}$ could be explained if $f(p, T)$ increases by $0.5 \%$ to $1 \%$ per ${ }^{\circ} \mathrm{C}$. 
Facing p. 69

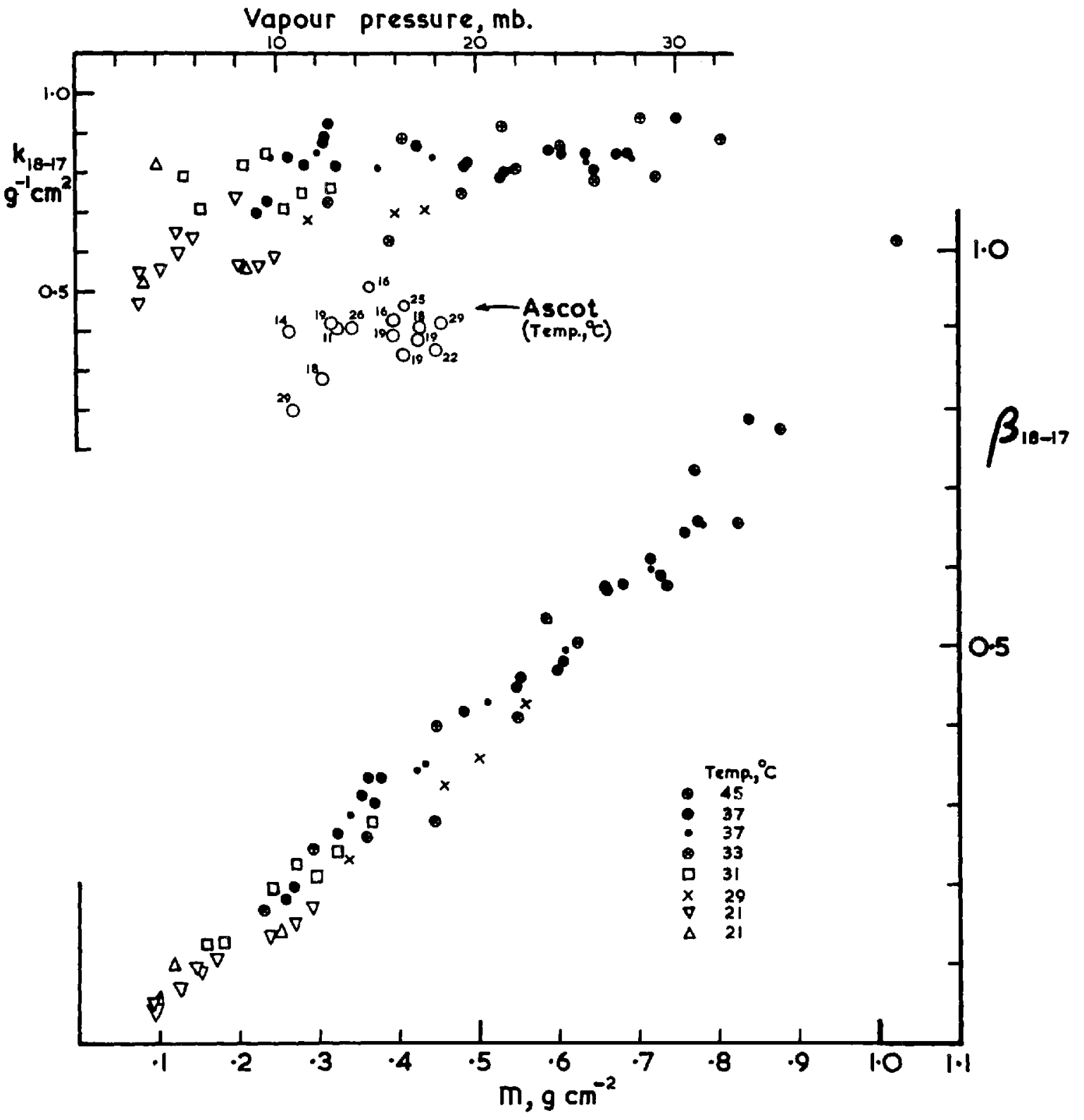

Fig 3.12. Extinction in window 18 and comparison with Ascot results. 


\section{(n.67)}

Fig 3.11 also shows all the results of the dscot experiment. They are on average $0.35 \mathrm{~g}^{-1} \mathrm{~cm}^{2}$ higher than the London results; this may be due to the isolation of a 'cleaner' window in the London experiment - a point discussed further in $\oint 3.5 .1 .3$. The Ascot results (h.67) show no systematic temperature dependence in Fig 3.11, al though on the basis of the London results one would not expect much at these vapour pressures, and in any case it would be masked by the large scatter. The vapour pressure dependence, on the other hand, is in good agreement with the Lond on results.

3.5.1.2. Windows 18,19 and 20

$\Lambda_{s}$ in the case of window 17 , it is necessary to measure $A_{17, i}$ by extrapolation of low humidity runs, and to assume that it remained the same in the other runs.

\section{(a) Window 18}

All the observations for window 18 are show in Fig 3.12 . The regression between $\beta_{18-17}$ and $m$ seems to be linear, but with a suggestion of a negative intercept which indicates a slight upward curvature arising from a self broadened contribution. Fig 3.12 also shows values of $k_{18}-17$ as a function of e, and the data are tabulated in $\Delta$ ppendix 3.1 . It is interesting to note that the self-broadened contribution is a smaller fraction of the whole than in the case of $\mathrm{k}_{17-4}$; this suggests that the self-broadened line shape is fundamental $1 y$ different from the foreign-broadened one. 
Facing p. 70

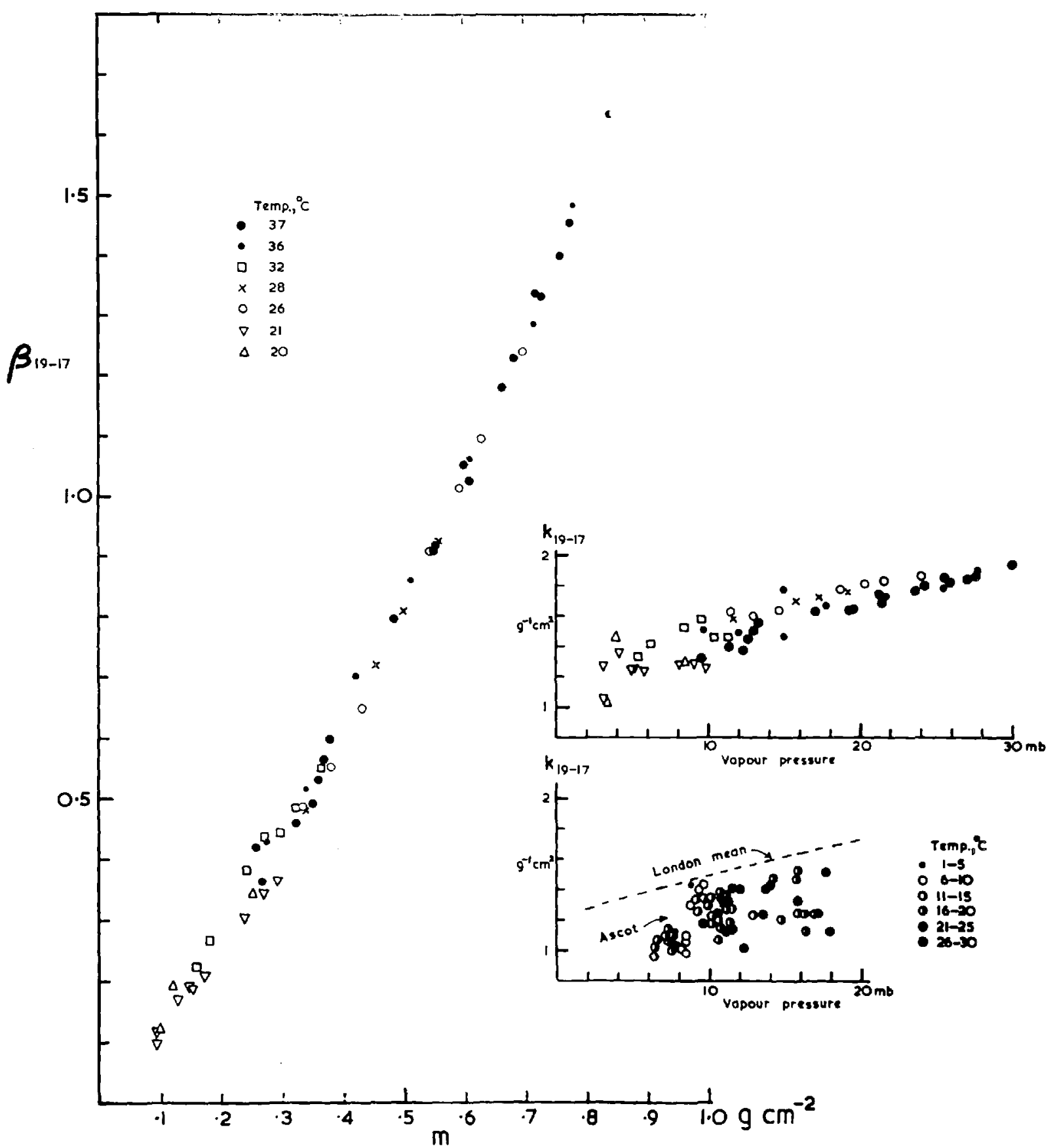

Fig 3.13. Extinction in window 19, and comparison with Ascot results. 
Facing p. 70

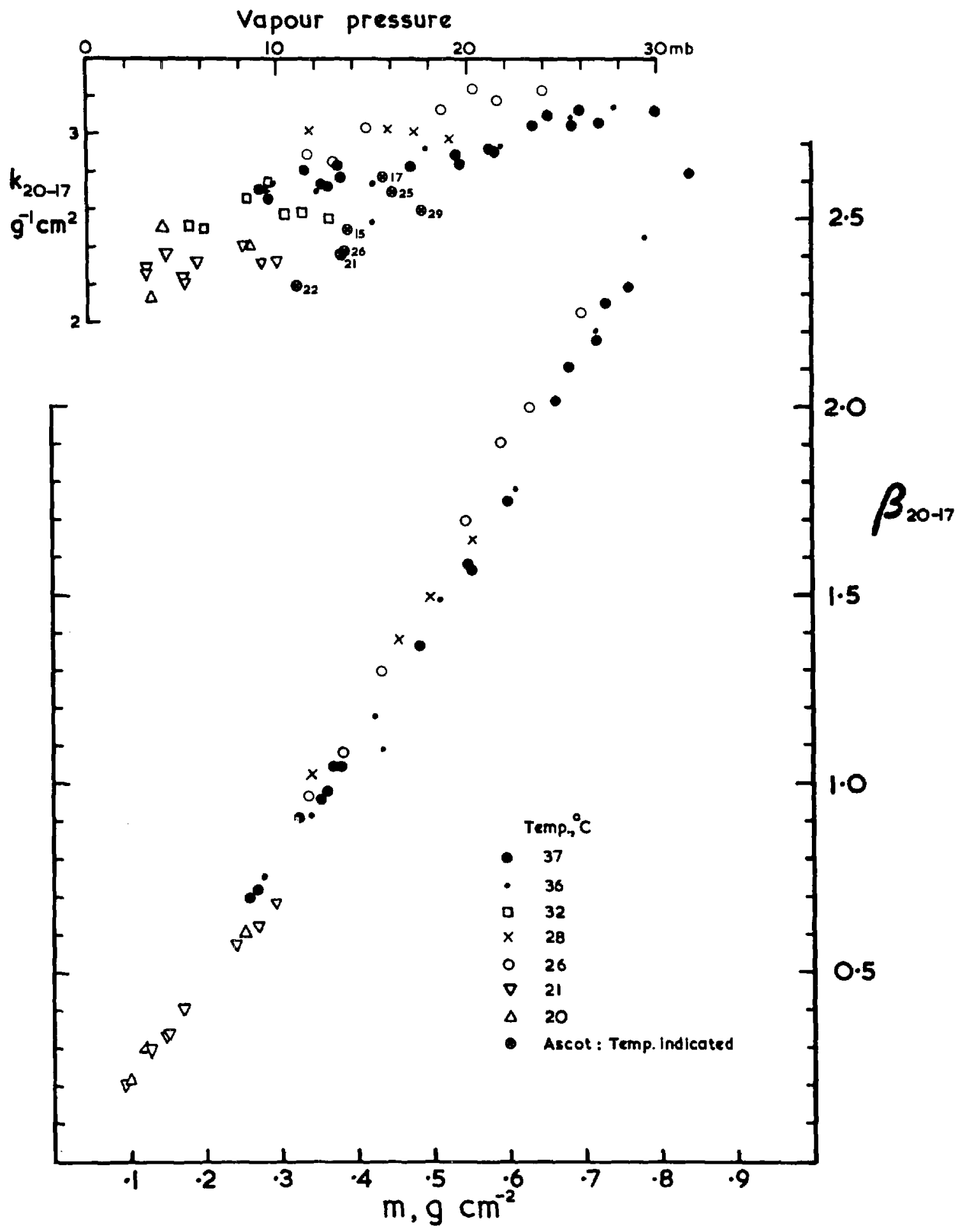

Fig 3.14. Extinction in window 20. 
There is evidence of a positive temperature dependence (about $1 \%$ per ${ }^{\circ} \mathrm{C}$ ) over the whole range of $\theta$, and this fits in with the picture inferred for $\mathrm{k}_{17}-4$ since in this case the negatively dependent part is relatively small.

The Ascot results are also shom in Fig 3.12. They are about $0.35 \mathrm{~g}^{-1} \mathrm{~cm}^{2}$ lower than the London ones - a discrepancy which is discussed further in $\$ 3.5 .1 .3$.

(b) Window 12 .

Fig 3.13 shows all the results for $\beta 19-17$ as a function of $\mathrm{m}$. The curvature is more obvious than in the case of window 18, implying a larger self-broadened contribution. The resulting values of $k_{19}-17$ as a function of e are also shown in Fig 3.13 and the data are tabulated in $\Lambda$ ppendix 3.1. Although scatter masks any temperature dependence at low vapour pressures (e $<15 \mathrm{mb}$ ), it should be noted that for $e>15 \mathrm{mb}, \mathrm{k}_{19-17}$ tends to be higher for lower temperatures。

The Ascot results are also shown in Fig 3.13 with mean London values for comparison; the former are seen to be about $0.3 \mathrm{~g}^{-1} \mathrm{~cm}^{2}$ lower than the latter - a difference similar to that observed for window 18 , to be discussed in $\oint 3.5 .1 .3$.

\section{(c) Window 20}

Fig 3.14 shows all the results for $\beta 20-17$ as a function of 
$m$, together with the resulting values of $k_{20}-17$ as a function of $e$, They again show a distinct self-broadened contribution, and although the accuraay does not werrant a quantitative statement about the temperature dependence, it seems to be negative for large e (>15 mb) and positive for small $e(<10 \mathrm{mb})$. All the data are tabulated in Appendix $3.1^{\text {h. }}$.

\section{(n.70)}

The Ascot results are also shown in Fig 3.14. They are about $0.3 \mathrm{~g}^{-1} \mathrm{~cm}^{2}$ lower than the London ones, and this point is discussed in the next section. Although the Ascot sample is small, the observations taken at higher e show the negative temperature dependence exhibited by the London results.

3.5.1.3 Systematic differences between Ascot and London resuIts

We have seen that $k_{17}-4$ is about $0.35 \mathrm{~g}^{-1} \mathrm{~cm}^{2}$ lower, and

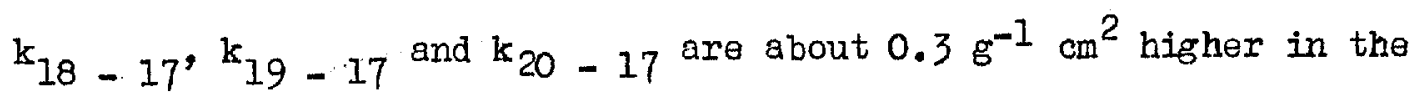
London observations than in the Ascot ones. One explanation of all these feetures might be that window 17 as isolated in the London experiment was in fact more transparent than at Ascot. This is indeed possible, because the resolution in London $\left(1.2 \mathrm{~cm}^{-1}\right)$ was better than that at Ascot $\left(1.7 \mathrm{~cm}^{-1}\right)$, the former being sufficient to exclude two weak water vapour Iines at $\nu=560.42 \mathrm{~cm}^{-1}$ and $560.89 \mathrm{~cm}^{-1}$ which were partly included in the Ascot window (the smaller image on the entrance slit in the Iondon experiment precluded the use of the lower resolution to check the measurement under the same conditions). 
Facing $p .72$

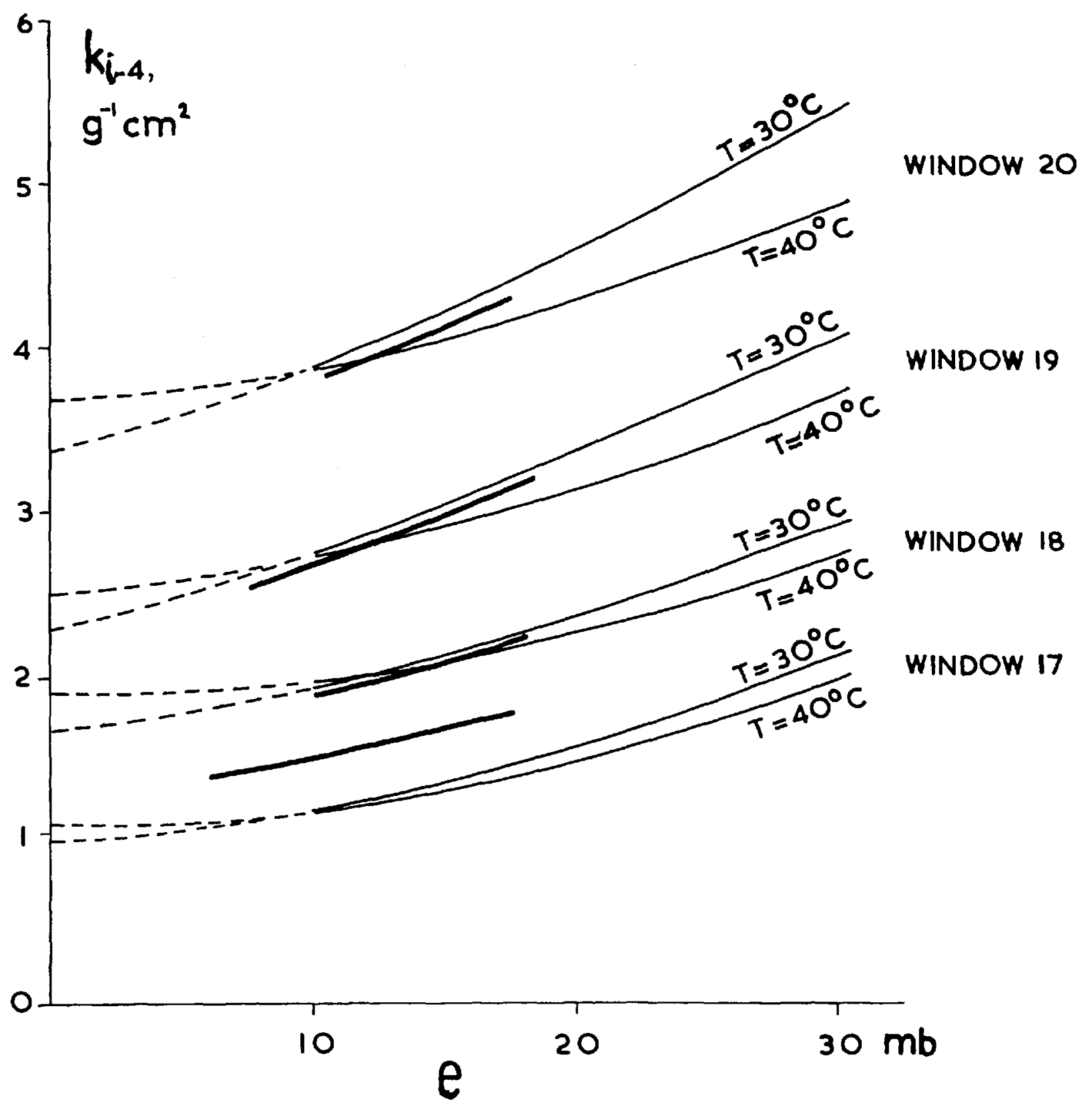

Fig 3.15. Summary of results as a function of vapour pressure and temperature.

Thin lines: observed values from the laboratory experiment (the dashed lines have been extrapolated smoothly).

Thick lines: Ascot results. 
However, assuming a triangular slit function, it was estimated graphically that these lines could have accounted for no more than $0.1 \mathrm{~g}^{-1} \mathrm{~cm}^{2}$ of the above discropancy.

It should also be pointed out that the lower London result for $k_{17-4}$ (but not the higher ones for windows 18, 19 and 20) could be explained by anomalously high absorption in window 4 . The results presented in $\oint 3.5 .3$ do indeed indicate much greater absorption here than would be expected from previous work in this region, though this may be due to a much increased self-broadened contribution at the higher vapour pressures ( $30 \mathrm{mb}$ ) necessary in a short path experiment, compared with the long path low vapour pressure ( $<10 \mathrm{mb}$ ) conditions in all previous work.

It is thought to be most unlikely that the differences can be attributed to aerosol absorption because if this had been significant the results would not have been so exactly reproducible owing to inevitable variation of the aerosol concentrations.

\subsubsection{Summary of results}

The results for the $17-21 \mu$ region are summarised in Fig 3.15. The intention is to show the qualitative aspects of the results and not too much weight is attached to the apparent curvature or the derived value of the temperature dependence. The evidence on the latter is rather scanty for low e, and a longer path length is required to settle this point. The dotted parts of the curves are extrapolated 
as smooth curves from the regions of higher e where scatter is much Iess. There is good agreement between the Ascot and London results except for the discrepancy in the case of window 17, which has already been discussed.

\subsubsection{Discussion and previous work}

There has been little previous work on the atmospheric continuum beyond $17 \mu$, and only that of Anthony (1952) and Bolle et al (1963) seems to have been directed specifically to the determination of absorption coefficients. Both investigations were carried out in the open atmosphere, employing, moreover, a slant path, so that variation of the temperature and vapour pressure along the path render the interpretation rather uncertain in the light of the present results.

Anthony (1952) deduced continuum absorption coefficients from the variation of solar intensity with zenith angle during the day and obtained a value of $1.0 \mathrm{~g}^{-1} \mathrm{~cm}^{2}$ at $19 \mu$, compared with valuos between 1.2 and $2.0 \mathrm{~g}^{-1} \mathrm{~cm}^{2}$ in the present work. This observation was made from Table Mountain, California, but temperatures, humidities and instrumental details were not reported (though the vapour pressure was probably below $10 \mathrm{mb}$ ), so that whilst/departure is in the direction expected, it is not possible to make a quantitative test.

Bolle (1963, 1964) reported the results of some very careful emission studies made under widely different conditions in different 


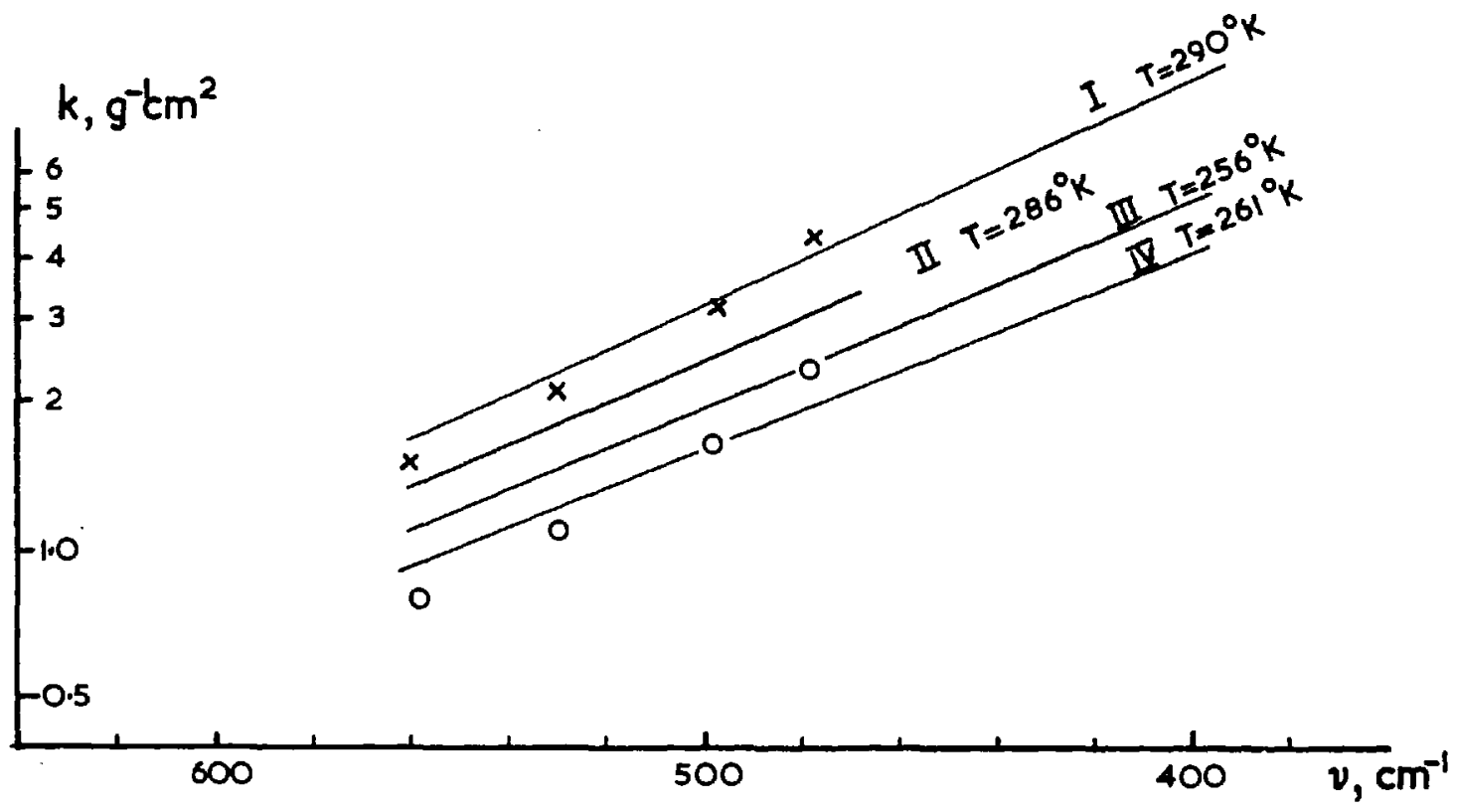

Fig 3.16. Comparison between present work and that of Bolle. Bolle (lines):

I Beer Sheva; $\quad T \sim 290^{\circ} \mathrm{K}$, e $15 \mathrm{mb}: 32 \cdot 0^{\circ} \mathrm{N}, 34 \cdot 9^{\circ} \mathrm{E} ; 280 \mathrm{~m}$.

II S. Agato; $\quad T \sim 286^{\circ} \mathrm{K}$, e $15 \mathrm{mb}: 40.6^{\circ} \mathrm{N}, 14.2^{\circ} \mathrm{E} ; 455 \mathrm{~m}$.

III Jungfraujoch; $T \sim 256^{\circ} \mathrm{K}, e<3 \mathrm{mb} ; 46.5^{\circ} \mathrm{N}, 800^{\circ} \mathrm{E} ; 3570 \mathrm{~m}$.

IV Munich; $\quad T \sim 261^{\circ} \mathrm{K}, e<3 \mathrm{mb}: 48.2{ }^{\circ} \mathrm{N}, 11.6^{\circ} \mathrm{E} ; 530 \mathrm{~m}$.

Present work (points):

$$
\begin{aligned}
& \times \quad T \sim 290^{\circ} \mathrm{K}, \quad=15 \mathrm{mb} . \\
& \text { O T 260 }
\end{aligned}
$$



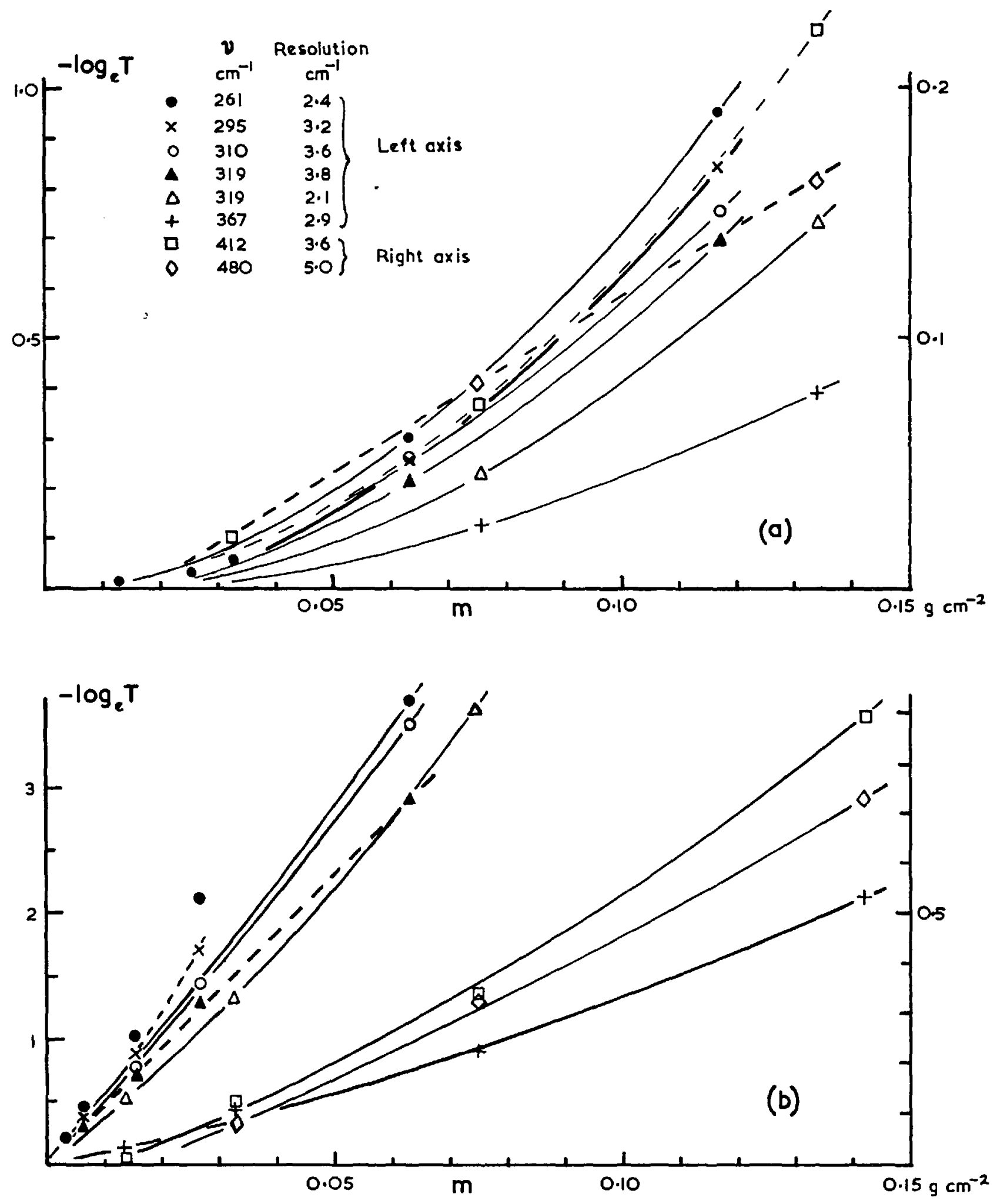

Fig 3.17. Laboratory measurements of Palmer $(1957 b, c)$

(a) Pure water vapour

(b) Water vapour-nitrogen mixture $\left(\mathrm{P}_{\mathrm{N}_{2}}=800 \mathrm{mb}\right)$ 
parts of the world, listed in the legend to Fig. 3.16. He used a high resolution grating spectrometer similar in performance to that used in the present rork. He dovised an ingenious method of analysis in which isolines of continuum emission were calculated for several values of the absorption coefficient, using humidities and temperatures determined in most cases by a simultaneous radio-sonde ascent on the site. With the isolines plotted on the observed emission spectrum it was a simple matter to read off window absorption coefficients by inspection.

The results are shown in Fig 3.16, from which it may be seen that values determined at Beer Sheva and S. Agata are nearly double those measured at Jungfraujoch and Munich. Bolle interpreted this as a positive temperature dependence; however, the difference observed is al so oomistent with a large self-broadening effect, the high temperature observations being associated with high partial vapour pressure ( $\sim 20 \mathrm{mb}$ at the surface, with a nean of about $15 \mathrm{mb}$ along the slant path) and the low temperature ones with low partial vapour pressure $(<3 \mathrm{mb})$. Values inferred from the present work (Fig 3.15) for the approximate conditions encountered by Bolle are included in Fig 3.16 and show surprisingly good agreement. in $\xi 2.7$ will now be considered in detail. Fig 3.17 a shows the
extinction due to pure water vapour (i.e. no foreign broadening) for
windows at $\nu=261,295,310,319,367,412$ and $480 \mathrm{~cm}^{-1}$, and Fig $3.17(\mathrm{~b})$ The laboratory experiment of Palmer ( $1957 \mathrm{~b}, \mathrm{c}$ ), described 


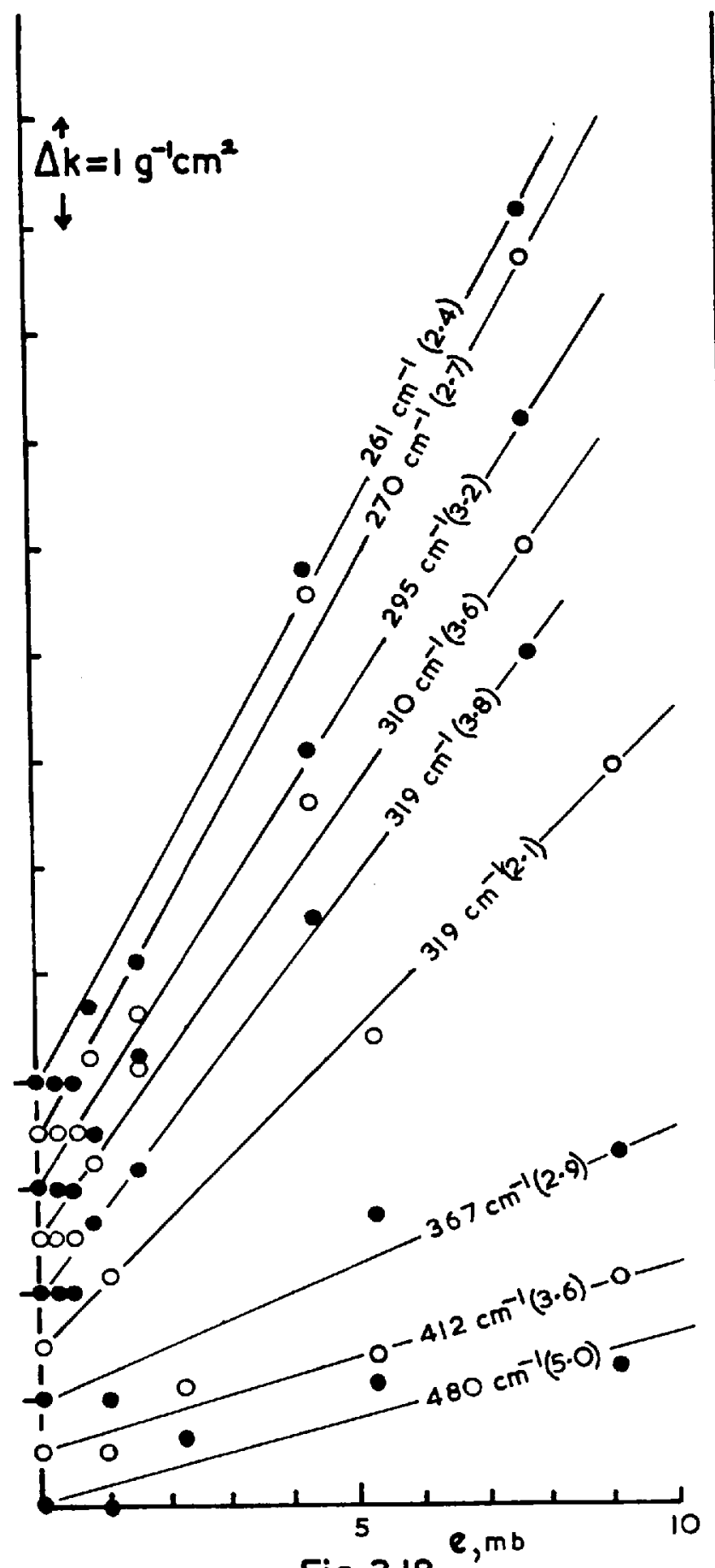

Fig 3.18.

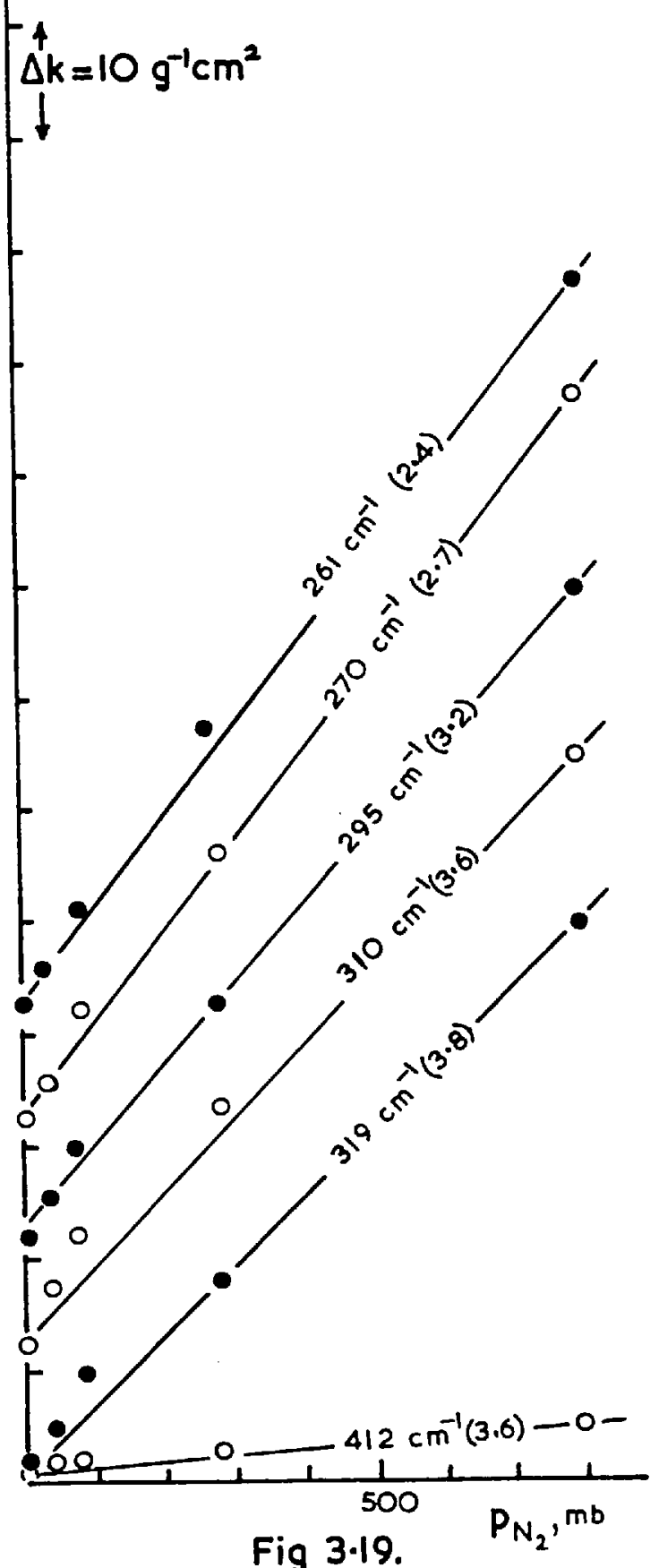

Fig 3.19.

\section{Absorption coefficients derived from Palmer $(1957 b, c)$.}

Fig 3.18. Pure water vapour, pressure e mb.

Fig 3.19. Constant vapour pressure $(2.7 \mathrm{mb})$, variable nitrogen pressure.

The origin is displaced for each curve, and the resolution ( $\left.\mathrm{cm}^{-1}\right)$ is shown in brackets (full width at halt-height). 
shows the corresponding results when nitrogen at $800 \mathrm{mb}$ pressure was added. All lines show an upward curvature (as indeed they must in Fig $3.17(\mathrm{a})$ ), indicating significant self-broadening. However, it is apparent that these results aen not be accounted for in terms of a self - to - foreign broadening factor of about 6 , because the ratio of the extinctions in Figs $3.17 \mathrm{a}$ and $\mathrm{b}$ for the same value of $a(\mathrm{mb})$ would then be $\frac{6 \mathrm{e}}{800+6 e}$, which is about $\frac{1}{28}$ for $e=5 \mathrm{mb}$, compared with the observed values of $\frac{1}{4}$ and $\frac{1}{5}$ respectively for the windows at $V=480$ and $412 \mathrm{~cm}^{-1}$. On further inspection it becomes apparent that the self and foreign contributions have a different frequency dependence, suggesting that they arise in fundamentally different ways, and that it is not appropriate to think in terms of a constant selfbroadening factor.

Fig 3.18 shows values of the self-broadened absorption coefficients as a function of vapour pressure, derived from the data (n.78, plotted in Fig 3.17a. It can be seen that within the limits of reasonable experimental error they increase linearly with vapour pressure; the regression coefficients are tabulated in Table 3.1 .

Fig 3.19 shows average values of the absorption coefficient as a function of nitrogen pressure, derived from 6 runs at constant water vapour pressures between 0.16 and $10 \mathrm{mb}$, with a mean of $2.7 \mathrm{mb}$. Again the values show an almost linear increase with pressure, but with a definite suggestion of a decrease in slope at the higher pressures. This might be due to failure to exclude the effects of 


\section{Table 3.1}

Self - and foreign - broadened absorption coefficients (derived from palmer, $1957 \quad \mathrm{~b}, \mathrm{c}$ )

$\begin{array}{lrrrrrrrr}\nu, \mathrm{cm}^{-1} & 261 & 270 & 295 & 310 & 319 & 367 & 412 & 480 \\ \mathrm{k}_{\mathrm{s}}, \mathrm{g}^{-1} \mathrm{~cm}^{2} \mathrm{~atm}^{-1} & 1050 & 1050 & 910 & 840 & 650 & 250 & 180 & 150 \\ \mathrm{k}_{f}, & 85 & 85 & 76 & 64 & 53 & 13 & 5.0 & 2-5 \\ k_{f / k_{f}} & 12.4 & 12.4 & 12.0 & 13.1 & 13.4 & 19.2 & 36 & 50\end{array}$

nearby lines because of inadequate resolution. Indeed, in one window $\left(\nu=319 \mathrm{~cm}^{-1}\right)$ measurements were made with two gratings giving resolutions of 3.8 and $2.0 \mathrm{~cm}^{-1}$, and the absorption coefficients rosulting from the latter are smaller by about $20 \%$. However, except in the case of $\nu=480 \mathrm{~cm}^{-1}$, it is thought that the effect of nearby lines is small since the windows were selected only if no major lines were listed within $5 \mathrm{~cm}^{-1} \begin{gathered}\text { Benedict and } \\ \text { in/Kaplan's tables (1963). The } \\ (\mathrm{n} \text {.75) }\end{gathered}$ regression coeficients from Fig 3.19 are tabulated in Table 3.1 .

Compaxed with the present work, Palmer's results at $\nu=480 \mathrm{~cm}^{-1}$ are about 2.5 and 1.6 times larger for self - and foreign - broadening respectively: this is probably due to much lower resolution $\left(5 \mathrm{~cm}^{-1}\right.$ compared with $1.2 \mathrm{~cm}^{-1}$ ) so that two lines are included in Palmer's case.

In conclusion, Palmer's work provides excellent confirmation 


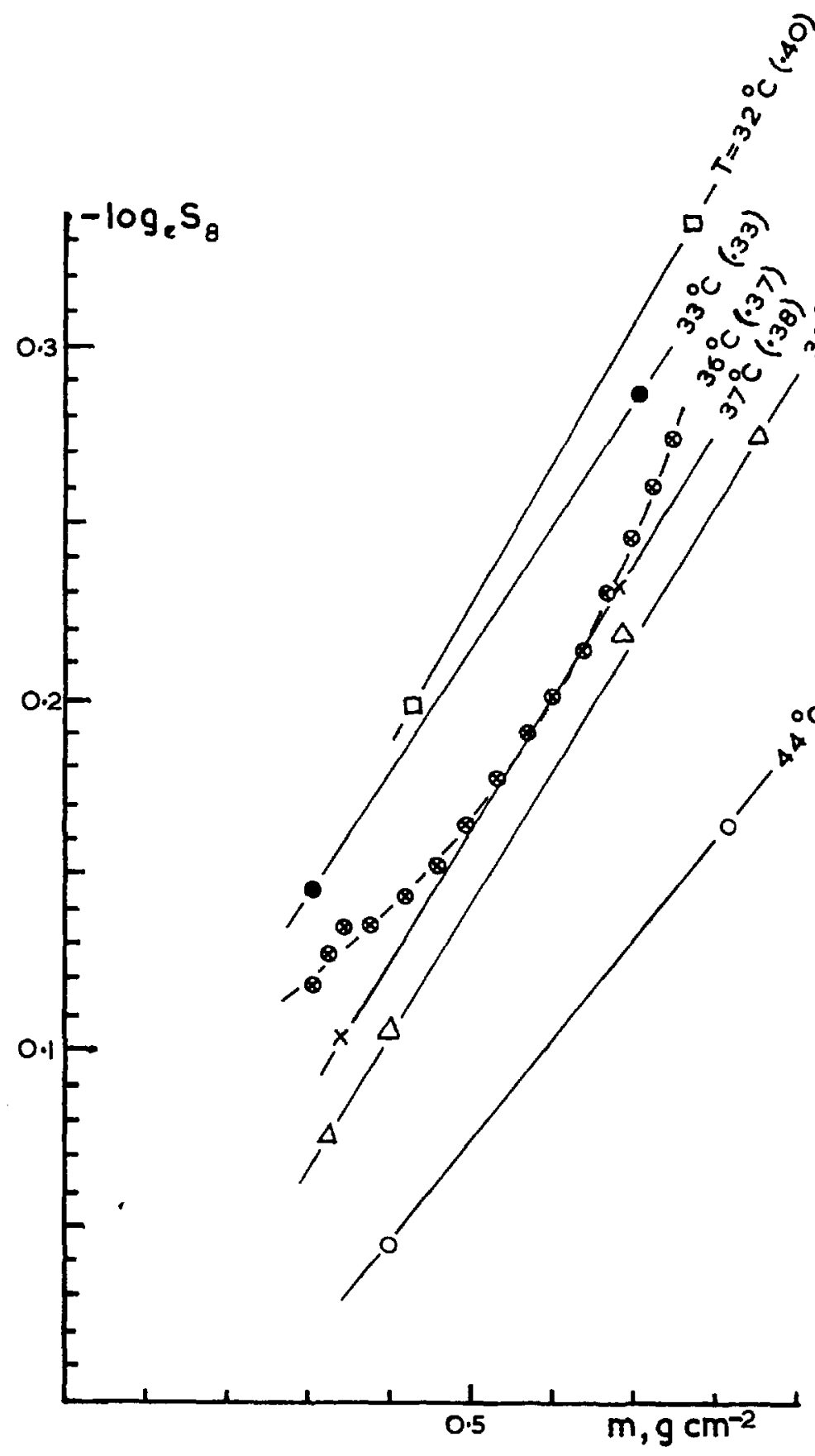

(a)

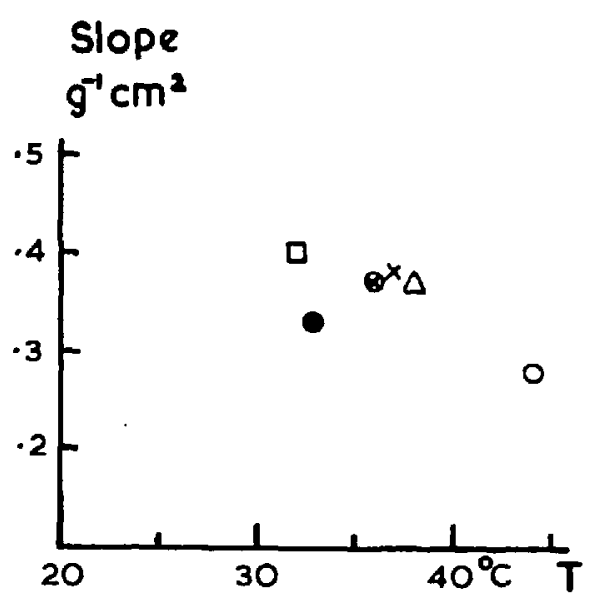

(b)

Fig 3.20. Extinction in window $8\left(90 \mathrm{~cm}^{-1}\right)$ and its temperature dependence.

(a) Absolute measurements of signal, $\mathrm{s}_{8}, 03$ a function of $\mathrm{m}$. Six runs at different temperatures are shown, with the slopes $\left(g^{-1} \mathrm{~cm}^{2}\right)$ in brackets.

(b) Slopes $\left(g^{-1} \mathrm{~cm}^{2}\right)$ as a function of temperature. 
of a strong self - broadening effect which agrees roughly with the present work at $20 \mu$ and extends at least to $40 \mu$. 3.5.2. $7-12 \mu$ region and $4 \mu$ windows 3.5.2.1 Windows $8,11,13$ and 4.

Fig 3.20 (a) shows the variation of signal in window 8 with n for 6 runs. The long time taken to dry the cell below e $=10 \mathrm{mb}$ Iuled out measurements at low vapour pressures. Observations were made only at the highest and lowest humidities, except on one mun when very frequent humidity measurements were made. This latter mun is seen to give a very curved plot, suggesting strong self broadening. It was hoped to obtain more mans in this way but a breakdown in the detector prevented further work before the end of the investigation.

The remarkable feature of these results is that the absorption is much greater than expected on the basis of all previous work in this region. In the abscence of the mun with many closely spaced observations, there would be no alternative but to connect the points by a straight line, giving absorption coefficients of order $0.4 \mathrm{~g}^{-1} \mathrm{~cm}^{2}$, about four times the usually accepted result. However, the detailed run suggests a strong curvature, and it is possible that the curves in Fig 3.20 (a) approach the abscissa in such a way that the absorption coefficient is indeed much lower at low vapour pressure (all previous measurements except one have been made with 


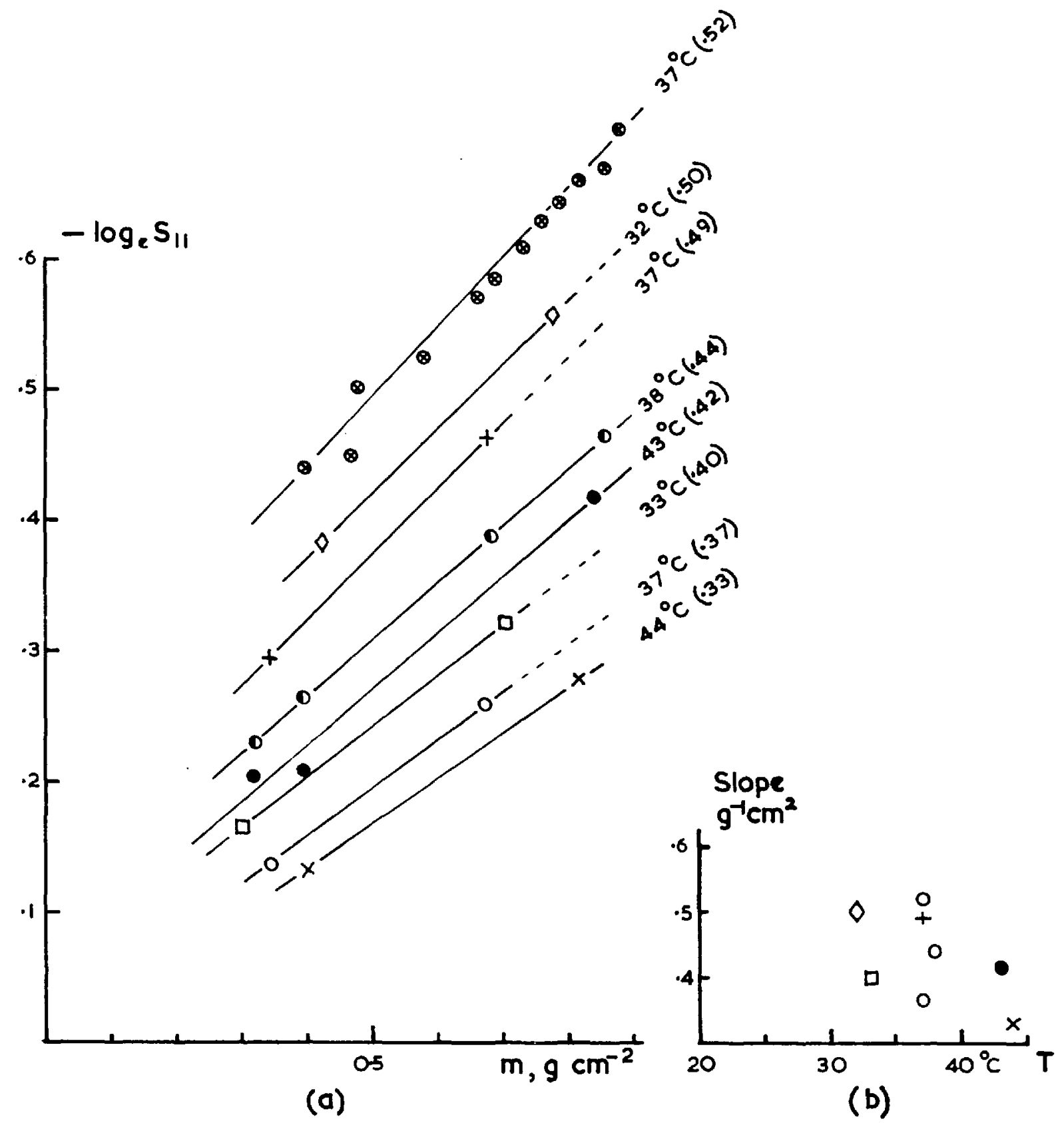

Fig 3.21. Extinction in window $11\left(832 \mathrm{~cm}^{-1}\right)$ and its temperature dependence.

(a) Absolute measurements of signal, $S_{11}$, as a function of $m$. Eight runs at different temperatures are shown, with the slopes $\left(\mathrm{g}^{-1} \mathrm{~cm}^{2}\right)$ in brackets.

(b) Slopes $\left(\mathrm{g}^{-1} \mathrm{~cm}^{2}\right)$ as a function of temperature. 


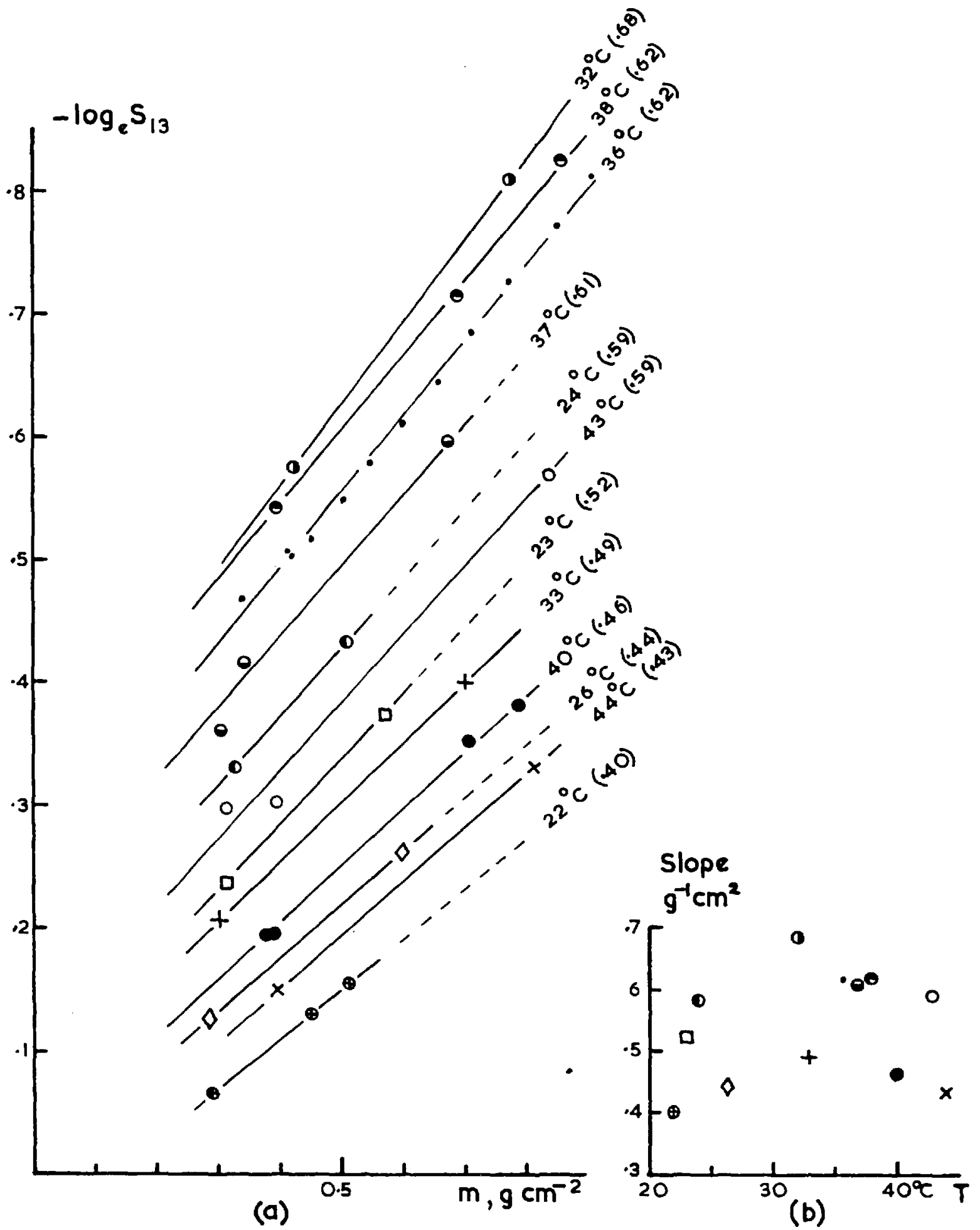

Fig 3.22. Extinction in window $13\left(790 \mathrm{~cm}^{-1}\right)$ and its temperature dependence.

(a) Absolute measurements of signal, $s_{13}$,as a function of $\mathrm{m}$. Twelve runs at different temperatures are shown, with the slopes $\left(g^{-1} \mathrm{~cm}^{2}\right)$ in brackets.

(b) Slopes $\left(9^{-1} \mathrm{~cm}^{2}\right)$ as a function of temperature. 


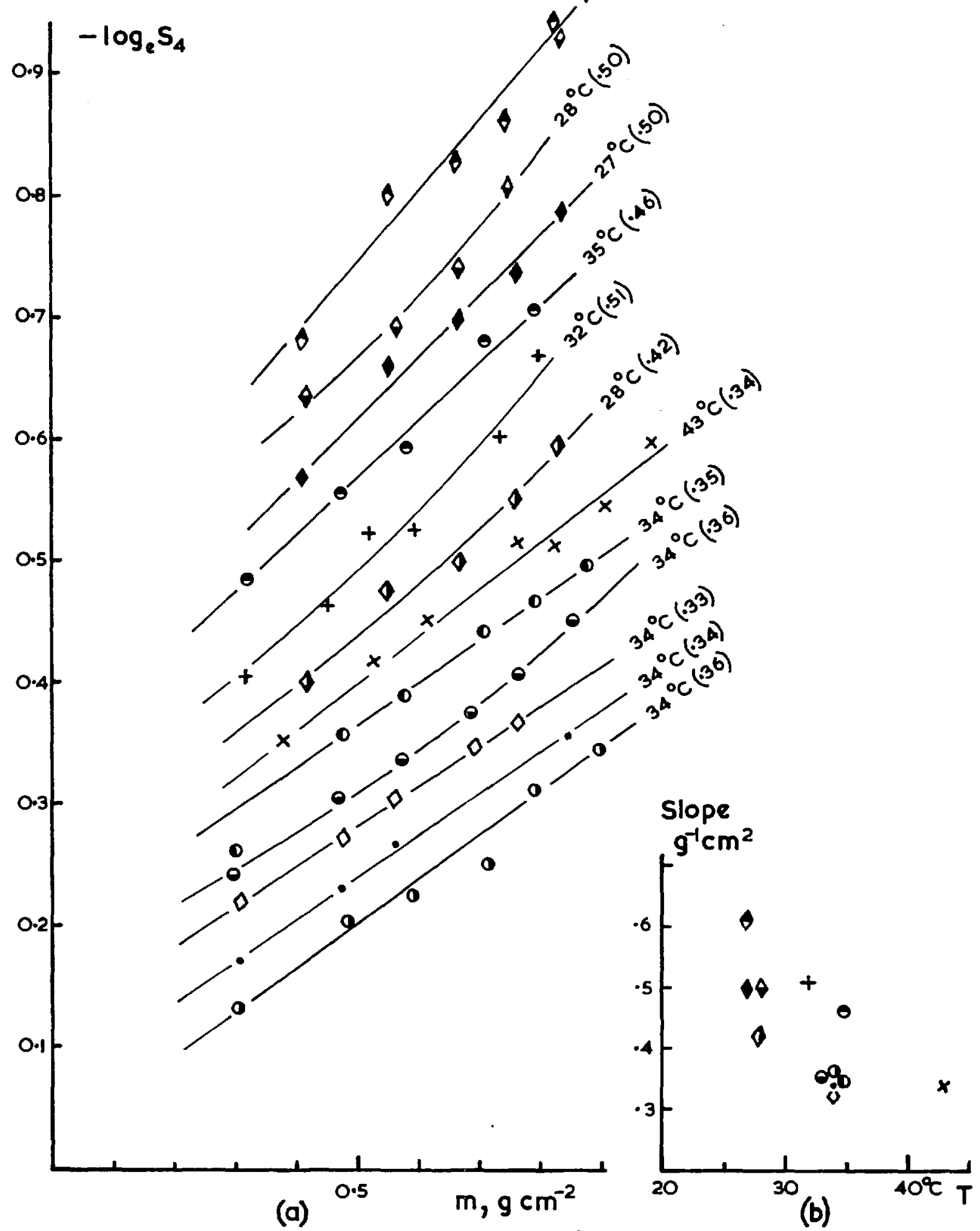

Fig 3.23. Extinction in window $4\left(1118.8 \mathrm{~cm}^{-1}\right)$ and its temperature dependence.

(a) Absolute measurements of signal, $S_{4}$, as a function of $\mathrm{m}$. Twelve runs at different temperatures are shown, with the slopes $\left(g^{-1} \mathrm{~cm}{ }^{2}\right)$ in brackets.

(b) Slopes $\left(\mathrm{g}^{-1} \mathrm{~cm}^{2}\right)$ as a function of exmperature. 
$e<10 \mathrm{mb})$. Assuming this to be the case, we can find the value of the intercept which gives agreement with previous work, i.e. $k_{8} \simeq$ $0.1 \mathrm{~g}^{-1} \mathrm{~cm}^{2}$ at $e=10 \mathrm{mb}$, and then estimate the magnitude of the self - broadened component. This works out to be $0.010 \mathrm{~g}^{-1} \mathrm{~cm}^{2} \mathrm{mb}^{-1}$, or $10 \mathrm{~g}^{-1} \mathrm{~cm}^{2} \mathrm{~atm}^{-1}$.

The slope of straight lines dram through runs made between roughly the same vapour pressures shows slight evidence of a negative temperature dependence (Fig $3.20(\mathrm{~b})$ ). This is cons istent with the picture of the self - broadened contribution inferred for the $18-21 \mu$ region $(\$ 3.5 .1$ ).

The reality of the unexpectedly high absorption was doubted for a considerable time, and exhaustive tests were made to try to find another explanation. The results were the same with or without the polyethylene cell window; the mirror reflectivities did not vary h.58

with humidity $(\oint 3.3 .3)$; two different gratings gave the same results, suggesting that stray radiation from a poor grating was unlikely to bo the cause.

Figs $3.21,3.22$ and 3.23 show similar presentations for windows 11,13 and 4 respectively. They all show the same unexpectedly high absorption, again with a suggestion of a negative temperature dependence. The self - broadened contribution was estimated as for window 8 , resulting in the values 13,17 and $12 \mathrm{~g}^{-1} \mathrm{~cm}^{2} \mathrm{~atm}^{-1}$ for windows 11,13 and 4 respectively. 


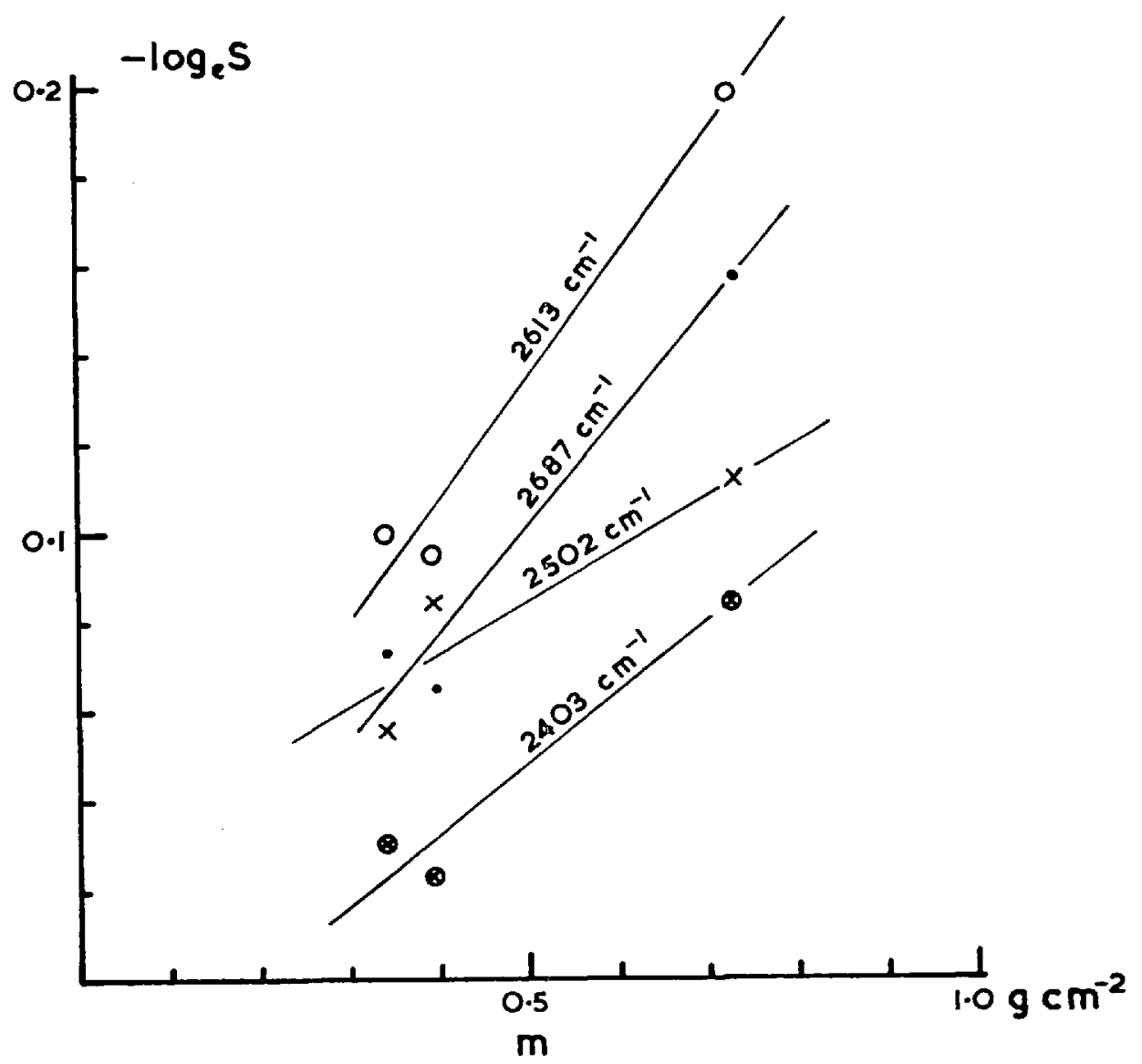

Fig 3.24. Extinction in $4 \mu$ window. 
All the observational data are given in Appendix 3.2.

\subsubsection{2. $4 \mu$ windows}

Fig 3.24 shows the results of one run in four windows near $4 \mu$. The slopes of the lines are about half of those for window 11, so that considerable absorption is indicated here. If it is assumed that this absorption is lergely due to self - broadening, the absorption coefficient may be estimated as $6 \mathrm{~g}^{-1} \mathrm{~cm}^{2} \mathrm{~atm}^{-1}$ in the $4 \mu$ region.

3.5.2.3. Discussion and comparigon with previous work

The major problem posed by the results in this section is that the absorption in the $8-12 \mu$ window is apparently much greater than that usually accepted. One possible explanation suggesta itself immediately. If the strong self-broadening effect observed in the $17-21 \mu$ region extends to $4 \mu$, then the present work at vapour pressure near $30 \mathrm{mb}$ would give much higher results than the values deduced. from observations carried out mostly below $15 \mathrm{mb}$. The previous measurements were therefore examined for evidence of systematic variation with vapour pressure.

Roach and Goody (1958) determined continuum absorption coefficients in several wide bands of the $8-12 \mu$ window by observing the variation of solar intensity with solar zenith angle. Some of his observations were made from central London and some from Ascot; the results from the former were about double those from the 


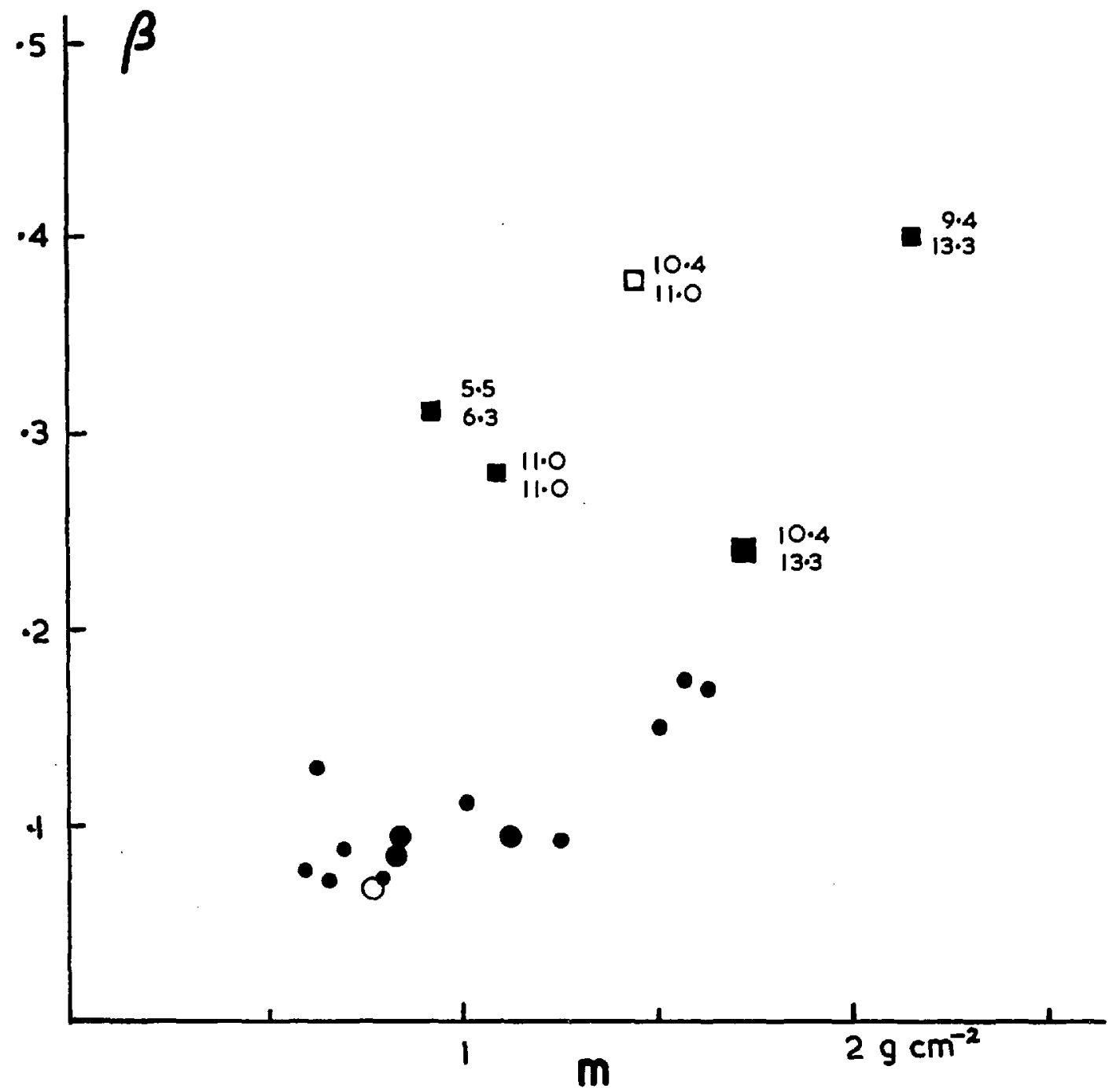

Fig 3.25. Extinction of solar radiation in the region $871-908 \mathrm{~cm}^{-1}$. (Roach and Goody, 1958)

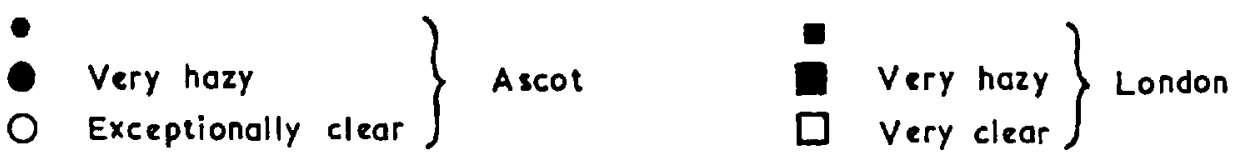

The upper and lower numbers to the right of the London points are the surfoce vapour pressures (mb) for 0600 and $1800 \mathrm{hrs}$, respectively, at London Airport. 


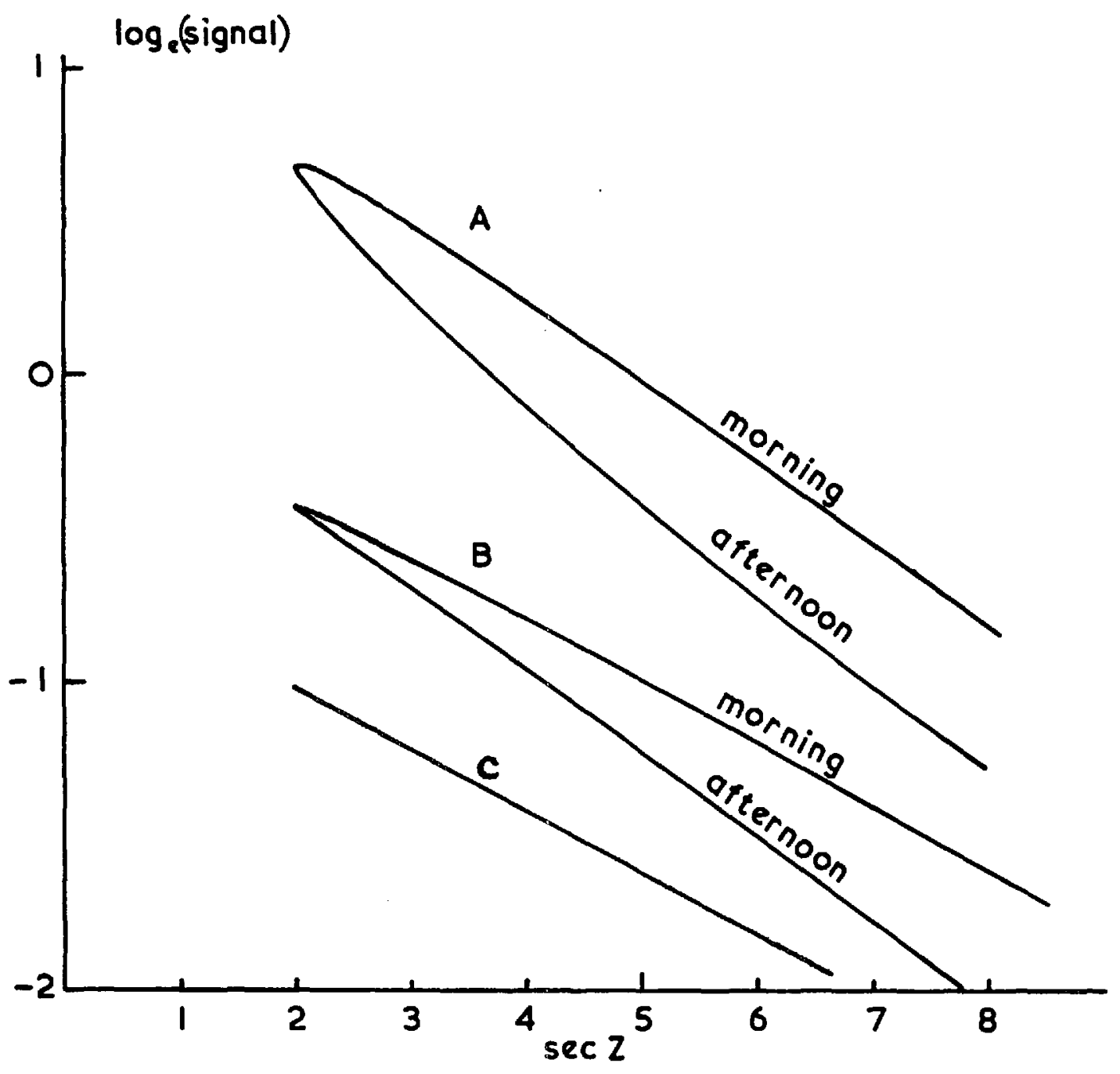

Fig 3.26. Effect of diurnal evaporation on solar intensity.
A. Mean of 4 whole-day observations of solar microwave intensity (Bostin et al, 1964)
B. Calculated variation of solar-10 $\mu$ intensity, assuming a $10 \%$ increase, by evaporation, of precipitable water during the day.
C. No evapotation. 
latter, and Roach attributed this to aerosol absorption. The evidence for this view is not convincing because inspection of the visibility dato and current weather situations suggests that some of the Lond on observations were probably made under clearer conditions than some of the Ascot ones. Again, of the Liondon results, the highest was obtained on the clearest day, and the lowest on the haziest day (see Fig 3.25, showing results for a typical region, $\left.871-908 \mathrm{~cm}^{-1}\right)$. Similarly, of the $\Delta$ scot results, those taken on particularly hazy days are no higher than the average.

It is possibly significant that all of the Lond on observations were made in the afternoon and all except two of the Ascot ones in the morning, and moreover, the vapour pressures were on average higher in the former case. It seems possible that a systematic difference may arise between morning and afternoon observations, which is best explained by reference to Fig 3.26. Consider the variation of solar intensity during a uniformly clear day on which the amount of precipitable water remains constant, Early in the morning, with large zenith angle $(z)$, the intensity is relatively low but increasing as the sun rises; the plot of $\log I_{z}$ against sec $Z$ will be a straight Iine, At local noon $I_{z}$ reaches a maximum, and themeafter returns along the same line as the sun sinks.

However, the assumption of constant water vapour is hardly likely to be valid, especially since these observations must of necessity be made on the type of day when evaporation frcin the ground 
is favoured. An examination of the humidity data for London Airport on the days of Roach's London observations showed that the surface vapour pressure increased on average by $18 \%$ between 0600 and $1800 \mathrm{hrs}$, the largest increase being $42 \%$. It is unfortunate that radio - sonde ascents are not timed favourably to observe the diurnal evaporation, the midnight - to - midnight difference probably having as much to do with large scale transport as with evaporation from the ground.

Let us suppose that on a typical sunny day the evaporation amounts to $0.2 \mathrm{~cm}$, which seems reasonable and is about $10 \%$ of that already present in the vertical path. Then the morning and aftemoon (n. 80 )

curves in Fig 3.26 become separated, so that the afternoon slope is steeper than the morning one. If in addition one assumes that there is a self - broadening effect proportional to the partial vapour pressure, the separation is even greater. Assuming that most of the evaporation occurs during the middle part of the day, a rough idea of the separation may be obtained; this is shown in Fig 3.26, It can be seen that an increase of only $10 \%$ in precipitable water during the day results in about $40 \%$ difference between the slopes of the morning and afternoon curves. On occasion the difference may be much more.

Since Roach took the midday radiosonde ascent, his moming results (Ascot) would be expected to be below the correct value, and conversely for the afternoon ones (Iondon).

The work of Bastin et al (1964) provides good evidence of 


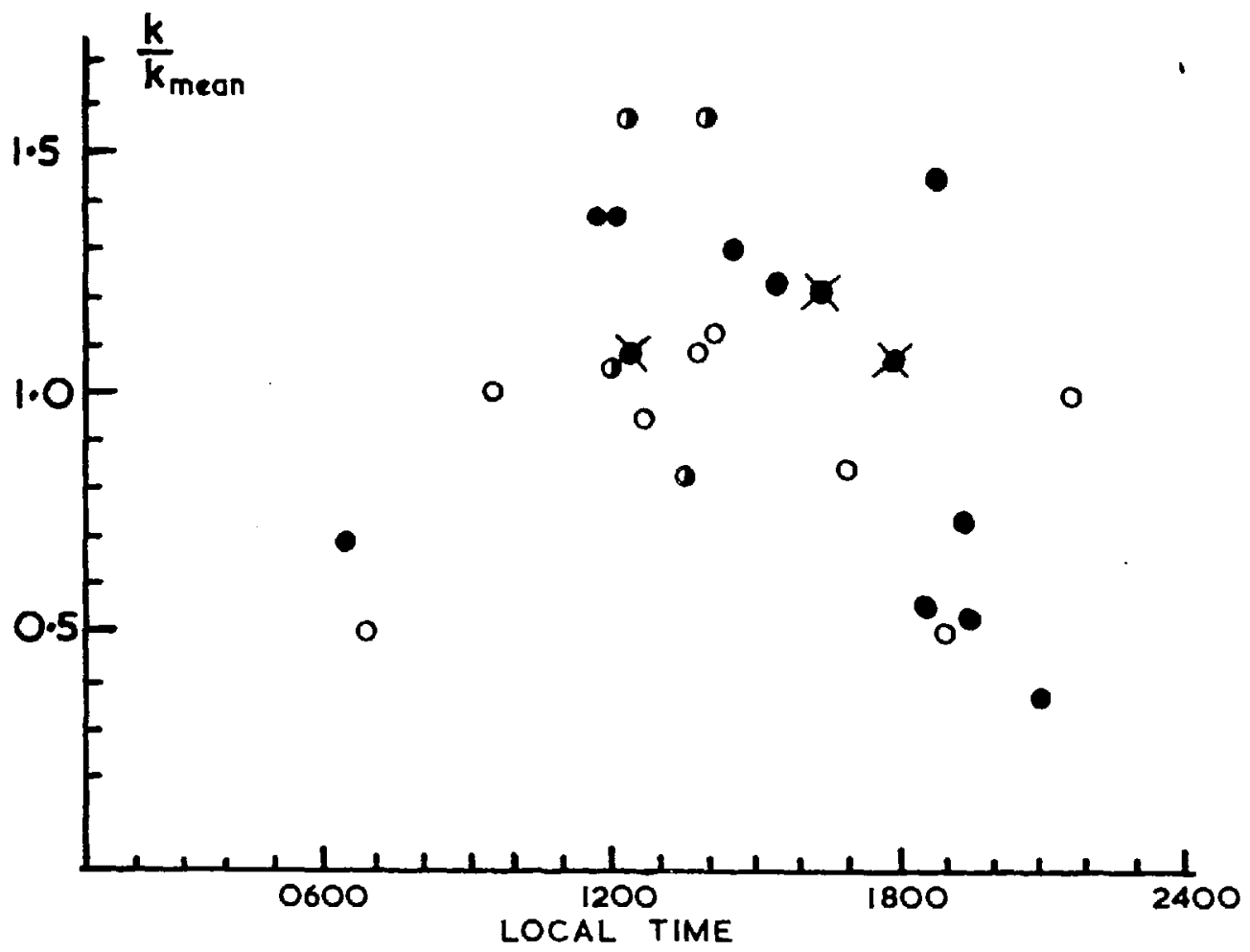

Fig 3.27. Variation of apparent absorption coefficient with time of day and zenith precipitable water. (Derived from emission measurements in 14 windows between 8.1 and $12.9 \mu$ made by Bolle (1963) from S. Agata).

The ratio of the values at any hour to the mean for all observations is shown on the ordinate. A measure of the vapour pressure is obrained from the precipitable water, $W$, in the zenith and is indicoted os follows :-

$$
\begin{aligned}
& \text { - } w>2.3 \mathrm{~g} \mathrm{~cm}^{-2} \\
& \text { - } 2.3>w>2.0 \mathrm{~g} \mathrm{~cm}^{-2} \\
& \text { o } w<2.0 \mathrm{~g} \mathrm{~cm}^{-2}
\end{aligned}
$$

Very hazy conditions are indicated by a cross. 
the diurnal increase of precipitable water. They observed the variation of solar microwave radiation as a function of solar zenith angle from central London, and although their sample is rather small, the difference between morming and aftermoon observations is unmistakeable (see Fig 3.26). curve $A, p .80$

Saiedy (B.S.S., (1963)), using the same technique as Roach and Goody (1958), but observing only in the mornings from $A_{s c o t}$, obtained results in the $8-12 \mu$ window throughout the year. Though it was not recognized by Saiedy, the summer results were higher than the winter ones and this is not inconsistent with the self - broadening hypothesis inferred from the present work.

The emission studies of Bolle (1963, 1964), discussed in A.73

$\oint 3.5 .1 .5$, raise some interesting questions. Meanurements from Jungfraujoch in the $8-12 \mu$ region gave results up to five times greater than those from S. Agata, where the vapour pressure was moch higher. This could arise if there were some emission from something other than water vapour, since the effect becomes very large as the amount of water vapour decreases. On examination, it is found that the S. Agata results seem to be correlated with the time of day, being maximum at about local noon when they are about double the values in the early morning and in the evening (Fig 3.27). The question arises as to whether this is due to scattering of solar radiation by aerosol or molecules, or to increased self - broadened absorption coefficients in the middle of the day following the diurnal evaporation cycle. The 


\section{$k_{897.9}$}

$.18 \mathrm{f}^{\mathrm{g}^{-1} \mathrm{~cm}^{2}}$

$.14-00$
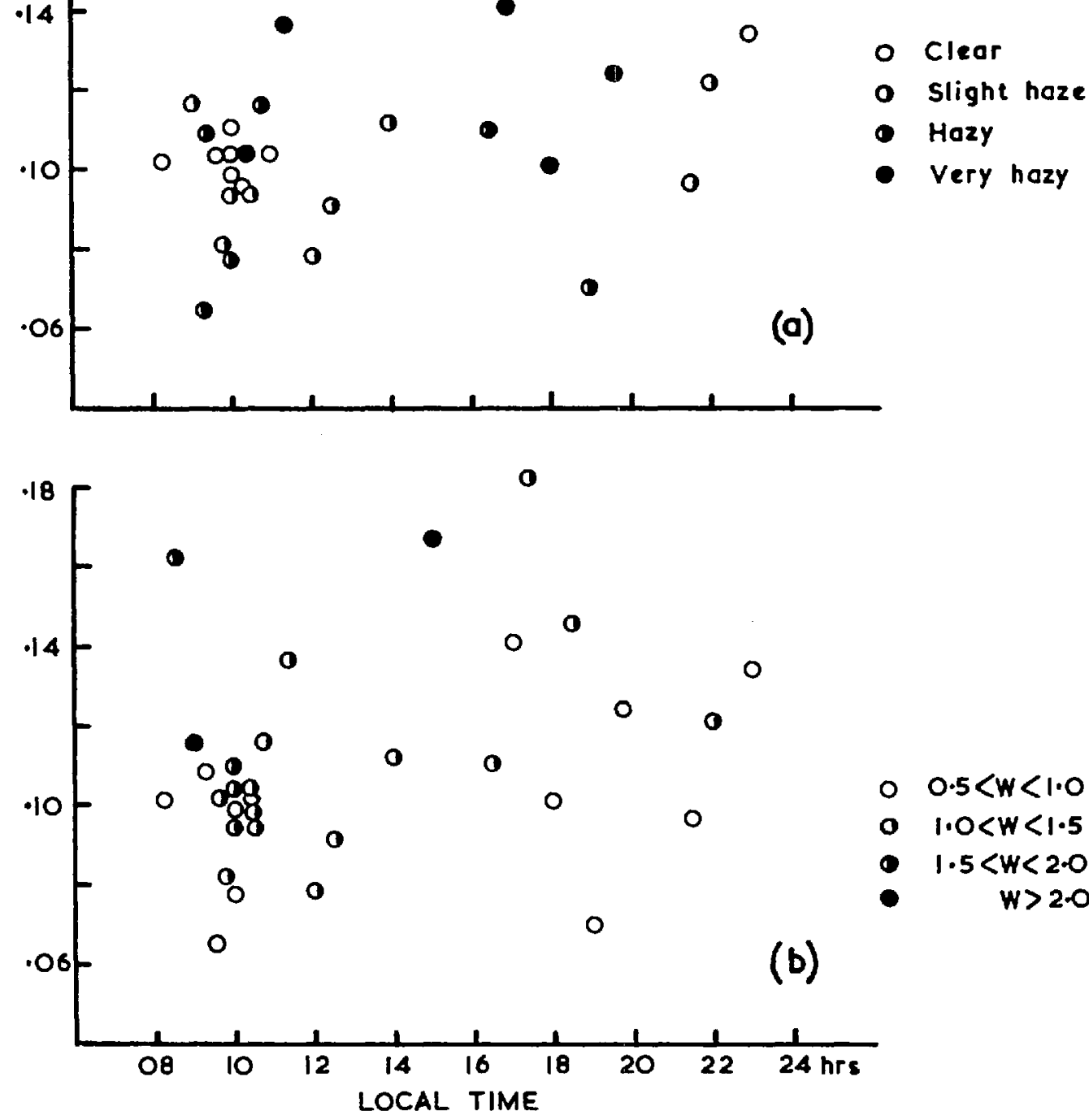

Fig 3.28. Variation of apparent absorption coefficient with time of day, visual opacity and precipitable water in the zenith. (From the emission measurements of Dave et al (1963) at Ascot in a window at $y=897.9 \mathrm{~cm}^{-1}$ ).

(a) An index of the aerosol content is obtained from surface visibility data.

(b) An index of the vapour pressure is obtained from the precipitable water, $w$, in the zenith. 
former seems rather unlikely, because three results obtained on particularly hazy days (excluding fog) are no higher than the average; on the other hand there is a tendency for the results to be higher on days with more water vapour in the zenith, which gives a rough measure of the mean vapour pressure in the atmosphere.

Dave et al (1963), with the spectrometer used in the present work, measured the water vapour continuum in four windows between $897.9 \mathrm{~cm}^{-1}$ and $1159.0 \mathrm{~cm}^{-1}$. Dave concluded that aerosol played a significant role in continuum emission, since the latter appeared to be greater under hazy conditions. In a search for other possible correlations, the results for $\nu=897.9 \mathrm{~cm}^{-1}$ were plotted as a function of time of day, with vapour pressure and haziness as parameters (Figs 3.28.(a) and (b)). The pressure - corrected mass of vapour in the zenith was taken as a rough index of the vapour pressure, and the visibility data from the site and from Lond on Airport (16 km to the north-east) were used to assess the aerosol content in a scal $\theta$ ranging from 1 for clear to 4 for very hazy. Whilst it is true that four of the six highest results occur under very hazy conditions, the rest are uniformly scattered. The alternative interpretation in terms of vapour pressure seems to be at least as good, the higher results at a given hour tending to occur at higher vapour pressures, with an added tendency for the afternoon results to be higher. This latter effect is similar to that found in the results of Roach and Goody (1958) and Bolle et al (1963), and could be explained by an increase 


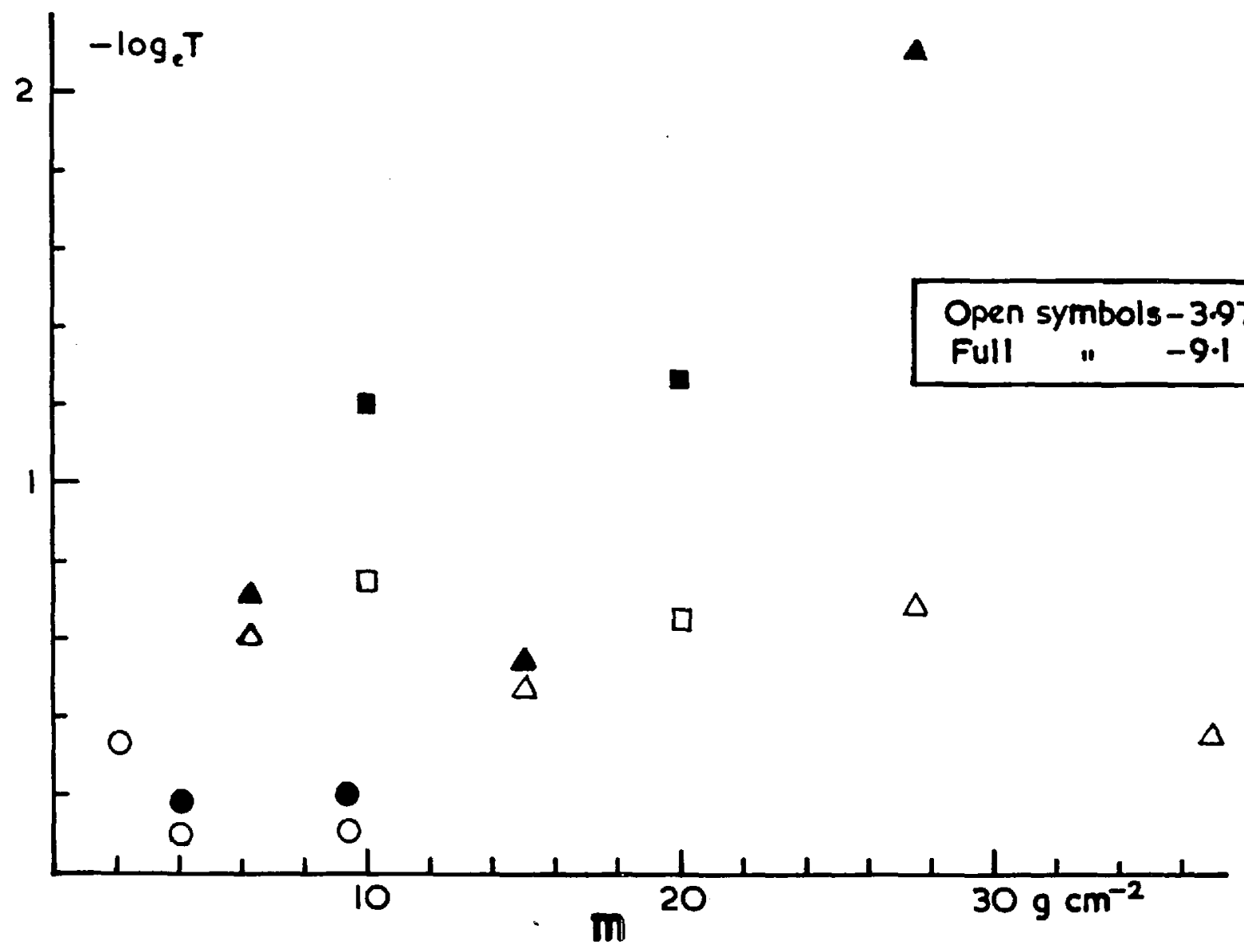

Fig 3.29. Extinction at $3.97 \mu$ and $9.1 \mu$ (Taylor and Yates, 1957).

Horizontal paths of $5.5 \mathrm{~km}$ (circles) and $16.25 \mathrm{~km}$ (triangles) over Chesapeake Bay, and of $27.7 \mathrm{~km}$ (squares) between Mauno Loo and Mauno Keo (10OOOft approx) in the Howaitan Islands.

Data :-

$\begin{array}{lcccccccccc}\text { Path length } & \mathrm{km} & 5.5 & 16.25 & 5.5 & 16.25 & 5.5 & 16.25 & 16.25 & 27.7 & 27.7 \\ \text { Ppl. water } 9 \mathrm{~cm}^{-2} & 2.2 & 0.7 & 4.2 & 15.1 & 9.4 & 27.7 & 37 & 20 & 8-13 \\ \text { Rel. Hum. } & \% & 06 & 41 & 51 & 53 & 73 & 82 & 50 & 100 & 41 \\ \text { Vapour press. } \mathrm{mb} & 5.1 & 5.6 & 10.4 & 12.8 & 23.8 & 23.5 & 26.0 & 9.4 & 4-6 \\ \text { Temperature } & { }^{\circ} \mathrm{C} & 3 & 12 & 18 & 20 & 26 & 23 & 31 & 6 & 0 \\ -\log _{\mathrm{e}} \mathrm{T}(9.1 \mu) & & .04 & .732 & .186 & .545 & .211 & 2.12 & - & 1.273 & 1.205 \\ -\log _{\mathrm{e}} \mathrm{T}(3.97 \mu) & .342 & .018 & .104 & .478 & .116 & .693 & .356 & .655 & .755 \\ -\log _{\mathrm{e}} \mathrm{T}(\mathrm{vis}) & & .915 & 1.23 & .358 & .840 & 1.20 & 2.30 & 3.91 & 1.35 & -\end{array}$


of humidity by evaporation between the $1100 \mathrm{Z}$ radio-sonde ascent and the afternoon observations.

The only other relevant investigation is that of Taylor and 1.43

Yates (1957), described in $\xi 2.7$. It seems to be the only published measurement at high vapour pressures $(>20 \mathrm{mb})$ so that it is more readily comparable with the present work, both at $4 \mu$ and near $9 \mu$. Values of $-\log _{e}$ (transmittance) derived from the published spectra are plotted as a function of precipitable water in Fig 3.29. Although there is a lot of scatter, the absorption coefficients in both windows show no sign of increasing with vapour pressure, and at $9.1 \mu$ the value of $0.07 \mathrm{~g}^{-1} \mathrm{~cm}^{2}$ is in good agreement with all previous. work. The $4 \mu$ observations show no correlation with water vapour at all, and evidently the extinction has to be explained otherwise; however, nor is there any correlation with the visual extinction.

Mention should al so be made of the $8-12 \mu$ window observations made by Tiros III. Although there is some uncertainty regarding absolute calibration of the radiometer, it seems that the inferred effective temperatures are considerably lower $\left(5\right.$ to $\left.15^{\circ} \mathrm{K}\right)$ than the actual temperature, even after allowing for continuum and line emission in the window (see, e.g., Nordberg et al, 1962). This points to a 'dirtier' window than had been expected. The differences between between satellite inferred and actual temperatures are being examined for a correlation with vapour pressure for regions where the relevant conditions are known. This implies restriction to sea surface 
Method: Resolution: Vap.press.

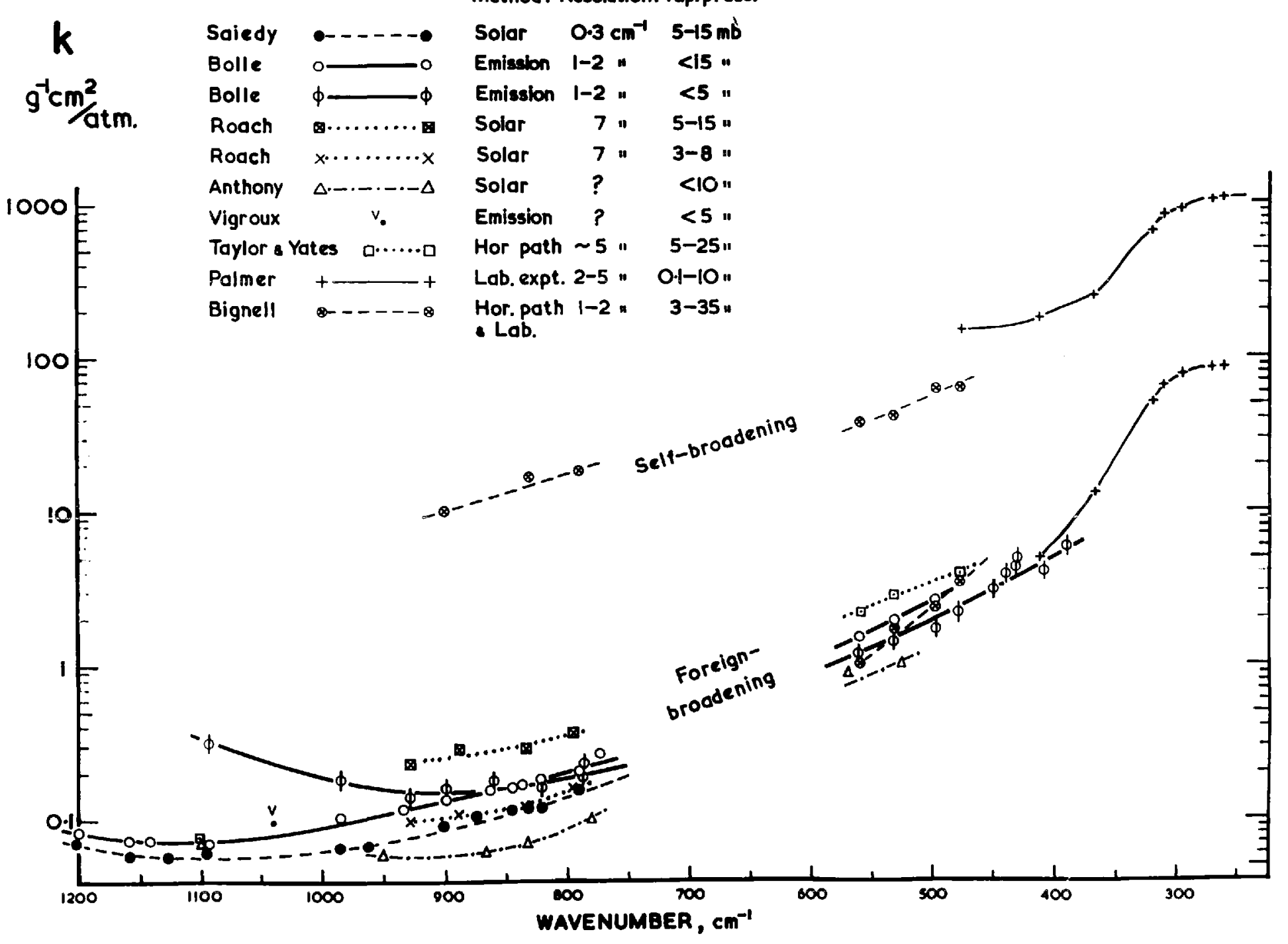

Fig 3.30. Observed self- and foreign-broadened continuum absorption coefficients, $8 \cdot 5-40 \mu$. 
observations with a clear atmosphere to avoid uncertainty regarding the surface emissivity. No results are available yet.

In conclusion, were it not for the results of Taylor and Yates' measurement at high vapour pressure, it would be possible to clain that the work described in $\oint 3.5 .2 .1$ and $\oint 3.5 .2 .2$. is not inconsistent with previous results, though no positive evidence has been found to support it. A possible explanation of the differences between earlier works has been suggested, but clearly difficulties remain to be resolved.

3.5 .3 Summary of all results

All available data for the rogion $8-40 \mu$ have been assembled in Fig 3.30. It falls naturally into two groups, attributed to self and foreign - broadening. Much of the work in the $8-12 \mu$ region was conducted at low vapour pressure so that these results correspond largely to foreign - broadening, with, however, a systematic spread arising from the effects of self - broadening described in $\$ 3.5 .2 .3$. The increase in the foreign - broadened component from $1100 \mathrm{~cm}^{-1}$ to $1200 \mathrm{~cm}^{-1}$ is probably due to the wings of lines in the $6.3 \mu$ water vapour band.

3.6. Comparison between observation and theory

The results given in $\oint 3.5 .3$ are now compared with the values expected on the basis of accumulated wings of the profiles 

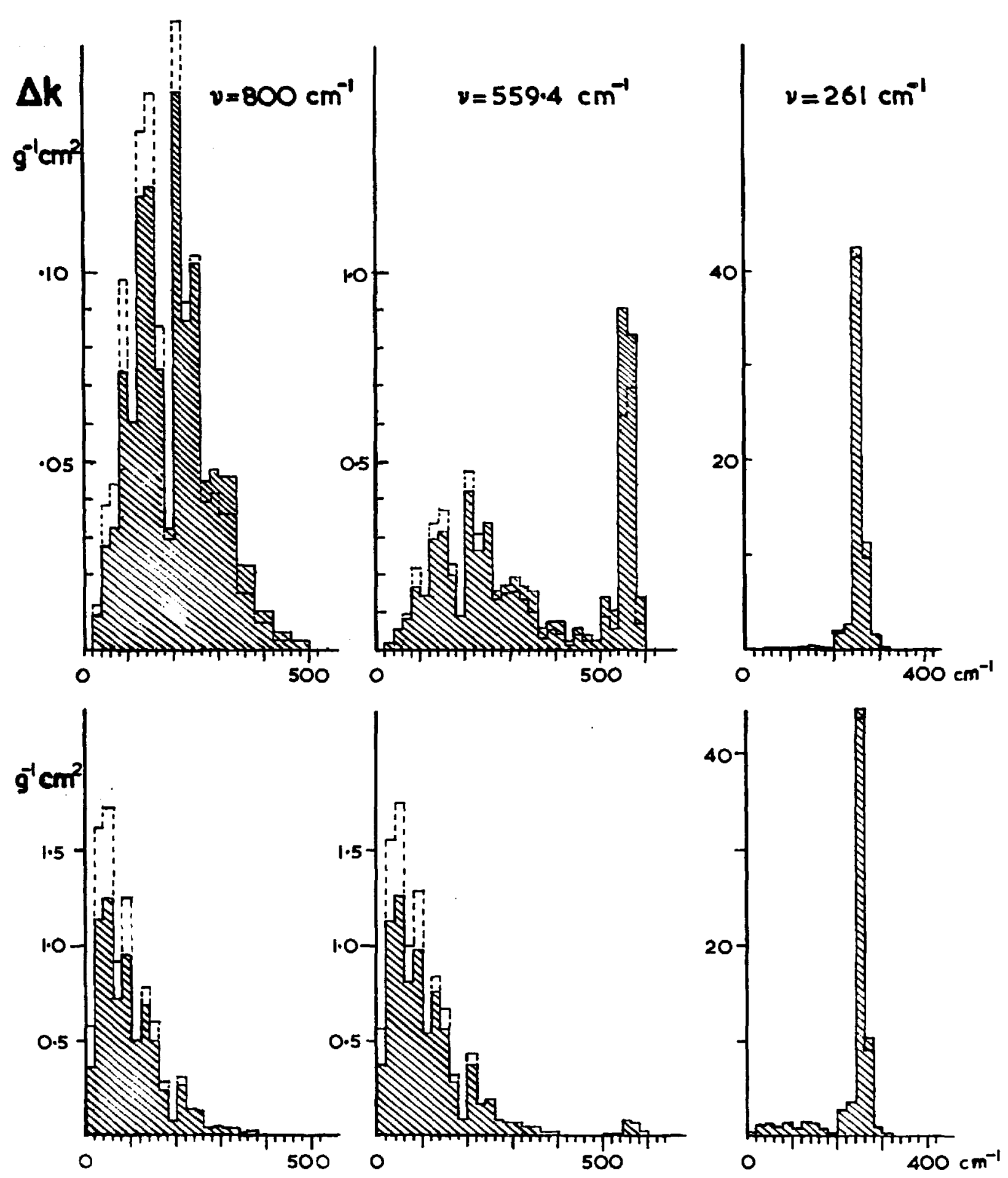

Fig 3.31. Contribution of rotation lines to continuum at $v=800,559.4$ and $261 \mathrm{~cm}^{-1}$.

Upper section: Lorentz line shape. Lower section: Van Vleck line shape. computed for nitrogen-broadened half-width for temperatures of $300^{\circ} \mathrm{K}$ (solid lines) and $260^{\circ} \mathrm{K}$ (dashed lines) 
Benedict and

discussed in $\$ 1.2 .2 .2$. Using/Kaplan's (1963) tables of rotation line intengities and half widths, and $\mathrm{H}_{2} \mathrm{O}-\mathrm{H}_{2} \mathrm{O}$ line half widths derived from/Kaplan (1964), the foreign - and self - broadened absorption coefficients were calculated for 7 windows between 800 and $261 \mathrm{~cm}^{-1}$ for the Lorentz, full Lorentz and Van Vleck profiles. The calculations were made for temperatures of $300^{\circ} \mathrm{K}$ and $260^{\circ} \mathbf{K}$, and the results are given in Table 3.20 (

To illustrate the relative contributions of lines in the $50 \mu$ band, a selection of the results is plotted for $20 \mathrm{~cm}^{-1}$ intervals in Fig 3.31. The temperature dependence of the contributions changes from negative in the $0-260 \mathrm{~cm}^{-1}$ region to positive thereafter. For the Lorentz line shape, most of the absorption at $800 \mathrm{~cm}^{-1}$ arises from lines in the region $50-350 \mathrm{~cm}^{-1}$, so that the overall temperature dependence is $\operatorname{smal}\left(-0.1 \% \operatorname{per}^{\circ} \mathrm{C}\right.$ at $300 \%$ ) : at $559.4 \mathrm{~cm}^{-1}$, about $30 \%$ of the total absorption arises from lines within $20 \mathrm{~cm}^{-1}$, largely accounting for the overall temperature dependence of $+0.3 \%$ per ${ }^{\circ} \mathrm{C}$ : at $261 \mathrm{~cm}^{-1}$ nearly all absorption arises from lines within $20 \mathrm{~cm}^{-1}$, so that the temperature dependence is again very small $(+0.1 \%$ per $\left.{ }^{\circ}\right)$.

The full Lorentz shape gives results only slightly higher than ordinary Lorentz in the region $250-400 \mathrm{~cm}^{-1}$, but then gives progressively larger values until they are twice Lorentz at $800 \mathrm{~cm}^{-1}$.

For the Van IIeck shape the continuum for $\nu>500 \mathrm{~cm}^{-I}$ arises largely from lines between 0 and $100 \mathrm{~cm}^{-1}$, so that here the * See also Addendum. (n.(6) 
Table $3.2^{*}$ Computed absorption coefficients for various zine shapes

\begin{tabular}{|c|c|c|c|c|c|c|c|}
\hline & $\begin{array}{l}\text { Ordin } \\
\text { Loren }\end{array}$ & $\begin{array}{l}\operatorname{ary} \\
\operatorname{tz}\end{array}$ & $\begin{array}{l}\text { Ful } \\
\text { Iore }\end{array}$ & $\begin{array}{l}11 \\
\text { entz }\end{array}$ & \multicolumn{2}{|c|}{ Van Vleck } & \multirow[b]{2}{*}{$\mathrm{T},{ }^{\circ} \mathrm{K}$} \\
\hline$\nu, \mathrm{cm}^{-1}$ & 300 & 260 & 300 & 260 & 300 & 260 & \\
\hline 261 & 62.5 & 60.4 & 65.5 & 64.0 & 73.5 & 73.5 & \\
\hline 310 & 59 & 48 & 61 & 50 & 69 & 60 & \\
\hline 367 & 12.2 & 9.4 & 13.2 & 10.5 & 19.9 & 18.9 & NITROGEN \\
\hline 412 & 4.65 & 3.54 & 5.45 & 4.34 & 12.5 & 13.1 & BROADENING \\
\hline 478.8 & 2.60 & 2.22 & 3.16 & 2.92 & 10.0 & 11.2 & . \\
\hline 559.4 & 0.560 & 0.500 & 0.873 & 0.930 & 7.93 & 9.30 & \\
\hline 800 & 0.115 & 0.121 & 0.300 & 0.318 & 6.81 & 8.54 & \\
\hline 261 & 364 & 348 & 354 & 344 & 429 & 431 & \\
\hline 310 & 322 & 265 & 340 & 285 & 379 & 334 & \\
\hline 367 & 67 & 54 & 73 & 60 & 107 & 106 & \\
\hline 412 & 26.0 & 20.5 & 30.4 & 25.3 & 69 & 75 & SELF \\
\hline 478.8 & 14.4 & 12.0 & 17.6 & 15.4 & 55 & 63.7 & BROADENING \\
\hline 559.4 & 3.19 & 2.94 & 5.39 & 5.41 & 42 & 53 & \\
\hline 800 & 0.643 & 0.732 & 1.68 & 1.87 & 37.0 & 48.1 & \\
\hline
\end{tabular}

The tabulated quantities are mass absorption coefficients, in units of $\mathrm{g}^{-1} \mathrm{~cm}^{2} \mathrm{~atm}^{-1}$. * See also Addendum. p.43. 
Facing $p .88$

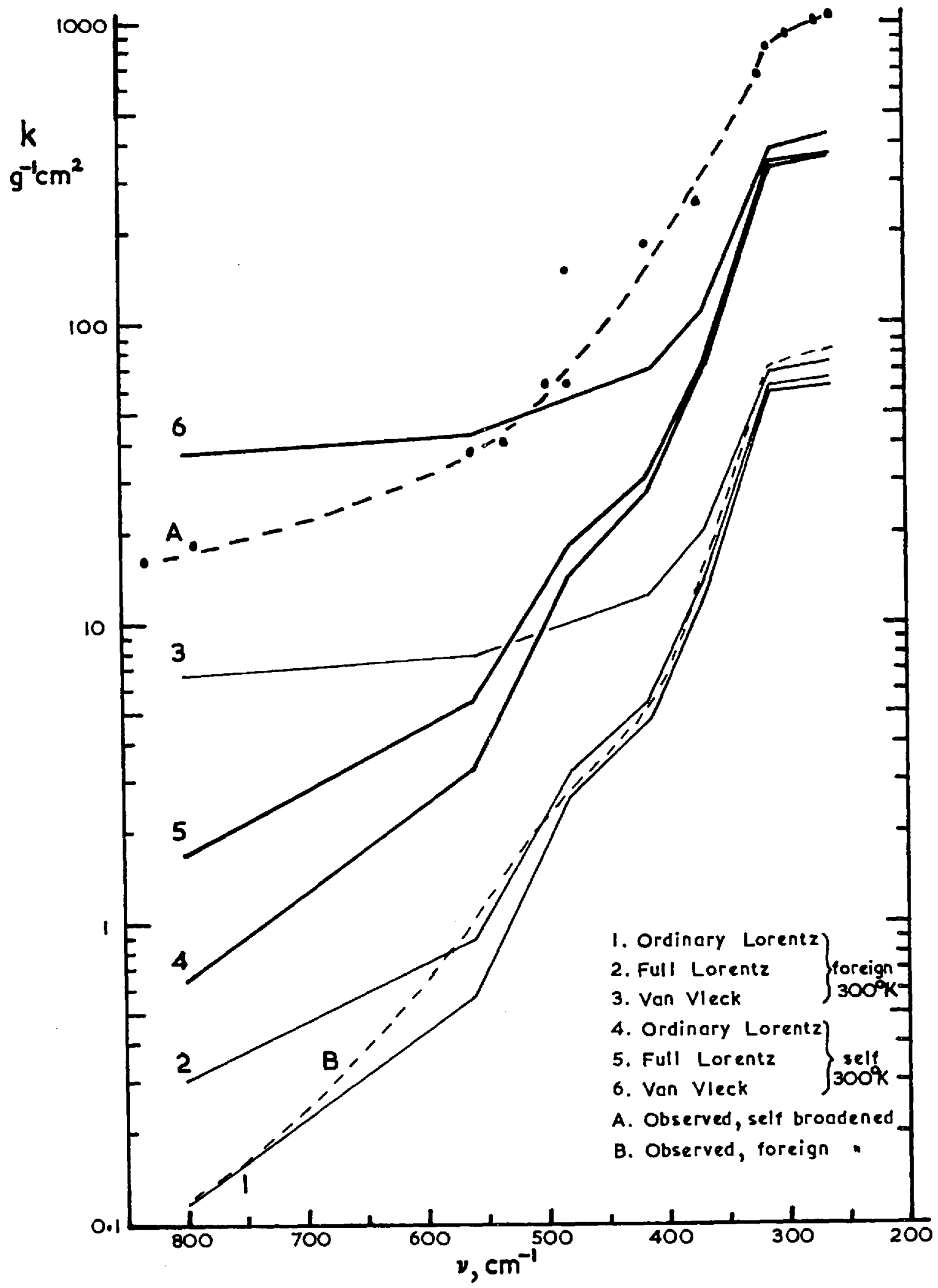

Fig 3.32. Comparison between observation and theory. (SEE ALSO ADDENDUM) 
temperature dependence is negative $\left(0.5 \%\right.$ per $\left.{ }^{\circ} \mathrm{C}\right)$; for $\nu<500$ $\mathrm{cm}^{-1}$ the contribution from lines within $20 \mathrm{~cm}^{-1}$ becomes more important so that the temperature dependence is very small near $260 \mathrm{~cm}^{-1}$.

Since all three line profilegare very similar within ebout $20 \mathrm{~cm}^{-1}$ of line centres, the oslculated absorption coefficient in the region $260-300 \mathrm{~cm}^{-1}$ is not sensitive to the choice of line profile, most of the absorption arising from nearby lines.

On average, continuum absorption coefficients computed from $\mathrm{H}_{2} \mathrm{O}-\mathrm{H}_{2} \mathrm{O}$ collision half widths are between 5.5 and 6.0 times those for $\mathrm{H}_{2} \mathrm{O}-\mathrm{N}_{2}$ collisions.

The computed values for $300^{\circ} \mathrm{K}$ are shown in Fig 3.32 , together n.85

with the observations summarisod in $\oint 3.5 .3$ for comparison. Agreement betwoen the observed foreign - broadened contribution and that computed from the Lorentz profile is very good. On the other hand, the self - broadened component is not well represented by any of the computed curves, because al though there is quantitative agreement with the Van Vlock curve at $20 \mu$, the frequency and temperature dependence is not correct.

It is possible that the absorption attributed here to self broadening of water vapour lines is due instead to a broad band of the molecule $\left(\mathrm{H}_{2} \mathrm{O}\right)_{2}$. Rough calculations suggest that there should be such a band in the far infrared and, moreover, that it should have * See also Addendum. (193) 
very wide lines resulting in continuum - like absorption. All evidence suggests that $\left(\mathrm{H}_{2} \mathrm{O}\right)_{2}$, if it occurs in water vapour, forms only a very small fraction under atmospheric conditions $(<0.2 \%$ in saturated vapour at $20^{\circ} \mathrm{c}$, Dorsey, 1940, p 56). However, its abundance would be expected to be roughly proportional to vapour pressure and to decrease rather rapidly with temperature, which might explain qualitatively the vapour pressure and temperature dependence of the observed absorption.

\subsection{Conolusion}

Partly from the present work, and partly from a reexamination of previous work inspired by it, the following pioture of continum extinction in the region from $7 \mu$ to $40 \mu$ is suggested

1) There seem to be two separate sources of absorption with different frequency and temperature dependenoe: a) a foreign - broadened component which, at least in the region $20 \mu-40 \mu$, is roughly proportional to the foreign gas pressure. Although it was not possible to measure its temperature dependence directly, it seems likely to be positive and of order $0.5 \%-1 \%$ per ${ }^{\circ} \mathrm{C}$. Its magnitude in the region $12 \mu-40 \mu$ is roughly what would be expected from accumulated Lorentz line-wings from the $50 \mu$ rotation band; b) a self - broadened component, roughly proportional to the partial vapour pressure, with 
strong negative temperature dependence $\left(\sim 2 \%{ }^{\circ} \mathrm{C}^{-1}\right.$ at $30^{\circ} \mathrm{C}$ ). Its magnitude is not well represented on the basis of any proposed line shape, but the Van Vleck shape together with the half - width for water - water collisions gives the nearest agreement (a factor of 2); however, the frequency dependence is not correct. $*$

2) There is little evidence that aerosol absorption (other than fog) plays any important role, and examination of the positive inferences dram by previous workers shows that the evidence is equally well (or better) explained on the basis of self broadening together with an inherent systematio error in their technique arising from diurnal evaporation.

3) Unexpectedly high absorption (4 times expeated) was observed in the relatively transparent $4-12 \mu$ region. The measurements had to be conducted at high vapour pressure $(\sim 30 \mathrm{mb})$, and the results might be reconciled with the previous work at lower pressures ( $<10 \mathrm{mb}$ ) on the besis of self broadening. However, one previous investigation at vapour pressures up to $25 \mathrm{mb}$ shows no evidence of this, and, moreover, gives essentially the same result as that of all other workers. This point requires further careful inrestigation

* See aIso nddendum. 
4) The $15 \mu \quad \mathrm{CO}_{2}$ band does not give any detectable continuum outside the range $12.7 \mu<\lambda<17.8 \mu$ (transmittance $>99 \%$ for 43 atm - om of $\mathrm{CO}_{2}$ ). This confirms theonetical evidence that $\mathrm{CO}_{2}$ line - wings cut off more sharply than the Lorentz profile.

The results have important consequences, both theoretically and practically. Regarding the foreign - broadened continum, the results show very good agreement with computation based on the Lorentz profile thereby giving confidence in its application in extreme line wings. The self - broadened contribution, however, is not well represented, particularly regarding the frequency and temperature dependence, by any suggested line shape. There is a possibility that water molecules polymerise, giving a small fraction of $\left(\mathrm{H}_{2} \mathrm{O}\right)_{2}$, and the latter may give rise to a band of very broad lines, resembling a continuum.

The inference of the temperature and composition of the earth and atmosphere from satellite radiation observations requires correction for the water vapour continuum. It is possible that the discrepancies already found from early Tiros observations between actual and inferred temperature may be explained by a proper treatment of the continuum; this has not been attemped in the present work because the results in the $8-12 \mu$ region are open to doubt, so that further measurements must be awaited.

\footnotetext{
*

See also Addendum ( 1.93 )
} 
Anj future experimental work must be very carefully controlled if the parameters of the absorption are to be disentangled - clearly, any open atmosphere measurement is bound to fail. The experiment described in this thesis was not designed with such a complicated picture in mind and consequently the measurements are in some cases pushed to the limit to reach a conclusion. 


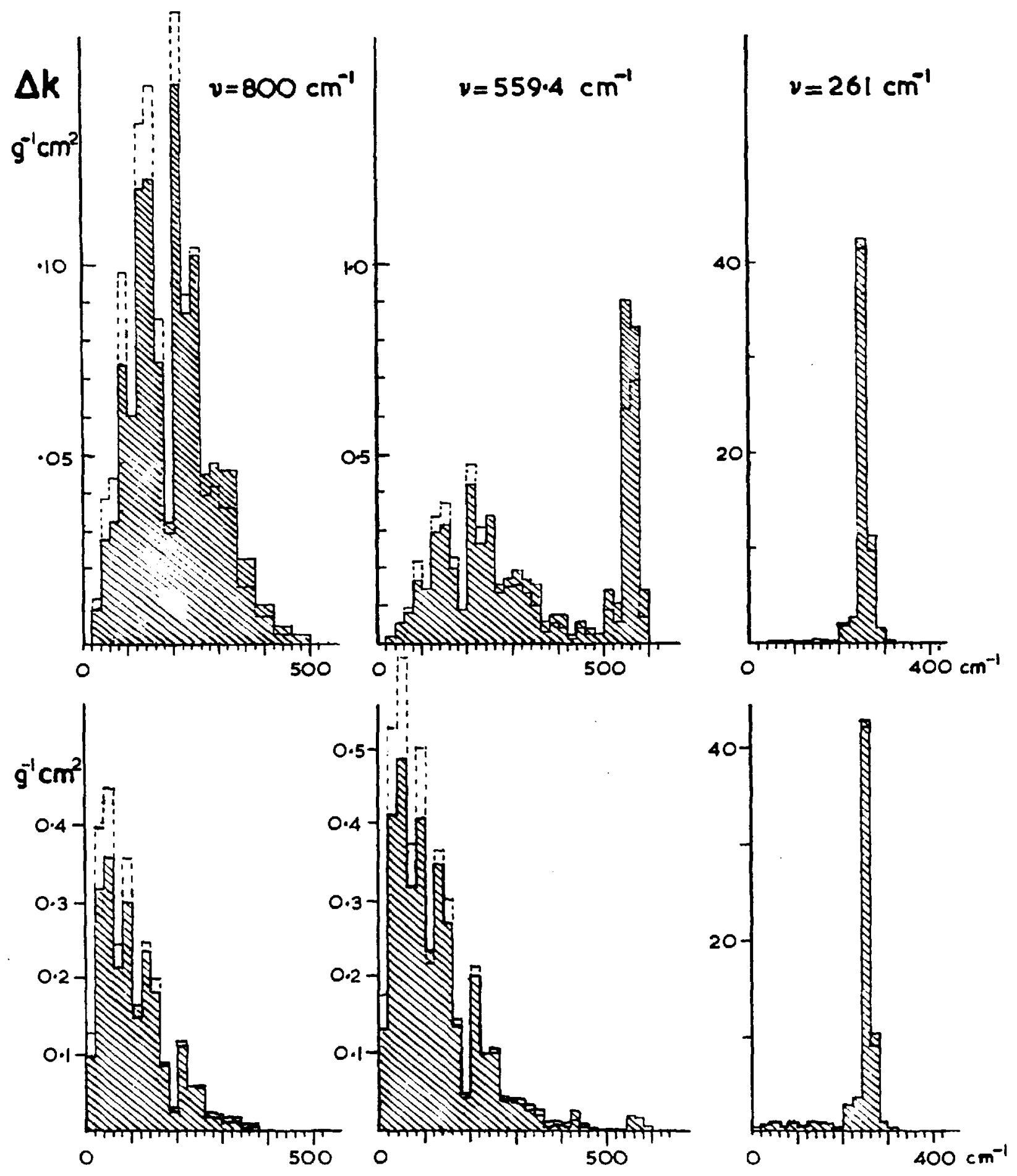

Fig 3.31. Contribution of rotation lines to continuum at $v=800,559.4$ and $261 \mathrm{~cm}^{-1}$ (amended).

Upper section: Lorentz line shape. Lower section: Von Vleck line shape. Computed for nitrogen-broadened half-width for temperatures of $300^{\circ} \mathrm{K}$ (solid lines) and $260^{\circ} \mathrm{K}$ (dashed lines) 
Facing p. 93

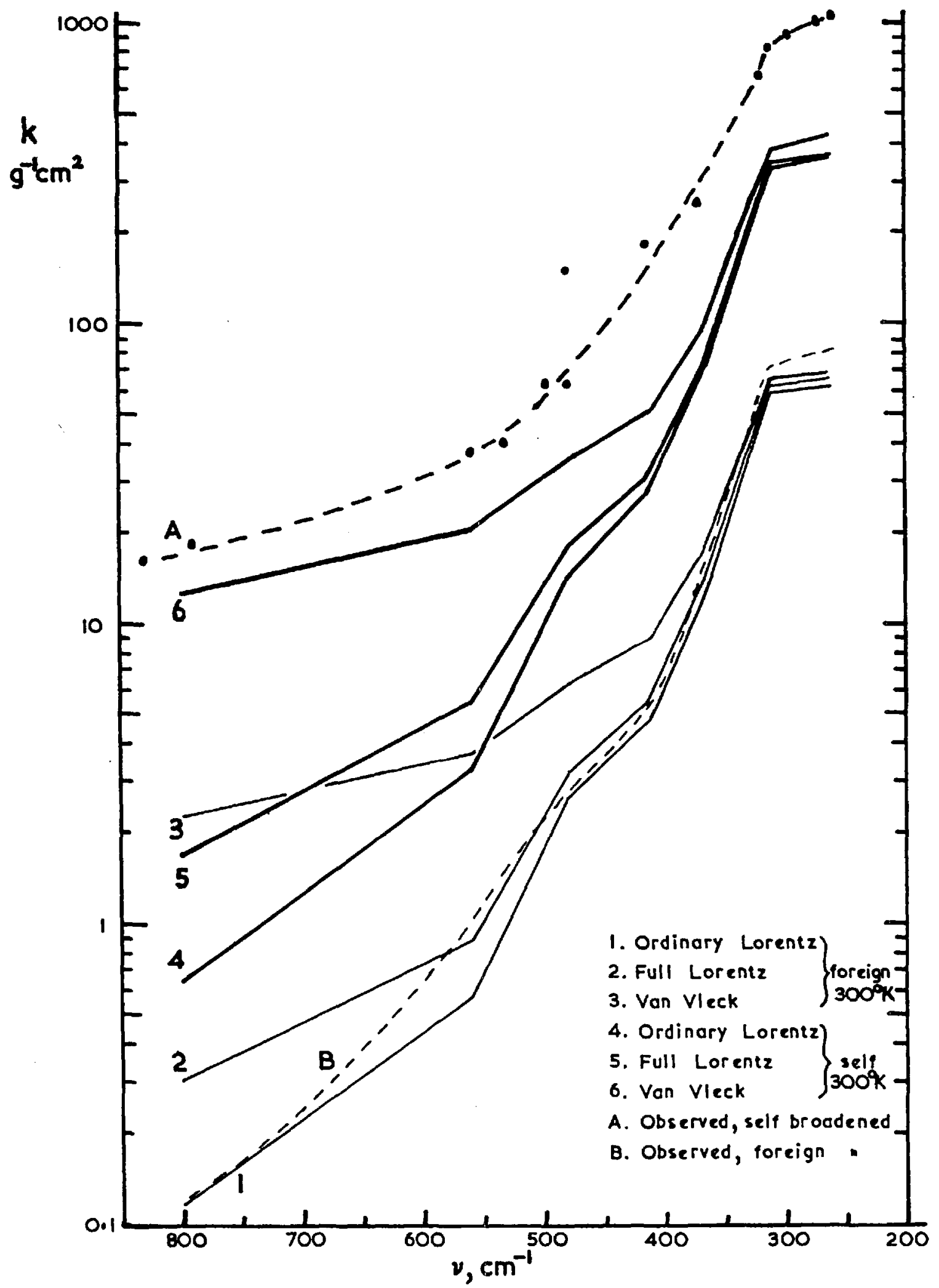

Fig 3.32. Comparison between observation and theory (amended). 
$\underline{\text { ADDENDUM }}$

1.7. I am indebted to Dr. L. D. Kaplan for pointing out that Eq. 1.4 is only strictly valid when $\nu$ and $\nu_{0}$ are both small, or, alternatively, nearly equal. The general expression, allowing for induced emission, is

$$
k(\nu)=\frac{s \alpha}{T} \frac{1-e^{-\frac{h \nu}{k T}}}{1-e^{-\frac{h \nu_{0}}{k T}}}\left(\frac{\nu}{\nu_{0}}\right)\left[\frac{1}{\left(\nu-\nu_{0}\right)^{2}+\alpha^{2}}+\frac{1}{\left(\nu+\nu_{0}\right)^{2}+\alpha^{2}}\right] 1.4
$$

(p.87) The effect of this is to modify the values given in Table 3.2x and those in Figs. 3.31 and 3.32 as shown in the following amenced versions

Table 3.2 (amended). Computed continuum for Van Vleck profile.

\begin{tabular}{|ll|l|l|l|l|r|r|r|}
\hline & $y, \mathrm{~cm}^{-1}$ & 261 & 310 & 367 & 412 & 478.8 & 559.4 & 800 \\
\hline Seif- & $\left\{300^{\circ} \mathrm{K}\right.$ & 404 & 363 & 92 & 50 & 34.9 & 20.4 & 12.7 \\
hroadening & $260^{\circ} \mathrm{K}$ & 384 & 303 & 83 & 48 & 37.0 & 23.3 & 14.9 \\
\hline Foneign- & $\left\{30^{\circ} \mathrm{K}\right.$ & 69.0 & 66.4 & 16.7 & 9.1 & 6.3 & 3.7 & 2.3 \\
broadening & $260^{\circ} \mathrm{K}$ & 68.1 & 54.4 & 14.6 & 7.9 & 6.3 & 3.9 & 2.6 \\
\hline
\end{tabular}

The quantities takulated are the mass absorption coefficients, in $\mathrm{g}^{-1} \mathrm{~cm}^{2}$ atmo

The frequency dependence of the computed values is now much closer to that observed, although the latter are larger than the former by a factor of 2 or 3 for $\nu<500 \mathrm{~cm}^{-1}$, and by 1.5 to 2.0 for $\nu>500 \mathrm{~cm}^{-1}$.

The temperature dependence is still negative for $\nu>400 \mathrm{~cm}^{-1}$, but is reduced in magnitude, being about - $0.4 \%$ per ${ }^{\circ} \mathrm{C}$ at $\gamma=800 \mathrm{~cm}^{-1}$ for self-broadening at $300^{\circ} \mathrm{K}$. 
Appendix 2.1. Observational data For WINDOWS 14, 7 AmD 19 (ASCOT).

$Y-$ YEAR :- $\quad 0=1960 ; 1=1961$.

MM - MONTH: DD - DAY: HHHH - TIME, GMT.

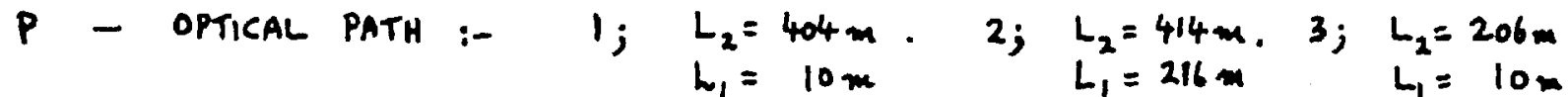

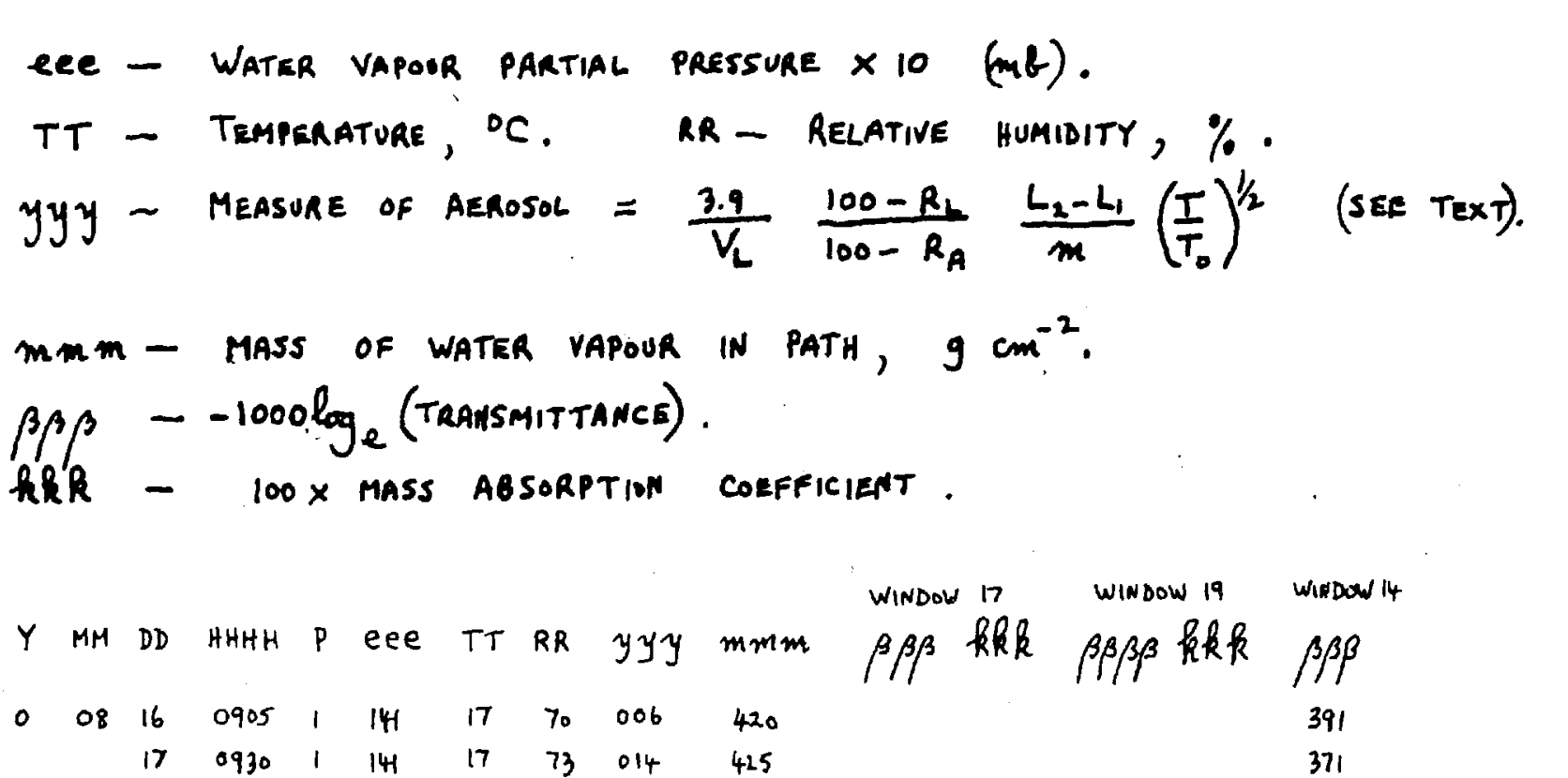

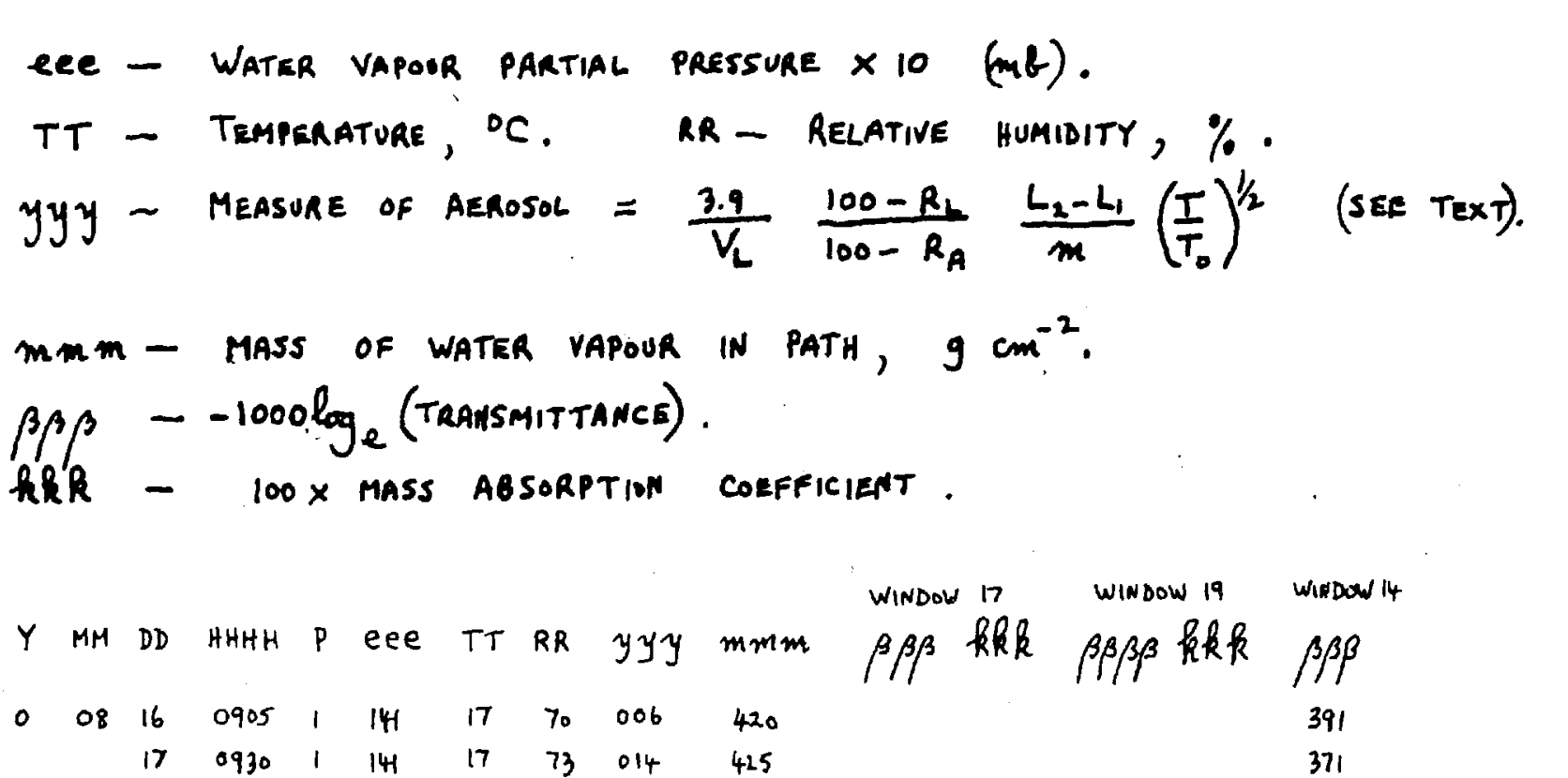

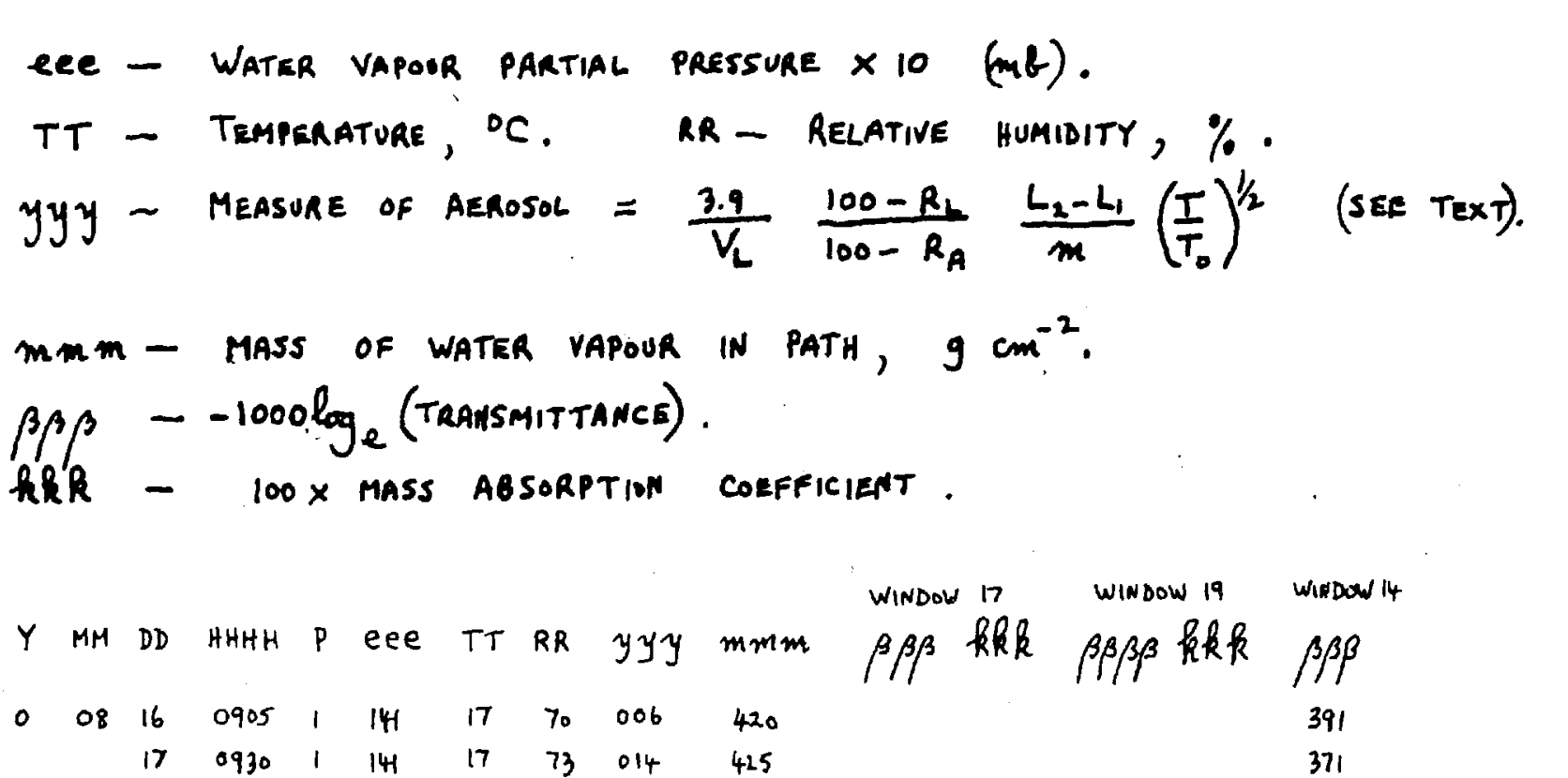

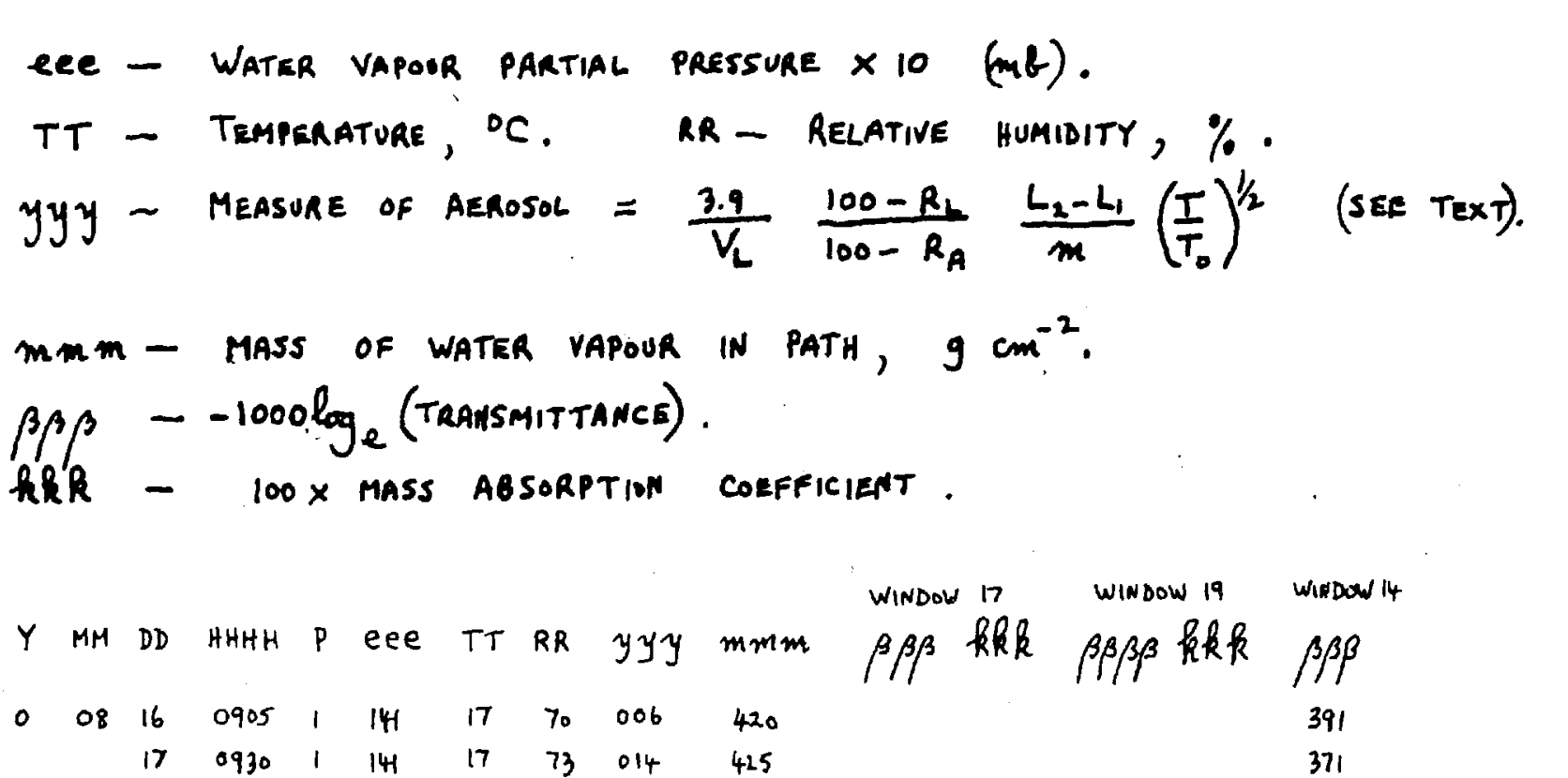

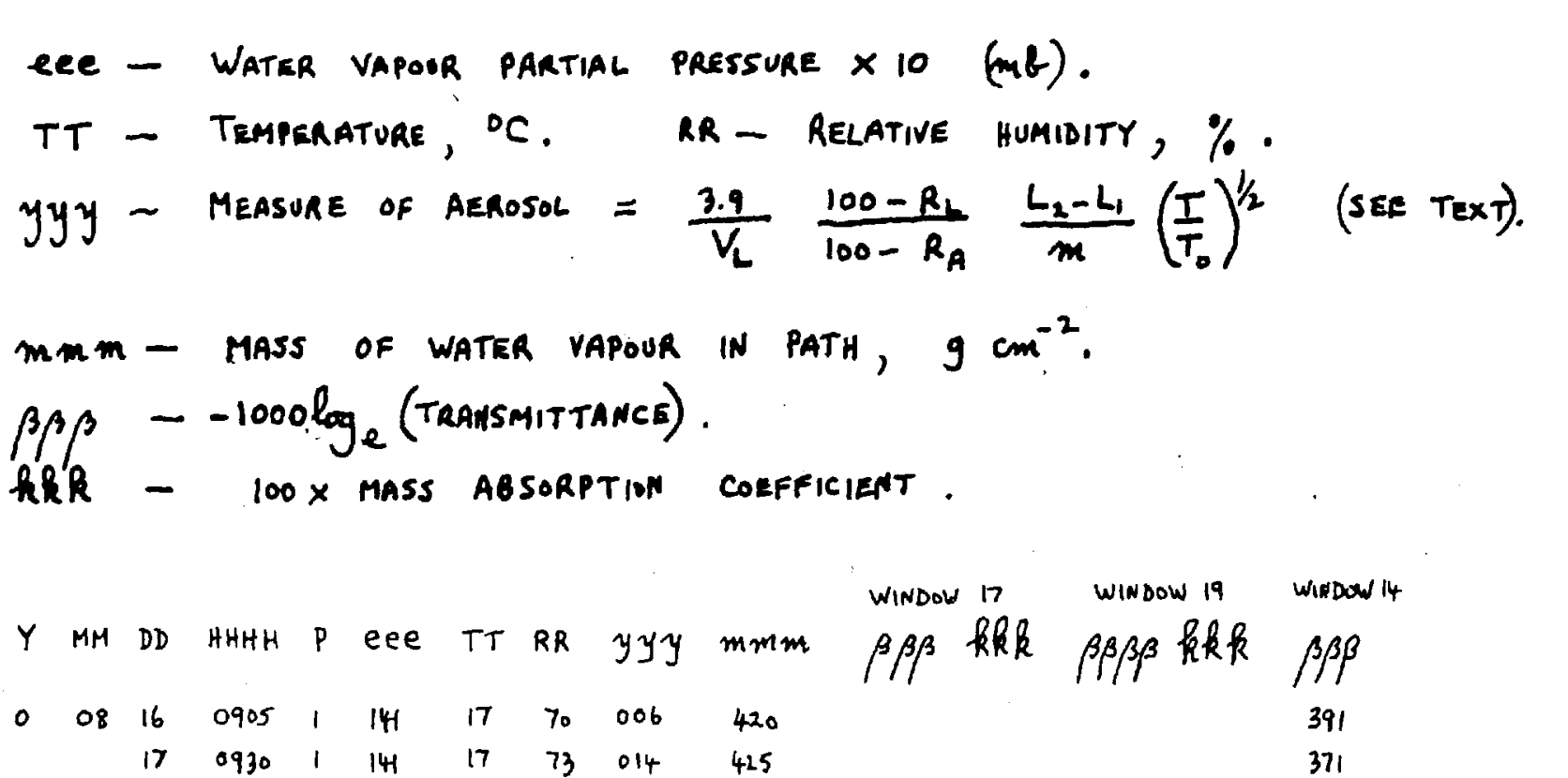

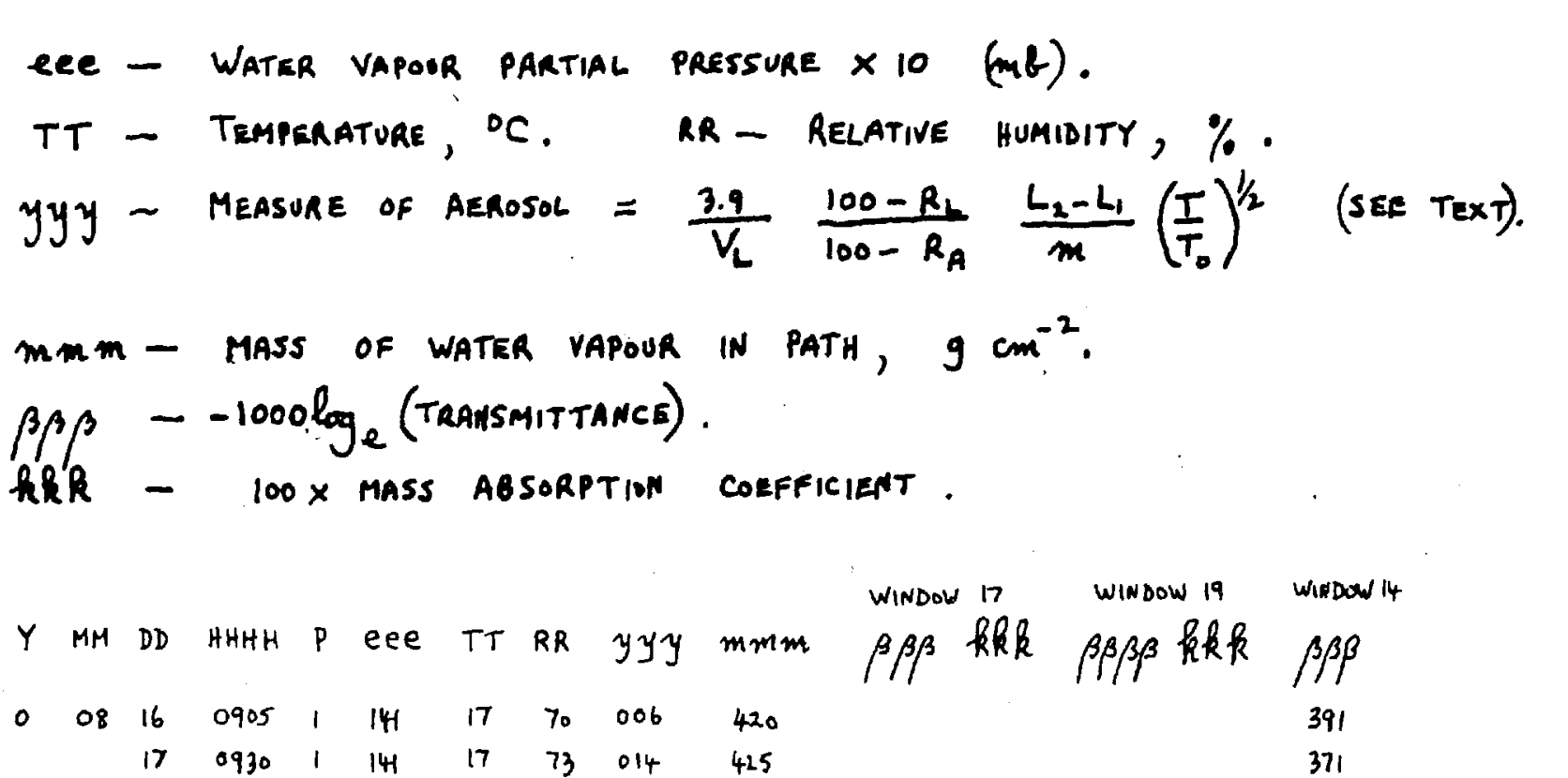

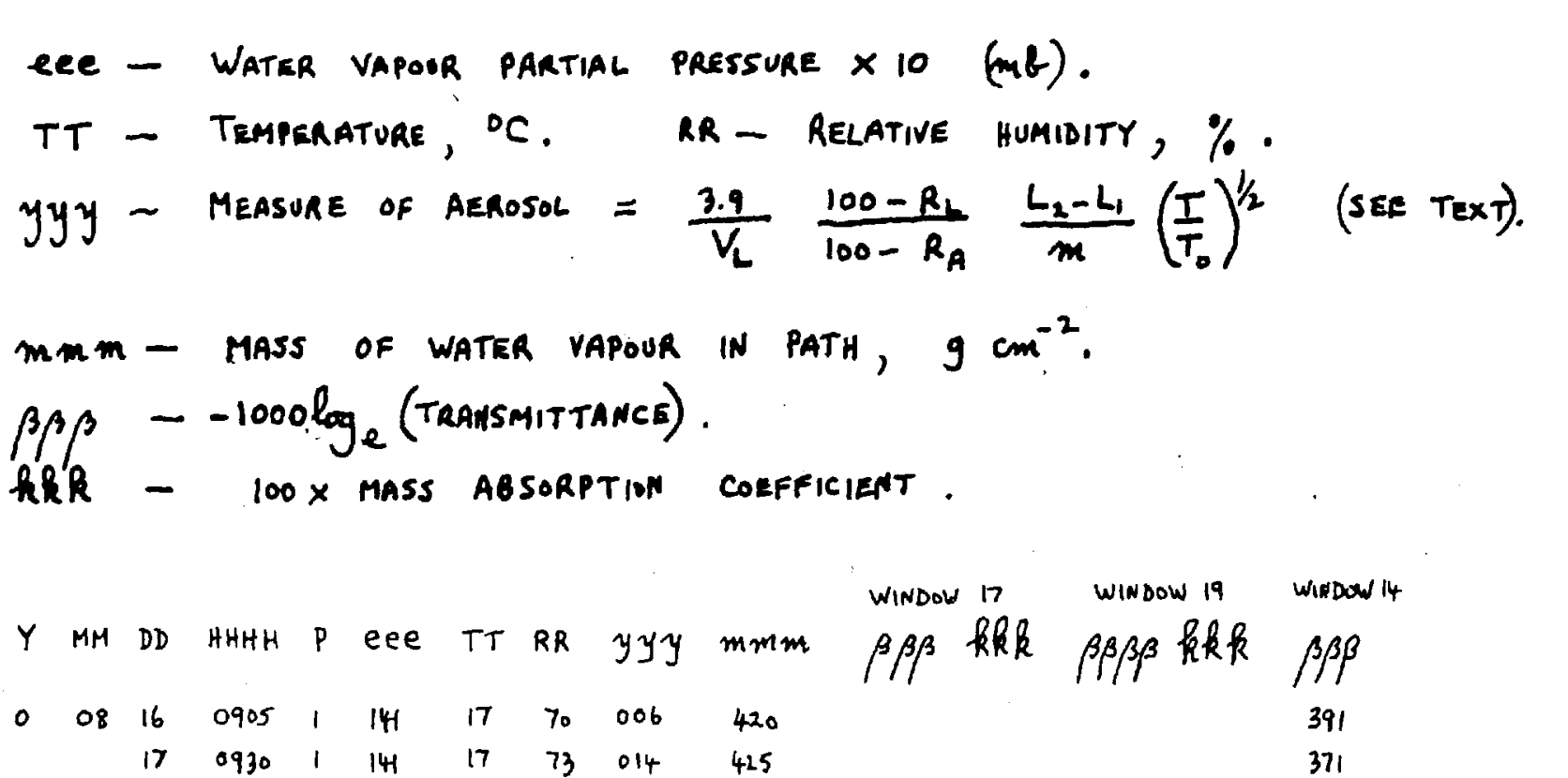

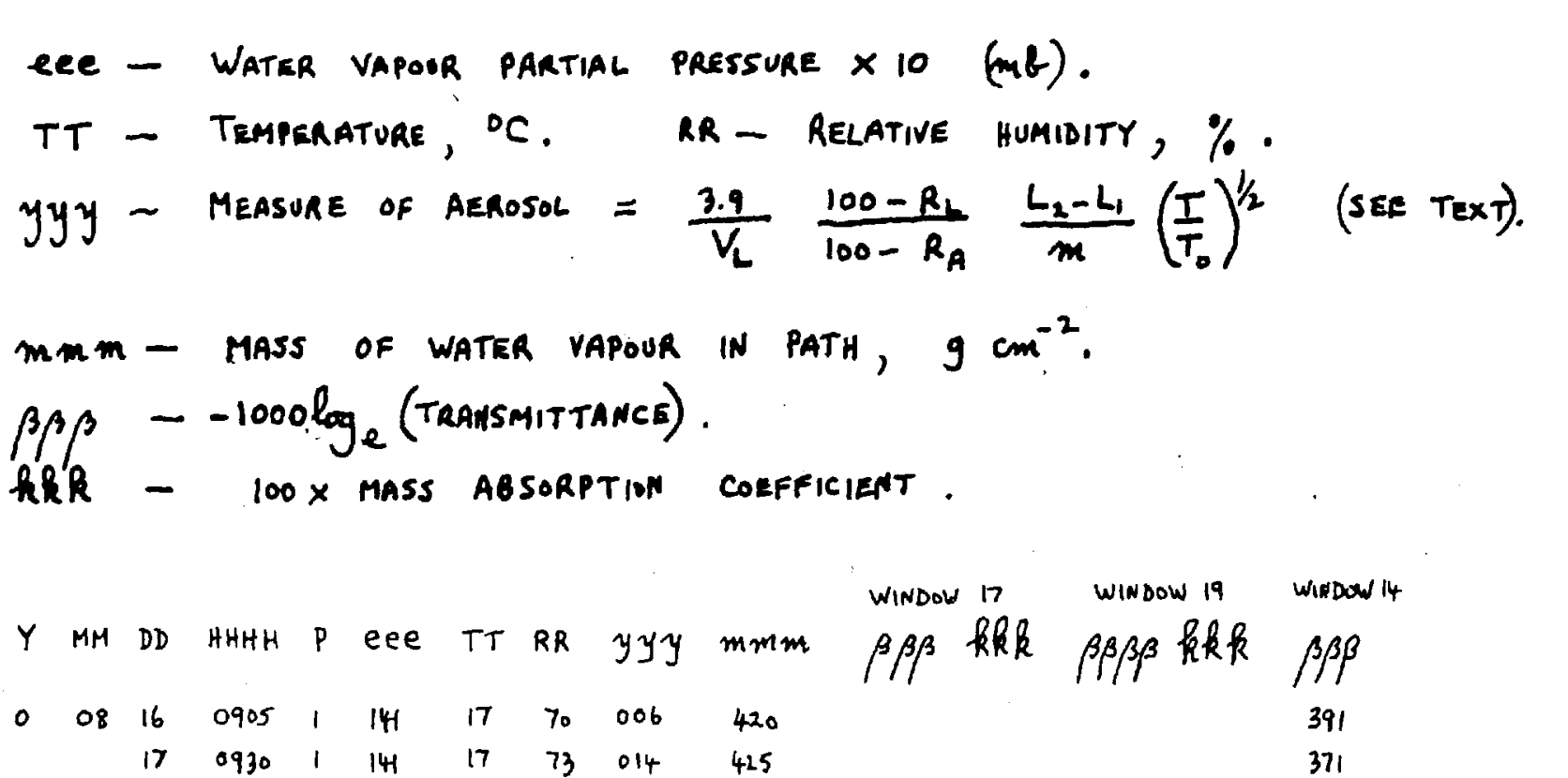

$\begin{array}{lllllllll}17 & 9930 & 1 & 141 & 17 & 73 & 014 & 425 & 371\end{array}$

$\begin{array}{lllllllll}17 & 1630 & 1 & 17 & 18 & 56 & 010 & 352 & 646\end{array}$

$\begin{array}{llllllllll}18 & 1030 & 1 & 71 & 19 & 88 & 031 & 545 & 783\end{array}$

$\begin{array}{lllllllll}18 & 1350 & 1 & 167 & 19 & 77 & 018 & 485 & 765\end{array}$

$\begin{array}{lllllllll}18 & 2000 & 3 & 134 & 12 & 97 & 158 & 210 & 398\end{array}$

$\begin{array}{lllllllll}19 & 0900 & 3 & 129 & 15 & 74 & 012 & 202 & 323\end{array}$

$\begin{array}{lllllllll}22 & 1650 & 1 & 189 & 20 & 80 & 011 & 553 & 712\end{array}$

$\begin{array}{lllllllll}23 & 2200 & 1 & 154 & 13 & 99 & 999 & 472 & 712\end{array}$

$\begin{array}{lllllllll}25 & 2300 & 3 & 137 & 12 & 98 & 091 & 218 & 398\end{array}$

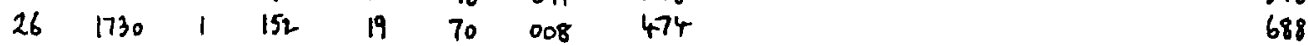

$\begin{array}{llllllll}27 & 1200 & 165 & 21 & 67 & 007 & 497 & 666\end{array}$

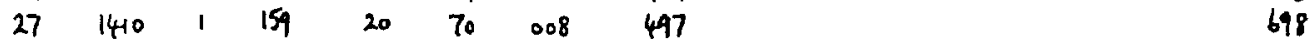

$\begin{array}{lllllllll}28 & 1540 & 1 & 156 & 19 & 71 & 009 & 465 & 698\end{array}$

$\begin{array}{llllllllll}28 & 1855 & 3 & 158 & 16 & 86 & 011 & 243 & 411\end{array}$

$\begin{array}{llllllllll}29 & 1618 & 3 & 146 & 19 & 66 & 005 & 226 & 380 \\ 31 & 1200 & 3 & 143 & 20 & 62 & 014 & 223 & 378\end{array}$

$\begin{array}{lllllllllll}- & 09 & 02 & 1015 & 3 & 159 & 18 & 80 & 012 & 251 & 399\end{array}$

$\begin{array}{lllllllll}08 & 1730 & 1 & 151 & 18 & 73 & 050 & 435 & 688\end{array}$

$\begin{array}{lllllllll}09 & 1510 & 1 & 162 & 19 & 74 & \text { 04 } & 505 & 727\end{array}$

$\begin{array}{lllllllll}09 & 1630 & 1 & 149 & 19 & 69 & 023 & 445 & 698\end{array}$

$\begin{array}{lllllllll}10 & 1810 & 1 & 163 & 20 & 72 & 028 & 505 & 717\end{array}$

$\begin{array}{lllllllll}12 & 1027 & 1 & 162 & 18 & 74 & 047 & 483 & 736\end{array}$

$\begin{array}{lllllllll}12 & 1236 & 3 & 176 & 23 & 62 & 035 & 269 & 409\end{array}$

$\begin{array}{lllllllll}13 & 1650 & 3 & 115 & 19 & 53 & 014 & 179 & 377\end{array}$

$\begin{array}{llllllllllllllll} & 15 & 1650 & 1 & 108 & 15 & 63 & 013 & 323 & & & & 635 \\ 0 & 09 & 24 & 1852 & 1 & 135 & 12 & 96 & 580 & 417 & 678 & 156 & 1170 & 280 & 690\end{array}$ 
APPENDIX 2.1 (CONTINUED).

$Y$ MM DD HHHH P eE TT RR yyy $\mathrm{mmm}$

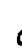

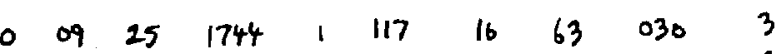

$\begin{array}{lllllll}09 & 27 & 2212 & 091 & 82 & 045\end{array}$

$\begin{array}{lllllllllll}09 & 29 & 1655 & 118 & 14 & 77 & 046\end{array}$

$\begin{array}{lllllll}10 & 11 & 1242 & 1 & 072 & 10 & 58\end{array}$

11

11

$\begin{array}{llllll}11 & 1437 \quad 070 & 10 & 56 & 021\end{array}$

$\begin{array}{llllllll}08 & 1155 & 1 & 075 & 05 & 88 & 020 & 283 \\ 08 & 1245 & 1 & 075 & 06 & 80 & 126 & 283\end{array}$

912

1512,082 o8 74

$\begin{array}{llllll}1529 & 1 & 082 & 08 & 76 & 026\end{array}$

$\begin{array}{lllll}1615 & 1 & 085 & 07 & 82\end{array}$

17301081 or 83

1803,081 ob

$1817 \quad 1$ o8० ob

18451077 of

$\begin{array}{llll}1858 & 1 & 075 & 06 \\ 1075 & 1 & 075 & 05\end{array}$

$\begin{array}{llll}1955 & 1 & 075 & 05 \\ 1948 & 1 & 075 & 05\end{array}$

$\begin{array}{lllll}1948 & 1 & 075 & 05 & 87\end{array}$

$15 \quad \begin{aligned} & 2009 \\ & 1243 \\ & 1610\end{aligned}$

$075 \quad 05$

18

1610

$092 \quad 11$

$$
08505
$$

87

73

$098 \quad 09$

95

$1610 \quad 1 \quad 096 \quad 08$

$\begin{array}{llll}1645 & 1 & 097 & 07\end{array}$

221600

24

1613

25

$29 \quad 1039$

- 1201

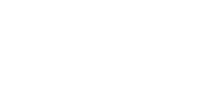

143510008

$\begin{array}{llll}1535 & 1 & 101 & 11 \\ 1500 & 1 & 100 & 11\end{array}$

$1525 \quad 1101 \quad 11$

$1530 \quad 1101 \quad 11$

$1600 \quad 1 \quad 102 \quad 11$

$1617 \quad 1 \quad 104 \quad 11$

$1677 \quad 1$ 104 11

$02 \quad 1410 \quad 1084$ 08

$1451 \quad 1084 \quad 08$

$\begin{array}{llll}1519 & 1 & 084 & 07\end{array}$

$1626 \quad 1$ or of

$1701 \quad 107905$

$\begin{array}{llll}1727 & 077 & 04\end{array}$

$1750 \quad 1077$ of

$\begin{array}{llll}12 & 02 & 1805\end{array}$

ol $12^{\prime}$

$20 \quad 1635$

03 of

$14301076 \quad 07$

16. 1 1 079 ०7

17.53 o79 06

$\begin{array}{llll}1635 & 3 & 078 & 04 \\ 1722 & 1 & 075 & 04\end{array}$

$1740,074 \quad 0$

$1457,102 \quad 12$

$\begin{array}{lllllll}1515 & 1 & 014 & 12 & 72 & 355 & 314\end{array}$

$\begin{array}{lllllll}1534 & 1 & 101 & 12 & 72 & 351 & 317\end{array}$

1629

$364 \quad 150$
WINDOW 17

wispowh

WINDOW 19 WINOOW 14

$\beta \beta \beta \beta k k \beta \beta \beta$

$519 \quad 143 \quad 624$

$362 \quad 121$

591

619

$270 \quad 118 \quad 542$

$25 \quad 112$

515

623

$364 \quad 150$

633

$355 \quad 143$

566

$367 \quad 140$

571

570

564

582

575

577

575

577

$372 \quad 159$

569

$359 \quad 152$

564

564

623

589

612

603

653

620

662

666

656

603

600

589

589

589

598

$490 \quad 159$

601

$476 \quad 157$

$500 \quad 157$

604

$405 \quad 153 \quad 0681254 \quad 587$

$371 \quad 142 \quad 0176 \quad 254 \quad 591$

$381 \quad 144 \quad 0676 \quad 254 \quad 579$

$370 \quad 143 \quad 0645 \quad 248 \quad 575$

$\begin{array}{lllll}314 & 146 & 0637 & 253 & 575\end{array}$

$361 \quad 148 \quad 0630 \quad 256 \quad 581$

$\begin{array}{lllll}350 & 143 & 0632 & 257 & 582\end{array}$

$\begin{array}{lllll}367 & 148 & 0637 & 255 & 582\end{array}$

$359 \quad 146 \quad 591$

$377 \quad 146$

615

$220 \quad 167$

356

$207 \quad 146$

359

$360 \quad 148$

567

$360 \quad 160$

564

$498 \quad 153 \quad 0876 \quad 273 \quad 712$

$510 \quad 160 \quad 0913 \quad 291 \quad 730$

$\begin{array}{lllll}415 & 15 x & 0922 & 291 & 727\end{array}$

$\begin{array}{lllll}5 \circ & 158 & 0888 \quad 280 & 738\end{array}$ 
APPENDIX 2.1 (CONTINUED).

WINDOW 17 WINDOW 19 WINDOW 14

$Y$ MM DD HHHH $P$ eee TT RR yyy mmm $\beta \beta \beta$ kRk $\beta \beta \beta \beta k R k$ $\beta \beta \beta$

\begin{tabular}{|c|c|c|c|c|c|c|c|c|c|c|c|c|c|}
\hline \multirow[t]{15}{*}{03} & \multirow[t]{7}{*}{09} & 1643 & 1 & 096 & 11 & 73 & 392 & $\begin{array}{l}305 \\
314\end{array}$ & $\begin{array}{l}482 \\
492\end{array}$ & $\begin{array}{l}156 \\
155\end{array}$ & $\begin{array}{l}0878 \\
0898\end{array}$ & 288 & $\begin{array}{l}742 \\
758\end{array}$ \\
\hline & & 1729 & 1 & $\begin{array}{l}099 \\
096\end{array}$ & $\begin{array}{l}11 \\
\text { of }\end{array}$ & $\begin{array}{l}76 \\
85\end{array}$ & $\begin{array}{l}45 \\
430\end{array}$ & $\begin{array}{l}314 \\
305\end{array}$ & $\begin{array}{l}412 \\
S_{12}\end{array}$ & $\begin{array}{l}155 \\
165\end{array}$ & $\begin{array}{l}0898 \\
0917\end{array}$ & $\begin{array}{l}283 \\
301\end{array}$ & $\begin{array}{l}758 \\
795\end{array}$ \\
\hline & & 1739 & 1 & 097 & 09 & 85 & 425 & 310 & 507 & 161 & 0904 & 292 & 788 \\
\hline & & 1755 & 1 & 095 & 09 & 84 & 414 & 302 & 528 & 173 & 0130 & 308 & 801 \\
\hline & & 1817 & 1 & 093 & 08 & 88 & 550 & 298 & $S_{41}$ & 179 & 0955 & 321 & 15 \\
\hline & & 1840 & 1 & o11 & 07 & 12 & 860 & 293 & 537 & 180 & 0925 & ओi & 811 \\
\hline & & 1920 & 1 & 089 & 06 & 95 & $>999$ & 285 & 550 & 190 & 0917 & 322 & 834 \\
\hline & \multirow[t]{8}{*}{15} & 1455 & 1 & 072 & 20 & 31 & 022 & 222 & 340 & 154 & $0<90$ & 266 & 661 \\
\hline & & 1520 & 1 & $\Delta 73$ & 20 & 32 & 022 & 223 & 337 & 152 & 0570 & 256 & 665 \\
\hline & & 1545 & 1 & 074 & 20 & 33 & 022 & 24 & 337 & 149 & 0572 & $2 \sqrt{2}$ & 677 \\
\hline & & 1615 & 1 & 075 & 19 & 35 & 021 & 231 & 307 & 133 & 0540 & 234 & 648 \\
\hline & & 1640 & 1 & 071 & 18 & 34 & 022 & 218 & 299 & 137 & 0525 & $2 H$ & 646 \\
\hline & & 12.5 & 1 & 066 & 17 & 33 & 0.24 & 208 & 3.7 & $|5|$ & OS21 & 257 & 654 \\
\hline & & 1735 & 1 & 064 & 17 & 33 & 024 & 199 & 286 & 143 & 0491 & 246 & 643 \\
\hline & & 1800 & 1 & 073 & 14 & 16 & 026 & 230 & 267 & 114 & 0485 & 211 & 636 \\
\hline & \multirow[t]{5}{*}{17} & 1505 & 1 & 100 & 14 & 64 & 018 & 310 & 521 & 168 & 0901 & 291 & 629 \\
\hline & & 1529 & $i$ & 019 & 14 & 64 & 018 & 309 & Sor & 163 & 0886 & 287 & $6 \% 4$ \\
\hline & & 1136 & 1 & 094 & 12 & 49 & 020 & 273 & 54 & $m$ & 0882 & 301 & 643 \\
\hline & & 1756 & 1 & 097 & 10 & 78 & 031 & 301 & 556 & 183 & 0950 & 316 & 641 \\
\hline & & 1823 & 1 & 095 & 10 & 77 & 030 & 296 & 500 & 167 & 0887 & 300 & 625 \\
\hline 05 & 31 & 1644 & 1 & 074 & 15 & 42 & 018 & 226 & 354 & 161 & & & 639 \\
\hline \multirow[t]{32}{*}{$\alpha$} & \multirow[t]{5}{*}{$\begin{array}{l}01 \\
02\end{array}$} & $\begin{array}{l}0.036 \\
1141\end{array}$ & 1 & $\begin{array}{l}077 \\
112\end{array}$ & $\begin{array}{l}\alpha \\
16\end{array}$ & $\begin{array}{l}85 \\
59\end{array}$ & $\begin{array}{l}.70 \\
034\end{array}$ & $\begin{array}{l}233 \\
342\end{array}$ & $\begin{array}{l}378 \\
502\end{array}$ & $\begin{array}{l}164 \\
151\end{array}$ & 0956 & 278 & $\begin{array}{l}610 \\
659\end{array}$ \\
\hline & & 1329 & 1 & 1.5 & 16 & 55 & 034 & 320 & 481 & 157 & 0898 & 281 & 657 \\
\hline & & 1423 & 1 & 102 & 18 & 51. & 031 & 308 & 477 & 160 & 0875 & 284 & 672 \\
\hline & & 1539 & 1 & 107 & 16 & 59 & 035 & 330 & 530 & 165 & 1000 & 303 & 675 \\
\hline & & 2325 & 1 & 096 & .7 & 96 & 400 & 303 & 498 & 166 & 0942 & 311 & 730 \\
\hline & \multirow[t]{15}{*}{03} & 0006 & 1 & 092 & 06 & 95 & 330 & 289 & 478 & 168 & 0849 & 294 & 763 \\
\hline & & 0.23 & 1 & 088 & .5 & 18 & 910 & 280 & 473 & 170 & 0887 & 317 & 767 \\
\hline & & 0150 & 1 & 092 & ob & 96 & 414 & 290 & 480 & 168 & & & 734 \\
\hline & & 0820 & 1 & 113 & 16 & 61 & 036 & 344 & 505 & 151 & 0929 & 270 & 680 \\
\hline & & 0858 & 1 & 1.7 & 17 & 55 & 033 & 330 & 484 & 151 & 0891 & 270 & 678 \\
\hline & & 0930 & I & 108 & 18 & 53 & $O O_{1}$ & 330 & 495 & 155 & osq1 & 270 & 690 \\
\hline & & 1020 & 1 & 107 & 19 & 49 & 030 & 326 & 504 & 160 & 0925 & 284 & 698 \\
\hline & & 1029 & 1 & 104 & 19 & 4 & 029 & 318 & 501 & 163 & 0915 & 288 & 687 \\
\hline & & 1.59 & 1 & 108 & 20 & 47 & 028 & 328 & 517 & 163 & 0970 & 296 & 696 \\
\hline & & 1130 & 1 & 111 & 20 & 47 & 028 & 336 & 529 & 163 & 0918 & 273 & 700 \\
\hline & & 1203 & 1 & 110 & 20 & 47 & 028 & 334 & 525 & 163 & 0971 & 291 & 705 \\
\hline & & 129 & 1 & 45 & 21 & 45 & 025 & 348 & 547 & 163 & 0956 & 275 & 710 \\
\hline & & 1337 & 1 & II3 & 22 & 43 & 025 & 342 & 516 & 157 & 0985 & 288 & 665 \\
\hline & & 1525 & 1 & 115 & 20 & 48 & 027 & 348 & 540 & 161 & 1043 & 300 & 685 \\
\hline & & 1208 & 1 & 120 & 20 & si & 027 & 361 & 598 & 171 & 1113 & 309 & 679 \\
\hline & \multirow[t]{12}{*}{16} & 1345 & 1 & 148 & 20 & 64 & 017 & 448 & 811 & 185 & & & \\
\hline & & 1413 & 1 & 150 & 21 & 61 & 016 & 455 & 803 & 181 & & & \\
\hline & & 1432 & 1 & 156 & 22 & 6o & 015 & 466 & 819 & 179 & & & \\
\hline & & 1434 & 1 & 166 & 23 & 60 & 014 & 497 & 795 & 163 & & & \\
\hline & & 1436 & 1 & 158 & 22 & 60 & 014 & 474 & 764 & 164 & & & \\
\hline & & 1437 & 1 & 161 & 22 & 59 & 014 & 484 & 795 & 168 & & & \\
\hline & & 1523 & 1 & 153 & 22 & 58 & 015 & 459 & 794 & 177 & & & \\
\hline & & 1540 & 1 & 144 & $\begin{array}{l}20 \\
21\end{array}$ & $\begin{array}{l}61 \\
61\end{array}$ & $\begin{array}{l}016 \\
116\end{array}$ & 440 & 772 & $\begin{array}{l}179 \\
180\end{array}$ & & & \\
\hline & & 1600 & 1 & $\begin{array}{l}151 \\
146\end{array}$ & $\begin{array}{l}21 \\
21\end{array}$ & $\begin{array}{l}61 \\
60\end{array}$ & $\begin{array}{l}116 \\
015\end{array}$ & $\begin{array}{l}456 \\
440\end{array}$ & $\begin{array}{l}800 \\
779\end{array}$ & $\begin{array}{l}180 \\
181\end{array}$ & & & \\
\hline & & $\begin{array}{l}1633 \\
1815\end{array}$ & 1 & 144 & 19 & 65 & 018 & $\begin{array}{l}100 \\
438\end{array}$ & 769 & 179 & & & \\
\hline & & 1857 & 1 & 148 & 18 & 70 & 020 & 453 & 810 & 182 & & & \\
\hline & & 1934 & 1 & 151 & 17 & 77 & 008 & 460 & 839 & 184 & & & \\
\hline
\end{tabular}


WINDOW 17 WINDOW 19 WINDOW 14 $Y$ MM DD HHHH $P$ eee $T T$ RR yyy mmm $\beta \beta \beta$ kRR $\beta \beta \beta \beta$ RKR $\beta \beta \beta$

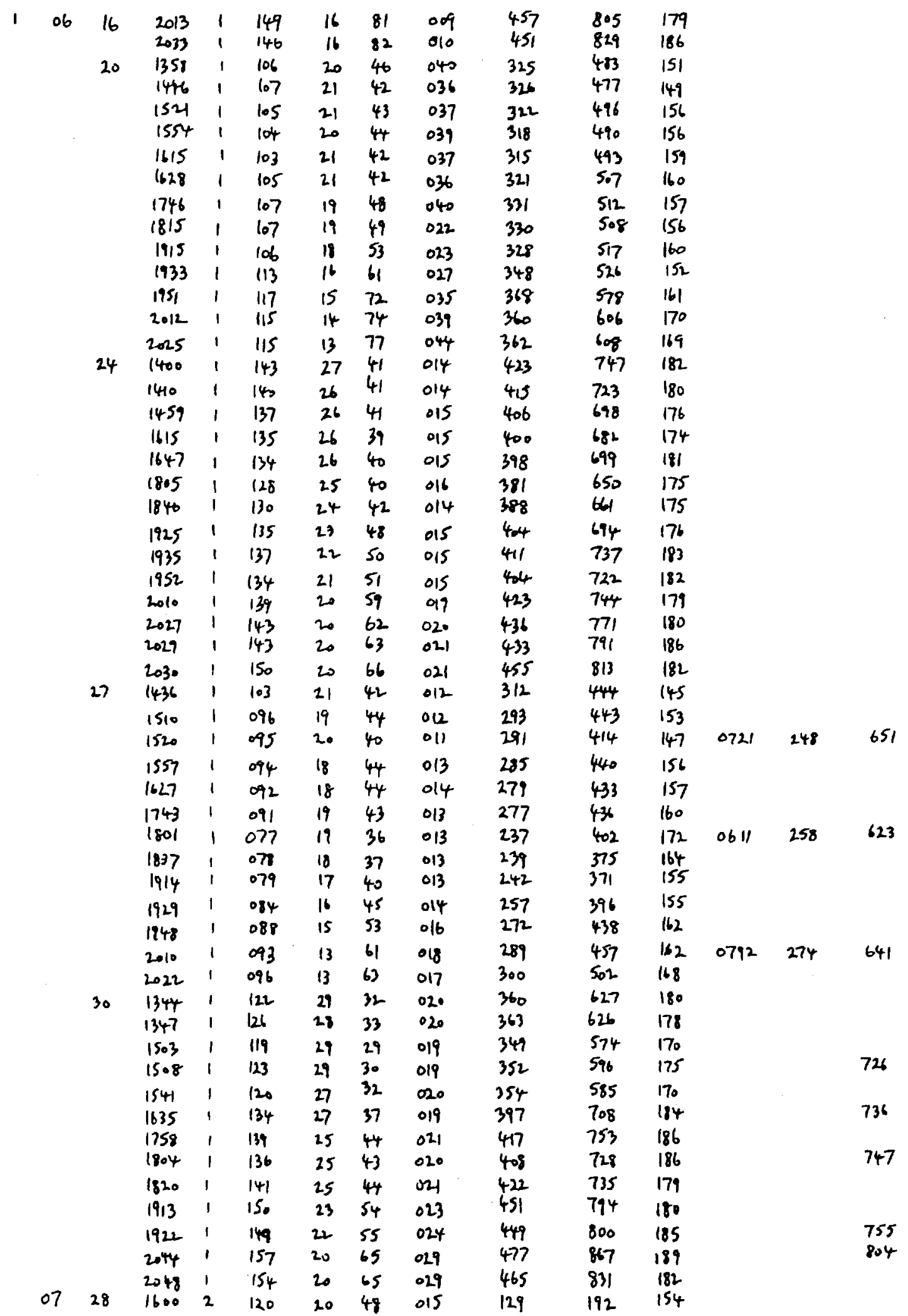




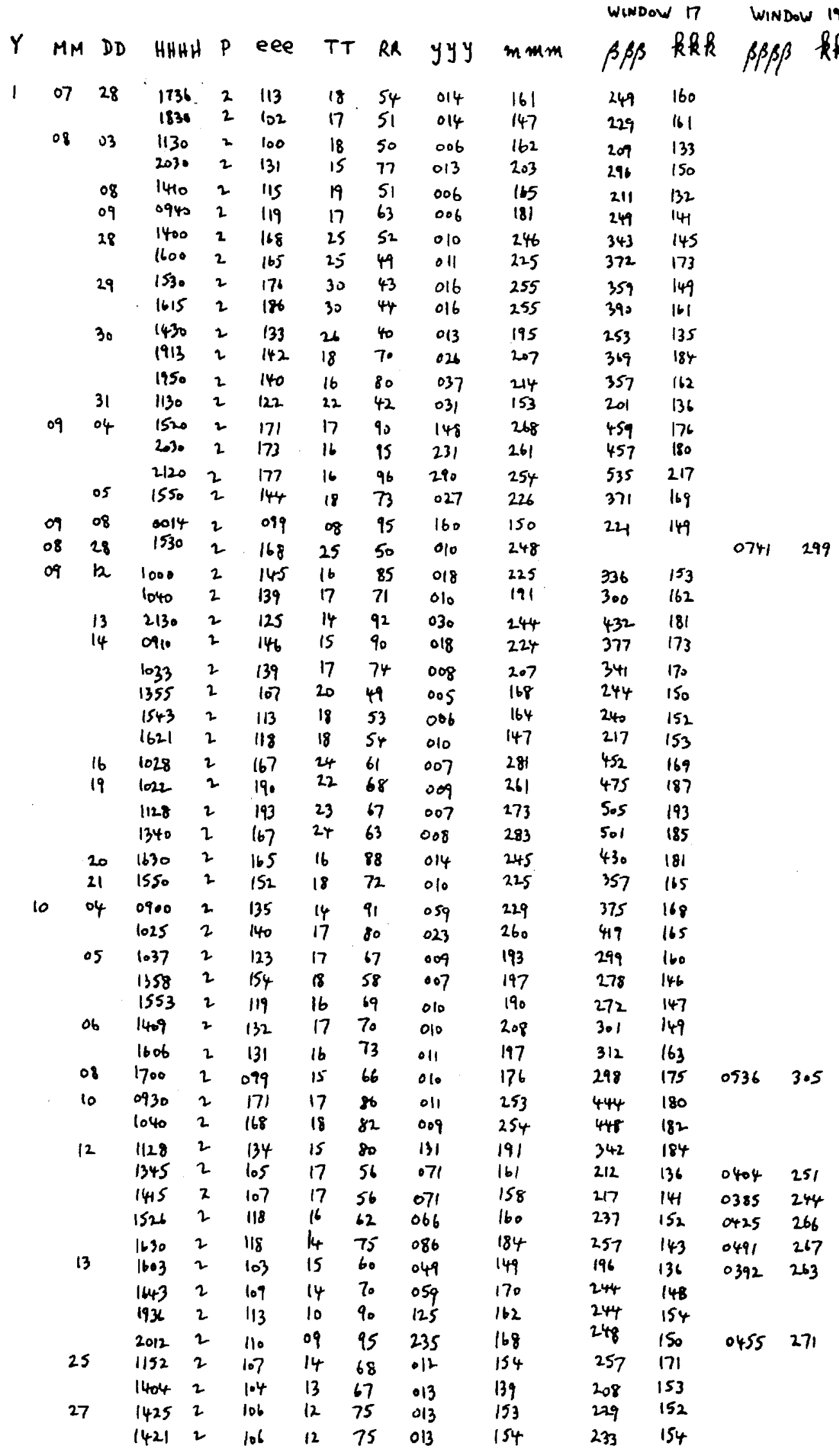


APPENDIX 2.2. OBSERVATIONAL DATA FOR WINDOWS 15, 16, 18 AND20 (ASCOT). FOR EXPLANATION OF SYMBOLS, SEE APPENDIX 2.1 .

\begin{tabular}{|c|c|c|c|c|c|c|c|c|c|c|c|c|c|c|c|c|c|}
\hline$y$ & $M M$ & $D D$ & HHHH & $p$ & eer & TT & $R R$ & yyy & $\mathrm{mmm}$ & $\begin{array}{c}\beta \beta \beta \beta \\
17-15\end{array}$ & $\begin{array}{c}\beta \beta \beta \\
17-16\end{array}$ & $\beta_{18-17}^{\beta \beta \beta}$ & $\begin{array}{l}k R \\
18-17\end{array}$ & $\beta \beta \beta$ & $\begin{array}{l}k R R \\
20-17\end{array}$ & $\begin{array}{l}\beta \beta \beta \\
17-4\end{array}$ & $\begin{array}{c}R R R \\
17-4\end{array}$ \\
\hline \multirow[t]{7}{*}{0} & 08 & $\begin{array}{l}27 \\
28\end{array}$ & $\begin{array}{l}1520 \\
1600\end{array}$ & 1 & $\begin{array}{l}127 \\
158\end{array}$ & $\begin{array}{l}19 \\
19\end{array}$ & $\begin{array}{l}68 \\
73\end{array}$ & $\begin{array}{l}008 \\
009\end{array}$ & $\begin{array}{l}430 \\
491\end{array}$ & $\begin{array}{r}028 \\
-006\end{array}$ & $\begin{array}{l}074 \\
047\end{array}$ & $\begin{array}{l}189 \\
202\end{array}$ & $\begin{array}{l}44 \\
41\end{array}$ & & & $\begin{array}{l}661 \\
766\end{array}$ & $\begin{array}{l}154 \\
156\end{array}$ \\
\hline & 09 & $\begin{array}{l}23 \\
09\end{array}$ & $\begin{array}{l}1924 \\
1653\end{array}$ & $\begin{array}{l}3 \\
1\end{array}$ & $\begin{array}{l}158 \\
163\end{array}$ & $\begin{array}{l}16 \\
19\end{array}$ & $\begin{array}{l}87 \\
75\end{array}$ & $\begin{array}{l}011 \\
029\end{array}$ & $\begin{array}{l}255 \\
509\end{array}$ & $\begin{array}{l}021 \\
018\end{array}$ & $\begin{array}{l}029 \\
079\end{array}$ & $\begin{array}{l}115 \\
183\end{array}$ & $\begin{array}{l}45 \\
36\end{array}$ & & & $\begin{array}{l}439 \\
794\end{array}$ & $\begin{array}{l}172 \\
156\end{array}$ \\
\hline & & 10 & 1837 & 1 & $|7|$ & 18 & 81 & 041 & 533 & 028 & 057 & 229 & 43 & & & 804 & 151 \\
\hline & & 12 & 1118 & 1 & 170 & 19 & 76 & 051 & 526 & 070 & 084 & 211 & 40 & & & 768 & 146 \\
\hline & & $\begin{array}{l}12 \\
13\end{array}$ & $\begin{array}{l}1450 \\
1715\end{array}$ & $\begin{array}{l}3 \\
3\end{array}$ & $\begin{array}{l}179 \\
122\end{array}$ & $\begin{array}{l}22 \\
18\end{array}$ & $\begin{array}{l}67 \\
58\end{array}$ & $\begin{array}{l}040 \\
027\end{array}$ & $\begin{array}{l}282 \\
197\end{array}$ & $\begin{array}{l}040 \\
100\end{array}$ & $\begin{array}{l}034 \\
042\end{array}$ & $\begin{array}{l}098 \\
057\end{array}$ & $\begin{array}{l}36 \\
29\end{array}$ & & & $\begin{array}{l}406 \\
248\end{array}$ & $\begin{array}{l}44 \\
26\end{array}$ \\
\hline & & 15 & 1710 & 1 & 106 & 14 & $\$ 3$ & 013 & 326 & 161 & 087 & 134 & 41 & & & 456 & \\
\hline & & 24 & 1917 & 1 & 129 & 11 & 98 & 900 & 416 & 085 & 055 & 175 & 42 & & & 649 & \\
\hline & 08 & 28 & 1530 & 2 & 163 & 25 & 50 & 010 & 241 & 016 & 053 & 122 & 49 & 700 & 282 & 360 & \\
\hline & & 28 & 2050 & 2 & 143 & 17 & 90 & 055 & 419 & & & & & 628 & 287 & 378 & \\
\hline & & 29 & 1628 & 2 & 182 & 29 & 43 & 016 & 254 & - vof & 055 & 112 & 44 & 693 & 273 & 409 & \\
\hline & & 30 & 1512 & 2 & 137 & 26 & 42 & 013 & 198 & 045 & .046 & 085 & 43 & 471 & 238 & 267 & \\
\hline & & 30 & 1936 & 2 & 146 & 16 & 79 & 037 & 220 & 029 & 035 & 121 & 55 & 565 & 257 & 356 & \\
\hline & & 31 & 1142 & 2 & 108 & 22 & 40 & 431 & 159 & 044 & 066 & 031 & 20 & 359 & 226 & 216 & \\
\hline
\end{tabular}


APPENDIX 3.1. OBSERYATIONAL DATA FOR WIMDOWS 17, 18, 19 AMD 20 (LONDON).

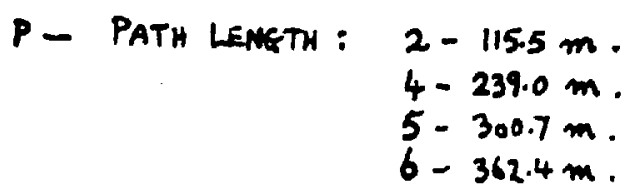

TT - temperature, ${ }^{\circ} \mathrm{C}$.

eee - WATER VAPMOR PARTIAL PRESSURE $\times 10, m b$.

num - MASS of WATER VAPOUR IN PATH $\times 1000$, (SCALEO TO COMMON PATH LEMETH of $402 \mathrm{~m}), g \mathrm{~cm}^{-2}$.

$\begin{aligned} & \beta \beta \beta- \text { - } 1000 \text { loge (TRAMSMITTANCE) } \\ &(\text { SCALLD To COMMON PATH LENGTH } \\ & \text { OF } 402 \mathrm{~m} \text { ). }\end{aligned}$

$R R R$ - $100 \times$ MASS ABSORPTION COLFFICIENT, $g^{-1} \mathrm{~cm}^{2}$.

No. TT $\frac{17-4}{\text { eee mmm } \beta \beta \beta \beta \text { RRK }}$

$9426 \quad 115 \quad 331$ ofo 124

$9430160.4600617 \quad 134$

$\begin{array}{lllllll}9 & 4 & 29 & 177 & 510 & 0768 & |5|\end{array}$

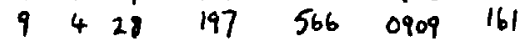

$10 \cdot 2130$

$102: 36$

$\begin{array}{ll:l}10 & 2 & 37\end{array}$

\begin{tabular}{ll|l}
10 & 2 & 37
\end{tabular}

$102 \quad 31$

$1 0 2 \longdiv { 3 6 }$

10 $2 \longdiv { 2 6 }$

$1 0 2 \longdiv { 3 4 }$

II 432

11433

11 438

11437

11437

$11 \quad 437$

$11 \quad 437$

$11 \quad 437$

11437

11435

11 435

11436

$11 \quad 436$

11434

11434

11435

11435

11433

11434

17519

$096 \quad 283 \quad 0325 \quad 115$

$\begin{array}{llllll}17 & 522 & 169 & 498 & 0768 & 154\end{array}$

$\begin{array}{llllll}17 & 522 & 156 & 460 & 0663 & 144\end{array}$

$\begin{array}{llllll}17 & 520 & 135 & 398 & 0512 & 129\end{array}$

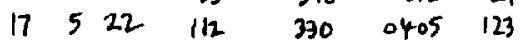

$18 \quad 540 \quad 163 \quad 450$ o981 131

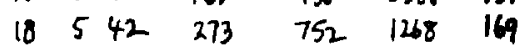

eee $\operatorname{minm} \frac{18-17}{\beta \beta \beta} \frac{k R}{\beta \beta \beta \beta} \frac{19-17}{R Q R} \frac{20-7}{\beta \beta \beta \beta}$ kRR

$\begin{array}{llllllll}116 & 337 & 230 & 68 & 0532 & 157 & 1025 & 302\end{array}$

$159 \quad 458 \quad 322 \quad 70 \quad 0770 \quad 169 \quad 1380 \quad 303$

$\begin{array}{llllllll}174 & 502 & 357 & 71 & 0858 & 172 & 1497 & 301\end{array}$

$\begin{array}{llllllll}193 & 560 & 462 & 76 & 0973 & 175 & 1647 & 297\end{array}$

$\begin{array}{llllllll}150 & 431 & 350 & 81 & 0630 & 146 & 1090 & 253\end{array}$

$\begin{array}{llllllll}277 & 780 & 655 & 84 & 1470 & 189 & 2450 & 314\end{array}$

$\begin{array}{llllllll}255 & .716 & 997 & 83 & 1270 & 177 & 2203 & 308\end{array}$

$\begin{array}{llllllll}217 & 609 & 493 & 81 & 1046 & 172 & 1782 & 293\end{array}$

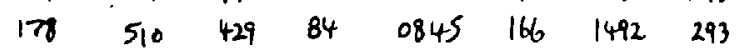

$\begin{array}{llllllll}150 & 422 & 341 & 81 & 0746 & 177 & 1177 & 278\end{array}$

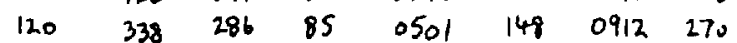

$\begin{array}{llllllll}097 & 275 & 231 & 84 & 0413 & 150 & 0753 & 274\end{array}$

$\begin{array}{llllllll}123 & 351 & 312 & 89 & 0476 & 136 & 0960 & 273\end{array}$

$\begin{array}{llllllll}126 & 359 & 333 & 93 & 0519 & 144 & 0976 & 272\end{array}$

$\begin{array}{llllllll}300 & 840 & 799 & 94 & 1620 & 193 & 2620 & 312\end{array}$

$\begin{array}{llllllll}276 & 775 & 658 & 85 & 1444 & 186 & 2205 & 274\end{array}$

$\begin{array}{llllllll}270 & 758 & 645 & 85 & 1386 & 183 & 2320 & 306\end{array}$

$\begin{array}{llllllll}259 & 728 & 589 & 81 & 1317 & 181 & 2278 & 313\end{array}$

$\begin{array}{llllllll}255 & 716 & 611 & 85 & 1321 & 184 & 2187 & 305\end{array}$

242 680 580 $85 \quad 1216 \quad 179 \quad 2108 \quad 310$

$\begin{array}{llllllll}236 & 663 & 572 & 86 & 1165 & 176 & 2018 & 305\end{array}$

$\begin{array}{llllllllll}214 & 605 & 480 & 80 & 1014 & 168 & 1763 & 291\end{array}$

$\begin{array}{llllllllll}212 & 599 \quad 470 & 79 & 1040 & 174 & 1750 & 292\end{array}$

$196 \quad 552 \quad 460 \quad 83 \quad 0905 \quad 164 \quad 1568 \quad 284$

$\begin{array}{llllllll}194 & 547 \quad 48 & 82 & 0875 & 164 & 1582 & 289\end{array}$

$\begin{array}{llllllll}170 & 482 & 48 & 87 & 0782 & 162 & 1365 & 283\end{array}$

$\begin{array}{lllllllll}130 & 369 & 301 & 82 & 0550 & 149 & 1047 & 284\end{array}$

$\begin{array}{llllllll}133 & 377 & 333 & 88 & 0585 & 155 & 1042 & 277\end{array}$

$\begin{array}{llllllll}114 & 323 & 264 & 82 & 0445 & 138 & 0907 & 281\end{array}$

$\begin{array}{llllllll}090 & 257 & 181 & 70 & 0407 & 157 & 0698 & 271\end{array}$

$\begin{array}{llllllll}095 & 269 & 197 & 73 & 0352 & 131 & 0716 & 266\end{array}$ 
APPENDIX 3.1 (CONTINUED).

\begin{tabular}{|c|c|c|c|c|c|c|c|c|c|c|c|c|c|c|}
\hline \multirow[b]{2}{*}{$\begin{array}{l}\text { RuN } \\
\text { No. }\end{array}$} & \multirow[b]{2}{*}{$P$} & \multirow[b]{2}{*}{ TT } & \multicolumn{3}{|c|}{$17-4$} & & \multicolumn{2}{|c|}{$\overbrace{0}^{19-17}$} & \multicolumn{2}{|c|}{$20-17$} \\
\hline & & & eée & $\mathrm{mmm}$ & $A B P A$ & $R R k$ & eee & $\mathrm{mmm}$ & $\widehat{A \beta \beta}$ & $k R$ & $\beta \overparen{\beta \beta P}$ & $R R R$ & $\beta \beta \beta \beta$ & $k k k$ \\
\hline 18 & 5 & 43 & 258 & 712 & 1087 & 153 & & & & & & & & \\
\hline 18 & 5 & 41 & 206 & 596 & .772 & 130 & & & & & & & & \\
\hline $\begin{array}{l}18 \\
18\end{array}$ & $\begin{array}{l}5 \\
5\end{array}$ & $\begin{array}{l}38 \\
42\end{array}$ & $\begin{array}{l}118 \\
146\end{array}$ & $\begin{array}{l}326 \\
403\end{array}$ & $\begin{array}{l}0403 \\
0483\end{array}$ & $\begin{array}{l}124 \\
120\end{array}$ & & & & & & & & \\
\hline 26 & 5 & 27 & $.234 !$ & 680 & 1228 & $\theta|z| ?$ & 240 & 697 & & & 1290 & 185 & 2255 & 324 \\
\hline $\begin{array}{l}26 \\
26\end{array}$ & $\begin{array}{l}5 \\
5\end{array}$ & $\begin{array}{l}26 \\
26\end{array}$ & $\begin{array}{l}217 \\
205\end{array}$ & $\begin{array}{l}630 \\
595\end{array}$ & $\begin{array}{l}1095 \\
0978\end{array}$ & $\begin{array}{l}174 \\
164\end{array}$ & $\begin{array}{l}216 \\
203\end{array}$ & $\begin{array}{l}629 \\
590\end{array}$ & & & $\begin{array}{l}1145 \\
1061\end{array}$ & $\begin{array}{l}182 \\
180\end{array}$ & $\begin{array}{l}2002 \\
1910\end{array}$ & $\begin{array}{l}318 \\
324\end{array}$ \\
\hline $\begin{array}{l}26 \\
26\end{array}$ & $\begin{array}{l}5 \\
5\end{array}$ & $\begin{array}{l}26 \\
25\end{array}$ & $\begin{array}{l}191 \\
158\end{array}$ & $\begin{array}{l}555 \\
459\end{array}$ & $\begin{array}{l}0885 \\
0651\end{array}$ & $\begin{array}{l}159 \\
142\end{array}$ & $\begin{array}{r}187 \\
147\end{array}$ & $\begin{array}{l}544 \\
430\end{array}$ & & & $\begin{array}{l}0958 \\
0696\end{array}$ & $\begin{array}{l}176 \\
162\end{array}$ & $\begin{array}{l}1700 \\
1302\end{array}$ & $\begin{array}{l}313 \\
303\end{array}$ \\
\hline $\begin{array}{l}26 \\
26\end{array}$ & $\begin{array}{l}5 \\
5\end{array}$ & $\begin{array}{l}25 \\
28\end{array}$ & $\left\{\begin{array}{l}143 \\
123 .\end{array}\right.$ & $\begin{array}{l}415 \\
357\end{array}$ & $\begin{array}{l}0559 \\
0344\end{array}$ & $\begin{array}{l}139 \\
096\end{array}$ & $\begin{array}{l}130 \\
115\end{array}$ & $\begin{array}{l}380 \\
333\end{array}$ & & & $\begin{array}{l}0602 \\
0536\end{array}$ & $\begin{array}{l}158 \\
161\end{array}$ & $\begin{array}{l}1083 \\
0962\end{array}$ & $\begin{array}{l}285 \\
289\end{array}$ \\
\hline $\begin{array}{l}17 \\
27\end{array}$ & $\begin{array}{l}4 \\
4\end{array}$ & $\begin{array}{l}45 \\
45\end{array}$ & $\begin{array}{l}356 . \\
300\end{array}$ & $\begin{array}{l}972 \\
841\end{array}$ & $\begin{array}{l}1900 \\
1470\end{array}$ & $\begin{array}{l}195 \\
175\end{array}$ & $\begin{array}{l}374 \\
321\end{array}$ & $\begin{array}{r}1025 \\
880\end{array}$ & $\begin{array}{l}1013 \\
775\end{array}$ & $\begin{array}{l}99 \\
88\end{array}$ & & & & \\
\hline $\begin{array}{l}27 \\
27\end{array}$ & $\begin{array}{l}4 \\
4\end{array}$ & $\begin{array}{l}45 \\
45\end{array}$ & $\begin{array}{l}274 \\
2 \%\end{array}$ & $\begin{array}{l}748 \\
645\end{array}$ & $\begin{array}{l}1192 \\
0940\end{array}$ & $\begin{array}{c}1601 \\
146\end{array}$ & $\begin{array}{l}282 \\
242\end{array}$ & $\begin{array}{l}773 \\
663\end{array}$ & $\begin{array}{l}724 \\
574\end{array}$ & $\begin{array}{l}94 \\
87\end{array}$ & & & & \\
\hline 27 & 4 & 45 & 209 & 571 & 0771 & 135 & 213 & 584 & 535 & 92 & & & & \\
\hline 27 & 4 & 45 & 160 & 437 & 0526 & 121 & 167 & 446 & 399 & 89 & & & & \\
\hline 27 & 4 & 44 & 108 & 295 & 0329 & 111 & 106 & 291 & 245 & 84 & & & & \\
\hline 28 & 4 & 43 & 359 & 487 & 2100 & 213 & & & & & & & & \\
\hline $\begin{array}{l}48 \\
28\end{array}$ & $\begin{array}{l}4 \\
4\end{array}$ & $\begin{array}{l}43 \\
43\end{array}$ & $\begin{array}{l}330 \\
302\end{array}$ & $\begin{array}{l}907 \\
830\end{array}$ & $\begin{array}{l}1773 \\
1498\end{array}$ & $\begin{array}{l}196 \\
181\end{array}$ & & & & & & & & \\
\hline $\begin{array}{l}28 \\
28\end{array}$ & 4 & $\begin{array}{l}43 \\
43\end{array}$ & $\begin{array}{l}277 \\
225\end{array}$ & $\begin{array}{l}761 \\
619\end{array}$ & $\begin{array}{l}1302 \\
0927\end{array}$ & $\begin{array}{l}171 \\
150\end{array}$ & & & & & & & & \\
\hline 28 & 4 & 43 & 192 & 528 & 0690 & $|3|$ & & & & & & & & \\
\hline 28 & 4 & 43 & 140 & 385 & 0462 & 120 & & & & & & & & \\
\hline 28 & 4 & 42 & 097 & 267 & 0300 & 112 & & & & & & & & \\
\hline 30 & 5 & 33 & 342 & 971 & 2300 & 237 & & & & & & & & \\
\hline 30 & 5 & 33 & 310 & 880 & 1895 & 215 & & & & & & & & \\
\hline 30 & 5 & 33 & 271 & 770 & 1487 & 193 & 290 & 826 & 655 & 79 & & & & \\
\hline $\begin{array}{l}30 \\
30\end{array}$ & $\begin{array}{l}5 \\
5\end{array}$ & $\begin{array}{l}33 \\
33\end{array}$ & $\begin{array}{l}246 \\
226\end{array}$ & $\begin{array}{l}699 \\
642\end{array}$ & $\begin{array}{l}1238 \\
1082\end{array}$ & 177 & $\begin{array}{l}259 \\
219\end{array}$ & $\begin{array}{l}737 \\
624\end{array}$ & $\begin{array}{l}576 \\
505\end{array}$ & $\begin{array}{l}79 \\
81\end{array}$ & & & & \\
\hline 30 & 5 & 33 & 195 & 554 & 087 & 159 & 192 & 547 & 410 & 75 & & & & \\
\hline 30 & 5 & 33 & 152 & 432 & 0587 & 134 & 156 & 445 & 280 & 63 & & & & \\
\hline 30 & 5 & 33 & 120 & 34 & 0391 & 115 & 126 & 359 & 261 & 73 & & & & \\
\hline 30 & 5 & 30 & 073 & 208 & 0249 & 119 & 080 & 229 & 169 & 74 & & & & \\
\hline 40 & 5 & 21 & & & & & 085 & 252 & 140 & 56 & 0322 & 128 & 0608 & 241 \\
\hline 40 & 5 & 17 & & & & & 040 & 120 & 098 & 82 & 0173 & 144 & 0302 & 251 \\
\hline 40 & 5 & 15 & & & & & 033 & 100 & 052 & 52 & 0101 & 101 & $\Delta 212$ & 212 \\
\hline 41 & 6 & 21 & 051 & 151 & 0137 & 091 & 051 & 151 & 091 & 60 & 0188 & 124 & 0334 & 221 \\
\hline 41 & 6 & 21 & 104 & 308 & 0359 & 117 & 050 & 148 & 096 & 65 & 0185 & 124 & 0332 & 224 \\
\hline 41 & 6 & 22 & 086 & 255 & $\triangle 285$ & $1 / 2$ & 099 & 293 & 172 & 59 & 0367 & 125 & 0682 & 233 \\
\hline 41 & 6 & 21 & 062 & 184 & 0191 & 104 & 091 & 270 & 153 & 57 & 0346 & 128 & 0624 & 231 \\
\hline 41 & 6 & 18 & 045 & 133 & 0145 & 109 & 081 & 239 & 137 & 57 & 0305 & 128 & 0578 & 241 \\
\hline 41 & 6 & 14 & 032 & 095 & 0081 & 085 & 058 & 172 & 1.9 & 64 & 0211 & 123 & 0403 & 203 \\
\hline 4 & 6 & 11 & 029 & 088 & 0094 & 107 & 042 & 126 & 070 & 56 & 0170 & 135 & 0299 & 237 \\
\hline 41 & 6 & 11 & 029 & 088 & 0101 & 115 & .31 & 094 & 052 & 55 & 0119 & 127 & 0203 & 41 \\
\hline 41 & 6 & 11 & 032 & 095 & 0096 & 101 & 031 & 095 & of 5 & 47 & 0099 & 104 & 0217 & 229 \\
\hline 42 & 5 & 31 & 130 & 371 & 0428 & 115 & 127 & 364 & 276 & 76 & 0535 & 147 & 0927 & 255 \\
\hline 42 & 5 & 32 & 115 & 329 & 0373 & 113 & 113 & 323 & 24 & 75 & 0469 & 145 & 0833 & 258 \\
\hline 42 & 5 & 33 & 104 & 297 & 0333 & 112 & 104 & 296 & 211 & 71 & 0430 & 145 & 0760 & 257 \\
\hline 42 & 5 & 32 & 096 & 274 & 0324 & 118 & 095 & 271 & 230 & 85 & 0425 & 157 & 0742 & 274 \\
\hline 42 & 5 & 31 & 087 & 249 & 0272 & 109 & 084 & 241 & 197 & 82 & 0366 & 152 & 0642 & 266 \\
\hline 42 & 5 & 27 & 064 & 183 & 0210 & 115 & 062 & 180 & 128 & 71 & 0252 & 140 & 0448 & 249 \\
\hline 42 & 5 & 23 & 054 & 155 & 0185 & 119 & 054 & 159 & 126 & 79 & 0209 & 131 & 0398 & 251 \\
\hline 43 & 5 & 11 & 050 & 153 & & & 050 & 153 & 100 & 65 & 0190 & 124 & 0318 & 208 \\
\hline 43 & 5 & 20 & 061 & 18. & & & ا & 180 & 132 & 73 & 0225 & 125 & 0419 & 233 \\
\hline 43 & 5 & 28 & 078 & 224 & & & 078 & 224 & 155 & 69 & 0309 & 139 & 0550 & 245 \\
\hline 43 & 5 & 34 & 093 & 263 & & & 093 & 263 & 215 & $8 i$ & 0387 & 147 & D7ll & 270 \\
\hline 43 & 5 & 39 & 182 & 284 & & & 102 & 284 & 229 & 81 & 0438 & 154 & 0804 & 283 \\
\hline 43 & 5 & 10 & 049 & 151 & & & 049 & 151 & 095 & 63 & 0171 & 113 & 0309 & 205 \\
\hline
\end{tabular}


APPENDIX 3.2. OASERVATIONAL DATA FOR WIMDOWS $4,8,11$ AMD 13 (LONDON).

$$
\begin{aligned}
& \text { P- PatH LeNGTH :- } 2-115.5 \mathrm{~m} \text {. TT - Temperature, "C. }
\end{aligned}
$$

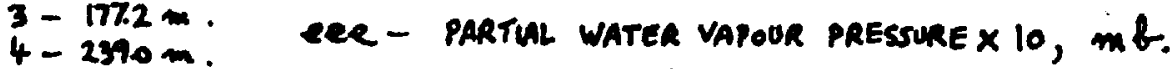

$$
\begin{aligned}
& 5-3007 \mathrm{~m} \text {. Mmmm- MASS OF WATER VAPOUR W PATH } \times 1000 \\
& \text { 7 - } 362.4 \mathrm{~m} \text {. (SCALED TO A PATH LEMATH OF FO2 } \mathrm{m} \text { ), } \mathrm{g} \mathrm{cm}^{-2} \text {. } \\
& \text { 8-485.9 m. } \quad S_{i} \text { - SIGMal IN WINDOW } i .\left(\lg _{e} S_{i}\right. \text { is } \\
& \text { SCALED TO A PATH LEMGTH OF } 402 \mathrm{~m} \text { ). }
\end{aligned}
$$

\begin{tabular}{|c|c|c|c|c|c|c|c|c|c|c|c|c|c|c|}
\hline $\begin{array}{l}\text { Rou } \\
\text { No. }\end{array}$ & & eve & $\operatorname{mmm}$ & $\lg _{e} s_{i}$ & Riven $p$ & & eee & $\operatorname{minm}$ & $\log _{i}$ & Row $p$ & $P$. & ese & $\operatorname{manm}$ & 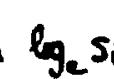 \\
\hline \multirow[t]{3}{*}{ 이 } & $\begin{array}{ll}4 & 31 \\
312\end{array}$ & $\begin{array}{l}112 \\
159\end{array}$ & $\begin{array}{l}318 \\
453\end{array}$ & $\begin{array}{l}121 \\
179\end{array}$ & 035 & $\begin{array}{l}38 \\
39\end{array}$ & $\begin{array}{l}208 \\
250\end{array}$ & $\begin{array}{l}581 \\
698\end{array}$ & $\begin{array}{l}196 \\
233\end{array}$ & 075 & $\begin{array}{r}527 \\
29\end{array}$ & $\begin{array}{l}191 \\
231\end{array}$ & $\begin{array}{l}553 \\
665\end{array}$ & $\begin{array}{l}301 \\
327\end{array}$ \\
\hline & $\begin{array}{l}32 \\
32\end{array}$ & $\begin{array}{l}182 \\
208\end{array}$ & $\begin{array}{l}519 \\
595\end{array}$ & $\begin{array}{l}239 \\
241\end{array}$ & & $\begin{array}{l}39 \\
40\end{array}$ & $\begin{array}{l}278 \\
313\end{array}$ & $\begin{array}{l}773 \\
815\end{array}$ & $\begin{array}{l}263 \\
307\end{array}$ & & $\begin{array}{l}31 \\
33\end{array}$ & $\begin{array}{l}262 \\
291\end{array}$ & $\begin{array}{l}748 \\
825\end{array}$ & $\begin{array}{l}364 \\
441\end{array}$ \\
\hline & $\begin{array}{l}32 \\
33\end{array}$ & $\begin{array}{l}257 \\
281\end{array}$ & $\begin{array}{l}735 \\
800\end{array}$ & $\begin{array}{l}320 \\
385\end{array}$ & 036 & $\begin{array}{l}30 \\
38\end{array}$ & $\begin{array}{l}107 \\
172\end{array}$ & $\begin{array}{l}306 \\
481\end{array}$ & $\begin{array}{l}088 \\
140\end{array}$ & 076 & $\begin{array}{r}6 \quad 23 \\
27\end{array}$ & $\begin{array}{l}142 \\
192\end{array}$ & $\begin{array}{l}417 \\
558\end{array}$ & $\begin{array}{l}131 \\
185\end{array}$ \\
\hline & 31 & 132 & 377 & 301 & & $x$ & 203 & 568 & 173 & & 30 & 232 & 165 & 236 \\
\hline \multirow[t]{3}{*}{02} & 336 & 132 & 370 & 112 & & 39 & 250 & 698 & 215 & & 31 & 262 & 750 & 303 \\
\hline & 37 & 182 & 500 & $|6|$ & & 39 & 275 & 767 & 238 & & 39 & 293 & 831 & 428 \\
\hline & 38 & 243 & 677 & 265 & & 40 & 307 & 850 & 302 & 077 & 723 & $14 ?$ & 418 & 133 \\
\hline & 39 & 290 & 805 & 341 & 037 & 30 & 107 & 307 & 070 & & 27 & 119 & 545 & 209 \\
\hline & 3 & 340 & 945 & 382 & & 38 & 169 & 475 & 127 & . & 30 & 232 & 667 & 231 \\
\hline & 38 & 365 & 1020 & 403 & & 38 & 200 & 561 & 165 & & 31 & 262 & 751 & 273 \\
\hline \multirow[t]{6}{*}{03} & 230 & 109 & 310 & $170^{\circ}$ & & 39 & 244 & 680 & 182 & & 33 & 299 & 828 & 328 \\
\hline & 38 & 175 & 488 & 241 & & 39 & $2 \pi 3$ & 760 & 203 & 274 & 45 & 356 & 972 & 424 \\
\hline & 38 & 2.12 & 592 & 262 & & to : & $3 d t$ & 845 & 252 & & 45 & 308 & 841 & 387 \\
\hline & 39 & 258 & 718 & 288 & 072 & 21 & 135 & 377 & 125 & & 45 & 274 & 748 & $3+2$ \\
\hline & 39 & 288 & 77 & 349 & & 26 & 189 & 547 & 222 & & 45 & 236 & 645 & 265 \\
\hline & 40 & 325 & 848 & 383 & & 29 & 234 & 672 & 317 & & 45 & 209 & 571 & 217 \\
\hline \multirow[t]{6}{*}{03} & 330 & 107 & 304 & 108 & & 29 & 220 & 630 & 343 & 284 & -3 & 359 & 97 & 340 \\
\hline & 38 & 172 & 480 & 204 & & 31 & 267 & 759 & 412 & & 43 & 330 & 907 & 290 \\
\hline & 38 & 207 & 580 & 234 & & 33 & 300 & 850 & Sol & & 43 & 302 & 130 & 256 \\
\hline & 39 & 258 & 716 & 289 & o7 3 & 22 & 137 & 404 & do & & 43 & 277 & 761 & 257 \\
\hline & 39 & 287 & 800 & 314 & & 26 & 191 & 553 & 186 & & 43 & 225 & 619 & (91 \\
\hline & 40 & 319 & 805 & 344 & & 292 & 235 & 677 & 196 & & 43 & 192 & 528 & 163 \\
\hline \multirow[t]{6}{*}{03} & 430 & 110 & 317 & 112 & & $3 i$ & 265 & 757 & 280 & & 43 & 140 & 385 & 094 \\
\hline & 38 & 170 & 475 & 187 & & 33 & $2 \pi$ & 833 & 314 & & $k 2$ & 097 & 267 & -038 \\
\hline & 38 & 208 & 583 & 227 & 074 & 22 & 138 & 406 & 118 & 425 & 31 & 130 & 371 & 322 \\
\hline & 39 & 253 & 707 & 314 & & 26 & 191 & 554 & 204 & & 32 & 115 & 329 & 317 \\
\hline & & 283 & 791 & 338 & & 29 & 234 & 670 & 247 & & 33 & 1.4 & 297 & 328 \\
\hline & to & 315 & 875 & 344 & & $3 i$ & 265 & 758 & 283 & & 32 & 096 & 274 & 277 \\
\hline \multirow[t]{2}{*}{03} & 30 & 107 & 306 & 102 & & 33 & 295 & 838 & 337 & & 31 & 087 & 249 & 268 \\
\hline & 38 & 170 & 475 & 161 & of 5 & 23 & 140 & 413 & 182 & & 27 & 064 & 183 & 175 \\
\hline
\end{tabular}

WINDOW 4 


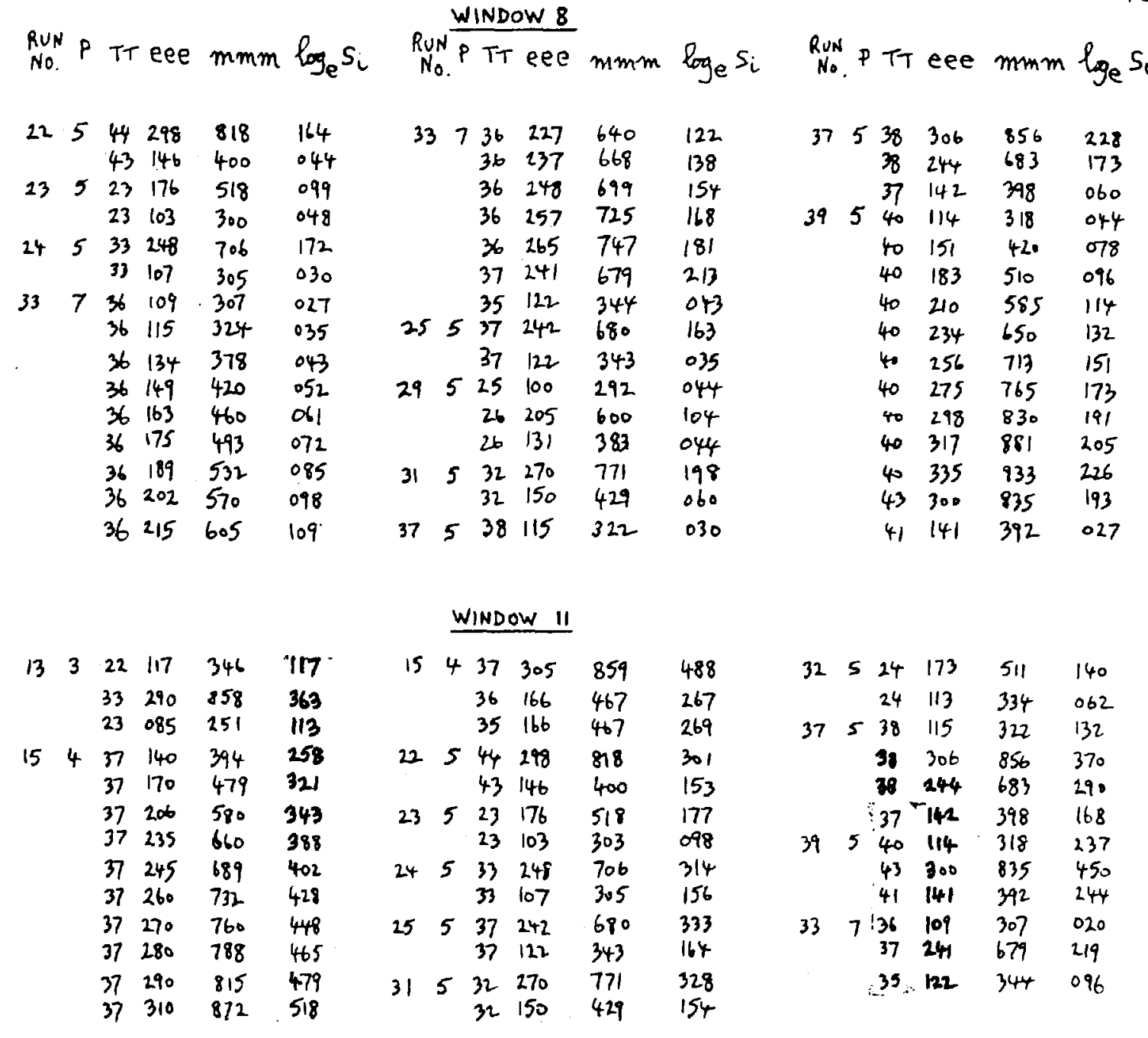

WINDOW 13

\begin{tabular}{|c|c|c|c|c|c|c|c|c|c|c|c|c|c|c|c|c|c|}
\hline \multirow[t]{8}{*}{16} & 4 & $\begin{array}{l}35 \\
36\end{array}$ & $\begin{array}{l}147 \\
150\end{array}$ & $\begin{array}{l}415 \\
423\end{array}$ & $\begin{array}{l}309 \\
305\end{array}$ & 19 & 5 & $\begin{array}{l}22 \\
21\end{array}$ & $\begin{array}{l}155 \\
1.1\end{array}$ & $\begin{array}{l}459 \\
299\end{array}$ & $\begin{array}{l}137 \\
073\end{array}$ & 29 & 5 & $\begin{array}{l}26 \\
26\end{array}$ & $\begin{array}{l}205 \\
131\end{array}$ & $\begin{array}{l}600 \\
383\end{array}$ & $\begin{array}{l}271 \\
182\end{array}$ \\
\hline & & $\begin{array}{l}36 \\
36\end{array}$ & $\begin{array}{l}162 \\
180\end{array}$ & $\begin{array}{l}457 \\
508\end{array}$ & $\begin{array}{l}319 \\
350\end{array}$ & 20 & 8 & $\begin{array}{l}23 \\
22\end{array}$ & $\begin{array}{l}193 \\
105\end{array}$ & $\begin{array}{l}570 \\
311\end{array}$ & $\begin{array}{l}272 \\
135\end{array}$ & 31 & 5 & $\begin{array}{l}32 \\
32\end{array}$ & $\begin{array}{l}270 \\
150\end{array}$ & $\begin{array}{l}771 \\
429\end{array}$ & $\begin{array}{l}460 \\
222\end{array}$ \\
\hline & & $\begin{array}{l}36 \\
36\end{array}$ & $\begin{array}{l}195 \\
215\end{array}$ & $\begin{array}{l}550 \\
606\end{array}$ & $\begin{array}{l}379 \\
415\end{array}$ & 21 & 8 & $\begin{array}{l}41 \\
40\end{array}$ & $\begin{array}{l}285 \\
253\end{array}$ & $\begin{array}{l}793 \\
T_{04}\end{array}$ & $\begin{array}{l}372 \\
340\end{array}$ & 32 & 5 & $\begin{array}{l}24 \\
24\end{array}$ & $\begin{array}{l}173 \\
113\end{array}$ & $\begin{array}{l}511 \\
334\end{array}$ & $\begin{array}{l}153 \\
053\end{array}$ \\
\hline & & $\begin{array}{l}36 \\
36\end{array}$ & $\begin{array}{l}235 \\
255\end{array}$ & $\begin{array}{l}663 \\
720\end{array}$ & $\begin{array}{l}450 \\
410\end{array}$ & & & $\begin{array}{l}38 \\
39\end{array}$ & $\begin{array}{l}138 \\
141\end{array}$ & $\begin{array}{l}386 \\
395\end{array}$ & $\begin{array}{l}186 \\
186\end{array}$ & 33 & 7 & $\begin{array}{l}36 \\
37\end{array}$ & $\begin{array}{l}109 \\
241\end{array}$ & $\begin{array}{l}307 \\
679\end{array}$ & $\begin{array}{l}143 \\
378\end{array}$ \\
\hline & & $\begin{array}{l}36 \\
36\end{array}$ & $\begin{array}{l}276 \\
304\end{array}$ & $\begin{array}{l}779 \\
857\end{array}$ & $\begin{array}{l}529 \\
575\end{array}$ & 22 & 5 & $\begin{array}{l}44 \\
43\end{array}$ & $\begin{array}{l}291 \\
146\end{array}$ & $\begin{array}{l}818 \\
400\end{array}$ & $\begin{array}{l}352 \\
173\end{array}$ & 37 & 5 & $\begin{array}{l}35 \\
38\end{array}$ & $\begin{array}{l}122 \\
306\end{array}$ & $\begin{array}{l}344 \\
856\end{array}$ & $\begin{array}{l}198 \\
581\end{array}$ \\
\hline & & 36 & $32-3$ & 910 & 615 & 23 & 5 & 33 & 176 & 518 & 209 & & & 38 & 144 & 683 & 472 \\
\hline & & 37 & 325 & 917 & 615 & & & 33 & 103 & 303 & 106 & & & 37 & 142 & 398 & 293 \\
\hline & 5 & $\begin{array}{l}32 \\
21\end{array}$ & $\begin{array}{l}119 \\
100\end{array}$ & $\begin{array}{l}340 \\
296\end{array}$ & $\begin{array}{l}270 \\
108\end{array}$ & 24 & 5 & $\begin{array}{l}33 \\
73\end{array}$ & $\begin{array}{l}248 \\
107\end{array}$ & $\begin{array}{l}706 \\
305\end{array}$ & $\begin{array}{l}388 \\
196\end{array}$ & 39 & 5 & $\begin{array}{l}40 \\
43\end{array}$ & $\begin{array}{l}114 \\
300\end{array}$ & $\begin{array}{l}318 \\
835\end{array}$ & $\begin{array}{l}260 \\
530\end{array}$ \\
\hline & & 23 & 174 & 515 & 164 & 29 & 5 & 25 & 100 & 292 & 134 & & & 41 & 141 & 392 & 260 \\
\hline
\end{tabular}




\title{
REFERENCEES
}

\author{
Adel, $A$. \\ Anderson, P.W. \\ Anthony, $\mathrm{R}$. \\ Bastin, J.A., Gear, A.E., \\ Jones, G,O., Smith H.J.T., and \\ Wright, P.J. \\ Benedict, W.S.
}

1939 Astrophys. J. 89, I.

1949 Phys. Rev. 76, 647.

1952 Ibid, 85,674

1964 Proc. Roy. Scc. (A) $278,543$.

1955 Conference on Broadening of Spectral Lines, University of Pittsburgh, 1955.

Benedict, W.S. and Kaplan, L.D. 1963 'Parameters for water vapour rotational lines'. To be published.

Benedict, W.S. and Kaplan, L.D. 1964 J. of quant. Spect. and Rad. Transfer, 4,453 .

Bignell, K.J., Saiedy, F., 1963 J. Opt. Soc. Amer. 53, 466.

and Sheppard, P.A.

Bolle, H.J., Moller, F., and 1963 Tech Report No. 2, Contract $\triangle F 61$

Zdunkowski, $W$. (052) -488 .

Bolle, HeJ.

1964 Paper presented at the International Sympossium on Radiation Processes, Leningrad, Aug. 1964.

Dave, J.V., Sheppard, P.A., and 1963 quart. J. Roy. Met. Soc. 89, 307. Wal shaw, C.D.

Deirmendjian, D.

1959 Ibid, 85, 404.

1960 Ibid, 86, 371. 
Dorsey, E.N.

Elsasser, W.M.

Gebbie, H.A., Harding W.R., Hilsum, C., Pryce, A., and

Roberts, V.

Goody, R.M.

Goody, R.M.

Kaplan, I.D。

Kaplan, I.D. and
Lindholm, E.

Middleton, W.E.K.

Migeotte, M., Neven, I., and Swensson, J.

Möller, F.

Nordberg, W., Bandeen, W.R., Conrath, B.J., Kunde, V.,

Persano, I.
1940 'Properties of Ordinary Water

$$
\begin{aligned}
& \text { Substancel, (Reinhold Publishing } \\
& \text { Corporation, New York). }
\end{aligned}
$$

1938 Phys. Rev. 53, 768.

1951 Proc. Roy. Soc. (A) 206, 87

1957 Quart.J. Roy. Met. Soc. 83, 517.

1964 'Atmospheric Radiation', Vol I, (Clarend on Press, oxford).

1953 Proc. Toronto Met. Conference, 1953, p.45.

1956 J. Chem. Phys. 25, 876.

1945 Ark. Mat. Astr. Fy s. Stockholm 32a, No. 17 .

1952 'Vision Through the Atmosphere'

(The University of Toronto Press, Toronto, Canada, 1952)。

1956/7 Mem. Soc. Roy. Sci. Liege, Vol. Hors Ser. 1 and 2. 1942 Beitr. Geophysik 58, 27.

1962 J. Atm. Sci. 19, 20. 
Palmer, C.H., Jr.

Penndorf, R, B.

Plyler, E.K. and Acquista, N. 1954 Ibid. 44, 505

Roach, W.T. and Goody, R.M.

Saiedy, F.

Strong, J. 1957a J. Opt. Soc. Amer. 47, 367

1957b Ibid. 47, I024.

19570 Ibid. 47, 1028.

1960 Ibid. 50, 1232.

1962 Ibid. 52, 896.

1958 Quart. J。 Roy. Met. Soc. 84, 319.

1959 Mon. Not. Roy. Ast. Soc. 119, 213.

1940 'Modern Physical Laboratory Practice' (BIackie and Son Ltd., London, 1940)

Taylor, J.H. and Yates, H.W. 1957 J. Cpt, Amer., 47, 223.

Van Vleck, J.H. and Weisskopf,V.1945 Rev. Mod. Phys. 1I, 227. Vigroux, F. 1959 Ann. Geophys. 15, 453.

White, J.ण. 1942 J. Opt. Soc. Amer. 32, 285

Wright, H.I.

Yates, H.W. and Taylor, J.H. 1960 NRL report No. 5453, AD NO. 2401.88. 


\section{ACKNOWLEDGENEANIS}

I am indebted to Dr. S.D. Smith who arouged my interest in infrared techniques, and who suggested this problem to me. I am also indebted to Professor P.A. Sheppard for supervising the research and for many fruitful discussions; to Dr. F. Saiedy who degigned the horizontal path optics at Ascot and enlightened me on many occasions; to the Royal Society for a research studentship during part of the research; to Mr. D. Tribble who designed and constructed the electrical wet bulb sensors; to Dr. J.T. Houghton and Mr.C. Farmer for the loan of Golay cells during part of the research; to Mr. D.A. Rogers who constructed much of the equipment and Mr. A. Pusey who assisted in observing and reduction of data; To Miss M. Street for computing and to Mr. E.G. Jennings and the Workshop staff for their unfailing belp over a long period. 
Reprinted from Journal of the Optical Society of America, Vol. 53, No. 4, 466-479, April, 1963

Printed in U. S. A.

\title{
On the Atmospheric Infrared Continuum
}

\author{
K. Bigneli, F. Satedy,* and P. A. Sheppard \\ Imperial College, London, S.W.7
}

(Received 7 September 1962)

\begin{abstract}
Observations of extinction in the atmospheric continuum at 19 frequencies between 1202 and $479 \mathrm{~cm}^{-1}$ have been made by two methods: (I) solar absorption, between 1202 and $790 \mathrm{~cm}^{-1}$; (II) 200 and $400 \mathrm{~m}$ horizontal paths using a Nernst source, between 716 and $479 \mathrm{~cm}^{-1}$. Method $I$ was made absolute by reference to a blackbody; Method II provided extinction coefficients relative to that for $1119 \mathrm{~cm}^{-1}$, given by Method I. In Method I, the water vapor in the path was deduced from the area of the line at $871 \mathrm{~cm}^{-1}$, and some measure of the particulate matter in the path was obtained from the extinction in the visible. In Method II, the horizontal visibility was used for the latter purpose, and observations with a cell of pure $\mathrm{CO}_{2}$ were made in order to determine the limits of $\mathrm{CO}_{2}$ absorption.

The following conclusions are drawn from the observations: (1). The results strongly support Elsasser's suggestion that the continuum is mainly due to the accumulated wings of distant lines in the water-vapor bands at 1595 and $200 \mathrm{~cm}^{-1}$. The observed absorption coefficient increases from $0.06 \mathrm{~g}^{-1} \mathrm{~cm}^{2}$ at $1100 \mathrm{~cm}^{-1}$ to about $4.1 \mathrm{~g}^{-1} \mathrm{~cm}^{2}$ at $480 \mathrm{~cm}^{-1}$, though nearby lines account for half of the latter. (2) None of the line shapes examined gives a satisfactory representation of the continuum over the whole range studied, though Lorentz shape, in both approximate and exact form, gives qualitative agreement with observation. (3) In the interpretation of the observations reported here, $\mathrm{CO}_{2}$ absorption may be ignored outside the frequency range 790 to $560 \mathrm{~cm}^{-1}$. It is much more confined than would be the case if the $\mathrm{CO}_{2}$ line wings had Lorentz structure. (4) The extinction due to particulate matter is small compared with that due to water vapor throughout the range observed, except under very hazy dry conditions. (5) Evidence is presented for a considerable self-broadening effect (about 30 times air broadening), and if correct, this will be of the utmost importance in the analysis of remote terrestrial radiation measurements which involve correction for the water-vapor continuum. This must, however, be confirmed under controlled conditions.
\end{abstract}

\section{INTRODUCTION}

$T$ HE existence of a continuum (Lambert's law absorption) in the so-called atmospheric window between 8 and $13 \mu$ and beyond, due to the wings of strong lines in the water-vapor bands on either side of the window, was first suggested by Elsasser (1938). Moller (1942) demonstrated its probable meteorological importance in representative conditions by calculating a cooling rate of about $1^{\circ} \mathrm{C} /$ day for the first two kilometers of the atmosphere, assuming a continuum absorption coefficient $\beta$ of 0.1 per unit air mass around $10 \mu$.

Observations on the transmission of infrared radiation through the atmosphere, using low-resolution spectrometry $\left(\sim 10 \mathrm{~cm}^{-1}\right.$ at $\left.1000 \mathrm{~cm}^{-1}\right)$ (a) over a long horizontal path (Gebbie et al., 1951; Taylor and Yates, 1957), and (b) using the sun as source (Adel, 1939; Anthony, 1952), showed the existence of larger attenuations than would be expected from selective absorption alone, while later, Roach and Goody (1958), from observations on the sun with a resolution of $7 \mathrm{~cm}^{-1}$, estimated a continuum absorption as a function of water vapor in the path from the combined effects of continuum and selective absorption. In the latter work, error in determining the amount of water vapor in the path, lack of data on atmospheric aerosol (already suggested as making a significant contribution to the atmospheric continuum), and the difficulty of separating selective and continuous absorption prevented a firm conclusion on the nature of the continuum.

The present paper describes new measurements made by relatively high-resolution spectrometry in order to

${ }^{*}$ Now at Meteorological Office, Damascus, Syria. obtain more precise information on the continuum and its origin. Two methods of observation have been used :

Method I: Measurement of continuum extinction between $832 \mathrm{~cm}^{-1}$ and $1202 \mathrm{~cm}^{-1}$, using the sun as source and a high-temperature blackbody as reference. The water vapor in the path was determined by simultaneous measurements of the area of a neighboring $\mathrm{H}_{2} \mathrm{O}$ rotation line and some indication of the aerosol in the path was obtained, in a part of the series, from the extinction in the visible using the Volz (1959) actinometer.

Method II: Measurement of the continuum extinction between 478.0 and $611.2 \mathrm{~cm}^{-1}$ over a horizontal path up to $400 \mathrm{~m}$ in length using a Nernst filament source. Observations were also made using a cell of pure $\mathrm{CO}_{2}, 43 \mathrm{~cm}$ long, in the path to determine the limits beyond which the continuum is not affected by $\mathrm{CO}_{2}$.

The observations were made at Ascot, $40 \mathrm{~km}$ to the west of London.

\section{METHOD I. BASIS}

\section{Let}

$k(\nu, \bar{p}, \bar{T})$ be the continuum mass absorption coefficient at frequency $\nu$, effective mean pressure $\bar{p}$, and mean temperature $T$

$m, c$, the mass of water vapor and carbon dioxide, respectively, in the vertical atmospheric column above unit area;

$\gamma(v)$, the extinction coefficient per unit air mass due to aerosol;

$N$, the air mass (relative to zenith) in line of sight, corrected for earth's curvature and refraction; and 

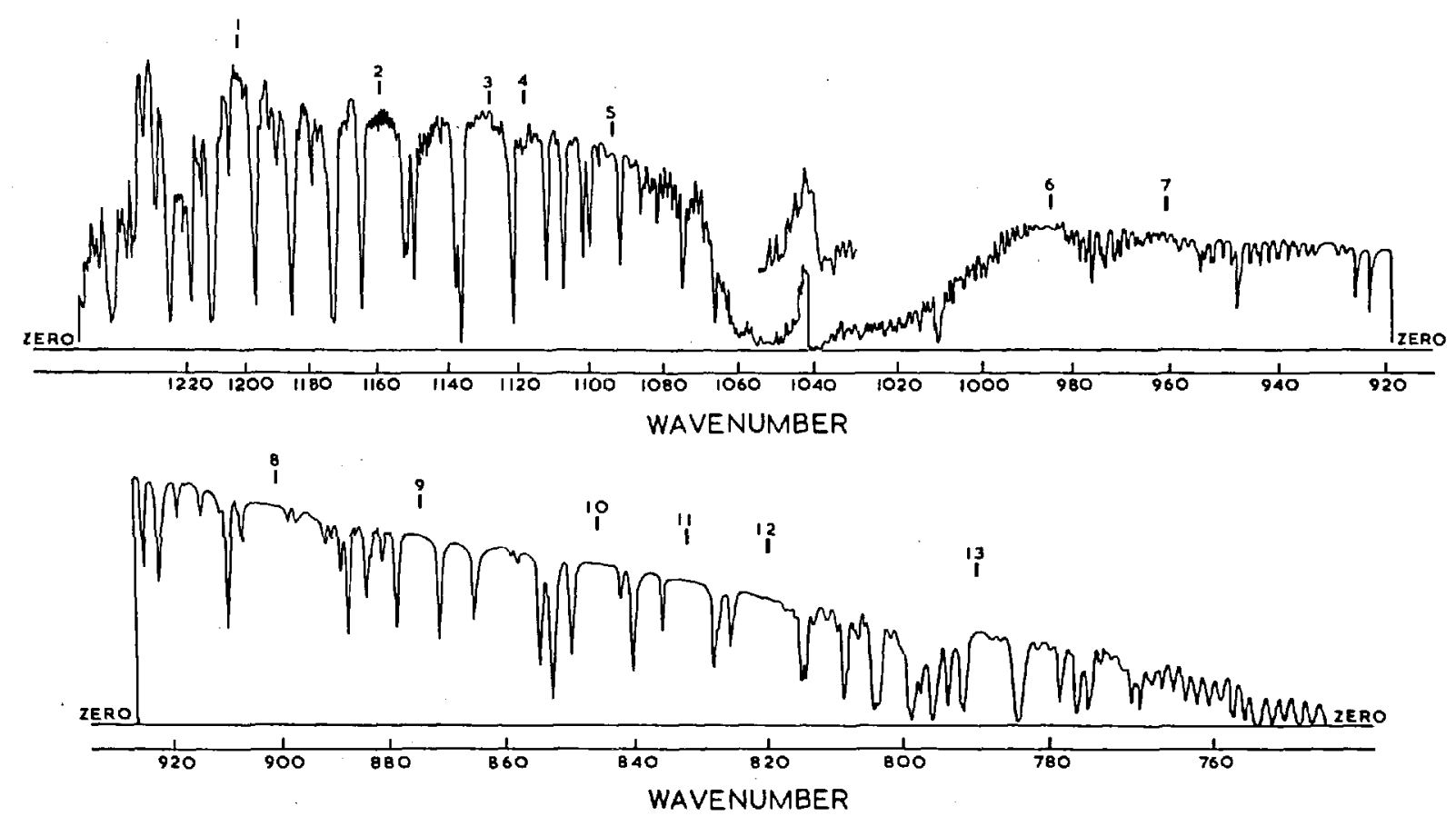

FIG. 1. Solar spectrum showing the windows used for measurement. Regular $\mathrm{N}_{2} \mathrm{O}$ lines may be seen in Window 2. The full spectrum was recorded with an unbloomed indium antimonide filter, while the small section near $1040 \mathrm{~cm}^{-1}$ shows the increased resolution achieved with a bloomed filter.

$I_{0}(v), I(\nu)$, the solar intensity at the top and bottom, respectively, of the earth's atmosphere.

Then, assuming no selective absorption,

where

$$
I(\nu)=I_{0}(\nu) \exp [-N \beta(\nu, \bar{p}, \bar{T})]
$$

$$
\beta(\nu, \bar{p}, \bar{T})=k(\nu, \bar{p}, \bar{T})_{\mathbf{H}_{2} \mathrm{o} m}+k(\nu, \bar{p}, \bar{T})_{\mathrm{CO}_{2}} c+\gamma(\nu) .
$$

Assuming now that the continuum absorption is due to the wings of distant strong lines whose half-width $\alpha_{i}$ is proportional to the effective pressure, $\bar{p}$ (in the absence of self-broadening, which is assumed to be the case, $\bar{p}$ corresponds to the mean air pressure, defined below), then or

$$
\begin{gathered}
\beta(\nu, \bar{p})=k\left(\nu, p_{0}\right)_{\mathrm{H}_{2} \mathrm{O}}\left(\bar{p} / p_{0}\right) m+k\left(\nu, p_{0}\right) \mathrm{CO}_{2} c^{\prime}+\gamma(\nu), \\
\beta(\nu, \bar{p})=k\left(\nu, p_{0}\right)_{\mathrm{H}_{2} \mathrm{O}} m_{\bar{p}}+k\left(\nu, p_{0}\right)_{\mathrm{CO}_{2}} c^{\prime}+\gamma(\nu),
\end{gathered}
$$

where

$$
\bar{p}=\frac{1}{m} \int_{0}^{m} p\left(m^{\prime}\right) d m^{\prime} ;
$$

$p_{0}=$ standard pressure (taken to be $1000 \mathrm{mbar}$ ) ;

$m_{p}=m \bar{p} / p_{0}$;

$c^{\prime}=$ mass of $\mathrm{CO}_{2}$ in the vertical column, scaled for pressure, $=c / 2$ for constant mixing ratio.

The temperature dependence of a continuum due to the wings of distant strong lines is not known, but is likely to be small because line intensities at the center of a band are negatively dependent, and just away from the center are positively dependent, on temperature. As a first approximation, therefore, $k$ is assumed independent of temperature. It then follows from (2.1) and (2.3) that a plot of measured $\beta_{\bar{p}}$ against $m_{\bar{p}}$ will have a slope of $k\left(\nu, p_{0}\right)_{\mathrm{H}_{2} \mathrm{O}}$ and an in tercept of $k\left(\nu, p_{0}\right)_{\mathrm{CO}_{2}} c^{\prime}+\bar{\gamma}(\nu)$ provided $\gamma$ is not correlated with $m_{\bar{p}}$. Differences of $\gamma$ from its mean value $\bar{\gamma}$ will add scatter to the plot. The questions of temperature dependence, self-broadening, and correlation of $\gamma$ with $m_{\bar{p}}$ will be taken up again later in the light of the results.

Regarding the determination of $m_{\bar{p}}$, the equivalent width $W$ of a line in the $\mathrm{H}_{2} \mathrm{O}$ rotation band, in the square-root region of absorption, is related to $m_{\bar{p}}$ by

$$
m_{\bar{p}}=\mathrm{V}^{2} /\left(4 S_{0 \alpha_{0}} \bar{\phi} N^{\top}\right),
$$

where $S_{0}, \alpha_{0}=$ line intensity at $T_{0}\left(273^{\circ} \mathrm{K}\right)$ and half-width at $p_{0}$, and $\bar{\phi}=$ mean temperature factor $=1 / m \int_{0}^{m} \phi\left(m^{\prime}\right) d m^{\prime}$, where $\phi$ is given by Eq. (4) of Saiedy (1961). The constant $S_{0 \alpha_{0}}$ for the particular line chosen $\left(871 \mathrm{~cm}^{-1}\right)$ has been measured by Saiedy (1961). $\vec{\phi}$ for this line was found empirically to be related to the surface dew point $t_{d}\left({ }^{\circ} \mathrm{C}\right)$ by

$$
\bar{\phi}=0.02 t_{d}+0.90 \text {, }
$$

to $\pm 3 \%$ in $\bar{\phi}$, provided no sharp inversion was present. In the latter case $\bar{\phi}$ was calculated from the appropriate upper-air sounding.

The square-root law used in (2.4) is valid for the particular line used $\left(S_{0}=0.444 \mathrm{~g}^{-1} \mathrm{~cm}\right)$ from Schwende- 


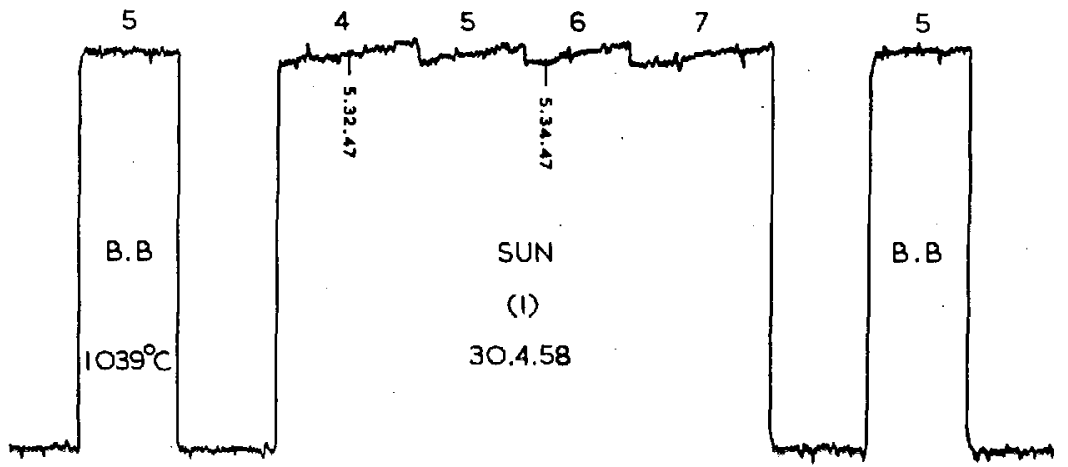

Fig. 2. Typical records of sun and blackbody at $901 \mathrm{~cm}^{-1}(11.10 \mu)$. The electrical attenuator, the time, the sector disk number used, and the temperature of blackbody are shown on the record. The rapid increase of solar intensity in the early morning is illustrated. man and Laurie (1958); $\alpha_{0}=0.047 \mathrm{~cm}^{-1}$ from Benedict and Kaplan (1959), provided $N>1 \mathrm{~g} \mathrm{~cm}^{-2}$, a quantity exceeded throughout the observations reported. The effect of particulate matter, by absorption or scattering, on the equivalent width of a molecular line is negligible since both are slowly varying functions of frequency.

\section{METHOD I. OBSERVATIONAL PROCEDURE}

The infrared spectrometer (see Saiedy and Goody, 1959), was a small double monochromator using a 7 $\times 5 \mathrm{~cm}$ Merton replica grating having 1000 lines $/ \mathrm{cm}$ and blazed for $10 \mu$ in the first-order spectrum. Higher-order spectra of shorter wavelengths were eliminated by means of an indium antimonide filter with an antireflection coating of lead chloride. A Golay cell detector was used, and the radiation was chopped at $11 \mathrm{cps}$. A sample solar spectrum in which the resolution is about $0.3 \mathrm{~cm}^{-1}$ at $1000 \mathrm{~cm}^{-1}$ is shown in Fig. 1. The windows used for measurement are indicated by numbers 1-13 (except Window 4, which was used for Method II), and are listed in Table I.

Absolute measurements of $\beta$ were made in Windows 11 and 8 which are well away from any absorption lines, and in Window 2 where there are some weak $\mathrm{N}_{2} \mathrm{O}$ lines. If the latter are significant they should provide a positive intercept on the $\beta$ axis of the $\beta, m_{\bar{p}}$ plot.

The value of $I(\nu)$ Eq. (2.1) was determined by comparing the solar intensity at these frequencies with that of a blackbody at approximately $1300^{\circ} \mathrm{K}$, the slitwidth being $2 \mathrm{~cm}^{-1}$. Approximate equality $( \pm 1 \mathrm{~dB})$ in signal was achieved by use of an appropriate sector disk (of geometrically determined attenuation) in the solar path, together with a calibrated electrical attenuator. Errors due to nonlinearity in the system were thereby kept to not more than $0.3 \%$. Each solar observation was bracketed between blackbody observations, to allow for slight changes in gain, a representative sequence of observations being shown in Fig. 2 .

The value of $I_{0}(v)[\mathrm{Eq} .(2.1)]$ at the three frequencies has been determined to better than $1 \%$ by Saiedy and Goody (1959) and Saiedy (1960a) and thus $\beta(\nu, \bar{p}, \bar{T})$ can be inferred.

Windows 8 and 11 were examined carefully for any weak absorption lines unreported in the literature, using a slitwidth of $0.4 \mathrm{~cm}^{-1}$ and high water vapor $(\sim 25 \mathrm{~g}$ $\mathrm{cm}^{-2}$ ) in the path to the sun. A weak unreported line was indeed found at $902.7 \mathrm{~cm}^{-1}$ but its intensity, if due to water vapor, is only $0.001 \mathrm{~g}^{-1} \mathrm{~cm}$ and its contribution to the continuum using a slitwidth of $2 \mathrm{~cm}^{-1}$ could not exceed $0.1 \%$. The effect of other neighboring but more distant lines $\left(\sim 10 \mathrm{~cm}^{-1}\right)$ on these windows, assuming Lorentz line shape, is less than $1 \%$.

In addition to the absolute determination of $\beta$ for windows 2,8 , and 11 , relative values of $\beta$ were obtained for these and nine other windows (see Table I) between 790 and $1202 \mathrm{~cm}^{-1}$, so as to delineate the frequency

TABLE I. Details of frequencies used in Method I and observed continuum extinction (comparison method).

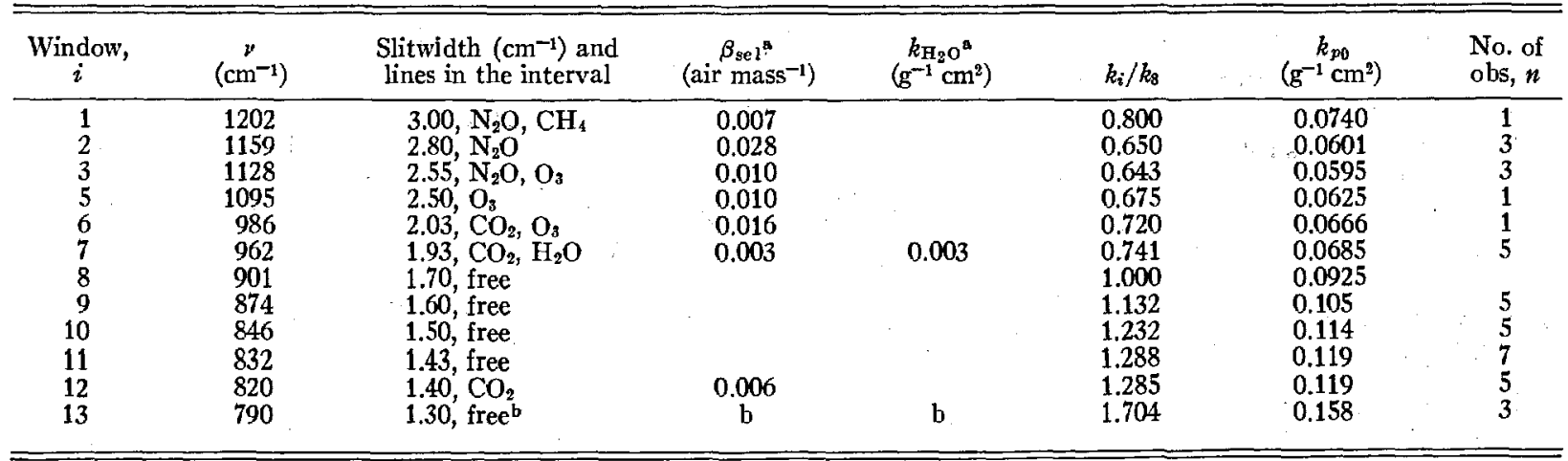

a $\beta_{\mathrm{tel}}$ is the computed selective extinction coefficient for $\mathrm{N}_{2} \mathrm{O}, \mathrm{CO}_{2}, \mathrm{O}_{3}$, and $\mathrm{CH}_{4}$, and $k_{\mathrm{H}} \mathrm{O}$ is that for $\mathrm{H}_{2} \mathrm{O}$, for the lines in each window.

$b$ The contribution from nearby strong $\mathrm{CO}_{2}$ and $\mathrm{H}_{2} \mathrm{O}$ lines may be appreciable. The absorption coefficients $k_{p_{0}}$ are computed from $k_{i} / k_{3}$ (mean of $n$ obs taking $k_{\mathrm{g}}=0.0925 \mathrm{~g}^{-1} \mathrm{~cm}^{2}$ from Sec. 4 . 
Fig. 3. Observations of continuum extinction coefficient per unit air mass, $\beta_{\vec{p}}$, for (a) Window $11\left(832 \mathrm{~cm}^{-1}\right)$, (b) Window $8\left(901 \mathrm{~cm}^{-1}\right)$, and (c) Window 2 (1159 $\mathrm{cm}^{-1}$ ) as a function of scaled water vapor in the zenith.

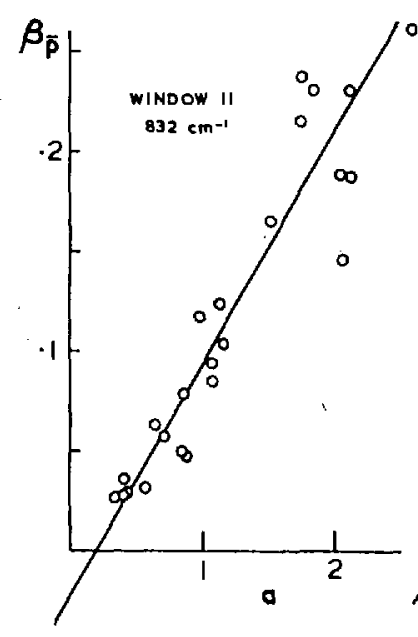

dependence of $\beta(\nu)$ more precisely by avoiding error in the absolute measurement of intensities. For this purpose series of observations of relative intensity as a function of air mass were made at several frequencies on suitable clear days, the slope of the regression of $\log$ (relative intensity) against air mass providing $\beta$. A constant geometrical slitwidth was used in these observations (see Table I). Since only half the number of windows chosen could be included in one observational day, Window 8 was used as the normalizing point between the two sections of the spectrum to allow for changes in water vapor, etc., from day to day. Blackbody observations at one frequency were used to measure the gain change during a run and the solar signal was kept close to that of the blackbody by means of the sector disks. At frequencies above $960 \mathrm{~cm}^{-1}$ all windows (see Table I) contain weak lines of one or other of $\mathrm{N}_{2} \mathrm{O}, \mathrm{CO}_{2}$, $\mathrm{CH}_{4}$, and $\mathrm{H}_{2} \mathrm{O}$ and an estimated correction to $\beta$ was made for their selective absorption based on the solar atlas of Migeotte, Neven, and Swensson (1956-57) and our own high-resolution spectra.

The solar absorption (including equivalent linewidth $W$ ) measurements reported here covered the period summer 1958 to summer 1959 and were restricted to clear skies but did not exclude haze. Misty conditions were avoided as signals then fluctuated considerably, sometimes by an order of magnitude. Measurements of extinction at $0.44 \mu$ using the Volz actinometer on the sun were introduced in October 1958 to provide some measure of particulate matter in the line of sight.

Saiedy (1961) has estimated the standard error in $m_{\bar{p}}$ from $W$ to be $\pm 18 \%$, which is about a third of the error in $m_{\bar{p}}$ obtained from radio sonde humidities from a nearby Meteorological Office station, Crawley.

\section{METHOD I. ABSOLUTE VALUES OF CONTINUUM EXTINCTION AND THEIR INTERPRETATION}

The results of the absolute measurements of $\beta_{\bar{p}}$ as a function of $m_{\bar{p}}$ for Windows 11,8 , and 2 are given in Fig. 3, $(\mathrm{a}-\mathrm{c})$, and the properties of the regressions there shown are listed in Table II. The high correlations provide good evidence for the source of the continuum being in water vapor, with absorption coefficients $k$ of the amount shown. Since the effect of neighboring lines is small there is a strong presumption that the wings of the lines in the two major $\mathrm{H}_{2} \mathrm{O}$ bands are responsible.

The positive intercept $(0.042 \pm 0.012)$ on Fig. 3(c) may be attributed to $\mathrm{N}_{2} \mathrm{O}$ absorption of 0.028 (air mass) ${ }^{-1}$ in Window 2 (cf. Table I). Regarding the small negative intercepts in Fig. 3(a) and (b), it was assumed in Sec. 2 that $k$ is independent of temperature and selfbroadening effects. But a positive temperature coefficient and a self-broadening greater than air-broadening would both cause similar nonlinearity in the relation between $\beta_{\bar{p}}$ and $m_{\bar{p}}$, since high values of $m_{\bar{p}}$ tend to occur with high temperature and high partial pressure of water vapor. Whilst the resulting nonlinearity could not be detected against the scatter in the available observations, with a reasonable magnitude $\left(2 \%\right.$ per $\left.{ }^{\circ} \mathrm{C}\right)$ for the former effect, a straight line fitted to them would then have a negative intercept of about the magnitude which is in fact noticed in Figs. 3(a) and (b) ; $\mathrm{N}_{2} \mathrm{O}$ absorption masks this effect in Fig. 3(c). Equally, a self-broadening to air-broadening ratio of 30 [this high value receives considerable support from the results (Sec. 10) of Method II] would account for the negative intercepts. Apart from this uncertainty in interpretation, Figs. 3(a) and (b) suggest that the contribution of $\mathrm{CO}_{2}$ to the continuum at these frequencies is very small. Direct evidence is presented later (Sec. 8) that this is indeed so.

TABLE II. Properties of the correlation between $\beta_{\vec{p}}$ and $m_{\vec{p}}$ for windows 2,8 , and 11 .

\begin{tabular}{|c|c|c|c|c|c|}
\hline WVindow & $\left(\mathrm{cm}^{\nu}-1\right)$ & $\underset{\mathrm{g}^{-1} \mathrm{~cm}^{2}}{k_{p a^{2}}}$ & $r^{b}$ & $\begin{array}{c}\text { Intercept on } \\
\beta_{\bar{p} \text { axis }} \\
\text { (air mass) }^{-1}\end{array}$ & $\begin{array}{l}\text { No. of } \\
\text { obser- } \\
\text { vations }\end{array}$ \\
\hline $\begin{array}{r}11 \\
8 \\
2\end{array}$ & $\begin{array}{r}832 \\
901 \\
1159\end{array}$ & $\begin{array}{l}0.1144 \pm 0.0077 \\
0.0925 \pm 0.0061 \\
0.0545 \pm 0.0098\end{array}$ & $\begin{array}{l}0.95 \\
0.93 \\
0.86\end{array}$ & $\begin{array}{r}-0.021 \pm 0.014 \\
-0.015 \pm 0.009 \\
+0.042 \pm 0.012\end{array}$ & $\begin{array}{l}28 \\
35 \\
12\end{array}$ \\
\hline
\end{tabular}

a $k_{p 0}=$ the slope of the regression line, i.e., the absorption coefficient (base $\varepsilon$ ) per $g$ of water vapor at pressure $p_{0}$, with standard error.

(base $t$ ) per $g$ of water vapor at pressure $p_{0}$, with 


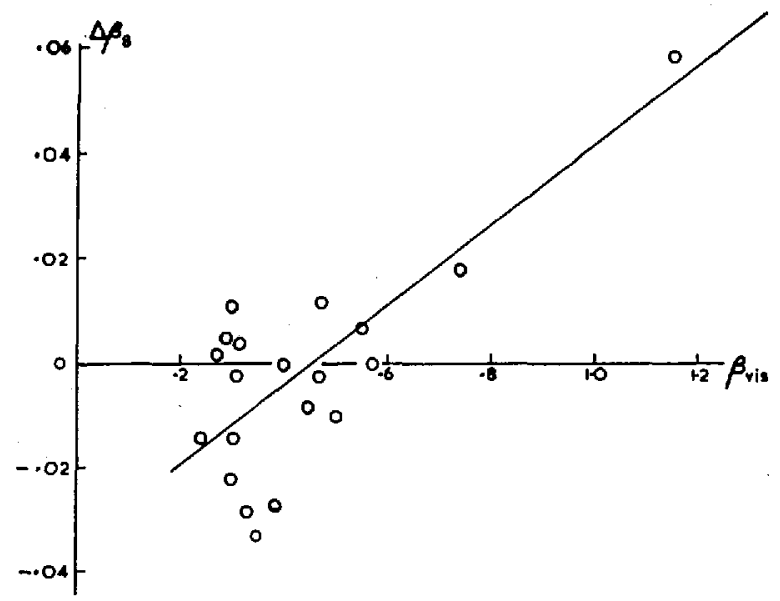

Fig. 4. Deviation $\Delta \beta_{8}$ of observed extinction from regression line of $\beta_{8}$ on $m_{\bar{p}}$ against $\beta_{\text {vis }}(0.44 \mu)$.

Although Fig. 3 implies that the continuum is primarily due to water vapor, the possible contribution of particulate matter to extinction needs examination. For this purpose the departures of observed $\beta_{8}$ from the regression line of Fig. $3(\mathrm{~b})\left(\equiv \Delta \beta_{8}\right)$ were correlated with the values of $\beta_{\text {vis }}$ obtained with the Volz actinometer, fitted for this measurement with a narrow band filter centered at $0.44 \mu$. The relation between them is shown in Fig. 4 in which the regression coefficient is 0.07 (this is in good agreement with the value of 0.05 predicted by computations cited in Sec. 9) and the correlation coefficient is 0.78 , but these values are seen to depend strongly on one or perhaps two only rather high values of each variable. (This procedure is equivalent to multivariate analysis of $\beta_{8}$ on $m_{\bar{p}}$ and $\beta_{\mathrm{vis}}$, provided there is no correlation between $m_{\bar{p}}$ and $\beta_{\mathrm{vis}}$; the correlation coefficient between the latter is in fact 0.26 for the 20 pairs of observations and is not significant.)

It is of interest to inquire whether the observed variance in $\beta_{\bar{p}}$ for Windows 8 and 11 can be satisfactorily accounted for by the above correlations and the estimated experimental variance arising from errors in chart measurement, in $m_{\bar{p}}$ and $I_{0}$. (The observations for Window 2 are too few to make the analysis here worthwhile.) Short-circuiting the details (see Saiedy, $1960 \mathrm{~b}$ ), the ratio of observed to expected total variance is found to be 1.27 and 1.75 for Windows 11 and 8 , respectively. These values are not unsatisfactory; as they would need to be 2.00 and 1.85 , respectively, to be significant at the $5 \%$ level.

\section{METHOD I. FREQUENCY DEPENDENCE OF CONTINUUM, 790 TO $1202 \mathrm{~cm}^{-1}$}

'A typical set of regression lines of $\log$ (relative intensity) against air mass for the lower frequencies $\left(\nu \leqslant 901 \mathrm{~cm}^{-1}\right.$ ) of Table I is given in Fig. 5. Figure 6 shows all the results of this series of observations in terms of $\beta_{i} / \beta_{8}$ against frequency. The experimental error in these ratios is estimated to be about $\pm 4 \%$, but for $\nu>901 \mathrm{~cm}^{-1}$ there may also be systematic error due to selective absorption. In particular, Window 13 is almost certainly affected by neighboring strong lines and the curve of Fig. 6 has accordingly been drawn below the points for this frequency. The mean of seven

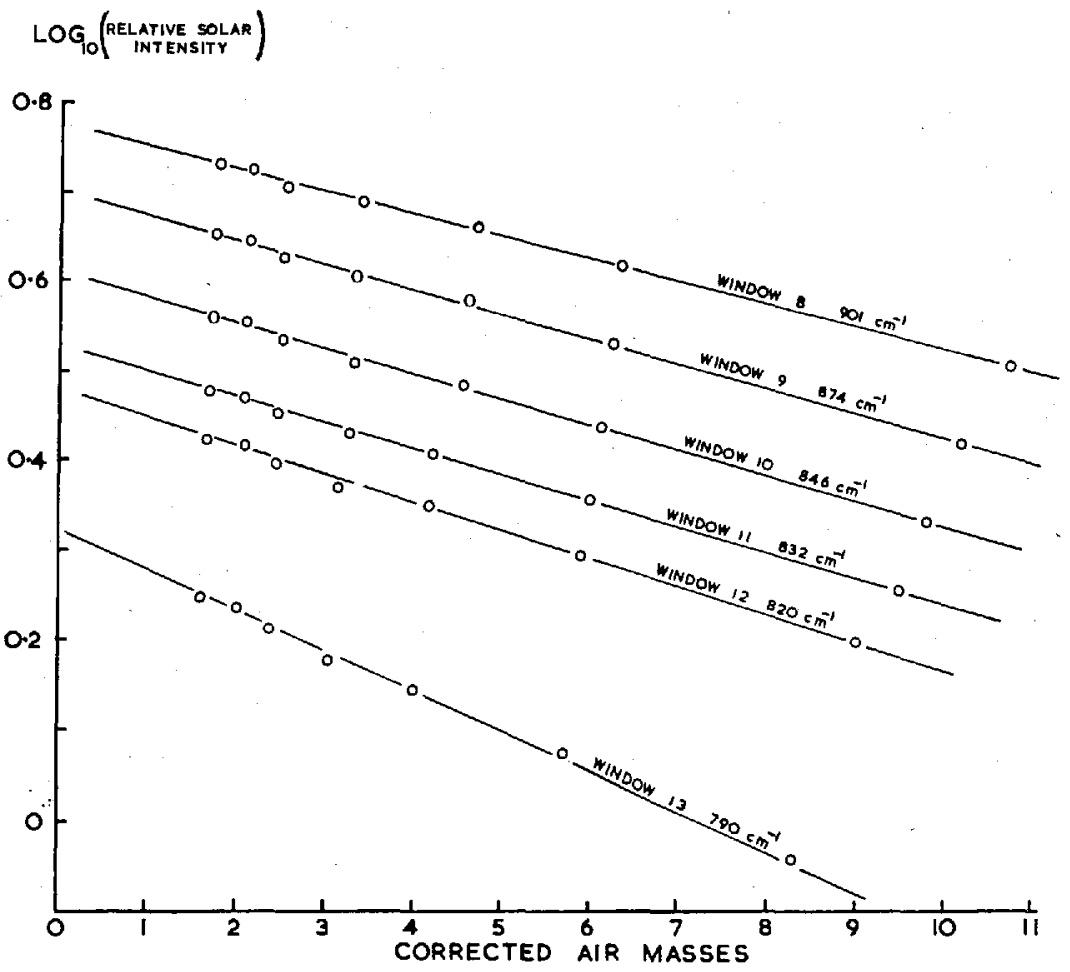

FIG. 5. Typical regression lines of $\log$ of relative intensity as a function of air mass, 14.5 (1959). 
values of $\beta_{11} / \beta_{8}$ is $1.28 \pm 0.05$, which is in reasonable agreement with the value $1.24 \pm 0.09$ derived from Sec. 4 .

We have already referred to the possible evidence for the effect of temperature or self-broadening on the continuum in the discussion of the negative intercepts on Figs. 3(a) and (b). Further evidence is afforded by apparent day-to-day changes in $\beta_{i} / \beta_{8}$ which appear to be correlated with the effective mean temperature,

$$
\bar{T}=\frac{1}{m} \int_{0}^{m} T\left(m^{\prime}\right) d m^{\prime},
$$

computed from nearby radiosonde data. Figure 7 illustrates this for Windows 9,10,11, and 12. Although there is little doubt that the ratio increases with temperature, it is questionable whether it is a true temperature effect, for this would imply an unreasonably large difference in temperature coefficient between Window 8 and Windows $9,10,11$, and 12 . Further observations are required before Fig. 7 can be interpreted with confidence.

\section{METHOD II. BASIS AND APPARATUS}

Method I cannot be applied near sea level in wavelengths beyond $14 \mu$ because of the high continuum absorption in that range. This is illustrated by the solar spectrum shown in Fig. 8 taken with $3 \mathrm{~g} \mathrm{~cm}^{-2}$ of precipitable water in the path. Satisfactory measurements of the continuum out to $21 \mu$ require only about 0.1 to $0.5 \mathrm{~g} \mathrm{~cm}^{-2}$ of vapor in the path, and were therefore made in a horizontal-path experiment with path lengths of 200 and $400 \mathrm{~m}$ which provide the required range of water vapor. A spectrum taken over a path of $200 \mathrm{~m}$ is shown in Fig. 8. An absolute determination of absorption is very difficult in this case, and the technique developed provides values of the difference between the absorption coefficients in any two windows. By choosing for one of the latter a window in the very transparent region treated by Method $I$, a good estimate of the absorption coefficient for the other is possible.

The external optical system is shown in Fig. 9. An image of the power-stabilized Nernst source is formed on the entrance slit of the spectrometer after the radiation has traversed a path of 200 or $400 \mathrm{~m}$, the external optical system $(f / 5)$ being matched to the spectrometer $(f / 10)$ by mirrors $M_{5}$ and $M_{6}$.

The spectrometer, described by Goody (195.7), was equipped for this experiment with a $15-\mathrm{cm}$-square Merton replica grating of 473 lines/cm blazed for $20 \mu$ in the first order. All radiation of $\lambda<7.3 \mu$ was eliminated by a bloomed filter of indium antimonide, and filters of terylene and (reststrahlen) magnesium oxide were used in various contexts. The transmissions of these filters are indicated qualitatively in Fig. 8.

A constant geometrical slitwidth was chosen to provide a signal to noise ratio better than 100:1 at all wavelengths except the longest, the resolution achieved being $2.2 \mathrm{~cm}^{-1}$ at $600 \mathrm{~cm}^{-1}$ and $1.2 \mathrm{~cm}^{-1}$ at $480 \mathrm{~cm}^{-1}$

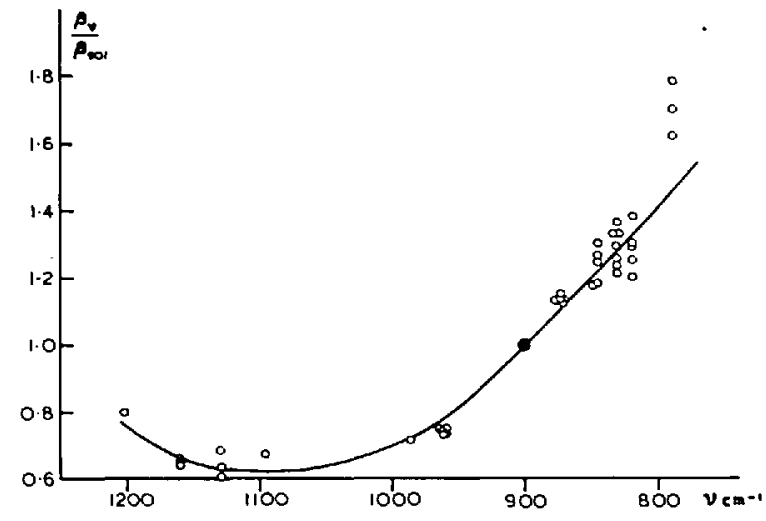

Fic. 6. Variation of continuum extinction coefficient with frequency relative to extinction at $901 \mathrm{~cm}^{-1}$.

(Table IV, Sec. 10B). Stray radiation was shown to be negligible by the complete absence of signal at several line centers under high resolution. By the use of sector attenuators of accurately measured transmittance for the control of input, the Golay detector and voltagestabilized amplifier system was found to be linear to better than $0.5 \%$ over the range of input used.

The windows chosen for measurement are identified on Fig. 8 by numbers $14-20$, and are listed in Table IV. Window 4 was used for comparison purposes and was chosen for its high transparency, freedom from lines, and so that it fell in an opaque band of the terylene filter at a frequency exactly double that of one of the other windows.

\section{OBSERVATIONAL PROCEDURE}

Three techniques were employed in the determination of the extinction coefficients. The first gives values of $\beta_{17}-\beta_{4}$, from which $\beta_{17}$ may be inferred with little uncertainty since $\beta_{17} / \beta_{4} \bumpeq 15$. The second gives values of $\beta_{14}-\beta_{4}$, and the third $\beta_{i}-\beta_{17}$, from which $\beta_{i}-\beta_{4}$ is inferred using $\beta_{17}-\beta_{4}$ already determined. The three techniques are now described in order. The notation $\beta_{i-}$ is used to denote $\beta_{i}-\beta_{r}$.

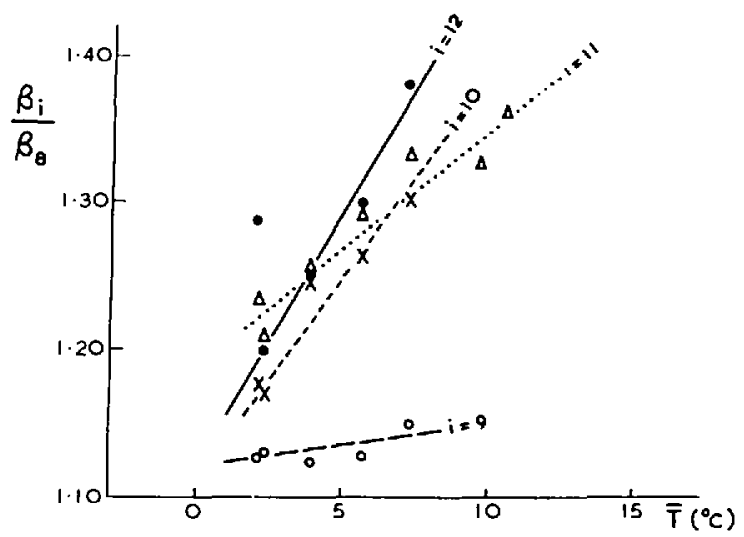

FIG. 7. Effect of temperature on $\beta_{i} / \beta_{9}$ for Windows $9,10,11$, and 12 . 

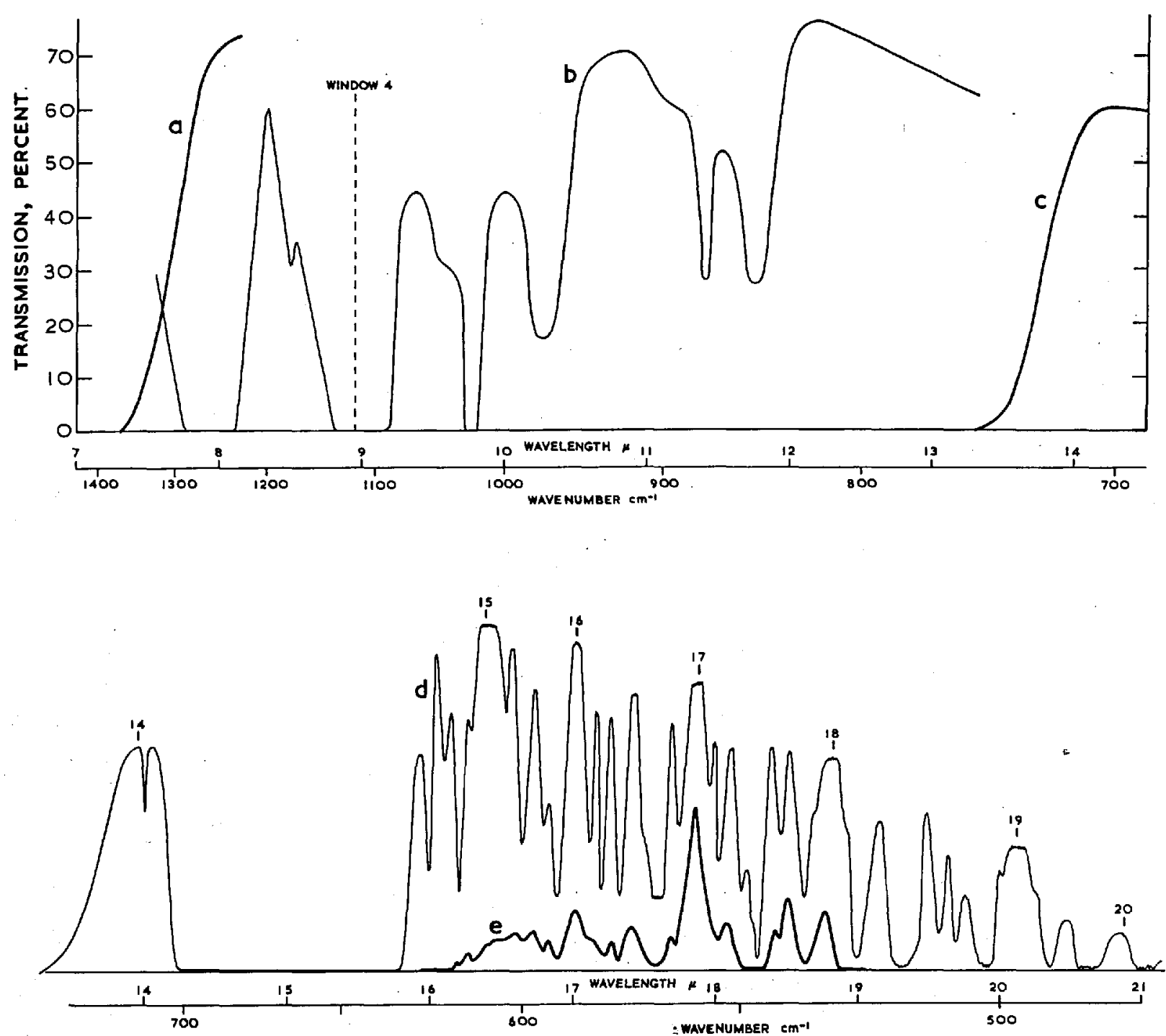

Fic. 8. Method II. Location of windows and filter characteristics. (a) Cut-on for bloomed indium antimonide. Beyond $8 \mu$ the transmission decreases slowly to about $50 \%$ at $20 \mu$. (b) Transmission of terylene film, $12 \mu$ thick. (c) Cut-on for double reststrahlen magnesium oxide. Beyond $14 \mu$ transmission remains at about $60 \%$. (d) Spectrum over horizontal path of $200 \mathrm{~m}$, with $0.250 \mathrm{~g} \mathrm{~cm} \mathrm{~m}^{-2}$ of water vapor in the path. Nernst source and filters (c) and (a). (e) Solar spectrum; $3 \mathrm{~g} \mathrm{~cm}^{-2}$ water vapor in slant path. Filters (c) and (a).

\section{A. Measurement of $\beta_{17-4}$}

With the grating set to $\nu_{17}=559.4 \mathrm{~cm}^{-1}$ in the first order, signals are obtained with and without the terylene filter, an auxiliary sector attenuator of transmission $K$ being used in the latter case to bring the signals to approximate equality. Let the ratio of these two signals be $y$. When the terylene filter is used, only the firstorder spectrum (Window 17) is transmitted; without it the much more intense second-order spectrum of Window 4 is also transmitted. Higher-order spectra are eliminated by the indium antimonide filter.

Let

$F_{i}$ be the transmittance of the terylene filter in window $i$;

$S_{i}$, the signal which would be obtained in window $i$ in the absence of absorption along the atmospheric path;

$\beta_{i}$, the extinction coefficient per unit length in window $i$; and

$l$, the path length $\left(l_{2}\right.$ and $l_{1}$ are used to denote different path lengths).

Then Lambert's law gives

$$
y=\frac{F_{17} S_{17} \exp \left(-\beta_{17} l\right)+F_{4} S_{4} \exp \left(-\beta_{4} l\right)}{K\left[S_{17} \exp \left(-\beta_{17} l\right)+S_{4} \exp \left(-\beta_{4} l\right)\right]} .
$$

For terylene film of $12 \mu$ thickness, $F_{4}=0$ and Eq. (7.1) can be written

$$
\beta_{17-4} l=\ln S_{17,4}+\ln \left[\left(F_{17} / K y\right)-1\right],
$$




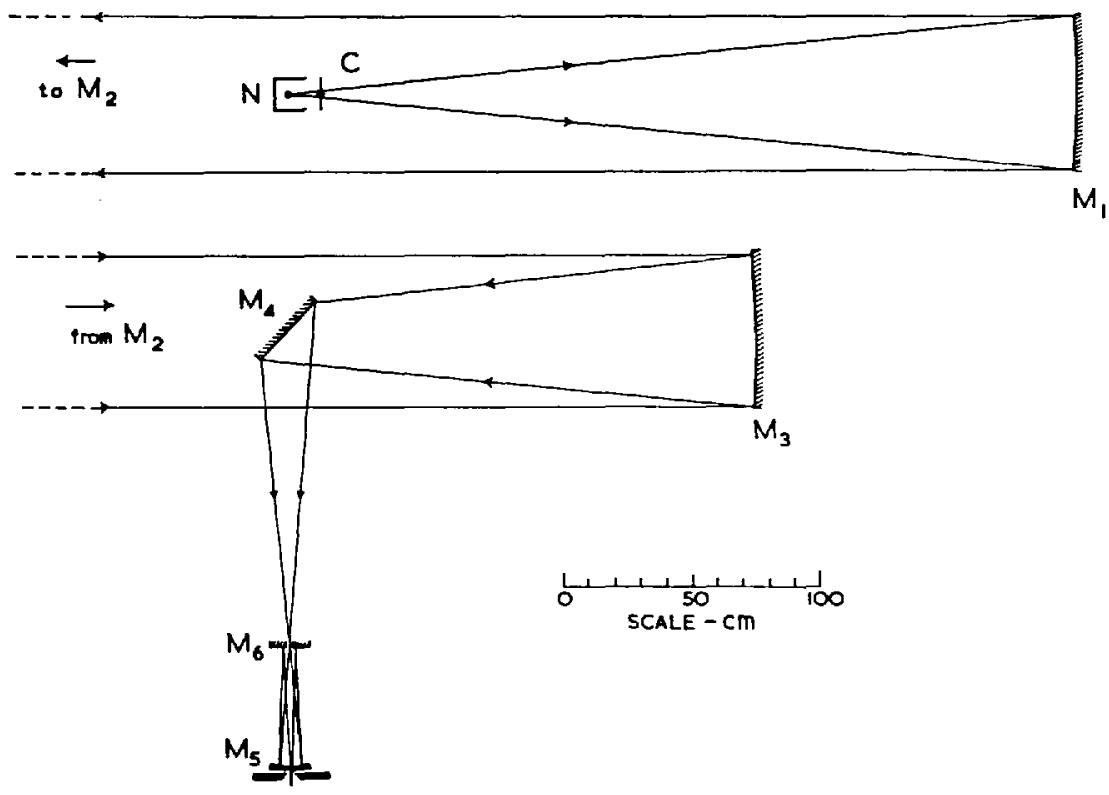

FIG. 9. External optics of horizontal path experiment. The Nernst filament $N$ is shielded from draughts and is mounted just outside the focus of paraboloid $M_{1}(f=305 \mathrm{~cm}$, diam 63 cm) so as to give an image on $M_{2}$, which is a spherical mirror of either $200 \mathrm{~m}$ radius, $50 \mathrm{~cm}$ diameter, mounted at $200 \mathrm{~m}$ distance, or of 100 $m$ radius, $25 \mathrm{~cm}$ diameter, mounted at $100 \mathrm{~m}$ distance. In each case the center of curvature of $M_{2}$ is midway between those of $M_{1}$ and $M_{3}$, so that $M_{1}$ is imaged on $M_{3}$. All mirrors are frontsurface aluminized. The chopper $(C)$ frequency is $10 \mathrm{cps}$. where $S_{17,4}=S_{17} / S_{4}$. Thus, given $F_{17}$, observations of $y$ for two values of $l$ provide $\beta_{17-4}$ provided $S_{17,4}$ is the same for both determinations of $y$. The value of $F_{17}$ is in fact measured for every pair of observations of $y$ by taking the ratio of the signals obtained with and without the filter, the second-order spectrum of Window 4 being eliminated in both by a second fixed terylene filter.

The condition of constancy of $S_{17,4}$ requires care for achievement. Its value depends on the relative magnitude in wavelengths 4 and 17 of (i) the intensity $I$ of radiation emitted by the source; (ii) the product, $R$, of the reflectances of all the mirrors in the system; (iii) the response of the detecting system, including the grating and filters.

Regarding (i), it was found that $I_{4} / I_{17}$ was greater by 5 to $10 \%$ at the center than at the edge of the filament. It was therefore necessary to focus and align the image very carefully to ensure that the same part of the source was used in each pair of observations. The variation of $I_{4} / I_{17}$ with filament temperature was less than $2 \%$ over the range $1500^{\circ}-2000^{\circ} \mathrm{K}$, which was certainly much greater than the temperature variations induced by draughts.

Regarding (ii), evidence (unconfirmed) was obtained that for the complete system of mirrors (13 reflections), $R_{17} / R_{4}$ decreased by about $10 \%$ for a change of relative humidity from 50 to $90 \%$, as inferred from a change of intercept, $\ln S$ in Eq. (7.2). The effect is however of no consequence since each pair of observations was made in the minimum interval (about $5 \mathrm{~min}$ ) to effect the necessary changes, so as to keep changes in humidity to a minimum. It was necessary moreover to assume that $R_{17} / R_{4}$ was the same at any one time for each of the mirrors used for $M_{2}$; which is reasonable because the mirrors were aluminized at the same time and were subsequently kept under similar conditions.
Regarding (iii), the transmission of the terylene filter was found to be uniform over its whole surface, but that of the indium antimonide was somewhat nonuniform, possibly because of variations in the antireflection coating. The efficiency of the grating was also nonuniform and it was therefore essential to ensure identity of position and distribution of illumination in the beams derived from the external optical systems-by accurate alignment and focusing, and the introduction of a stop on $M_{6}$ to cover the images of obstructions in the beam.

In the course of the experiment, several changes were made in order to improve the reproducibility of $S_{17,4}$. The experimental method and optical layout described in Sec. 6 was the final form. It superseded a version in which it was possible to obtain a short path of $10 \mathrm{~m}$ as well as paths of 200 and $400 \mathrm{~m}$, but this involved the off-axis use of spherical mirrors, giving considerable distortion. In this earlier method, the values of $l$ used for a pair of observations were $l_{2}=10 \mathrm{~m}$ and $l_{1}=200$ or $400 \mathrm{~m}$. Some systematic error was, however, possible: firstly, from the use of four mirrors not common to both beams (though with the same total number of reflections), with the possibility that different relative reflectances $R_{17} / R_{4}$ were involved; secondly, from uncertainty in fulfilling condition (iii) above owing to distortion and different beam geometry. These uncertainties were much reduced in the final method since only one mirror was not common to both beams, and with axial optics it was possible to ensure that both beams were identical.

There was reasonable agreement, however, between the results derived from both methods, indicating that the uncertainties present in the earlier method were not serious. It is probable that $S_{17,4}$ was reproduced to better than $1 \%$ in each pair of observations in the final method. Support for this view is afforded by the fact 


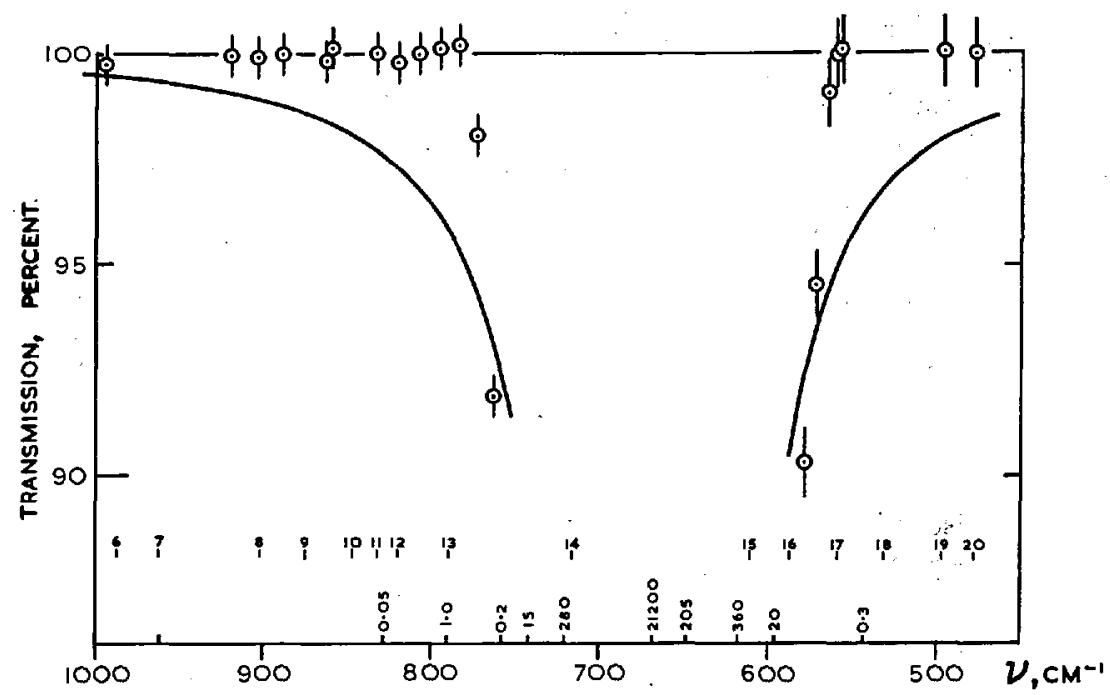

FIG. 10. Circled points: observed transmission of a $43-\mathrm{cm}$ cell of pure $\mathrm{CO}_{2}$ at atmospheric pressure. Continuous lines: calculated transmission, assuming Lorentz wings [neglecting minor bands, whose positions and strengths $\left(\mathrm{g}^{-1} \mathrm{~cm}\right)$ are shown on the abscissa]. The positions of Windows 6-20 are shown. that noticeable deliberate misalignments produced no systematic change in $y$.

\section{B. Measurement of $\beta_{14}-\beta_{4}$}

The ratio $x_{14,4}$ of the signals obtained in Windows 14 and 4 was measured, whence

$$
x_{14,4}=\left(S_{14} / S_{4}\right) \exp -\left(\beta_{14}-\beta_{4}\right) l .
$$

Then from observations over two paths, subject to the experimental precautions stated previously, a value of $\beta_{14}-\beta_{4}$ may be found.

\section{Measurement of $\boldsymbol{\beta}_{i}-\underline{\beta}_{17}$}

A double reststrahlen magnesium oxide filter was mounted kinematically behind the exit slit, cutting off almost entirely all radiation of $\lambda<13 \mu$. This filter was readily interchangeable with a pair of identically mounted aluminized mirrors used in Secs. (A) and (B). The ratios $x_{i, 17}$ of the signals for each of the Windows 15-20 to that for Window 17 were determined for two path lengths, and $\beta_{2-17}$ may be found as in (b).

\section{Measurement of Water Vapor}

The depth of precipitable water in the path was obtained from readings of an Assmann psychrometer exposed at the mean height $(\sim 1 \mathrm{~m})$ of the beam, occasional checks being made with a second psychrometer for uniformity along the path.

\section{8. $\mathrm{CO}_{2}$ ABSORPTION IN THE REGION $1300-478 \mathrm{~cm}^{-1}$}

Before discussing the results on the water-vapor continuum out to $21 \mu$, it is appropriate to consider the possibility of this continuum's being overlaid by that from carbon dioxide and aerosol. Regarding the former, a $43-\mathrm{cm}$ cell of pure $\mathrm{CO}_{2}$, with windows of polythene, was inserted in the beam, giving a "depth" of $0.082 \mathrm{~g}$ $\mathrm{cm}^{-2}$, the equivalent of $1.4 \mathrm{~km}$ of air at sea level. The transmissions on either side of the $\nu_{2}$ band are shown in Fig. 10, and are compared with those to be expected if the wings of the $\mathrm{CO}_{2}$ lines have Lorentz shape, taking the $\nu_{2}$ band intensity to be $1.22 \times 10^{5} \mathrm{~g}^{-1} \mathrm{~cm}$ and the mean line half-width $0.064 \mathrm{~cm}^{-1}$ at $1 \mathrm{~atm}$ and $298^{\circ} \mathrm{K}$ (Kaplan and Eggers, 1956). We see that the observed absorption is considerably less than from Lorentz wings until quite close to the band center, the absorption due to line centers of the weaker bands indicated in Fig. 10 being first apparent. Kaplan (1953) and Benedict (1955) have argued for a decrease faster than Lorentz in the $\mathrm{CO}_{2}$ wings, and they suggest a wing profile which is consistent with the negligible absorption observed in the present work outside the range 790 to $560 \mathrm{~cm}^{-1}$. Only Windows 14,15 , and 16 were found to be affected by $\mathrm{CO}_{2}$ absorption, this being attributed to nearby lines, and is therefore analyzed accordingly.

\section{EXTINCTION BY AEROSOL}

During the experiment, it was noted that the extinction was greater under very hazy conditions, and it was therefore necessary to allow for aerosol attenuation in the analysis. No direct measurements of particle concentration and size were made, but local visibility data were available and it is of interest to inquire to what extent these could be used to infer the opacity due to aerosol in the $10-20-\mu$ region. Deirmendjian (1959, 1960) has computed extinction coefficients from 0.625 to $14 \mu$ for a number of realistic aerosol distributions; the ratios of the extinction coefficient at $0.625 \mu$ to those at $10.0,12.0$, and $14.0 \mu$ are approximately 30,11 , and 7 , respectively, for all distributions except when there are many large particles, suggesting that the distribution is not very important. In the region beyond $14 \mu$, computations from the Mie theory are greatly simplified for droplets up to $1-\mu$ radius by an expansion given by Van de Hulst (1957, p. 270). Using this and the absorption coefficients given by Plyler and Acquista (1954) and 
refractive index data from Dorsey (1940, p. 185) for 18 and $20 \mu$, we find that $\beta_{0.625 \mu} / \beta_{18 \mu}=9$ and $\beta_{0.625 \mu} / \beta_{20 \mu}=11$, both ratios being insensitive to the aerosol distribution. It is concluded that the aerosol contribution, $\Delta \beta$, to the extinction in the region $10-20 \mu$, is proportional to that at $0.625 \mu$ within a factor of 2 for all likely aerosol distributions. With the further, more doubtful, assumption that the visual extinction coefficient $\beta_{\mathrm{vis}}$ [computed from the visibility $V$, by $\beta_{\mathrm{vis}}=3.9 / V$ (Middleton, 1952, p. 105)] is proportional to $\beta_{0.625 \mu}$, we may define a constant $D_{i}$ by $\Delta \beta_{i}=D_{i} \beta_{\text {vis }}$, and hence

$$
\Delta \beta_{i-r} \equiv \Delta\left(\beta_{i}-\beta_{r}\right)=D_{i-r} \beta_{\text {vis }}=(3.9 / V) D_{i-r},
$$

where $D_{i-r}=D_{i}-D_{r}$. For the purposes of the discussion (Sec. 10A) of observations in Windows 17 and 19 relative to Window 4 , and of those in Window 8 , Sec. (4), wenote from the above that if we assume $\beta_{\mathrm{vis}}=\beta_{0.625 \mu}$, then $D_{19}=0.09, D_{17}=0.11$ and by interpolation of the computations of Deirmendjian (1960), $D_{4}=0.05$ and $D_{8}=0.05$.

\section{METHOD II. RESULTS}

Values of absorption coefficients derived from early observations showed much more scatter than could be accounted for by errors of observation, in the elucidation of which effort was concentrated on the measurement of $\beta_{17-4}$ and $\beta_{19-4}$ (chosen for their freedom from $\mathrm{CO}_{2}$ absorption and for adequate signal). The interpretation of the observations for these windows will be discussed first, since the conclusions throw light on the interpretation of the smaller samples of data for the other windows.

\section{A. Windows 17 and 19}

Figure 11 shows the observations of extinction coefficients for Windows 17 and 19 as a function of the mass $m_{p}$ lof water vapor in the path. A strong correlation is evident, but the observations for each window fall distinctly into two groups according as $l_{2}-l_{1}=400$ or $200 \mathrm{~m}$, and the best straight lines through each set of points have significant negative intercepts. For both windows the extinction is apparently greater at a given value of $m_{p}$ lfor the shorter path for which the vapor density must be double that on the longer path, so that self-broadening suggests itself as an explanation. However, points of low $m_{p}$ lon all lines were obtained under cold, dry conditions and those of high $m$ lunder warm, humid conditions, so that it is equally possible that a positive temperature dependence of absorption is partly or wholly responsible for the difference in extinction coefficient. A sufficient number of observations ranging as widely as possible over these variables was therefore necessary, to discriminate between these effects by multiple regression analysis.

The regression equation relating the observed extinction in Windows 17 and 19 to vapor content and visibility (Sec. 9) may be written

$$
\beta_{i-4}=k_{i-4} m+(3.9 / V) D_{i-4},
$$

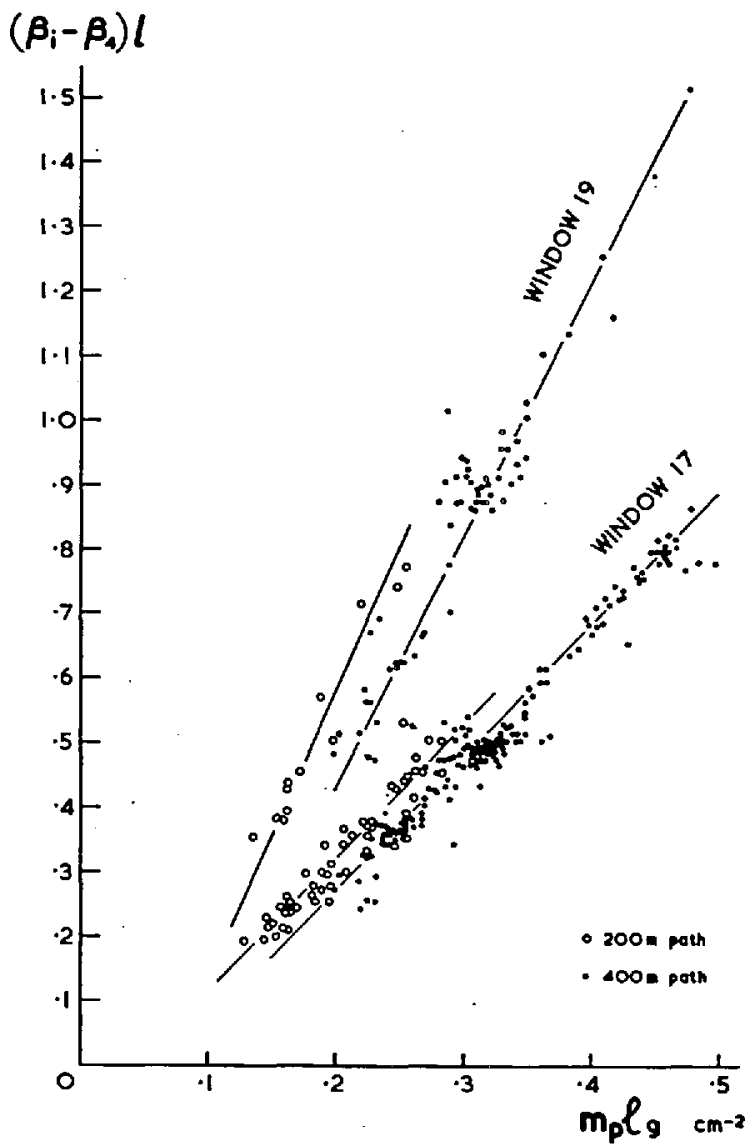

FIG. 11. Observed extinction coefficients $\beta_{i}-\beta_{1}$ for Windows 17 and 19 as a function of water vapor in the path $\left(m_{p}=m p / p_{0}\right)$.

where $k$ is the mass absorption coefficient for water vapor, $i=17$ or 19 , and $m$ is the mass of water vapor per unit length of path per $\mathrm{cm}^{2}$.

It will be assumed that the variation of the half-width $\alpha$ and intensity $S$ of absorption lines with temperature and pressure may be written

$$
\begin{aligned}
\alpha(P, T) & =\alpha\left(p_{0}, T_{0}\right)\left(P / p_{0}\right)\left(T_{0} / T\right)^{t}, \\
S(T) & =S\left(T_{0}\right)\left[1+\epsilon\left(T-T_{0}\right)\right],
\end{aligned}
$$

where $P=p+a e, p$ and $e$ being the partial pressures of dry air and water vapor, respectively, $a$ is the ratio of self- to air-broadening, and $p_{0}, T_{0}$ are standard values of pressure (1000 mbar) and temperature $\left(0^{\circ} \mathrm{C}\right)$. Then Eq. (10.1) can be written, to good approximation,

$$
\begin{array}{r}
\frac{\beta_{i-4}}{m_{p}}\left(\frac{T}{T_{0}}\right)^{t}=k_{i-4}\left(p_{0}, T_{0}\right)\left[1+\epsilon\left(T-T_{0}\right)+\frac{a e}{p}\right] \\
+\frac{3.9 D_{i-4}}{V m_{p}}
\end{array}
$$

where $m_{p}=m\left(p / p_{0}\right)$

With 224 sets of observations for Window 17, and 71 for Window 19, a multiple-regression analysis was pos- 
TABLE III. ${ }^{a}$ Results of the regression analysis for Windows 17 and 19.

\begin{tabular}{cccccccc}
\hline \hline $\begin{array}{c}\text { Window, } \\
i\end{array}$ & $\begin{array}{c}\lambda \\
(\mu)\end{array}$ & $\begin{array}{c}\nu \\
\left(\mathrm{cm}^{-1}\right)\end{array}$ & $\begin{array}{c}k_{i-4}\left(p_{0}, e_{0}, T_{0}\right) \\
\left(\mathrm{g}^{-1} \mathrm{~cm}^{2}\right)\end{array}$ & $a$ & $\begin{array}{c}\epsilon \\
\left({ }^{\epsilon} \mathrm{C}^{-1}\right)\end{array}$ & $D_{i-4}$ & $\begin{array}{c}\text { No. of } \\
\text { obs }\end{array}$ \\
\hline 17 & 17.88 & 559.4 & $1.22 \pm 0.13$ & $26 \pm 4$ & $0.0006 \pm 0.001$ & $0.022 \pm 0.005$ & 224 \\
19 & 20.12 & 497.0 & $2.09 \pm 0.16$ & $38 \pm 6$ & $-0.001 \pm 0.001$ & $0.034 \pm 0.008$ & 71 \\
\hline \hline
\end{tabular}

- Results of a least-squares fit of the observations to the relation

$$
k_{i-4}\left(p, c_{0} T\right)=k_{i-4}\left(p_{\left.0, \epsilon_{0}, T_{0}\right)}\left[(p+a e) / p_{0}\right]\left[1+\epsilon\left(T-T_{0}\right)\right] .\right.
$$

where $p, e$ are the partial pressures of dry air and water vapor, respectively ( $p_{0}=1000 \mathrm{mbar}, e_{0}=0 \mathrm{mbar}$ ), and $T_{0}=0^{\circ} \mathrm{C} . D_{i-1}$ represents the aerosol contribution (see Sec. 9).

sible, and the results are given in Table III. For both windows it appears that $\epsilon$ is not significantly different from zero, which lends support to the assumption tenta tively made in Sec. 2. The correlations with aerosol are weak but significant, and the observed values of $D_{17-4}$ and $D_{19-4}, 0.02$ and 0.03 , respectively, may be compared with 0.06 and 0.04 expected from the reasoning of Sec. 9; better agreement could hardly be expected in view of the uncertainties involved.

The correlation with vapor pressure is highly significant. The values of 26 and 38 for $a$ for windows 17 and 19 , respectively, are remarkably high compared with the figure between 5 and 10 which has been found for the central parts of lines (Palmer 1960); Benedict has suggested, however, that the wings are subject to greater self-broadening than are line centers. Although only about half of the total variance can be accounted for, and this almost entirely by the correlation with vapor pressure, we have fair confidence in ascribing the negative intercepts to self-broadening. If this inference is verified it will be of the utmost importance in the analysis of remote radiation measurements which involve correction for the water-vapor continuum.

\section{B. Windows 18 and 20}

With insufficient observations to permit a multipleregression analysis, it seems reasonable in the light of the results for Windows 17 and 19 to assume that the temperature and aerosol terms may be ignored in Eq. (10.2). Plots of $\beta / m_{p}$ against vapor pressure $e$ are shown in Fig. 12, where a tendency for the absorption to in-

TABLE IV. Frequencies used in Method II and abserved absorption coefficients.

\begin{tabular}{|c|c|c|c|c|c|c|}
\hline Window. & $\stackrel{\lambda}{(\mu)}$ & $\left(\mathrm{cm}^{\nu}-1\right)$ & $\begin{array}{c}\text { Reso- } \\
\text { lution } \\
\left(\mathrm{cm}^{-1}\right)\end{array}$ & $\begin{array}{l}k_{i}\left(p_{0, e}\right)^{\mathrm{a}} \\
\left(\mathrm{g}^{-1} \mathrm{~cm}^{2}\right)\end{array}$ & $\underset{\left(\mathrm{g}^{-1} \mathrm{~cm}^{2}\right)}{\Delta k_{i}\left(p_{0}, T_{0}\right) \mathrm{b}}$ & $\begin{array}{l}\text { No. of } \\
\text { obs }\end{array}$ \\
\hline 4 & 8.94 & 1118.8 & 3.5 & $0.08^{\mathrm{c}}$ & 0 & $\cdots$ \\
\hline 14 & 13.96 & 716 & 2.8 & $0.6 \pm 0.2$ & 0 & $M$ \\
\hline 15 & 16.38 & 610.5 & 2.2 & $0.8 \pm 0.1$ & $0.13,+0.7$ & 15 \\
\hline 16 & 17.02 & 587.4 & 1.9 & $1.4 \pm 0.1$ & $0.42,+1.3$ & 15 \\
\hline 17 & 17.88 & 559.4 & 1.7 & $1.7 \pm 0.1$ & $0.23+1.0$ & 224 \\
\hline 18 & 18.83 & 531.2 & 1.6 & $1.8 \pm 0.1$ & $0.44,+1.1$ & 15 \\
\hline 19 & 20.12 & 497.0 & 1.3 & $3.0 \pm 0.1$ & $0.78+1.2$ & 71 \\
\hline 20 & 20.88 & 478.9 & 1.2 & $3.6 \pm 0.1$ & $1.7+1.7$ & 6 \\
\hline
\end{tabular}

a $k_{i}\left(p_{0}, e\right)$ is the mass absorption coefficient for partial air pressure of 1000 mbar and water-vapor pressure of $12 \mathrm{mbar}$ (see Sec. 10B).

$\mathrm{b} \Delta k_{i}$ is the contribution to $k_{i}$ from wings of nearby water-vapor lines for $p_{0}=1000$ mbar and $T_{0}=14^{\circ} \mathrm{C}$; the computed temperature coefficient $\left(\%{ }^{\circ} \mathrm{C}^{-1}\right)$ of $\Delta k_{i}$ is also shown.

B By interpolation from Method I. crease with $e$ is again apparent. For neither window is the sample large enough to allocate a value of $a$, though for Window 18 it is of the order of 30 .

Mean values of $k_{18}$ and $k_{20} \ldots$ corresponding to the mean vapor pressure of 12 mbar are given in Table IV, with corresponding values for Windows 17 and 19 for comparison.

\section{Windows 14,15 , and 16}

$\mathrm{CO}_{2}$ absorbs significantly in these windows (see Fig. 10), and Eq. (10.2) must now be written (neglecting aerosol and temperature terms)

$$
\beta_{i-4}=k_{i-4}\left(p_{0}\right) m_{p}[1+(a e / p)]+c_{i},
$$

where $c_{i}$ is the $\mathrm{CO}_{2}$ contribution in window $i\left(C_{4}=0\right)$. Figures 13(a) and (b) show $\beta_{i-4}$ against $m_{p}$ lfor Windows 16 and 15 . We see that the best straight lines do not pass through the intercepts $c_{i}$ inferred by scaling the $\mathrm{CO}_{2}$ absorption measurements (Sec. 8) to the mass in the path according to the law appropriate to a regular band. Indeed, graphs of $\beta_{i-4}-c_{i}$ against $m_{1} \ell$ for these windows would have identical features to those for Windows 17 and 19 (Fig. 11) discussed in Sec. 10A, and it seems likely that the interpretation is the same. Mean

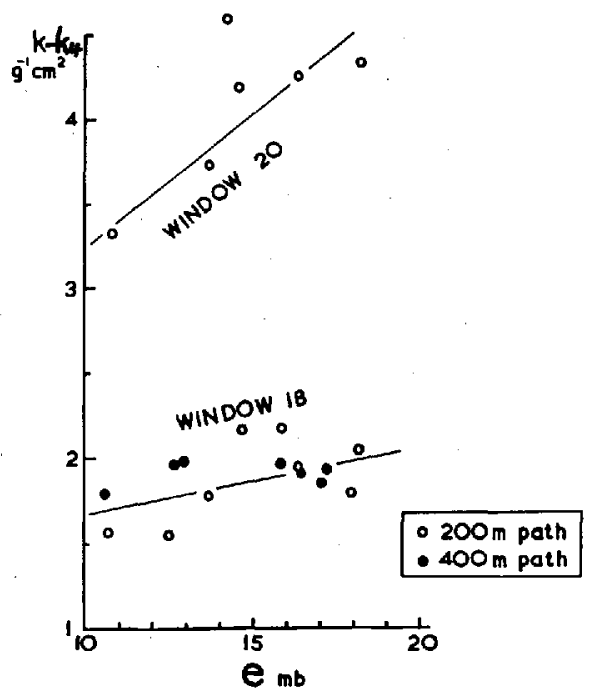

Fig. 12. Absorption coefficients for Windows 18 and 20 as a function of vapor pressure. It has been assumed that temperature dependence and aerosol absorption are negligible. 
FIG. 13. Observed extinction coefficients for Windows 14, 15, and 16. Full circles: $400 \mathrm{~m}$ path. Open circles: 200 $\mathrm{m}$ path. Points denoted by ' $C_{16}^{\prime}$ and ' $\mathrm{C}$ ' 15 represent the estimated $\mathrm{CO}_{2}$ contribution, from measurements with a cell of $\mathrm{CO}_{2}$.
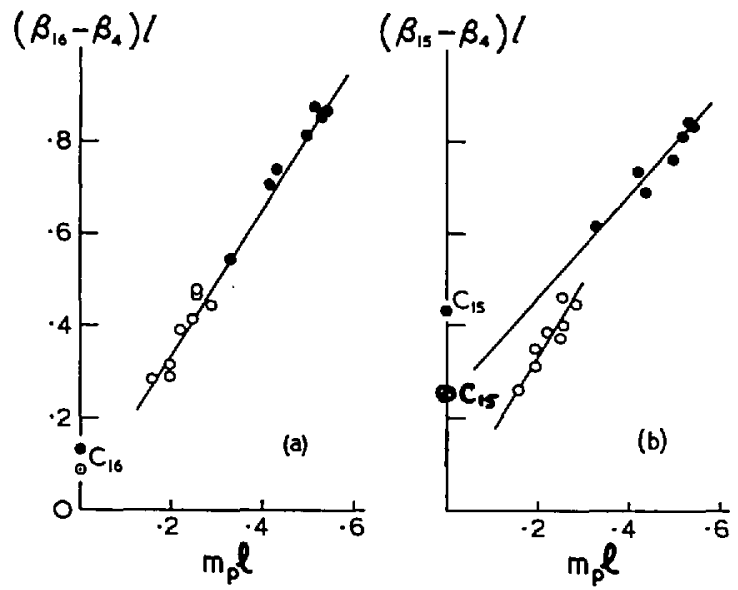

values of $k_{i}$, corresponding to the mean vapor pressure of $12 \mathrm{mbar}$, are given in Table IV, assuming $k_{4}=0.00 \mathrm{~g}^{-1} \mathrm{x}^{2}$,

Figure 13(c) shows the observations for Window 14; in this case absorption by $\mathrm{CO}_{2}$ is much greater and the scatter is increased by the diurnal and daily variations in the concentration of atmospheric $\mathrm{CO}_{2}$. Only a rough estimate of $k_{14-4}$ may be obtained from the slope of the regression line and this is also entered in Table IV.

\section{DISCUSSION OF RESULTS AND FORM OF THE CONTINUUM}

The results (Methods I and II) reported in this paper for the region $1200-800 \mathrm{~cm}^{-1}$ are on the average $20 \%$ less than those obtained by Roach and Goody (1958) by a solar method at the same site but with lower resolution, and agree with the result of Vigroux (1959) taken at Arosa at $1041 \mathrm{~cm}^{-1}$, and are some $30 \%$ larger than those of Anthony (1952) taken at Table Mountain, California, also by a solar method. Anthony also observed the continuum at 17.6 and $19.0 \mu$, but the results $\left(0.87\right.$ and $\left.0.98 \mathrm{~g}^{-1} \mathrm{~cm}^{2}\right)$ are not readily comparable with the present work since the circumstances of the observation were not reported.

It is significant that the results from Method II for Windows 17 to 20 are similar in character to those for Windows 8 and 11 from Method $I$, in that plots of $\beta$ against $m_{\bar{p}}$ [Figs. 3(a) and (b)] have negative intercepts, and it was noted in Sec. 4 that temperature dependence or self-broadening could produce this effect. Method II provides evidence that the latter is responsible in the region $\nu<600 \mathrm{~cm}^{-1}$, and it is suggested that the same is true for $v>600 \mathrm{~cm}^{-1}$, though confirmation is clearly needed from experiments carried out under controlled conditions. The negative intercepts in Figs. 3(a) and (b) provide a value of $a$ of order 30, which agrees with that determined independently from Method II, and it is possible that the differences between the present and previous results may also thereby be explained.

We now attempt to relate the observed features of the continuum to the properties of the water-vapor bands
$\left(\mathrm{CO}_{2}\right.$ may be neglected, Sec. 8), and to determine which of the line shapes variously suggested in the literature best fits the data, realizing however that wing forms so far from line centers can hardly be expected to be given by existing theories.

The line strengths and half-widths of the water-vapor rotation band have been computed by Schwendeman and Laurie (1958) and Benedict and Kaplan (1959), respectively, and observational support has been given to these computations (Saiedy 1960). The contribution to the continuum at $1000 \mathrm{mbar}$ from this band, assuming the Lorentz line shape, was kindly computed for us by $L$. D. Kaplan from

$$
k(\nu)=(1 / \pi) \sum S_{i} \alpha_{i} /\left(\nu-\nu_{i}\right)^{2},
$$

and the results can be represented to within $1 \%$ or $2 \%$ in the region $1200-800 \mathrm{~cm}^{-1}$ by

$$
k\left(\nu, p_{0}\right)=4.1 \times 10^{4} /(\nu-200)^{2} \mathrm{~g}^{-1} \mathrm{~cm}^{2},
$$

which is equivalent to a single strong line at $200 \mathrm{~cm}^{-1}$.

The absolute line intensities in the $\nu_{2}$ vibrationrotation band are not yet available, but the necessary data were extracted from an analysis by Cowling (1950) of earlier work and from the high-resolution spectra of Nielsen (1941). It was found that $k\left(\nu, p_{0}\right)$ due to the $\nu_{2}$ band can be represented to within $2 \%$ or $3 \%$ for $\nu<1200 \mathrm{~cm}^{-1}$ by

$$
k\left(\nu, p_{0}\right)=3.7 \times 10^{3} /(v-1550)^{2} \mathrm{~g}^{-1} \mathrm{~cm}^{2} .
$$

In comparing the observations with the sum of Eqs. (11.1) and (11.2), it must be remembered that if the hypothesis regarding self-broadening is correct, then the observations do not correspond to an effective pressure $p_{0}$, but to about $1.18 p_{0}$ in the case of Method I with $a \bumpeq 30$ and $e=6 \mathrm{mbar}$, and to $1.36 p_{0}$ in the case of Method II with $e=12$ mbar. Thus, the observations of Method I reanalyzed in the manner of Sec. $10 \mathrm{~B}$ give $k\left(901, p_{0}\right)=0.064 \mathrm{~g}^{-1} \mathrm{~cm}^{2}$.

Figure 14 shows (a) the values of $k(\nu)$, as observed, in the region $1202-479 \mathrm{~cm}^{-1}$; (b) values corrected to $p_{0}$ according to the self-broadening hypothesis; (c) values 


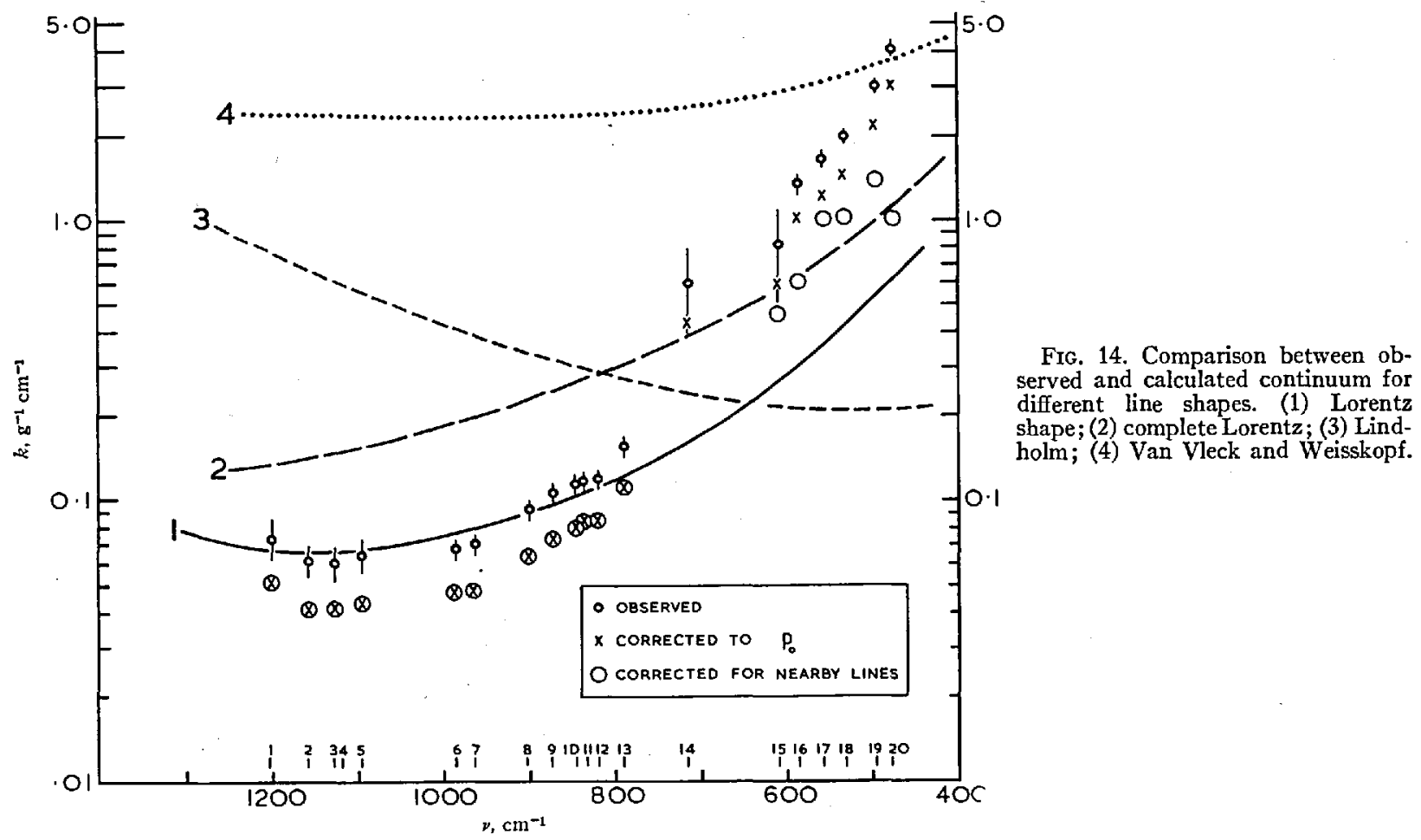

predicted by Eqs. (11.1) and (11.2) (Curve 1). Agreement between (a) and (c) is not unsatisfactory [better, indeed, than that between (b) and (c)] in the region $1200-800 \mathrm{~cm}^{-1}$, but the discrepancy increases rapidly for $\nu<800 \mathrm{~cm}^{-1}$. Better agreement might be expected here if the contribution from nearby lines were subtracted from the observed values. The strengths and half-widths of all lines in the region $1180-423 \mathrm{~cm}^{-1}$ were computed from the references cited earlier in this connection and their contribution, $\Delta k$, to the continuum in Windows 14 to 20 , assuming Lorentz line-shape, is given in Table IV. We see that neighboring lines are particularly important in Windows 18, 19, and 20, but even after allowing for their effect, a discrepancy of a factor of 3 remains between (c) and (b) at $500 \mathrm{~cm}^{-1}$. Although it may be argued that the effective band center must be moved nearer for this region, the shift required (to $\nu=340 \mathrm{~cm}^{-1}$ ) is far greater than can be accounted for by the profile of the rotation band, for which a shift to $\nu=235 \mathrm{~cm}^{-1}$ would be appropriate. It seems unlikely that the continuum can be represented over a wide region by any simple formula.

Benedict (1961) has suggested that the near wings (up to a few tens of wavenumbers) are stronger and the far wings weaker than Lorentz, and this would be consistent with the observations reported here. Much more precise observations of the absolute absorption coefficients and their temperature coefficients are required before a definite conclusion can be reached. Such observations are now being attempted by one of us.

For comparison with the prediction from the Lorentz shape, Fig. 14 also shows the continuum computed on the basis of other line shapes, which are:

Curve 2: the full Lorentz expression (Van Vleck and Weisskopf, 1945):

$$
k(\nu)=\sum \frac{S \alpha}{\pi} \frac{\nu}{\nu_{0}}\left[\frac{1}{\left(\nu-\nu_{0}\right)^{2}+\alpha^{2}}-\frac{1}{\left(\nu+\nu_{0}\right)^{2}+\alpha^{2}}\right] .
$$

Curve $3:$ the asymmetric Lindholm line shape (Plass and Warner, 1952):

$k(\nu)=0.933 \sum \frac{S \alpha}{\pi} M^{\frac{1}{3}}\left(\nu_{0}-\nu\right)^{-\frac{3}{3}} \quad$ for $\quad \nu<\nu_{0}$,
$k(\nu)=0.638 \sum \frac{S \alpha}{\pi} M^{-\frac{1}{3}}\left(\nu-\nu_{0}\right)^{-7 / 3}$ for $\nu>\nu_{0}$, where $M \bumpeq 3 \mathrm{~cm}$.

Curve $4:$ the line shape for the microwave and farinfrared region (Van Vleck and Weisskopf, 1945):

$$
k(\nu)=\sum \frac{S \alpha}{\pi} \frac{\nu^{2}}{\nu_{0}^{2}}\left[\frac{1}{\left(\nu-\nu_{0}\right)^{2}+\alpha^{2}}+\frac{1}{\left(\nu+\nu_{0}\right)^{2}+\alpha^{2}}\right] .
$$

We see that Curve 2 gives better agreement with the observations for $\nu<700 \mathrm{~cm}^{-1}$, but is too large by at least a factor of 2 in the region $1200-800 \mathrm{~cm}^{-1}$, whilst Curves 3 and 4 do not even give qualitative agreement. 


\section{ACKNOWLEDGMENTS}

Professor R. M. Goody advised on the inception of the solar absorption measurements and Dr. S. D. Smith on the horizontal path experiments. One of us (K.B.) is indebted to the Royal Society for a research studentship.

\section{BIBLIOGRAPHY}

Anthony, R., Phys. Rev. 85, 674 (1952).

Adel, A., Astrophys. J. 89, 1 (1939).

Benedict, W. S., Conference on Broadening of Spectral Lines, University of Pittsburgh, 1955.

Benedict, W. S. (private discussion, 1961).

Benedict, W. S. and Kaplan, L. D., J. Chem. Phys. 30, 388 (1959).

Cowling, T. G., Phil. Mag. 41, 109 (1950).

Deirmendjian, D., Quart. J. Roy. Meteorol. Soc. 85, 404 (1959); 86, 371 (1960).

Dorsey, E. N., Properties of Ordinary Water Substance (Reinhold Publishing Corporation, New York, 1940).

Elsasser, W. M., Phys. Rev. 53, 768 (1938); Heat Transfer by Infrared Radiation in the Atmosphere, Harvard Meteorol. Stud. No. 6 (Harvard University Press, 1942).

Gebbie, H. A., Harding, W. R., Hilsum, C., Pryce, A. W., and Roberts, V., Proc. Roy. Soc. (London) A706, 87 (1951).

Goody, R. M., Quart J. Roy. Meteorol. Soc. 83, 517 (1957).

Kaplan, L. D., Proc. Toronto Meteorol. Conf. 1953, 45.

Kaplan, L. D. and Eggers, D. F., J. Chem. Phys. 25, 876 (1956).
Middleton, W. E. K., Vision Through the Atmosphere (The University of Toronto Press, Toronto, Canada, 1952).

Migeotte, M., Neven, L., and Swensson, J., Mem. Soc. Roy. Sci. Liege, Vol. Hors Ser. 1 and $2(1956,1957)$.

Möller, F., Beitr. Geophysik 58, 27 (1942).

Nielsen, H. H., Phys. Rev. 59, 565 (1941).

Palmer, C. H., Jr., J. Opt. Soc. Am. 50, 1232 (1960).

Plass, G. N. and Warner, D., J. Meteorol. 9, 333 (1952).

Plyler, E. K. and Acquista, N., J. Opt. Soc. Am. 44, 505 (1954).

Roach, W. T. and Goody, R. M., Quart. J. Roy. Meteorol. Soc. 84, 319 (1958).

Saiedy, F. and Goody, R. M., Monthly Notices Roy. Astron. Soc. 119, 213 (1959).

Saiedy, F., Monthly Notices Roy. Astron. Soc. 121, 483 (1960a); Ph.D. thesis, London University (1960b); Quart J. Roy. Meteorol. Soc. 87, 578 (1961).

Schwendeman, R. H. and I,aurie, V. IV., Tables of Line Sirengths for Rolational Transitions of Asymmetric Rotor Molecules (Pergamon Press, New York, 1958). Taylor, J. H. and Yates, H. W., J. Opt. Soc. Am. 47, $223(195 \%)$.

Van de Hulst, H. C., Light Scallering by Small Particles (John Wiley \& Sons, Inc., New York, 1957).

Van Vleck, J. H. and Weisskopf, V., Rer. Mod. Phys. 17, 227 (1945).

Vigroux, F., Ann. Geophyss. 15, 453 (1959).

Volz, F., Arch. Meteorol. Geophys. Bioklimatol. B10, 100 (1959). 
(From the Quarterly Journal of the Royal Meteorological Society, Vol. 87, No. 372, April 1961)

Heat-balance measurements from an earth satellitean analysis of some possibilities

By K. J. BIGNELL

Imperial College, London 


\title{
Heat-balance measurements from an earth satellite- an analysis of some possibilities
}

\author{
By K. J. BIGNELL
}

Imperial College, London

(Manuscript received 3 August 1960; in revised form 7 December 1960)

\section{SUMMARY}

A detailed discussion of the basic 'black' and 'white' sphere experiment designed by Suomi, and successfully launched in more elaborate form in Explorer VII in October 1959, is presented. It is concluded that this experiment is in almost every respect well suited for making heat-balance measurements from a simple unstabilized satellite, but that it suffers from the serious disadvantage of any such system that the sampling rate is inadequate for giving the daily or short-term heat balance of any region of the earth. Other main conclusions are : the magnitude of the possible error incurred by employing a spherical detector to measure the vertical intensity of a diffuse, anisotropic radiation stream is estimated to be a few per cent only; corrections for heat transfer by conduction and radiation to the spheres from the main body of the satellite can be reduced to negligible proportions, but heating due to high velocity impacts with gas molecules may be considerable for low orbits $\left(0.16 \mathrm{cal} \mathrm{cm}^{-2} \mathrm{~min}^{-1}\right.$ at $\left.200 \mathrm{~km}\right)$; the time constant of the detector is shown to be not less than about two minutes; the sensitivity is of the order of $1^{\circ} \mathrm{K}$ per $0.01 \mathrm{cal} \mathrm{cm}^{-2} \mathrm{~min}^{-1}$; the prospects of checking the calibration of the equipment in flight seem reasonable.

\section{INTRODUCTION}

The importance of heat-balance measurements has been discussed in a paper by Suomi (1958) in which he describes apparatus for making the necessary observations from an earth satellite. Up to the date of writing, this appears to be the only satellite experiment proposed for heat-balance studies, although several writers mention the opportunities afforded by earth satellites (Kelly 1955; Widger and Touart 1957; Wexler 1960). The temperature variation of a satellite vehicle as a function of the radiative field is discussed by Gast (1956).

The instrumentation of a simple satellite must fulfil some very important requirements; the following are essential : simplicity, robustness, low weight and low power consumption. If the satellite is not attitude-controlled, a further very desirable property of a radiation instrument is that it should give the same response for all orientations and should not be influenced by spinning motions. The apparatus described by Suomi satisfies all of the above requirements. It consists essentially of two spherical detectors whose surfaces have different relative absorptivities in the visible and infra-red wavebands. By measuring the temperatures of the spheres it is possible to deduce the intensities of the long and short-wave radiation streams at the satellite, so that information on the heat balance of the earth-atmosphere system can be inferred. A recent article (National Academy of Sciences, Washington; I.G.Y. Bulletin No. 29) refers to a more elaborate array of sensing elements mounted on Explorer VII, consisting of four spheres and two hemispheres, but the principles of operation are not given.

The present study shows that while the technique described by Suomi is admirably adapted to an unstabilized satellite, there are certain difficulties in sampling and in the interpretation of the data. These difficulties are discussed in the following sections and summarized in $\S 7$. 
The following symbols are used :
A
$\frac{R}{R+h}$
B $\quad 2\left(\frac{1-\sqrt{1-A^{2}}}{A^{2}}\right)$
$B(\lambda, T)$ Planck function
$C_{L} \quad$ long-wave anisotropy factor
$C_{3} \quad$ short-wave anisotropy factor
$e_{\mathrm{L}} \quad$ long-wave absorptivity of a surface $(\lambda>4 \mu)$
$e_{L}^{\prime} \quad$ total hemispherical emissivity of a surface
e short-wave absorptivity of a surface $(\lambda<4 \mu)$
$F_{L} \quad$ outward vertical flux per unit area of long wave radiation from earth and atmosphere
$F_{N} \quad$ outward vertical flux per unit area of net radiation
$F_{s} \quad$ outward vertical flux per unit area of direct solar radiation, i.e., $F$, is negative
$F_{s s} \quad$ outward vertical flux per unit area of scattered solar radiation from earth and atmosphere
$h \quad$ height of satellite above earth's surface
$H \quad$ thermal capacity of sphere
$i \quad$ inclination of satellite orbit to the earth's equator
$k \quad \frac{e_{L}}{e_{s}} \quad k^{\prime}=\frac{e_{L}{ }^{\prime}}{e_{s}}$
$R \quad$ radius of earth
$r(p) \quad$ water vapour mixing ratio as function of pressure
$S$ solar constant at the outer limit of the earth's atmosphere $\left(2 \mathrm{cal} \mathrm{cm}^{-2} \mathrm{~min}^{-1}\right)$
$T(p) \quad$ temperature of atmosphere as function of pressure
$x \quad B C_{s} F_{s s}+S$
y $\quad B C_{L} F_{L}$
$Z \quad$ solar zenith angle
$\alpha \quad$ semi-angle subtended by earth at the satellite $=\sin ^{-1} A$
$\sigma \quad$ Stefan's constant $=5.73 \times 10^{-5} \mathrm{erg} \mathrm{cm}^{-2} \mathrm{sec}^{-1}{ }^{\circ} \mathrm{K}^{-4}$
$\left.\begin{array}{l}\psi \\ \theta\end{array}\right\}$ directional coordinates (see Fig. 1)

Other symbols are defined where they occur.

\section{SPECification of THE RADiation STREAMS}

Let us now specify the radiation streams at a point $\mathrm{P}$ height $h$ above $\mathrm{O}$ on the earth's surface (Fig. 1). The area visible from $P$ is indicated by the closed curve; the radius $r$ of this area (semi-angle at $\mathrm{P}=\alpha$ ) as a function of $h$ is given in Table 1 , together with the radii $\gamma_{0.5}$ and $\gamma_{0.75}$ of those areas subtending 50 per cent and 75 per cent respectively of the total solid angle subtended by the earth at $\mathrm{P}$. 


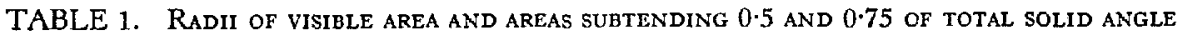

\begin{tabular}{lrrrrrrrrr}
\hline$h(\mathrm{~km})$ & 200 & 300 & 400 & 500 & 600 & 700 & 800 & 900 & 1,000 \\
$r(\mathrm{~km})$ & 1,591 & 1,912 & 2,190 & 2,450 & 2,670 & 2,860 & 3,040 & 3,200 & 3,360 \\
$r_{0.5}(\mathrm{~km})$ & 258 & 366 & 465 & 555 & 640 & 723 & 795 & 870 & 930 \\
$r_{0.75}(\mathrm{~km})$ & 450 & 615 & 770 & 905 & 1,030 & 1,135 & 1,255 & 1,360 & 1,457 \\
$B$ & 1.608 & 1.541 & 1.495 & 1.458 & 1.419 & 1.397 & 1.371 & 1.349 & 1.329 \\
\hline
\end{tabular}

The radiation streams at $\mathrm{P}$ are:

(i) Direct solar radiation denoted by $F_{s}$; very nearly all of this is confined to wavelengths shorter than $4 \mu$

(ii) Diffuse scattered solar radiation from the earth and atmosphere, denoted by $F_{s s} ;$ like $F_{s}$, this is confined to wavelengths shorter than $4 \mu$

(iii) Diffuse 'thermal' radiation from the earth and atmosphere, denoted by $F_{L}$; very nearly all of this is confined to wavelengths longer than $4 \mu$.

In general (ii) and (iii) will be anisotropic, so it is necessary to specify their intensities as functions of direction. In a system of cylindrical coordinates, let the intensities of (ii) and (iii) in a direction QP be $I_{s}(\theta, \psi)$ and $I_{L}(\theta, \psi)$ respectively, where

$$
I_{s}(\theta, \psi)=\int_{0}^{4 \mu} I_{\lambda}(\theta, \psi) d \lambda \quad I_{L}(\theta, \psi)=\int_{4 \mu}^{\infty} I_{\lambda}(\theta, \psi) d \lambda
$$

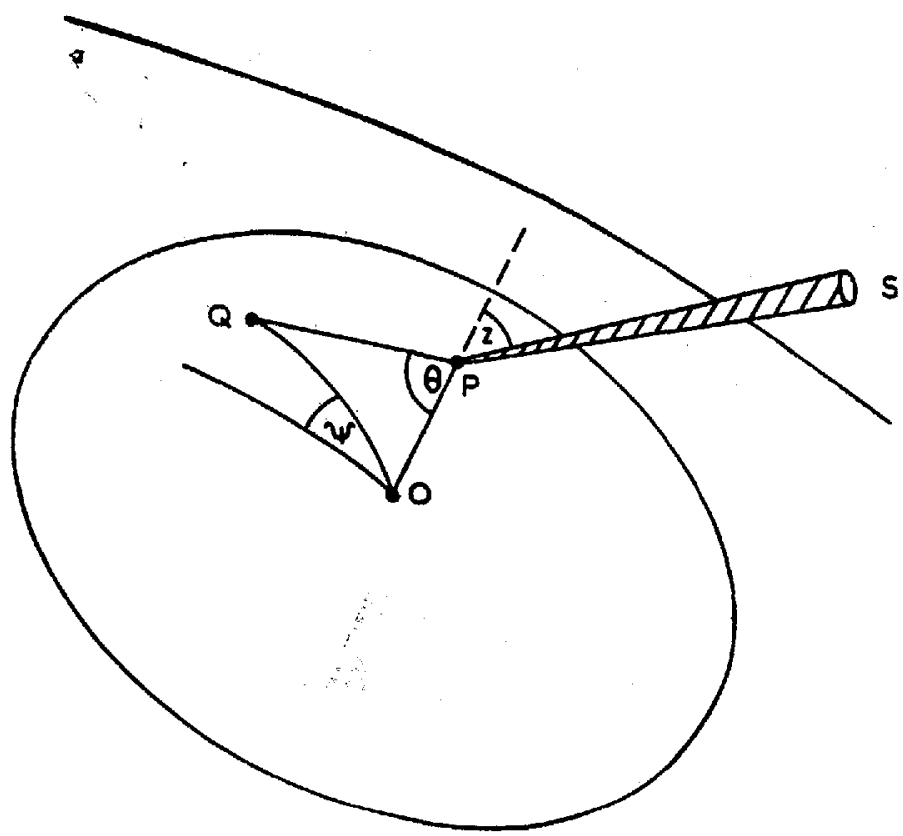

Figure 1. The area visible from the satellite at $\mathrm{P}$ is indicated by the closed curve. Solar radiation is incident along SP. $\mathrm{O}$ is vertically beneath $\mathrm{P}$ and the direction $\mathrm{PQ}$ is specified by $\theta, \psi$. 
The outward vertical fluxes of radiation per unit area for each radiation stream are then given by :

$$
\left.\begin{array}{l}
\text { (i) } F_{s}=-S \cos Z \\
\text { (ii) } F_{s s}=\int_{\psi=0}^{\psi=2 \pi} \int_{\theta=0}^{\theta=\alpha} I_{s}(\theta, \psi) \sin \theta \cos \theta d \theta d \psi=2 \pi \int_{0}^{\alpha} I_{s}(\theta) \sin \theta \cos \theta d \theta \\
\text { (iii) } F_{L}=\int_{\psi=0}^{\psi=2 \pi} \int_{\theta=0}^{\theta=\alpha} I_{L}(\theta, \psi) \sin \theta \cos \theta d \theta d \psi=2 \pi \int_{0}^{\alpha} I_{L}(\theta) \sin \theta \cos \theta d \theta
\end{array}\right\}
$$

where $I_{s}(\theta)$ and $I_{L}(\theta)$ are the mean intensities around a strip with constant $\theta$.

\section{Measurement of the radiative fluxes}

\section{(a) Introduction}

In general, the only direct way of measuring the flux of a diffuse radiation stream across unit area in a given direction is to employ a plane-sensing element placed normal to this direction. But this, for satellite use, would involve the difficult task of satellite stabilization in a terrestrial frame, and the use of an omnidirectional sensor is therefore suggested. It is shown in $\S 3(b)$ that it is then necessary to know the functions $I_{s}(\theta)$ and $I_{L}(\theta)$ in order to obtain a correct result. The only truly omnidirectional sensor is an isolated sphere.

\section{(b) Theory of the spherical sensor}

Consider a sphere, radius $a$, situated at $P$ (Fig. 1). We want to find the relation between the flux $f$ incident on the sphere (this determines its temperature, which is to be the measured quantity) and the outward vertical flux per unit area, $F$, of any radiation stream at $P$. We have

which with Eq. (1) gives

$$
f=\pi a^{2} \int_{0}^{\alpha} I(\theta) 2 \pi \sin \theta d \theta
$$

$$
F=\frac{1}{\pi a^{2}} \frac{\int_{0}^{\alpha} I(\theta) \sin \theta \cos \theta d \theta}{\int_{0}^{\alpha} I(\theta) \sin \theta d \theta}
$$

It is convenient to rearrange this by multiplying and dividing by

Then $\quad F=\frac{1}{\pi a^{2} C B} f$

$$
B=\frac{\int_{0}^{\alpha} \sin \theta d \theta}{\int_{0}^{\alpha} \sin \theta \cos \theta d \theta}=2 \frac{1-\sqrt{1-A^{2}}}{A^{2}}
$$

where

$$
C=\frac{\int_{0}^{\alpha} \sin \theta \cos \theta d \theta \int_{0}^{\alpha} I(\theta) \sin \theta d \theta}{\int_{0}^{\alpha} I(\theta) \sin \theta \cos \theta d \theta \int_{0}^{\alpha} \sin \theta d \theta}
$$

For numerical values of $B$ as a function of $h$, see Table 1. 
(c) Effects of anisotropic radiation

For isotropic radiation, $I(\theta)=$ constant and $C=1$ from Eq. (3). For all other cases $C$ will be different from unity because a spherical sensor gives equal weight to radiation from all directions, whereas the vertical flux per unit area, $F$, is a sum over all elements of solid angle weighted by $\cos \theta$. So if $I(\theta)$ is a decreasing function of $\theta$ (limb darkened), $C$ will be less than unity to offset the effect of the added weight given to the darker limb regions. Similarly, if the limb is brighter than the central regions, $C$ will be greater than unity.
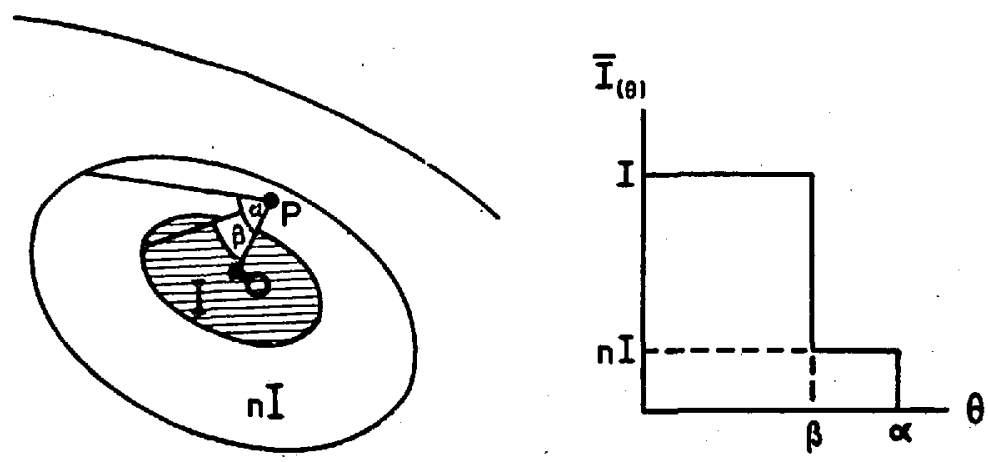

(a)
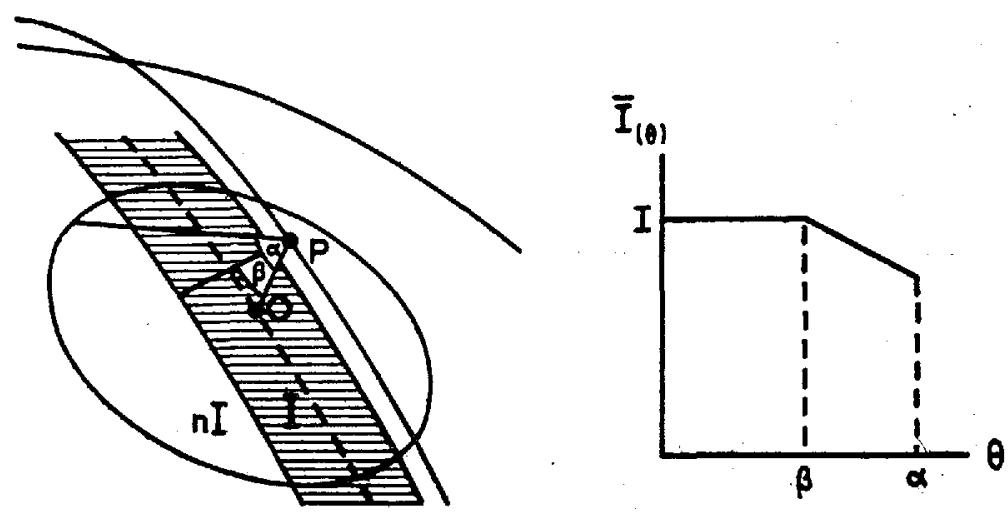

(b)

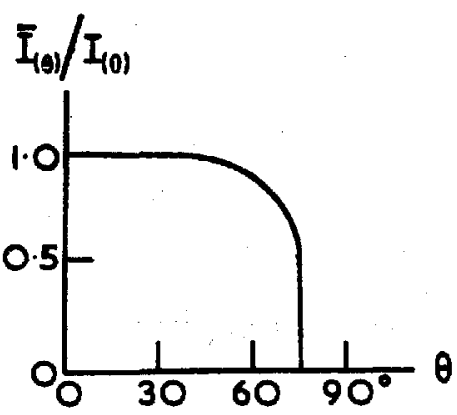

(c)

Figure 2 (a) (b) (c). Fields of anisotropic radiation : (a) for instantaneous response; (b) for slow response. The figures on the left in (a) and (b) show the bright (unshaded) and dark (shaded) areas corresponding to the figures on the right. Typical limb darkening in the infra-red is shown in (c) for $h=200 \mathrm{~km}$. 
It is of interest to know the limits between which $C$ must lie. The derivation of the function $I(\theta)$ giving a stationary value to $C$ is difficult, but a simple approximation which is particularly appropriate here is a step function, since bright and dark regions will often be separated by sharp boundaries, such as the edges of cloud systems. With this simplification the departure of $C$ from unity will be a maximum (see Fig. 2 (a)) when

$$
\left.\begin{array}{l}
I(\theta)=\operatorname{constant}(=I) \quad \text { for } \quad 0<\theta<\beta \\
I(\theta)=\text { constant }(=n I) \text { for } \quad \beta<\theta<\alpha
\end{array}\right\}
$$

where $n$ is a constant and $\beta$ is to be determined.

The value to be taken for $n$ is the ratio of the maximum and minimum intensities likely to occur over the area visible from the satellite. For long-wave terrestrial radiation $n$ is about 2 or 3 , corresponding to the ratio of the total black body intensities at around $280^{\circ} \mathrm{K}$ and $220^{\circ} \mathrm{K}$. For reflected solar radiation $n$ can be as high as 10 , corresponding to the albedo ratio of snow or cloud and the oceans. The stationary value $C_{0}$ of $C$ is easily determined by inserting Eq. (4) into Eq. (3) and eliminating $\beta$ by using the condition $(\partial C / \partial \beta)_{C=C_{0}}=0$. The result is

$$
C_{0}=\frac{A^{2}}{2\left(1-\sqrt{1-A^{2}}\right)} \frac{1+\sqrt{n}}{\left(1+\sqrt{n} \sqrt{1-A^{2}}\right)}
$$

Inspection of Eq. (5) yields the following :

$$
\begin{array}{lll}
\text { (i) For isotropic radiation } n=1 & \text { and } & C_{0}=1 \text { for all } h \\
\text { (ii) As } A \rightarrow 0 \text { (i.e., } h \rightarrow \infty) & & C_{0} \rightarrow 1 \text { for all } n \\
\text { (iii) } & \text { As } A \rightarrow 1 \text { (i.e., } h \rightarrow 0) & C_{0} \rightarrow(1+\sqrt{n}) / 2
\end{array}
$$

Values of $C_{0}$ for $n=2,10, \frac{1}{2}$ and $\frac{1}{10}$ as a function of $h$ are given in Table 2 .

TABLE 2. Values of $C_{0}$ as a function of height and $n$

\begin{tabular}{llllllllll}
\hline$h(\mathrm{~km})$ & 200 & 300 & 400 & 500 & 600 & 700 & 800 & 900 & 1.000 \\
$n=10$ & 1.46 & 1.40 & 1.35 & 1.31 & 1.29 & 1.27 & 1.25 & 1.24 & 1.22 \\
2 & 1.12 & 1.10 & 1.09 & 1.08 & 1.08 & 1.07 & 1.07 & 1.06 & 1.06 \\
$\frac{1}{2}$ & 0.903 & 0.916 & 0.921 & 0.926 & 0.935 & 0.937 & 0.940 & 0.943 & 0.948 \\
$\frac{1}{10}$ & 0.761 & 0.779 & 0.794 & 0.807 & 0.823 & 0.828 & 0.837 & 0.845 & 0.855 \\
\hline
\end{tabular}

We see that $\left(1-C_{0}\right)$ decreases with increasing $h$, i.e., uncertainties due to anisotropy are smaller for high orbits. It should be emphasized that these values of $C_{0}$ correspond to the most unfavourable distributions of radiating matter below the satellite, and would be encountered very rarely. They take the form of a circular bright (or dark) area centred under the satellite surrounded by a dark (or bright) region (see Fig. 2 (a)). For long-wave radiation, with $\frac{1}{2}<n<2$, we obtain $0.9<C_{\mathrm{L}}<1.1$ and for short-wave radiation, with $\frac{1}{10}<n<10$, we obtain $0.76<C_{s}<1.46$ at a height of $200 \mathrm{~km}$, which is the lowest height at which a satellite has a useful lifetime. These are instantaneous values, and, as the satellite traverses such regions, the form of $I(\theta)$ changes rapidly such that $C$ returns towards unity. Since the time constant of a practicable detector is likely to be of order one minute (see $\S 3(g)$ ) we are more interested in the possible extremes in the mean value $\bar{C}$ over about five minutes than in the instantaneous value. If in this time the satellite travels a distance comparable with the instantaneous diameter of its field of view the variation in intensity in the direction of motion is smoothed out and the only contrasts of importance are those perpendicular to the path. From Table 1 we see that this is a fair approximation for low orbits (speed $\bumpeq 8 \mathrm{~km} \mathrm{sec}^{-1}$ ). The configuration of radiating surfaces 
giving an extreme value to $\bar{C}$ for this case is a bright (or dark) lane placed centrally under the satellite's orbit in a dark (or bright) region (see Fig. 2 (b)). Approximate calculations show that, for the above values of $n$, we now have $0.98<\bar{C}_{L}<1.02$ and $0.9<\bar{C}_{s}<1.1$ at a height of $200 \mathrm{~km}$. Thus the smoothing effect of the slow detector is such that we may enter Table 2 with $0.8<n<1.2$ for long-wave radiation and $0.5<n<2$ for shortwave radiation.

A further cause of anisotropy, in the case of long-wave radiation, is the 'natural ' limb darkening due to obliquity of view of an atmosphere in which temperature and composition are height-dependent. Approximate calculations for a typical atmosphere (e.g., Elsasser 1942, p. 27) were made using the Elsasser radiation chart, giving the result shown in Fig. 2 (c) for a height of $200 \mathrm{~km}$. For this distribution we find that $1.01>C_{L}>1.005$ for $200 \mathrm{~km}<h<1,000 \mathrm{~km}$.

Summarizing the above discussion, we can state that in all cases

$$
\begin{aligned}
& 0.98<\bar{C}_{L}<1.02 \\
& 0.9<\bar{C}_{s}<1.1
\end{aligned}
$$

Since the special configurations of cloud giving rise to these limiting values will be very rare and the pattern of intensity contrasts will not often be highly organized, $\bar{C}$ will in general be much closer to unity than these limits.

\section{(d) Equilibrium temperature of the sphere as a function of the radiation field}

Initially we neglect any heat transfer by conduction and radiation from the main body of the satellite and by conduction to the very tenuous atmosphere. From Eq. (2) the long and short-wave fluxes absorbed by the sphere are

$$
\left.\begin{array}{l}
f_{L}=\pi a^{2} B C_{L} F_{L} e_{L} \\
f_{s}=\pi a^{2}\left(B C_{s} F_{s s}+S\right) e_{s}
\end{array}\right\}
$$

where $e_{L}$ and $e_{s}$ are the respective absorptivities of the surface defined by

$$
e_{L}=\frac{\int_{4 \mu}^{\infty} e_{\lambda} I_{\lambda} d \lambda}{\int_{4 \mu}^{\infty} I_{\lambda} d \lambda} \quad e_{s}=\frac{\int_{0}^{4 \mu} e_{\lambda} I_{\lambda} d \lambda}{\int_{0}^{4 \mu} I_{\lambda} d \lambda}
$$

where $e_{\lambda}$ is the hemispherical spectral emissivity of the surface and $I_{\lambda}$ is the spectral distribution of the incident radiation stream.

If the effective equilibrium temperature of the sphere is $T$, then

where

$$
f_{L}+f_{s}=4 \pi a^{2} \sigma T^{4} e_{L}^{\prime}
$$

$$
e_{L}^{\prime}=\frac{\int_{4 \mu}^{\infty} e_{\lambda} B_{(\lambda, T)} d \lambda}{\int_{4 \mu}^{\infty} B_{(\lambda, T)} d \lambda}
$$

In fact there will be some variation of temperature over the surface of the sphere, depending on the orientation of the spin axis relative to the incident radiation. In the worst case of solar radiation incident along the spin axis the temperature difference between the poles is proportional to $a^{2} e_{s} / K d$ where $K$ is the thermal conductivity of the shell and $d$ its thickness. For a black painted aluminium sphere $1 \mathrm{~cm}$ in diameter and $0.1 \mathrm{~mm}$ thick the temperature difference is of the order of $1^{\circ} \mathrm{C}$, assuming the paint to be a good conductor. 
Eqs. (6) and (7) give

where

$$
B\left(C_{L} F_{L} k+C_{s} F_{s s}\right)+S=4 \sigma k^{\prime} T^{4}
$$

$$
k=\frac{e_{L}}{e_{s}} \quad k^{\prime}=\frac{e_{L}^{\prime}}{e_{s}}
$$

For the ideal surface material $e_{\lambda}$ would be constant out to at least $20 \mu$. Then $e_{L}=e_{L}{ }^{\prime}$ and $k=k^{\prime}$ to a very close approximation. In practice, $e_{\lambda}$ would not be constant, but the difference between $e_{L}$ and $e_{L}^{\prime}$ should not be more than a few per cent since the weighting functions $B_{(\lambda, T)}$ and $I_{\lambda}$ are broadly similar, the main difference being that $I_{\lambda}$ is relatively large in the $8-13 \mu$ window region.

\section{(e) Measurement of $F_{N}$}

The quantity of greatest interest to the meteorologist is the net flux of radiation $F_{N}$ from the earth-atmosphere system; the earth satellite provides an opportunity of making world-wide measurements for the first time. We now discuss the determination of $F_{N}$ at the position of the satellite. We have $F_{N}=F_{L}+F_{s s}-S \cos Z$, considered as positive in the outward direction. This can be written, using Eq. (8), as

$$
F_{N}=\frac{4 \sigma k^{\prime} T^{4}}{B}-S\left(\frac{1}{B}+\cos Z\right)+(1-k) C_{L} F_{L}-\left(1-\frac{1}{\bar{C}_{L}}\right) C_{L} F_{L}-\left(1-\frac{1}{\bar{C}_{s}}\right) C_{s} F_{s s}
$$

In this form we separate those terms which can in principle be determined experimentally from those which can not. Since the product $\bar{C}_{L} F_{L}$ can be determined $(\S 3(f))$, while $\bar{C}_{L}$ and $\bar{C}_{s}$ are both unknown, only the last two terms on the right-hand side of Eq. (9) cannot be evaluated, though some indication of their values might be available from synoptic charts of cloud cover. The upper limits of these terms are estimated to be 0.01 and $0.1 \cos Z \mathrm{cal} \mathrm{cm}^{-2} \mathrm{~min}^{-1}$ respectively, since $F_{L}<0.5$ and $F_{s}<\cos Z \mathrm{cal} \mathrm{cm}^{-2} \mathrm{~min}^{-1}$ under the conditions giving rise to extreme values of $C_{L}$ and $C_{s}$.

In most cases these terms will be much smaller than the values given above so that their neglect would not lead to serious error in $F_{N}$ when $F_{N}$ is greater than $0.1 \mathrm{~S} \cos Z$.

A special case of Eq. (9) should be noted : if we choose $k=1$ and neglect the last two terms, the expression for $F_{N}$ reduces to

$$
F_{N}=\frac{4 \sigma k^{\prime} T^{4}}{B}-S\left(\frac{1}{B}+\cos Z\right)
$$

So a single sphere can give all the information necessary for measuring $F_{N}$ ( $S$ is to be assumed) without determining the component fluxes separately. However, it may not be possible to obtain a surface with $k=1$ in which case it would be necessary to determine $C_{L} F_{L}$ in order to evaluate the third term in Eq. (9); this problem is dealt with in the next section.

\section{(f) Discrimination between and determination of the fluxes}

Even if it were possible to obtain $F_{N}$ without measuring the long and short-wave fluxes separately, it would still be of great interest to measure the latter fluxes. In particular, a measure of $F_{s s}$ would give the albedo of the underlying surface, which in turn is a measure of the cloud amount.

A simple special case arises when the satellite is in the earth's shadow. Eq. (8) then reduces to

$$
B C_{L} F_{L}=4 \sigma T^{4} \frac{k^{\prime}}{k}=4 \sigma T^{4} \frac{e_{L}^{\prime}}{e_{L}}
$$

We see that $C_{L} F_{L}$ can be determined on the night side of the earth by measuring $T$ only. Further, since $k^{\prime} / k \bumpeq 1\left(=e_{L}^{\prime} / e_{L}\right)$ to a very good approximation for all surfaces [see $\S 3(d)$ ], $T$ will depend only slightly on the coating material of the sphere, especially as $T \propto\left(k / k^{\prime}\right)^{\frac{l}{4}}$. 
On the sunlit side of the earth we must employ two spheres whose surfaces have different values for $k\left(k_{1}\right.$ and $\left.k_{2}\right)$. We then obtain two equations of the form of Eq. (8) which are solved to give

$$
\begin{aligned}
& B C_{L} F_{L}=4 \sigma \frac{k_{1}^{\prime} T_{1}^{4}-k_{2}^{\prime} T_{2}^{4}}{k_{1}-k_{2}}=y \\
& B C_{s} F_{s s}+S=4 \sigma \frac{k_{1} k_{2}}{k_{2}-k_{2}}\left(\frac{k_{1}^{\prime}}{k_{1}} T_{1}^{4}-\frac{k_{2}^{\prime}}{k_{2}} T_{2}^{4}\right)=x
\end{aligned}
$$

The relation between the incident fluxes and the equilibrium temperature of a sphere is shown in Fig. 3 for $k_{1}=k_{1}{ }^{\prime}=20$ ('white' sphere) and $k_{2}=k_{2}{ }^{\prime}=1$ (' black' sphere), 'black' and 'white' referring to properties in the visible. The sensitivity $\Delta T / \Delta F$ is readily assessed from this diagram, which clearly illustrates the decrease of sensitivity with increase of sphere temperature. Typical values of $\Delta T / \Delta F_{L}$, with $B=1.5$, are $0.14^{\circ} \mathrm{K}$ and $0.04^{\circ} \mathrm{K}$ per $0.001 \mathrm{cal} \mathrm{cm}^{-2} \mathrm{~min}^{-1}$ at $T=200^{\circ} \mathrm{K}, 300^{\circ} \mathrm{K}$ respectively.

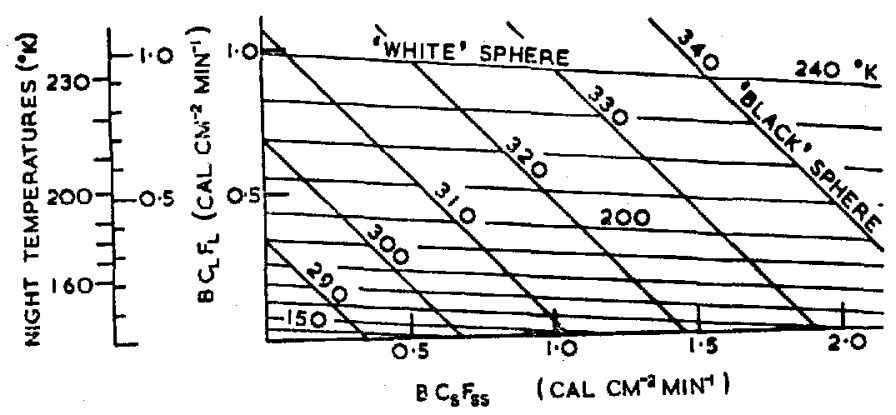

Figure 3. Relation between the incident fluxes and the equilibrium temperatures of black $\left(k_{2}=k_{2}^{\prime}=1\right)$ and white $\left(k_{1}=h_{1}^{\prime}=20\right)$ spheres $\left(S=2 \mathrm{cal} \mathrm{cm}^{-2} \mathrm{~min}^{-1}\right)$. Over the night side of the earth both spheres have the same temperature.

A discussion of the errors of the determination of $x$ and $y$ from Eqs. (11) and (12) is given in $\S 6$. It is shown there that the error in $x$ is considerably larger than that in $y$. This is particularly unfortunate from the point of view of estimating albedo since the relevant part of $x$ (i.e., $B C_{s} F_{s s}$ ) is often - with low sun - only a small fraction of $S . \cdot$ The consequence is that $F_{s s}$ can be measured only to moderate or poor relative accuracy, especially when it is small, i.e., when the solar zenith angle is large; under these conditions we can estimate the albedo only roughly.

Suomi (1958) refers to an alternative method of measuring $F_{s s}$ over areas where the sun is low. He employs two additional spheres of low long-wave emissivity (Tabor coating, $k=0.11$ ) and shielded from sunlight. It is difficult to assess the likely improvement in the precision of the measurement without a knowledge of the geometry of the shields and the effects of obscuration of the scattered radiation and their own long-wave emission, and possible incomplete shielding from the sun as the spin axis of the satellite precesses.

\section{(g) Effect of time constant and local sources of heat}

The incident flux of radiation will be a varying quantity, and the time constant of the sphere will lead to a lagging response. The effect on sphere temperature of the heat transfer by radiation and conduction from the main body of the satellite and from the residual atmosphere is also to be considered. 
The time constant of a spherical shell of thickness $d$, density $\rho_{s}$ at temperature $T$ is $\tau=d \rho_{s} C / 4 \sigma T^{3} e_{L}^{\prime}$ where $C$ is the specific heat of the material. This is the lower limit for $\tau$ since the conductivity of the shell and coating has been assumed infinite. For a magnesium shell $0.1 \mathrm{~mm}$ thick we find $\tau=60 \mathrm{sec}$ at $T=200^{\circ} \mathrm{K}$ and $20 \sec$ at $T=300^{\circ} \mathrm{K}$. Although it would seem desirable to have a faster response, the advantage is probably rather doubtful since the time averages $\bar{C}_{L}$ and $C_{s}$ are more uncertain for shorter intervals (see $\S(3 c)$ ). It is to be noted that in an interval of about 5 minutes the satellite traverses a distance of the same order as its instantaneous diameter of vision on the earth.

The heat transfer to the sphere by conduction and radiation from the main satellite body can be reduced to negligible proportions by separating these bodies sufficiently. Since only very slender supports are required there is in principle no difficulty in obtaining the required separation and the ideal conditions so far considered may almost be realised in practice.

The energy dissipation due to collisions with gas molecules is given by $\frac{1}{2} \pi a^{2} \rho V^{3}$ where $\rho$ is the air density and $V$ is the satellite velocity (large compared with molecular thermal velocities). Assuming this energy to be used in heating the sphere, putting $V=8 \mathrm{~km} \mathrm{sec}^{-1}$ and using recent satellite data for $p$ (King-Hele 1960), we find that this source of heat is equivalent to an increase of $0.15 \mathrm{cal} \mathrm{cm}^{-2} \mathrm{~min}^{-1}$ in the incident radiation stream at $h=2.00 \mathrm{~km}\left(\rho=4 \times 10^{-13} \mathrm{gm} \mathrm{cm}^{-3}\right)$ and $0.002 \mathrm{cal} \mathrm{cm}^{-2} \mathrm{~min}^{-1}$ at $h=400 \mathrm{~km}$ $\left(\rho=6 \times 10^{-15} \mathrm{gm} \mathrm{cm}^{-3}\right)$. Thus, provided perigee height is greater than about $400 \mathrm{~km}$, the effect is negligible.

\section{(h) Reduction of the observations to a standard level}

In general, the satellite's orbit will be elliptical and the flux measurements will be made from different heights at different points in the orbit. It is desirable, indeed essential for integral studies, to reduce the observations to a standard level, at height $h_{0}$, say. The flux per unit area at $h_{0}$ can be written:

$$
F_{h_{0}}=K\left(\frac{R+h}{R+h_{0}}\right)^{2} F_{h}
$$

where $K$ is a constant at any instant. When the region visible from the satellite is horizontally homogeneous the radiation field below the satellite is radial and $K=1$, but in all other cases it will differ from unity by an amount depending on the location and intensity of inhomogeneities. It becomes progressively more difficult to estimate $K$ as $h_{0} \rightarrow 0$, where the field can be appreciably non-radial, so that it is probably not profitable to reduce the observations to a level lower than perigee height. As an example, in the reduction of an observation made at $h=1,000 \mathrm{~km}$ to $h_{0}=500 \mathrm{~km}$, we find $0.5<K<2$ for $n=10$ and $0.8<K<1.2$ for $n=2$.

\section{Choice of $k$}

For a two-sphere system we must choose $k_{1}$ and $k_{2}$ so that the effect of errors in the measured values of $T_{1}, T_{2}, k_{1}$ and $k_{2}$ is a minimum. A statistical analysis shows that the errors are minimized by making $k_{1}-k_{2}$ as large as possible, i.e., the surfaces should have the largest possible difference in relative emissivities in the long and short wavebands.

There is a major disadvantage in employing a surface with $k<1$ since this can only be achieved by making $e_{L}<1$ and so increasing the time constant, which at best is already long ( $>1$ minute). Further, diminishing $e_{L}$ could lead to undesirably high temperatures, at which conventional thermistor materials cannot be used, e.g., a Tabor coated sphere with $k=0.11$ attains a temperature of $500^{\circ} \mathrm{K}$ to $600^{\circ} \mathrm{K}$ on the day side of the earth. 
The practicable upper limit of $k$ depends on how highly reflecting a surface can be made in the solar waveband. Suomi quotes a value of $k=19$ for lead carbonate white paint for which $e_{L}=0.95$ and $e_{s}=0.05$; other figures quoted are for black paint $\left(e_{L}=e_{s}=0.95\right)$ and for the Tabor coating $\left(e_{L}=0.10, e_{s}=0.90\right)$.

We conclude that the choice of $k$ is mainly determined by technical restrictions, with $k_{1} \simeq 20, k_{2} \bumpeq 1$.

\section{IN-FLIGHT CALIBRATION}

\section{(a) Introduction}

Ideally, once the satellite leaves the laboratory the instrumentation should maintain its calibration, i.e., the $k$ 's and the temperature calibrations (temperature vs signal parameter) should not change. There is the possibility that both of these conditions could fail, the first owing to surface erosion by micrometeorites or radiation damage (Lagow 1957) and the second owing to the development of minor faults in the electronics, including the temperature measuring elements. There are ways of detecting the occurrence of these defects from the observations and it might be possible to correct for them to a fair degree of accuracy.

\section{(b) Check on temperature calibration}

We have already seen from Eq. (10) that both spheres must have nearly the same temperature when on the dark side of the earth. If the observations indicate an abnormal systematic difference of temperature, then a fault must be inferred in the temperature calibration of at least one sphere, which may be located in either measuring element or in a part of the electronic circuits not common to both elements. In the event of a serious change of calibration it would be possible to recalibrate approximately by reversing the sense of the experiment on suitable occasions, e.g., when the satellite is known to be over a substantial area of reasonably homogeneous surface and atmosphere of known constitution $\left(T(p)\right.$ and $r(p)$ from radiosonde data). It would then be possible to compute $F_{L}$ from radiation charts to fair accuracy $( \pm 10$ per cent) and thence determine the temperature of the spheres to $\pm 5^{\circ} \mathrm{K}$ (from Eq. (10) $\Delta T / T=\frac{1}{4} \Delta F_{L} / F_{L}$ ). This provides a single check to $\pm 5^{\circ} \mathrm{K}$ at one point on the temperature calibration. By making repeated checks of this kind over different regions of the earth, the accuracy could be improved and the range covered would be about $160^{\circ} \mathrm{K}$ to $200^{\circ} \mathrm{K}$.

\section{(c) Check on surface emissivities}

The cooling and warming curves as the satellite enters or leaves the earth's shadow might allow estimates of the emissivities of the surface to be made. At these times there is a large known change $\left( \pm S\right.$ ) in the incident radiation and the slope of $d T / d t$ against $T^{4}$ is then proportional to $e_{L}{ }^{\prime}$ provided that the fluxes arriving from the earth are not also changing. The magnitude of the latter changes is, however, relatively small. With similar reservations, the value of $e_{s}$ can be inferred directly from the change in the value of $d T / d t$ at the instant of sunrise or sunset. Although the precision of an individual check of this kind is unlikely to be high, it will be possible to perform them about 30 times per day.

It should also be noted that the combination $k_{1} k_{2} / k_{1}-k_{2}$ could be estimated from observations taken when the satellite is in sunshine over the twilight region of the earth, for $\mathrm{Eq}$. (12) then provides, as $F_{s s} \rightarrow 0$,

$$
S=4 \sigma \frac{k_{1} k_{2}}{k_{1}-k_{2}}\left(\frac{k_{1}{ }^{\prime}}{k_{1}} T_{1}^{4}-\frac{k_{2}{ }^{\prime}}{k_{2}} T_{2}{ }^{4}\right)
$$

in which [see $\S 3(\mathrm{~d})] k_{1}^{\prime} / k_{1}, k_{2}^{\prime} / k_{2} \bumpeq 1$. Thus the precision in measuring $F_{s s}$ is aided (see, also, $\S 6$ below). This check can be made about 15 times daily, just before entry into the shadow (observations taken just after exit from the shadow will be subject to large lag corrections as the temperatures are then changing rapidly). 


\section{ERRORS}

Errors in the flux determinations due to uncertainties in $k_{1}$ and $k_{2}$ will be systematic, while those due to uncertainties in $T_{1}$ and $T_{2}$ will be partly random. For this reason these sources of error are considered separately. Table 3 gives estimated errors in the derived fluxes for uncertainties of \pm 5 per cent in $k_{1}$ and $k_{2}\left(k_{1}=20, k_{2}=1\right)$ and $\pm 1^{\circ} \mathrm{K}$ in $T_{1}$ and $T_{2}$.

It has been assumed for the purpose of this analysis that $k_{1}$ and $k_{2}$ are known only from laboratory measurements to \pm 5 per cent. The resulting relative error in $k_{1} k_{2} / k_{1}-k_{2}$ is about 10 per cent. As explained in $\S 5(c)$ this factor can be determined from in-flight data. If $T_{1}$ and $T_{2}$ are measured to $\pm 1^{\circ} \mathrm{K}$ then it is determined to about \pm 3 per cent, which may be better than the accuracy obtainable from laboratory measurements, giving improved precision in the measurement of $F_{s s}$.

TABLE 3. SUMMARY OF ERRORS DUE TO STATED UNCERTAINTIES IN $k$ AND $T$ (units are $\mathrm{cal} \mathrm{cm}^{-2} \mathrm{~min}^{-1}$ )

\begin{tabular}{|c|c|c|c|c|c|}
\hline Quantity & & $\begin{array}{c}\text { From error in } T \\
\pm 1^{\circ} \mathrm{K} \\
\text { (Partly random) }\end{array}$ & $\begin{array}{l}\text { From error in } h \\
( \pm 5 \text { per cent) } \\
\text { (Systematic) }\end{array}$ & $\begin{array}{c}\text { Anisotropy } \\
\text { error }\end{array}$ & $\begin{array}{c}\text { Range of } \\
\text { quantity }\end{array}$ \\
\hline$B C_{s} F_{s s}$ & & .04 to $.0 \mathrm{~s}$ & 0 to 0.2 & 0 & 0 to 2 \\
\hline \multirow{2}{*}{$B C_{L} F_{L}$} & Day & .003 to .018 & 0 to 0.2 & 0 & 0.2 to 1.0 \\
\hline & Night & .003 to .018 & 0 & 0 & 0.2 to 0.5 \\
\hline \multirow{2}{*}{$F_{N}$} & Day & $0 \quad$ to 0.02 & 0 to 0.1 & $0 \cdot 1 \cos Z$ & 0.1 to -1.5 \\
\hline & Night & to 0.02 & 0 & 0.01 & 0.2 to 0.3 \\
\hline
\end{tabular}

\section{SAMPLING}

We now examine the sampling obtainable by a satellite. Figure 4 shows the disposition of the satellite's orbit with respect to the earth's equator and orbit in the most general case. The terminator is the great circle dividing the day and night sides of the earth;

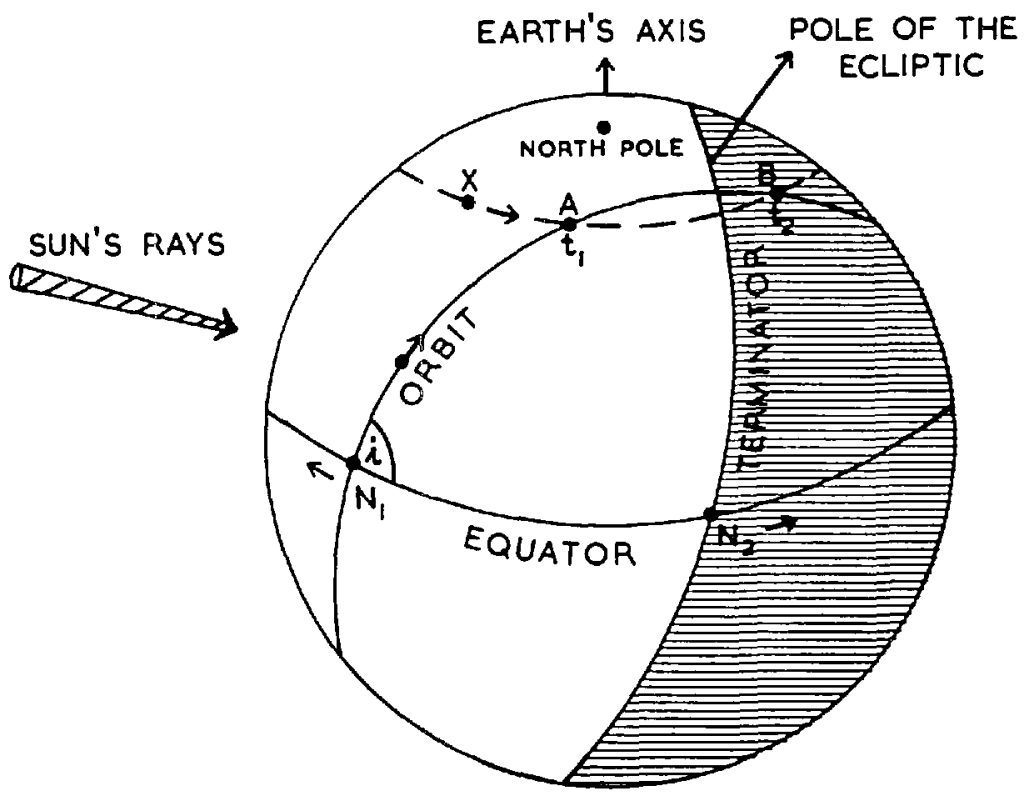

Figure 4. Geometry of a satellite orbit 
it rotates slowly in space (at about $1^{\circ}$ per day) about the pole of the ecliptic, which is the normal to the plane of the earth's orbit, so that its intersection $N_{2}$ with the equator moves in the direction indicated. The satellite's orbit precesses about the earth's axis in the direction shown at a rate of approximately $9 \cos i$ degrees per day (for a low, nearly circular orbit; King-Hele 1960), its inclination $i$ remaining constant. Consider a point $X$ situated on the earth at latitude $\phi(<i)$. Since the rotation of the earth carries $X$ under the orbit twice a day it follows that the satellite, unless otherwise controlled in flight, will, in general, pass close to $X$ only twice daily, when $X$ is near $A$ and $B$. It is convenient to specify $A$ and $B$ by their local solar times $t_{1}$ and $t_{2}$. It is apparent that all places with latitude $\phi$ will be observed by the satellite at about the same two local times $t_{1}$ and $t_{2}$. The effect of the earth's angular motion around the sun and the precession of the satellite's orbit is to cause a slow change in $t_{1}$ and $t_{2}$ given by

$$
\frac{\partial t_{1}}{\partial t}=\frac{\partial t_{2}}{\partial t} \bumpeq-.4(1+9 \cos i) \min \text { day }^{-1} \text { (for a low, nearly circular orbit) }
$$

So the satellite will cross a given latitude circle about 22 min earlier (in local time) each day for $i \bumpeq 60^{\circ}$. For the special case of $i=96 \cdot 5^{\circ}$ the orbital precession cancels the earth's angular motion and the satellite always crosses a given latitude circle at the same local times.

Since the orbital period is $1 \frac{1}{2}$ to 2 hours, we should obtain $12-16$ observations around each latitude circle in the course of a day at each of two nearly fixed local times determined initially by the time of launch. Since the useful area observed by the satellite is of order $1,000 \mathrm{~km}$ across, a good sample of observations will be provided in longitude, $L$.

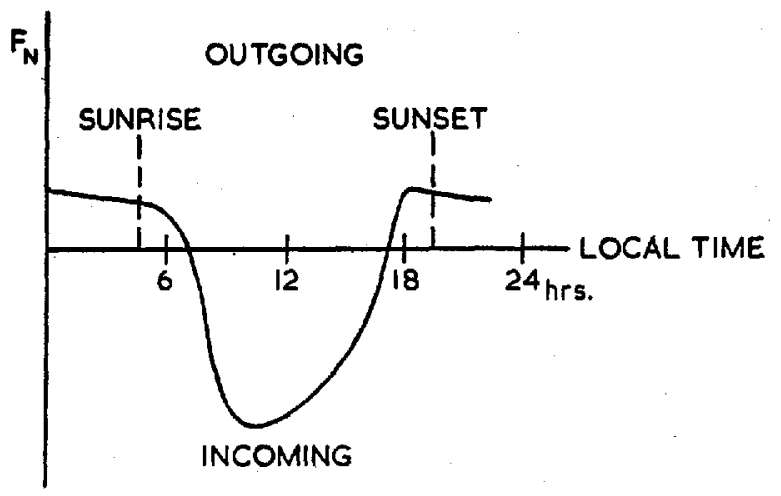

Figure 5. Qualitative nature of the diurnal variation of $F_{N}$ neglecting diurnal variation of cloud amount.

The problem now arises of how to obtain values of the heat balance as a function of latitude and longitude. A desirable aim is to arrive at a world-wide picture of the net radiation $Q(\phi, L)$ where $Q=\int F_{N} d t$ taken over a period of a day or at most a few days. Now there is a large diurnal variation in $F_{N}$, shown qualitatively in Fig. 5 in which the diurnal variation of cloud is neglected. Clearly, observations of $F_{N}$ at two points only of this curve, at practically the same local times in all longitudes, do not allow construction of the whole curve. Observations over a week would moreover only cover two sections of the curve each about $2 \frac{1}{2} \mathrm{hr}$ wide $\left(i \bumpeq 60^{\circ}\right)$, making use of the precession of the orbit. Wexler (1960) remarks that a solution to the sampling problem could involve the launching of a number of satellites into 'stationary' orbits of inclination $96.5^{\circ}$ so that they are suitably spaced in local time about the earth.

If a high satellite orbit were used, say $h=3,000 \mathrm{~km}$, then each place on the earth within the orbital zone would be observable over about 6 hours per day, but at the expense, in the two-sphere experiment, of large spatial smoothing. A high orbit recommends itself, 
however, for a restricted-aperture radiometer giving spatial resolution of order say $100 \mathrm{~km}$, but this requires an advanced, altitude-controlled satellite and it would then be necessary to assume (or measure) the form of the angular distribution of intensity of radiation leaving each area in order to obtain fluxes.

\section{Conclusions}

We state first the conclusions which are relevant to all satellite measurements of total radiation, no matter how they are made.

(1) Satellite measurements can only give the flux at the position of the satellite, i.e., at a height of $200 \mathrm{~km}$ or more. The flux at a lower level can only be inferred with precision under ideal conditions (visible area homogeneous).

(2) The sampling of data obtainable with a single satellite is inadequate for the purposes of world-wide heat balance studies because observations of $F_{N}$ at a point are made at only two times during the day. Since all points around a given latitude circle are observed at the same two local times the data will be sufficient to give a zonal mean of the net flux at these two times.

The following conclusions relate to the two-sphere experiment described.

(1) The use of an omnidirectional sensing element gives rise to an uncertainty in the determination of the vertical fluxes at the satellite. It is shown that this uncertainty is acceptably small ( $<2$ per cent for long wave flux and $<10$ per cent for short-wave flux) in most situations. The difficulty can only be avoided by using a plane sensing element maintained parallel to the earth's surface at all times.

(2) The experiment described is simple, and the apparatus required could be made very small and light, with small power requirements.

(3) The sensitivity is shown to be sufficient and the errors in the flux determinations are tolerably small in most cases. In the event of the occurrence of a minor defect not causing a complete breakdown of the experiment it should be possible to recalibrate the equipment in flight sufficiently well to make good use of continued observations.

(4) Conduction and radiation errors from the satellite itself can be made acceptably small. Heating by collision with gas molecules cannot be avoided and may be appreciable for low orbits $(<300 \mathrm{~km})$, but is negligible above $400 \mathrm{~km}$.

\section{ACKNOWLEDGMENTS}

I am indebted to Professor P. A. Sheppard for many helpful suggestions and discussions, to the Royal Society for a research grant, and to Miss M. Street for preparing the diagrams.

\begin{tabular}{|c|c|c|}
\hline \multicolumn{3}{|c|}{ REFERENCES } \\
\hline Elsasser, W. M. & 1942 & Harvard Met. Studies, No. 6. \\
\hline Gast, P. R. & 1956 & $\begin{array}{l}\text { Scientific uses of earth satellites, p. } 73 \text { (Chapman and Hall, } \\
\text { London). }\end{array}$ \\
\hline Kelly, J. J. & 1955 & Weatherwise, 8, p. 121 \\
\hline King-Hele, D. & 1960 & $\begin{array}{l}\text { Satellites and scientific research, p. } 19 \text { (Routledge and Kegan } \\
\text { Paul, London). }\end{array}$ \\
\hline Lagow, H. E. & 1956 & $\begin{array}{l}\text { Scientific uses of earth satellites, p. } 68 \text { (Chapman and Hall, } \\
\text { London). }\end{array}$ \\
\hline Suarni, V. E. & 1958 & I.G.Y. Annals, 6, pp. $331-340$ \\
\hline $\begin{array}{l}\text { Wexler, H. } \\
\text { Widger, W. K. Jr. and Touart, C. N. }\end{array}$ & $\begin{array}{l}1960 \\
1957\end{array}$ & $\begin{array}{l}\text { W.M.O. Bulletin, 9, p. } 2 . \\
\text { Bull Amer. Met. Soc, 38. D. } 521\end{array}$ \\
\hline Widger, W. K. Jr. and Touart, C. N. & 1957 & Bull. Amer. Met. Sac., 38, p. 521. \\
\hline
\end{tabular}

